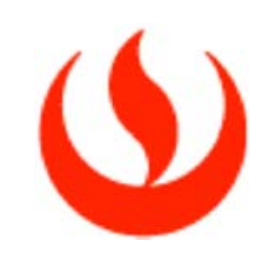

Facultad de Ingeniería

Programa Académico de Ingeniería de Sistemas de Información

\title{
ARQUITECTURA EMPRESARIAL AL PROCESO DE PRESTACIÓN SOCIAL DE SALUD
}

\author{
TESIS \\ para la optar el Título Profesional de Ingeniero de Sistemas de \\ Información
}

Autores

Joan Edison Motta Altamirano (0000-0001-6738-8386)

Sebastián Andrés Neira Medina (0000-0003-2922-0958)

Asesor

Herrera Trujillo, Emilio Antonio (0000-0001-8548-4849)

Lima, Julio 2018 


\section{Resumen Ejecutivo}

El desarrollo de este proyecto tiene como base la mejora del macro proceso de prestación social de EsSalud, ya que este es nuevo en la entidad de salud, puesto que no cuenta con estándares, flujos de trabajos definidos y tiene demasiados trabajos manuales por parte de los trabajadores. Prestación Social es el macro proceso encargado de brindar un servicio de reinserción social y/o laboral al discapacitado y por parte del adulto mayor mejorar su estilo de vida, los cuales se divide en CERP y CAM.

CERP (Centro Especializados de Rehabilitación Profesional): programa dedicado a la reinserción social y laboral, en lo posible, de personas en edad productiva que tengan alguna discapacidad mental o física. CAM (Centro del Adulto Mayor): programa recreativo para que el adulto mayor pueda desenvolverse en un ambiente óptimo para motivar sus habilidades interpersonales y creativas, mejorando el proceso de envejecimiento del mismo.

El objetivo del proyecto es brindar una propuesta de una arquitectura de negocios, tecnológica, aplicaciones y datos para la automatización del proceso mencionado en EsSalud bajo el Framework TOGAF 9.1 con la metodología ADM y la notación Archimate.

El proyecto se estará desarrollando en 2 ciclos académicos de la universidad peruana de ciencias aplicadas - UPC en el primer ciclo se definirá el alcance, herramientas, y se recabará toda la información relevante al macro proceso, mientras que en el segundo ciclo se diseñará y validará la propuesta de mejora en los 4 dominios. Además de proponer un plan de continuidad para el proyecto. El desarrollo se realizará con el acompañamiento del cliente del proyecto y la información obtenida del portal de transparencia. Por parte de la viabilidad de la solución se realizará una validación con simulación en notación BPMN 2.0 en Bizagi para demostrar la mejora del proceso, donde se evidenciará los resultados favorables de agilidad de actividades y atender mayor cantidad de asegurados de EsSalud logrando así cumplir con los objetivos de la organización de salud y del proceso

Palabras clave: Arquitectura Empresarial, Procesos, Seguro Social, EsSalud, Prestación Social, Adulto Mayor, Persona con Discapacidad, Rehabilitación, Simulación. 


\begin{abstract}
The development of this Project is based on the improvement of the macro process of social provision of EsSalud for the reason that this is new in the health entity since it does not have standards or defined workflows and has too much manual work by the workers. Social provision is the macro process in charge of providing a service of social and labor rehabilitation to the disable and by the older adult to improve their lifestyle, which is divided into CERP and CAM.
\end{abstract}

CERP (Specialized Vocational Rehabilitation Center): A program dedicated to the social and labor reinsertion where possible of people of productive age who have a mental or physical disability.

CAM (Center for the Elderly): A recreational program for the elderly to develop an optimal environment to motivate their interpersonal and creative skills improving the aging process of the same.

The objective of the project is to provide a metamodel and a proposal for a technological business architecture, applications and data for the automation in EsSalud under the TOGAF9.1 Framework with the ADM methodology and the Archimate notation. The project will be developed in two academic cycles of the Peruvian University of applied sciences-UPC. In the first cycle the scope and tools will be defined and all the information relevant to the macro process will be collected while in the second cycle the proposal of improvement in the four domains will be design and validated and a metamodel will be proposed. In addition to propose a continuity plan for the project.The development will be carried out with the accompaniment of the client of the project and the information obtained from the transparency portal. On the part of the viability of the solution will be carried out a simulation validation in BPM 2.0 notation in Bizagi to demonstrate the improvement of the process where the favorable results of agility of activities will be evidenced and to attend a greater number of clientes of EsSalud thus achieving the objectives of the health organization and the process.

Keywords: Enterprise Architecture, Process, social Welfare, EsSalud, Elders, Person with Disability, Rehabilitation, Simulation. 


\section{Contenido}

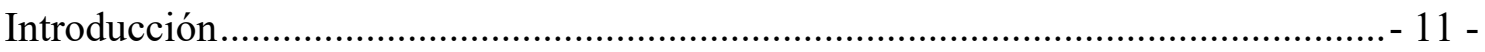

Descripcion del Proyecto................................................................................. 12 -

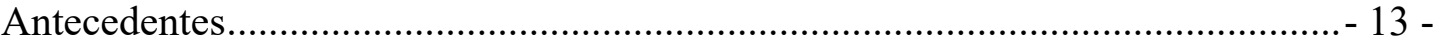

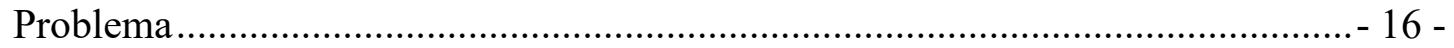

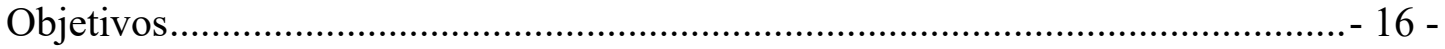

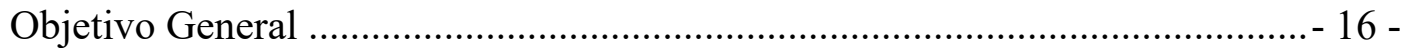

Objetivos Específicos ............................................................................... 16 -

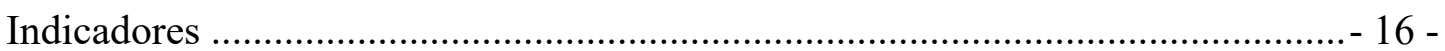

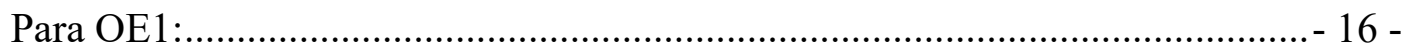

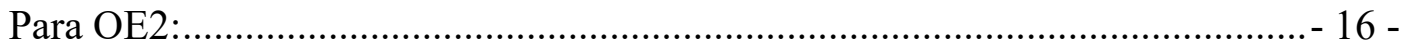

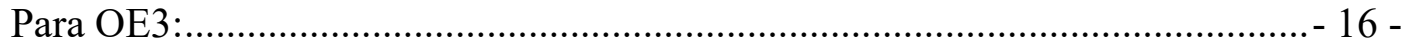

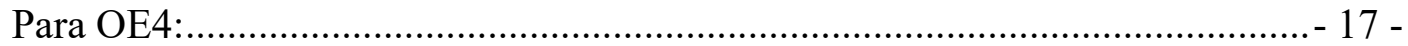

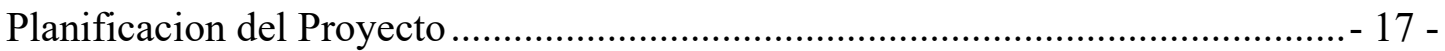

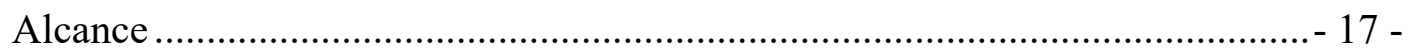

Plan de Gestión del Tiempo .......................................................................... 19 -

Plan de Gestión de Recursos Humanos ............................................................ 22 -

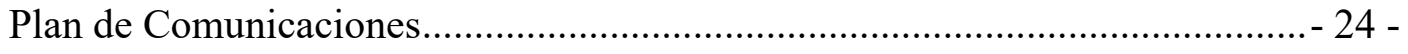

Plan de Gestión de Riesgos ............................................................................... 31 -

Logros de los Resultados de los Alumnos................................................................... 35 -

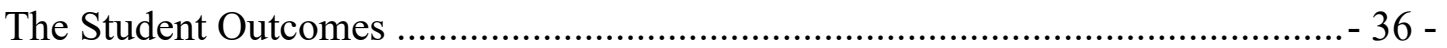

Criterios de Ingeniería de Sistemas de Información............................................ 36 -

Cumplimiento de los Student Outcome......................................................... 37 -

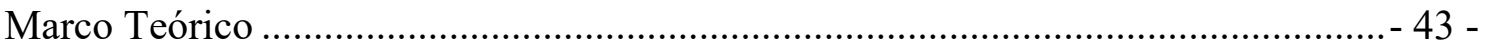

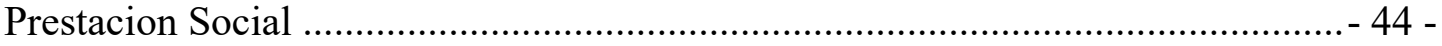

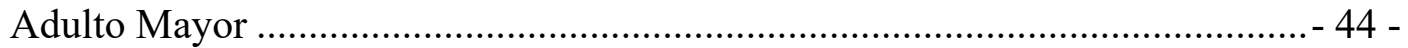

Adulto Mayor Independiente.......................................................................... 44 -

Adulto Mayor Independiente con Riesgo ........................................................ 44 -

Adulto Mayor Dependiente ................................................................................. 44 -

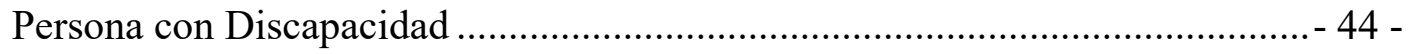

Reinserción / Rehabilitación Social.................................................................. 44 -

Reinserción / Rehabilitación Laboral .............................................................. 45 -

Project Management Body of Knowledge (PMBOK) ............................................ 45 - 
Áreas del Conocimiento PMBOK .................................................................. 48 -

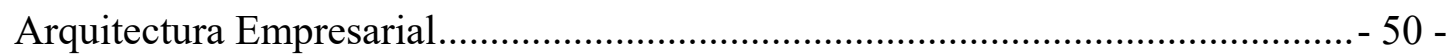

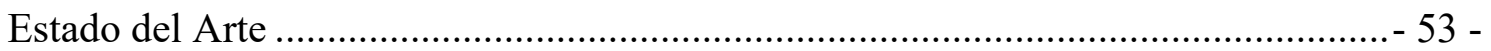

Investigación del Estado del Arte........................................................................ 54 -

Revisión de la Literatura ...................................................................................... 54 -

Beneficios de una Arquitectura Empresarial ................................................... 54 -

Beneficios de una Arquitectura Empresarial con TOGAF ................................. 55 -

Procesos BPM Alineados a la Fase de Negocio de TOGAF................................ 56 -

Arquitectura Empresarial en Hospitales ............................................................... 57 -

Solución Viable de Implementar una Arquitectura a un Hospital Europeo ....... 57 -

Solución Viable de Implementar una Arquitectura a un Centro Médico en América

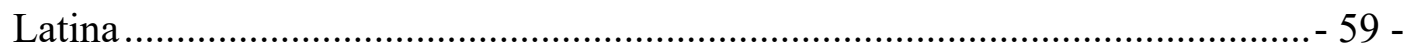

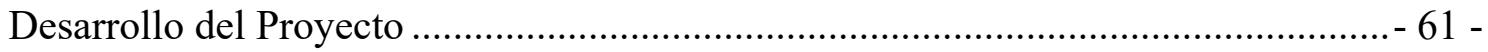

Benchmarking Arquitectura Empresarial .......................................................... 62 -

Analisis de Soluciones de Sistemas de Informacion para Seguros ........................ 63 -

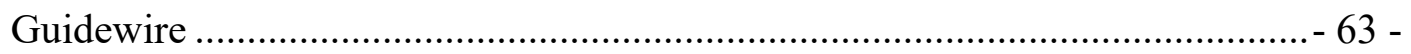

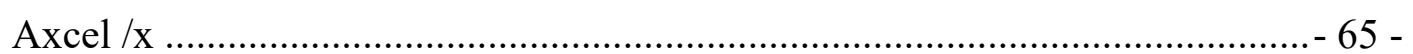

Sage 300 - ERP for Hospitals and Healthcare ................................................. 69 -

SIS.NET (SISTEMA INTEGRAL DE SEGUROS 10) ................................... 71 -

SPG-AIT (Software para Geriátricos) .............................................................. 73 -

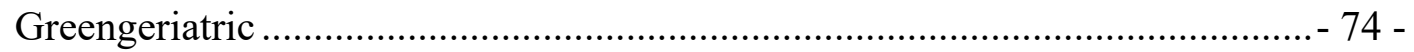

Descripcion del Proyecto y Alcance......................................................................... 77 -

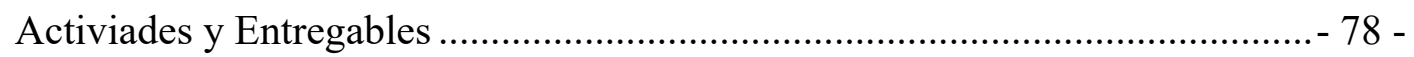

Desarrollo del Proyecto .................................................................................... 83 -

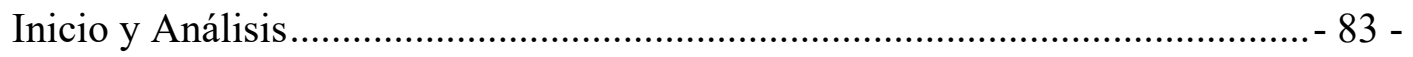

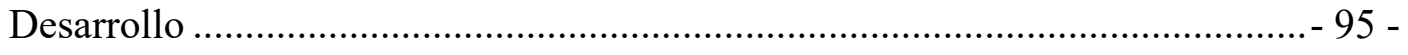

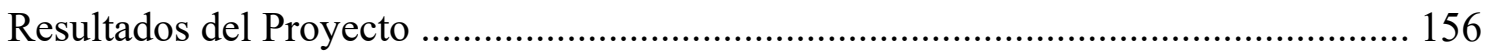

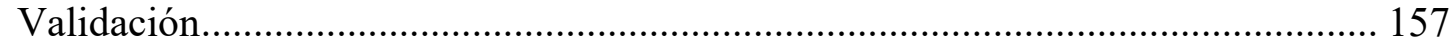

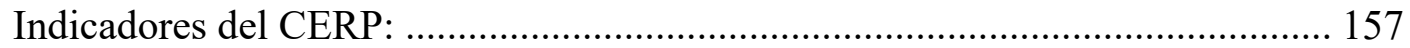

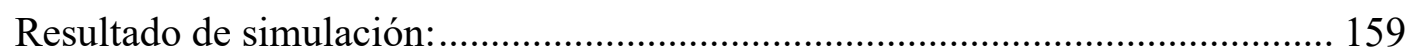

Metamodelo del Proceso de Prestación Social de EsSalud ..................................... 160

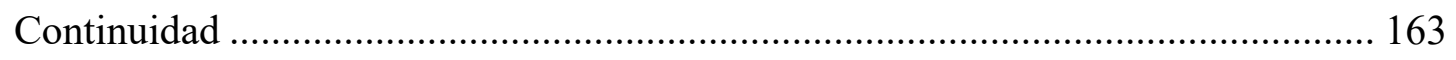

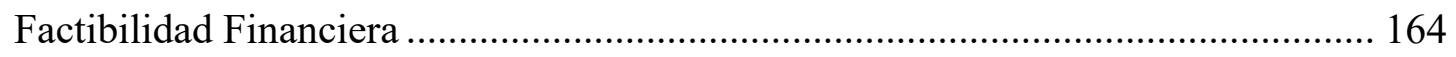




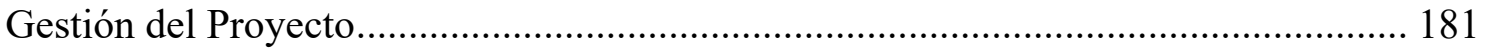

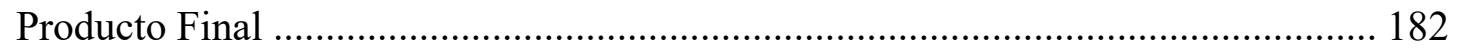

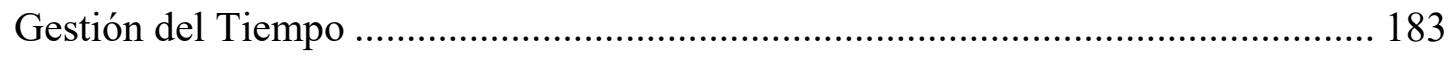

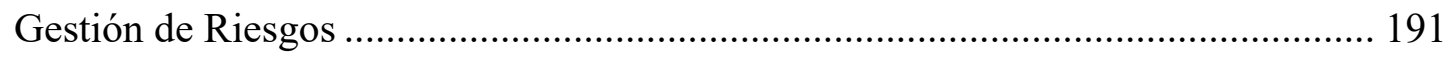

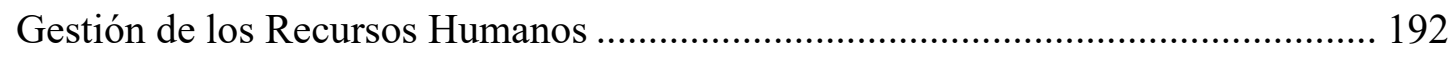

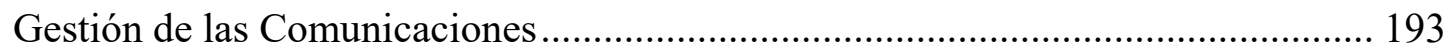




\section{Lista de Tablas}

Tabla 1: Fases del Proyecto de AE del Proceso de Prestación Social......................... 19 -



Tabla 3: Lista de Student Outcomes............................................................................. 36 -

Tabla 4: Resultado del Cumplimiento de los Student Outcomes .............................. 37 -

Tabla 5: Benchmarking de Framework de Arquitectura Empresarial ........................ 62 -

Tabla 6: Ficha de Definición, Alcance y Bosquejo del Proyecto ................................. 83 -

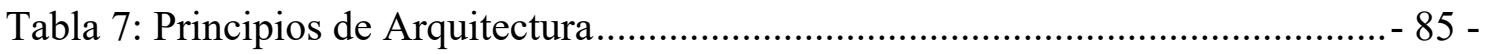

Tabla 8: Principios de Datos...................................................................................... 86 -

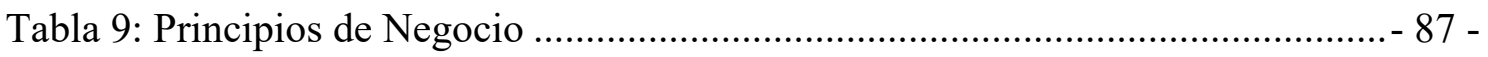

Tabla 10: Principios de Aplicación ........................................................................... 88 -

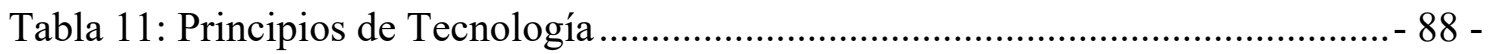

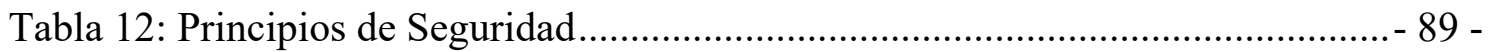

Tabla 13: Capacidades del Proceso de Gestionar Atención del CAM y CERP .......... 96 -

Tabla 14: Requerimiento de Negocios ................................................................. 110 -

Tabla 15: Dominio de Aplicaciones ...................................................................... 111 -

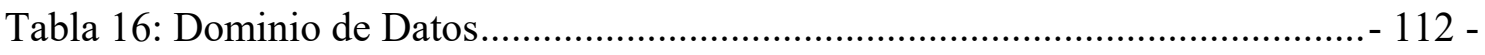

Tabla 17: Dominio de Tecnología ............................................................................ 112 -

Tabla 18: Caracterización de Gestión de Atención en CAM .................................... 113 -

Tabla 19: Caracterización de Gestionar Admisión del Adulto Mayor ...................... 116 -

Tabla 20: Caracterización de Recepción de Pacientes Derivados ............................. 119 -

Tabla 21: Caracterización de Evaluar Integralmente el Adulto Mayor.................... 120 -

Tabla 22: Caracterización de Derivar Paciente ....................................................... 121 -

Tabla 23: Caracterización de Definir Plan de Prestaciones Sociales del Adulto Mayor... $123-$

Tabla 24: Caracterización de Ejecutar Cartera de Servicios .................................... - 125 -

Tabla 25: Caracterización Gestión de Atención en CERPS ...................................... 126 -

Tabla 26: Caracterización de Realizar Admisión y Afiliación de PCD ................... - 129 -

Tabla 27: Caracterización de Recepción de Pacientes Derivados ............................ 131 -

Tabla 28: Caracterización de Realizar Evaluación y Establecer Plan de Trabajo de PCD$133-$

Tabla 29: Caracterización de Ejecutar Cartera Servicios Rehab. Profesional........... 134 -

Tabla 30: Caracterización de Realizar Proceso de IL Independiente........................ 136 - 
Tabla 31: Caracterización de Realizar Proceso de IL Dependiente con Vínculo.....- 138 -

Tabla 32: Caracterización Realizar Proceso de IL Dependiente sin Vínculo........... - 140 -

Tabla 33: Caracterización Ejecutar Cartera Servicios Rehab. Social........................ 142 -

Tabla 34: Caracterización de Derivar Paciente ........................................................ 144 -

Tabla 35: Matriz RACI To Be............................................................................... 153 -

Tabla 36: Simulación del Proceso Gestionar Atención del CERP ............................... 159

Tabla 37: Simulación del Proceso Gestionar Atención del CAM ................................ 159

Tabla 38: Costo de Capacitación de la Reestructuración de los Procesos CERP y CAM

Tabla 39: Tiempo de Capacitación de los Procesos CERP y CAM ............................. 164

Tabla 40: Costo del Desarrollo del Sistema Web......................................................... 165

Tabla 41: Tiempo de Gestión del Desarrollo del Sistema Web ................................... 166

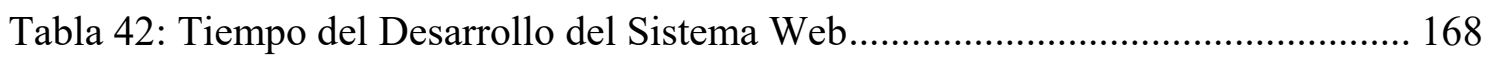

Tabla 43: Costo del Desarrollo del Servicio de Derivación ......................................... 170

Tabla 44: Tiempo de Gestión del Desarrollo del Servicio de Derivación..................... 171

Tabla 45: Tiempo de Desarrollo del Servicio de Derivación ........................................ 172

Tabla 46: Costo de Infraestructura de la Solución ........................................................ 173

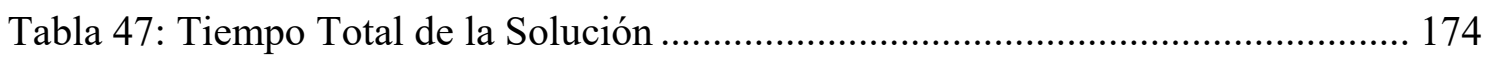

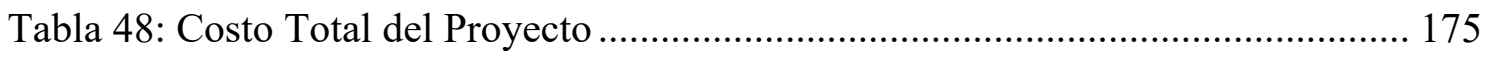

Tabla 49: Ahorro en Tiempo de Actividades del CERP ............................................ 176

Tabla 50: Ahorro en Tiempo de Actividades del CAM .............................................. 176

Tabla 51: Ahorro Total de los Procesos ..................................................................... 177

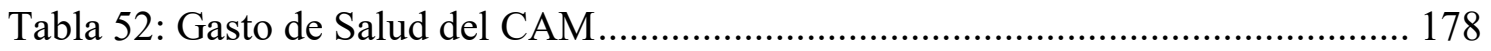

Tabla 53: Mejora en Atención de los Asegurados en el CAM.................................... 179

Tabla 54: Flujo de Costos y Beneficios del ROI ........................................................ 179

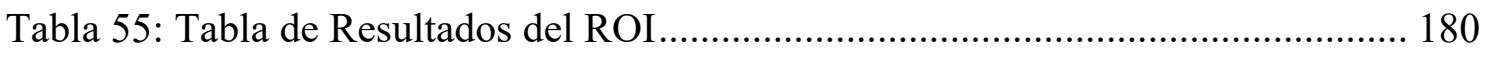

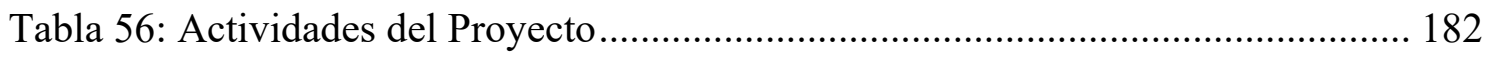

Tabla 57 Primera Etapa del Proyecto: ...................................................................... 183

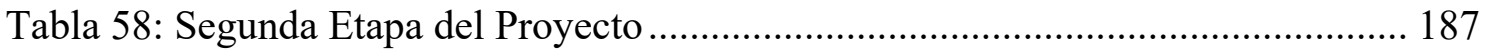

Tabla 59: Matriz de Recursos Humanos del Proyecto .................................................. 192

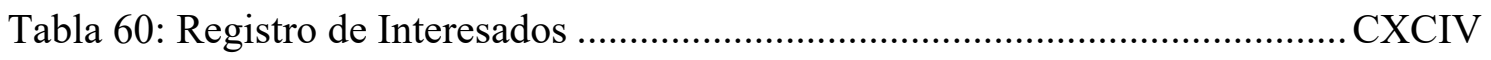

Tabla 61: Matriz de Comunicaciones del Proyecto.......................................................... CC 


\section{Lista de Ilustraciones}

Ilustración 1: Distribución porcentual de personas con discapacidad......................... 13 -

Ilustración 2: Pirámide de ancianidad la población peruana ...................................... 14 -

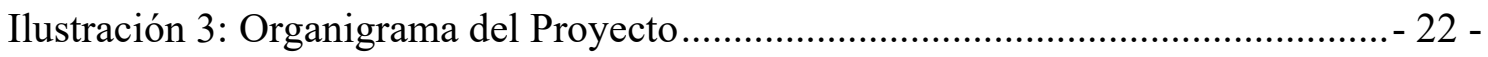

Ilustración 4: Roles y Miembros del Proyecto ......................................................... 23 -

Ilustración 5: Matriz de Comunicaciones ...................................................................... 24 -

Ilustración 6: Interacciones entre Procesos de la Dirección de Proyectos .................. 47 -

Ilustración 7: Ciclo del ADM ................................................................................... 51 -

Ilustración 8: Integración BPM CON ADM …........................................................ 57 -

Ilustración 9: Propuesta de Trabajo de AE .................................................................. 58 -

Ilustración 10: Integración de Servicios y Áreas......................................................... 60 -

Ilustración 11: Requerimiento Minimo de Greengeriatric ........................................ 76 -

Ilustración 12: Cadena de Valor EsSalud .................................................................... 90 -

Ilustración 13: Mapa de Procesos de EsSalud As Is.................................................... 92 -

Ilustración 14: Gestionar Atención en el CAM As Is................................................ 93 -

Ilustración 15: Gestionar Atención en el CERP As Is............................................... 93 -

Ilustración 16: Relación de Arquitectura entre CERP y CAM As Is ......................... 94 -

Ilustración 17: Gestionar Atención del CAM - As Is .............................................. 97 -

Ilustración 18: Admitir y Evaluación Integral del Adulto Mayor ............................... 98 -

Ilustración 19: Definir Plan de Prestaciones Sociales del Adulto Mayor.................... 99 -

Ilustración 20: Ejecutar Cartera de Servicios ......................................................... 100 -

Ilustración 21: Gestionar atención del CERP - As Is............................................. 101 -

Ilustración 22: Realizar Admisión y Afiliación de PCD .......................................... 101 -

Ilustración 23: Realizar Evaluación y Establecer Plan de Trabajo de PCD .............. 102 -

Ilustración 24: Ejecutar Cartera Servicios Rehab. Profesional.................................. 103 -

Ilustración 25: Realizar Proceso de IL Independiente............................................. 104 -

Ilustración 26: Realizar Proceso de IL Dependiente con Vínculo............................. - 106 -

Ilustración 27: Realizar Proceso de IL Dependiente sin Vínculo............................. - 107 -

Ilustración 28: Ejecutar Cartera Servicios Rehab. Social......................................... 108 -

Ilustración 29: Macro Proceso de Prestación Social Versus los Sistemas TI As Is .- 109 -

Ilustración 30: Procesos Misionales Versus Sistemas TI As Is................................ 109 -

Ilustración 31: Gestionar Atención del CAM To Be............................................... 113 -

Ilustración 32: Gestionar Admisión del Adulto Mayor............................................. 115 - 
Ilustración 33: Recepción de Pacientes Derivados $117-$

Ilustración 34: Evaluar Integralmente el Adulto Mayor $-119-$

Ilustración 35: Derivar Paciente $-120-$

Ilustración 36: Definir Plan de Prestaciones Sociales del Adulto Mayor. $-122-$

Ilustración 37: Ejecutar Cartera de Servicios $-123-$

Ilustración 38: Gestionar Atención del CERP $-125-$

Ilustración 39: Realizar Admisión y Filiación de PCD . $127-$

Ilustración 40: Recepción de Pacientes Derivados $-130-$

Ilustración 41: Realizar Evaluación y Establecer Plan de Trabajo de PCD. $-132-$

Ilustración 42: Ejecutar Cartera Servicios Rehab. Profesional. $-134-$

Ilustración 43: Realizar Proceso de IL Independiente. $-135-$

Ilustración 44: Realizar Proceso de IL Dependiente con Vínculo. $-137-$

Ilustración 45: Realizar Proceso de IL Dependiente sin Vínculo. $-139-$

Ilustración 46: Ejecutar Cartera Servicios Rehab. Social $141-$

Ilustración 47: Derivar Paciente $143-$

Ilustración 48: Prestación de Salud $-144-$

Ilustración 49: Mapa de Procesos de EsSalud To Be $-146-$

Ilustración 50: Gestionar Atención del CAM To Be. $-147-$

Ilustración 51: Gestionar Atención del CERP To Be -147 -

Ilustración 52: Vista de Estructura de Información. $-148-$

Ilustración 53: Vista de Estructura de Aplicación $148-$

Ilustración 54: Vista de Infraestructura de Tecnología $-149-$

Ilustración 55: Vista Proceso de Negocios $-150-$

Ilustración 56: Vista de Realización de Servicios $-151-$ Ilustración 57: Vista general To Be de la Arquitectura Empresarial del Macro Proceso de Prestación Social $-152-$

Ilustración 58: Metamodelo de Arquitectura Empresarial del Proceso de Prestación Social de EsSalud 162 


\section{Introducción}

La presente memoria muestra el desarrollo de una arquitectura empresarial para el macro proceso de prestación social de ESSALUD con los cuatro dominios de negocio, datos, aplicación y tecnología basada en el framework TOGAF 9.1 y metodología ADM. Para ello el documento en mención se divide en 7 capítulos:

El primer capítulo, describe los antecedentes, análisis, problema, objetivo general, objetivo específico e indicadores de éxito del proyecto.

El segundo capítulo, describe como se ha cumplido los "student outcomes" que propone la carrera de ingeniería de sistemas de información de UPC para el desarrollo del proyecto.

En el tercer capítulo, describe el marco teórico y los principales conceptos que se vieron durante el desarrollo del presente proyecto.

El cuarto capítulo, describe el estado del arte de las investigaciones que sustentan la viabilidad de una arquitectura empresarial como solución para un proceso de la rama de salud que presenta problemas.

El quinto capítulo describe el desarrollo del proyecto. Se detalla el producto final y los resultados obtenidos.

El sexto capítulo describe los resultados, validación, continuidad y factibilidad económica obtenidos con el desarrollo del proyecto.

El séptimo capítulo describe la gestión del proyecto. Se detalla, la gestión del tiempo, la gestión de recursos humanos, gestión de comunicaciones, gestión de riesgos y lecciones aprendidas. 


\section{Capítulo 1: Descripción del Proyecto}

En este capítulo, se describe el proyecto en sus antecedentes, análisis y problema del macro proceso de prestación social. Asimismo, se mostrará los objetivos generales, objetivos específicos e indicadores de éxito para el proyecto en mención. También la gestión del proyecto de arquitectura empresarial en base a la guía del PMBOK y el framework TOGAF. 


\section{Antecedentes}

EsSalud es una empresa peruana encargada de asegurar a los trabajadores y pensionistas mientras estén afiliados. Para lograr este objetivo, EsSalud divide su gestión en dos partes, IAFAS e IPRES, el primero encargado de gestionar los fondos del asegurado, mientras que el segundo se encarga de prestar servicios de salud.

Prestación social es uno de estos servicios (IPRES) que "presta" EsSalud, este proceso se centra en brindar apoyo a dos grupos de población, que les denomina como vulnerables: Adultos mayores y personas con discapacidad.

Para los adultos mayores se busca mejorar su condición de vida, evitando que caigan en una vida monótona y enfermen con frecuencia. Mientras que con los discapacitados se busca reinsertarlos socialmente, y en lo posible, laboralmente.

En la práctica, esta población nunca ha sentido el apoyo del gobierno con sus situaciones (Anonimo, Diario el comercio, 2016). Es por eso que EsSalud, siendo parte del gobierno y según el artículo 2 de la ley 27056 (ESSALUD) está buscando mejoras en su proceso de prestación social, para poder dar abasto al gran número de población vulnerable del país.

Según el artículo 33 del capítulo IV de la Ley 27050 (Ministerio de educación, 2010), las personas con discapacidad, que, si pueden, y deben, ser reinsertadas laboralmente, en lo posible, no están reintegrándose como deberían. En la siguiente imagen vemos el porcentaje de personas con discapacidad que pertenecen al PEA.

Ilustración 1: Distribución porcentual de personas con discapacidad 


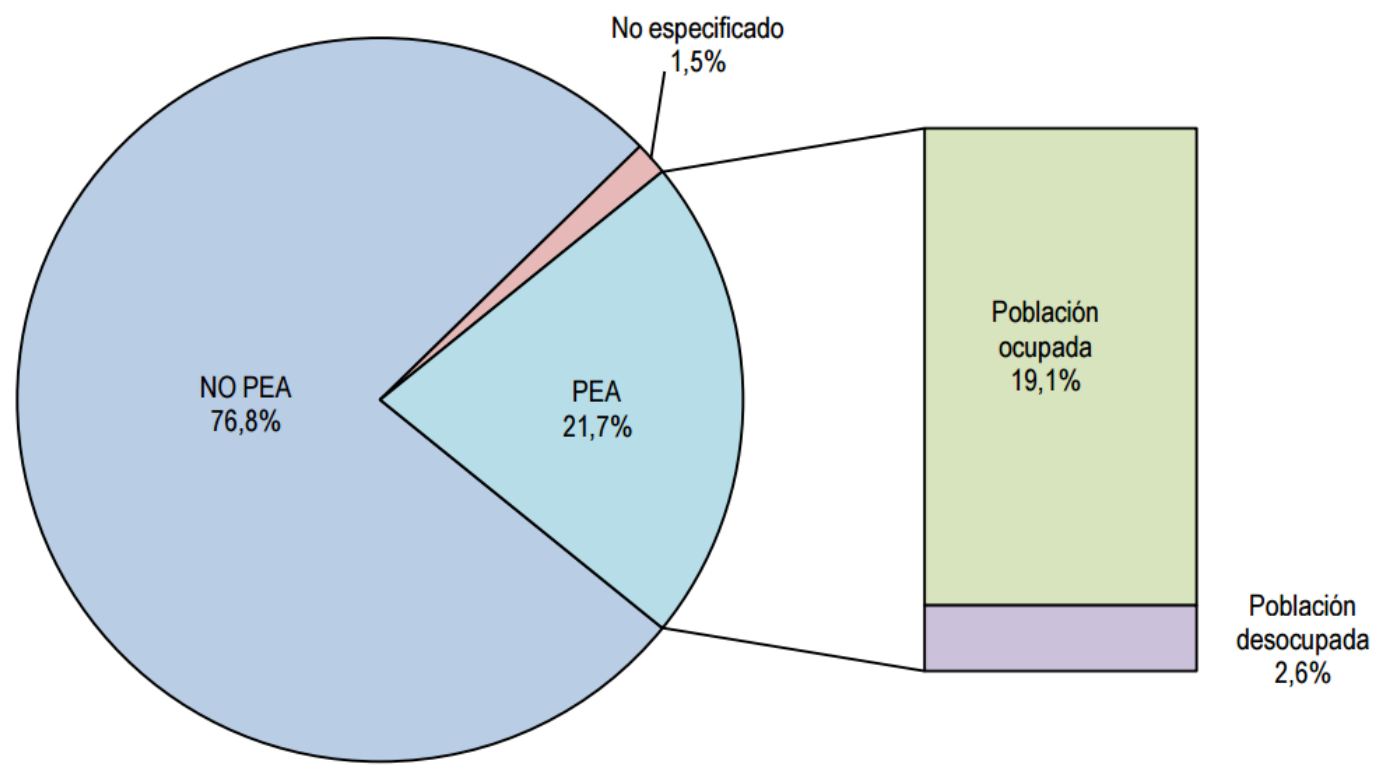

Fuente: INEI

Por otro lado, los adultos mayores, que, según el INEI, cada vez aumentan, tampoco están siendo tratados como se deberían. A continuación, una imagen de las proyecciones de cambio de la población (Instituto nacional de estadistica e informatica(INEI), 2015).

Ilustración 2: Pirámide de ancianidad la población peruana

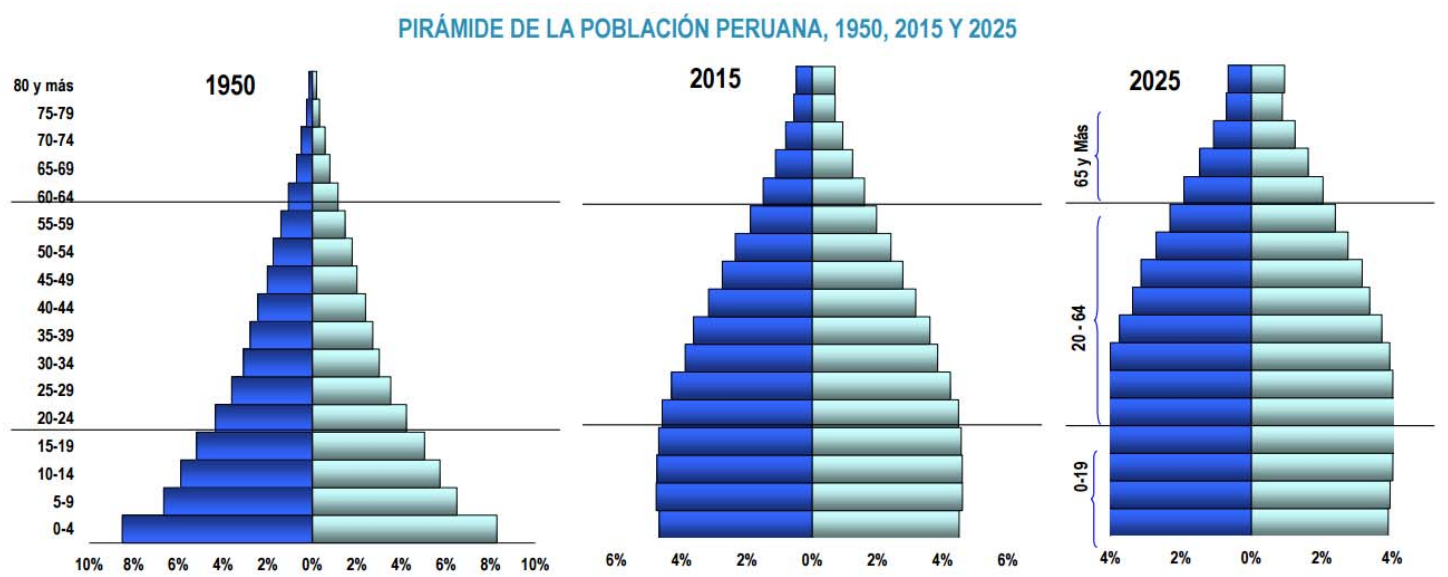

Fuente: INEI

Con los adultos mayores, la situación es diferente, según los artículos 10 y 11 de la ley 28803 (Ministerio de la mujer y población vulnerable), ellos no pueden ser reinsertados 
laboralmente, al igual que los discapacitados, pero si pueden crear pequeñas microempresas o se puede mejorar sus estilos de vida con diversas actividades recreativas (Anonimo, Diario el comercio, 2015).

Teniendo esta información EsSalud, diseña este proceso para ambos grupos, creando 2 conceptos, CAM (Portal del centro del adulto mayor) que son los centros del adulto mayor con programa recreativo para que el adulto mayor pueda desenvolverse en un ambiente óptimo para motivar sus habilidades interpersonales y creativas, mejorando el proceso de envejecimiento del mismo (Gerencia central de las persona adulta mayor, 2016) y CERP (Portal del centro especialisado derehabilitación) que son los Centro Especializados de Rehabilitación Profesional con programas dedicado a la reinserción social y laboral, en lo posible, de personas en edad productiva que tengan alguna discapacidad mental o física (Gerencia central de la persona con discapacidad, 2016). El proceso actualmente se realiza para ambos grupos vulnerables, y atiende asegurados (Anonimo, Andina, 2015), pero podría ser mucho mejor.

El problema está en que el proceso no se da abasto para la demanda que EsSalud necesita atender, según los estudios de EsSalud, de 8'147,268 asegurados de EsSalud en el 2012, aproximadamente 1'229,960 asegurados son Adultos Mayores. De esa población, EsSalud determino que 799,474 debían ser atendidos pero los CAM solo lograron atender 53,704 Adultos Mayores, lo que representa un 6,7\% del público objetivo (Congreso de la republica, 2012), luego se realizó el mismo estudio para el año 2016, donde el número de asegurados llego a 1’465,216 pero los CAM solo lograron atender 77,952 asegurados (EsSalud, 2016). Por el lado del CERP, no se tiene un flujo de trabajo definido ni un sistema que lo soporte, puesto que el registro y trabajo es manual y elaborado en Excel. Además, se tarda demasiado tiempo en la atención de un asegurado al momento de su registro/actualización de información y más al momento de asignar y derivar la rehabilitación respectiva. Por ende, no se da abasto para atender a los asegurados por el tiempo perdido entre cada una de las interacciones entre el requerimiento del asegurado y el trabajo interno de cada centro de rehabilitación.

Estos problemas se deben a que el proceso no cuenta con una documentación a nivel de actividades, no tiene sistemas que soporten el proceso y no es estandarizado ${ }^{1}$. Por

\footnotetext{
${ }^{1}$ RESOLUCION_227_GG_ESSALUD_2016
} 
consecuencia, los centros especializados no brindan los resultados que la directiva de la empresa espera.

\section{Problema}

Mejorar el alcance del macro proceso de Prestación Social de EsSalud, para que logre atender a un mayor porcentaje de público objetivo.

\section{Objetivos}

\section{Objetivo General}

Implementar una arquitectura empresarial para el proceso de Prestación Social de EsSalud.

\section{Objetivos Específicos}

OE1: Analizar el proceso de Prestación Social de EsSalud.

OE2: Diseñar una propuesta de mejora para el proceso de Prestación Social.

OE3: Validar que la propuesta cumpla con los requerimientos del negocio.

OE4: Elaborar un plan de continuidad para la solución propuesta.

\section{Indicadores}

\section{Para OE1:}

- IE1: Aprobación del cliente de la información levantada acerca del proceso.

- IE2: Aprobación del cliente del correcto levantamiento de los requerimientos mínimos para la propuesta de solución.

\section{Para OE2:}

- IE3: Aprobación del cliente del Diseño de la Propuesta de solución.

\section{Para OE3:}

- IE4: Aprobación del cliente de que la propuesta soluciona el problema o necesidad. 


\section{Para OE4:}

- IE5: Aprobación del plan de continuidad por el cliente.

\section{Planificación del Proyecto}

\section{Alcance}

Este trabajo es un proyecto de desarrollo de arquitectura empresarial para la empresa EsSalud, usaremos el marco de trabajo TOGAF como referencia y la metodología ADM, centrándonos en el proceso de prestación social de EsSalud.

Se desarrollarán las siguientes fases con sus entregables:

- Preliminar

- Organizational Model for Enterprise Architecture

- Principles catalog

- Visión de Arquitectura

- Statement of Architecture Work

- Architecture Vision

- Architecture Definition Document

- Value Chain diagram

- Arquitectura de Negocio

- Dominio de Negocio:

- Architecture Definition Document

- Architecture Requirements Specification

- Architecture Roadmap

- Role catalog

- Business Service/Function catalog 
- Arquitectura de Sistemas de Información (Aplicaciones y Datos)

- Dominio datos y aplicaciones

- Architecture Definition Document (Datos y Aplicaciones)

- Architecture Requirements Specification (Datos y Aplicaciones)

- Architecture Roadmap (Datos y Aplicaciones)

- Application Portfolio Catalog (Datos y Aplicaciones)

- Arquitectura de Tecnología

- Dominio de Infraestructura de TI

- Architecture Definición Documento

- Architecture Requirements Specification

- Tecnología Portfolio catalog

- Architecture Roadmap

La propuesta final del proyecto será un metamodelo de arquitectura empresarial como solución a los problemas encontrados y/o presentados por el cliente.

El proyecto no abarca la implementación de la solución planteada, solo la propuesta de arquitectura empresarial con un plan de continuidad que lo soporte.

La propuesta no involucrara el manejo de personal internos (contrataciones nuevas o recortes de personal).

Si contendrá propuestas de reasignación de recursos, como el personal y cambios en los flujos de algunos procesos, sobre todo el de prestación social, también propuestas de mejora para el manejo de aplicaciones y servidores.

La propuesta está considerada para ser implementada solo en la región de Lima. 
Las soluciones serán basadas en mejores prácticas, sugerencias personales, modelos de referencia internacionales, tanto privados como estatales y, aún más importante, en la visión de la empresa.

Este proyecto no contemplará ningún cambio de la estructura de la empresa ni del contexto, así como tampoco será tomado en consideración algún cambio en la visión de la empresa a partir de la firma y conformidad con este presente documento.

\section{Plan de Gestión del Tiempo}

A continuación, se detallare las fases del proyecto en relación al PMBOK versus las fases del ADM de TOGAF.

Tabla 1: Fases del Proyecto de AE del Proceso de Prestación Social

\begin{tabular}{|l|l|l|l|l|}
\hline Fase & Fase ADM & $\begin{array}{l}\text { Hito del } \\
\text { proyecto }\end{array}$ & Fecha Estimada & $\begin{array}{l}\text { Entregables } \\
\text { incluidos }\end{array}$ \\
\hline Inicial & $\begin{array}{l}\text { Fase } \\
\text { Preliminar }\end{array}$ & $\begin{array}{l}\text { Aprobación } \\
\text { del Project } \\
\text { Charter }\end{array}$ & Semana 5 & Project Charter \\
\hline Inicial & $\begin{array}{l}\text { Fase } \\
\text { Preliminar }\end{array}$ & $\begin{array}{l}\text { Exposición } \\
\text { Parcial con el } \\
\text { Comité }\end{array}$ & Semana 5 & Project Charter \\
\hline Planificación & $\begin{array}{l}\text { Fase } \\
\text { Preliminar / } \\
\text { Fase A }\end{array}$ & $\begin{array}{l}\text { Aprobación } \\
\text { de la Fase } \\
\text { Preliminar } \\
\text { por QS y } \\
\text { cliente. }\end{array}$ & Semana 5 & $\begin{array}{l}\text { Project Charter, } \\
\text { Documento de } \\
\text { Alcance, Gantt, } \\
\text { EDT, Architecture } \\
\text { Statement, } \\
\text { Organizational } \\
\text { Model for } \\
\text { Enterprise }\end{array}$ \\
\hline
\end{tabular}




\begin{tabular}{|c|c|c|c|c|}
\hline & & & & $\begin{array}{l}\text { Architecture, } \\
\text { Principles catalog }\end{array}$ \\
\hline Planificación & Fase $\mathrm{A}$ & $\begin{array}{l}\text { Aprobación } \\
\text { de la Fase A } \\
\text { por el Cliente }\end{array}$ & Semana 6 & $\begin{array}{lr}\text { Todos } & \text { los } \\
\text { artefactos } & \text { y } \\
\text { Entregables de la } & \text { lase A }\end{array}$ \\
\hline Planificación & Fase A & $\begin{array}{l}\text { Aprobación } \\
\text { de la Fase A } \\
\text { por QS }\end{array}$ & Semana 6 & $\begin{array}{lr}\text { Documentos } & \text { de } \\
\text { Gestión } & \text { y } \\
\text { Architecture } & \\
\text { Vision } & \end{array}$ \\
\hline Ejecución & Fase B & $\begin{array}{l}\text { Aprobación } \\
\text { del Diagrama } \\
\text { As Is por el } \\
\text { Cliente }\end{array}$ & Semana 8 & $\begin{array}{lll}\text { Diagramas } & \text { de } & 4 \\
\text { Dominios } & & \end{array}$ \\
\hline Ejecución & Fase B & $\begin{array}{l}\text { Aprobación } \\
\text { del Diagrama } \\
\text { To Be por el } \\
\text { Cliente }\end{array}$ & Semana 10 & $\begin{array}{lll}\text { Diagramas } & \text { de } & 4 \\
\text { Dominios } & & \end{array}$ \\
\hline Ejecución & Fase B & $\begin{array}{l}\text { Aprobación } \\
\text { de la Fase } \mathrm{B} \\
\text { con el } \\
\text { Cliente }\end{array}$ & Semana 14 & $\begin{array}{l}\text { Service function } \\
\text { catalog As Is y To } \\
\mathrm{Be}\end{array}$ \\
\hline Ejecución & Fase B & $\begin{array}{l}\text { Exposición } \\
\text { Final con el } \\
\text { Comité }\end{array}$ & Semana 16 & $\begin{array}{l}\text { Todos los } \\
\text { entregables de la } \\
\text { fase } B \text {. }\end{array}$ \\
\hline Ejecución & Fase B & $\begin{array}{l}\text { Aprobación } \\
\text { de } \quad \text { los }\end{array}$ & Semana 18 & $\begin{array}{l}\text { Validar los } \\
\text { entregables Fase } \mathrm{B}\end{array}$ \\
\hline
\end{tabular}




\begin{tabular}{|c|c|c|c|c|}
\hline & & $\begin{array}{l}\text { documentos } \\
\text { de TOGAF }\end{array}$ & & \\
\hline Ejecución & Fase C y D & $\begin{array}{l}\text { Aprobación } \\
\text { de los } \\
\text { documentos } \\
\text { de TOGAF }\end{array}$ & Semana 18 & $\begin{array}{l}\text { Architecture } \\
\text { Definition As Is y } \\
\text { Roadmap. }\end{array}$ \\
\hline Ejecución & Fase C y D & $\begin{array}{l}\text { Aprobación } \\
\text { de los } \\
\text { documentos } \\
\text { de TOGAF }\end{array}$ & Semana 21 & $\begin{array}{l}\text { Architecture } \\
\text { Requirements } \\
\text { Specification }\end{array}$ \\
\hline Ejecución & Fase C y D & $\begin{array}{l}\text { Aprobación } \\
\text { de los } \\
\text { documentos } \\
\text { de TOGAF }\end{array}$ & Semana 22 & $\begin{array}{l}\text { Diagramas de fase } \\
\text { C y D As Is en } \\
\text { archimate y Bizagi } \\
\text { de los procesos. }\end{array}$ \\
\hline Ejecución & Fase C y D & $\begin{array}{l}\text { Aprobación } \\
\text { de los } \\
\text { documentos } \\
\text { de TOGAF }\end{array}$ & Semana 18 & $\begin{array}{l}\text { Architecture } \\
\text { Definition To Be. }\end{array}$ \\
\hline Ejecución & Fase C y D & $\begin{array}{l}\text { Aprobación } \\
\text { de los } \\
\text { documentos } \\
\text { de TOGAF }\end{array}$ & Semana 26 & $\begin{array}{l}\text { Diagramas de fase } \\
\text { C y D To Be en } \\
\text { archimate y Bizagi } \\
\text { de los procesos. }\end{array}$ \\
\hline Control & $\begin{array}{l}\text { Fase B, C y } \\
\text { D }\end{array}$ & $\begin{array}{l}\text { Aprobación } \\
\text { de la Fase B, } \\
\text { C y D con el } \\
\text { Cliente }\end{array}$ & Semana 31 & $\begin{array}{l}\text { Firmar Actas de } \\
\text { Aprobación de los } \\
\text { entregables de } \\
\text { TOGAF. }\end{array}$ \\
\hline
\end{tabular}




\begin{tabular}{|l|l|l|l|l|}
\hline Cierre & Fase & $\begin{array}{l}\text { Aprobación } \\
\text { preliminar, } \\
\text { de la Fase pre } \\
\text { A, B, C y D }\end{array}$ & $\begin{array}{l}\text { Semana 32 } \\
\text { B, C y D con } \\
\text { el Cliente }\end{array}$ &
\end{tabular}

Fuente: Elaboración Propia

\section{Plan de Gestión de Recursos Humanos}

Ilustración 3: Organigrama del Proyecto

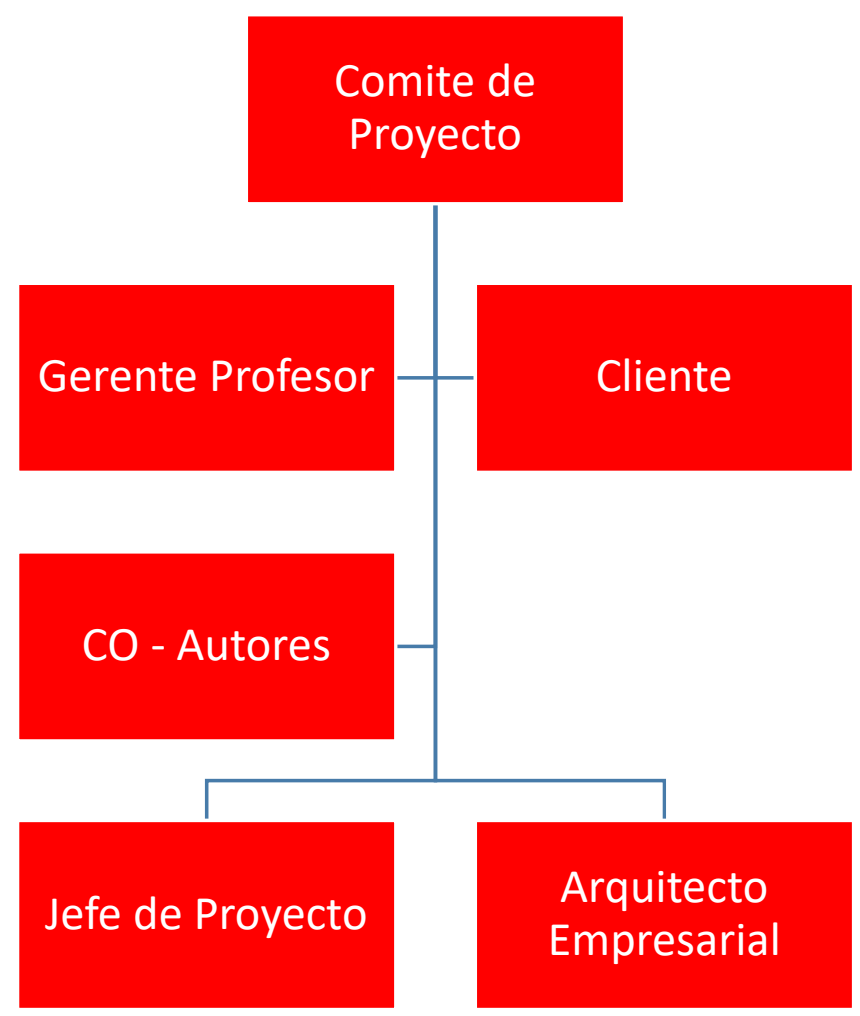

Fuente: UPC

Los roles involucrados en el desarrollo del proyecto son los siguientes:

Comité de Proyectos: Rol correspondiente a los profesores encargados de evaluar los proyectos de tesis desarrollados por los alumnos de la UPC. Para mayor información ver el documento Descripción de Roles y Responsabilidades - Comité 1.2 
Gerente Profesor: Rol correspondiente al gerente profesor de la empresa virtual IT Consulting, encargado de establecer y cumplir los objetivos principales de la empresa IT Consulting; con respecto a la participación en el proyecto, el gerente profesor realizará las siguientes funciones:

Presentar oportunidades de mejora para el cumplimiento de objetivos de la empresa IT Consulting en base a los proyectos propuestos.

Realizar un seguimiento del proyecto con el fin de evaluar si se cumple con lo estipulado de acuerdo al cronograma establecido.

Brindar comentarios y observaciones de los entregables realizados para su mejora y levantamiento antes de la presentación de estos al cliente y comité.

Para mayor información ver el documento Descripción de Roles y Responsabilidades Gerente Profesor 1.2

Cliente: Rol encargado de transmitir las necesidades o problemas del proyecto además de brindar información relevante a los alumnos para desarrollar el proyecto. Para mayor información ver el documento Descripción de Roles y Responsabilidades - Cliente 1.2

Jefe de Proyecto: Rol del alumno encargado de velar por el cumplimiento del proyecto bajo lo estimado en el cronograma, dentro del presupuesto y que cumpla con los objetivos establecidos. Para mayor información ver el documento Descripción de Roles y Responsabilidades - Jefe de Proyecto 1.2

Arquitecto Empresarial: Rol del alumno encargado de desarrollar la arquitectura que cumpla con las normas y lineamientos del marco de referencia y metodologías establecidas. Para mayor información ver el documento Descripción de Roles y Responsabilidades - Arquitecto Empresarial 1.2

Ilustración 4: Roles y Miembros del Proyecto

\begin{tabular}{|l|l|}
\hline Rol & Miembro \\
\hline Jefe de Proyecto & Sebastián Neira \\
\hline
\end{tabular}




\begin{tabular}{|l|l|}
\hline Arquitecto Empresarial & Joan Motta \\
\hline Comité de Proyectos & Rosario Villalta \\
& Pedro Shiguihara \\
\hline Gerente Profesor - IT Consulting & Emictor Parasi \\
\hline
\end{tabular}

Fuente: Elaboración Propia

\section{Plan de Comunicaciones}

Las reuniones para la coordinación y avance del proyecto serán entre el Jefe de Proyecto y/o Arquitecto Empresarial.

Cliente: Reunión presencial una vez a la semana por mínimo una hora, comunicación vía correo durante la semana.

Profesor Gerente: Reunión presencial dos veces a la semana por mínimo quince minutos, comunicación vía correo durante la semana.

Comité: Cuatro exposiciones divididas entre las 34 semanas del proyecto.

Ilustración 5: Matriz de Comunicaciones

\begin{tabular}{|c|c|c|c|c|c|}
\hline $\begin{array}{l}\text { Información } \\
\text { requerida }\end{array}$ & Contenido & $\begin{array}{l}\text { Respons. } \\
\text { De } \\
\text { elaborarlo }\end{array}$ & $\begin{array}{l}\text { Para su } \\
\text { entrega a los } \\
\text { Stakeholder }\end{array}$ & $\begin{array}{l}\text { Método de } \\
\text { comunicació } \\
\text { n a utilizar }\end{array}$ & $\begin{array}{l}\text { Código } \\
\text { de EDT } \\
\text { asociad }\end{array}$ \\
\hline Inicio & $\begin{array}{l}\text { Reunión con el } \\
\text { Profesor } \\
\text { Gerente } \\
\text { Reunión con el } \\
\text { Cliente }\end{array}$ & $\begin{array}{l}\text { Joan Motta } \\
\text { Altamiran } \\
\text { o y } \\
\text { Sebastián }\end{array}$ & $\begin{array}{l}\text { Profesor } \\
\text { Gerente IT } \\
\text { consulting y } \\
\text { Cliente } \\
\text { Profesor }\end{array}$ & $\begin{array}{l}\text { Email(escrita } \\
\text { ) y Oral }\end{array}$ & $\begin{array}{l}1.1 \\
1.1 .1 .1 \\
1.1 .1 .2 \\
1.1 .1 .3\end{array}$ \\
\hline
\end{tabular}




\begin{tabular}{|c|c|c|c|c|c|}
\hline & $\begin{array}{l}\text { Definir } \\
\text { Alcance } \\
\text { Definir los } \\
\text { Entregables de } \\
\text { TOGAF(ADM) } \\
\text { Validación del } \\
\text { Charter con el } \\
\text { Profesor } \\
\text { Gerente } \\
\text { (Alcance) } \\
\text { Validación con } \\
\text { el Cliente del } \\
\text { Alcance } \\
\text { entregables } \\
\text { Validación del } \\
\text { Charter con el } \\
\text { Profesor } \\
\text { Gerente } \\
\text { (Entregables) } \\
\text { Elaboración del } \\
\text { Plan de Trabajo } \\
\text { Presentación del } \\
\text { Project Charter } \\
\text { Prabajo del }\end{array}$ & $\begin{array}{l}\text { Neira } \\
\text { Medina }\end{array}$ & & & $\begin{array}{l}1.1 .2 .1 \\
1.1 .2 .2 \\
1.1 .2 .3 \\
1.1 .2 .4 \\
1.1 .2 .5 \\
1.1 .2 .6 \\
1.1 .2 .7\end{array}$ \\
\hline $\begin{array}{l}\text { Planificació } \\
\mathrm{n}\end{array}$ & $\begin{array}{l}\text { Aprobación del } \\
\text { Project Charter }\end{array}$ & $\begin{array}{l}\text { Joan Motta } \\
\text { Altamiran } \\
\text { o y } \\
\text { Sebastián }\end{array}$ & $\begin{array}{l}\text { Profesor } \\
\text { Gerente IT } \\
\text { consulting y }\end{array}$ & $\begin{array}{l}\text { Email(escrita } \\
\text { ) y Oral }\end{array}$ & $\begin{array}{l}1.2 .1 .1 \\
1.2 .1 .2\end{array}$ \\
\hline
\end{tabular}




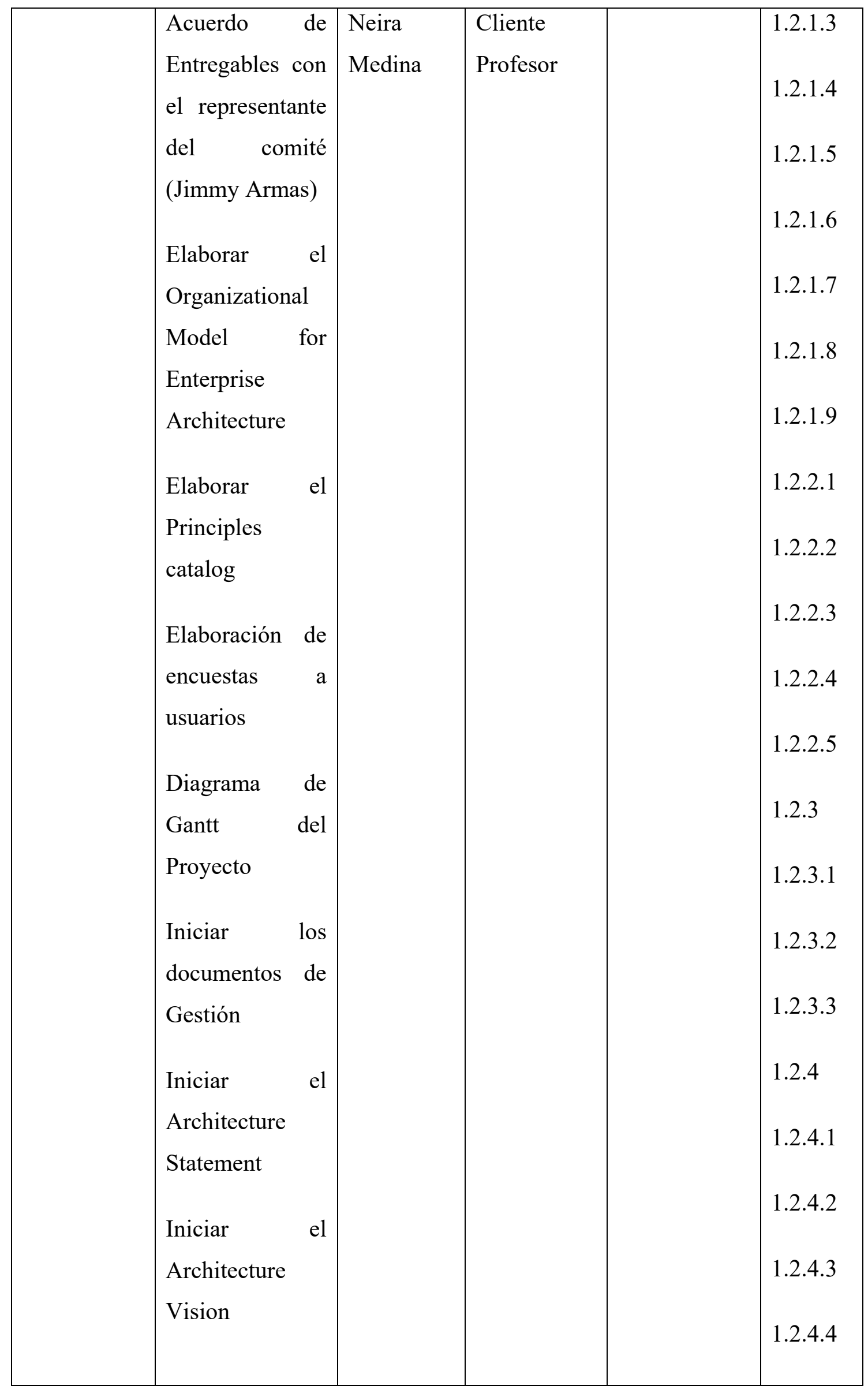




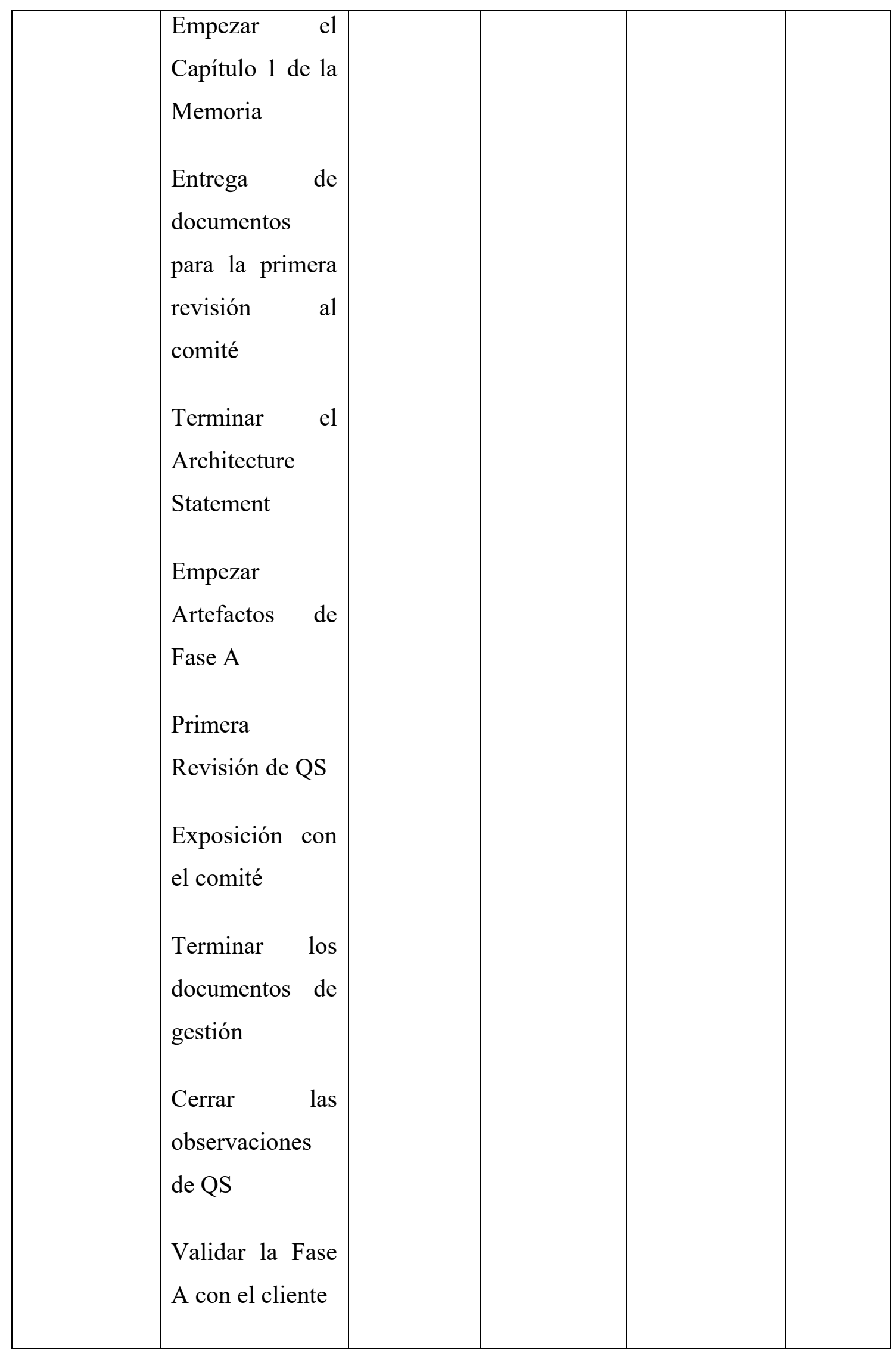




\begin{tabular}{|c|c|c|c|c|c|}
\hline & $\begin{array}{l}\text { Segunda } \\
\text { Revisión de QS } \\
\text { Levantar } \\
\text { observaciones } \\
\text { de la Fase A } \\
\text { Entregar } \\
\text { Capítulo } 1 \\
\text { Memoria }\end{array}$ & & & & \\
\hline 更 & $\begin{array}{l}\text { Iniciar los } \\
\text { diagramas } \\
\text { Empezar el } \\
\text { Capítulo } 3 \text { de } \\
\text { la Memoria } \\
\text { Entregar el } \\
\text { capítulo } 3 \\
\text { Empezar el } \\
\text { capítulo } \quad 4 \\
\text { memoria } \\
\text { Validación } \\
\text { de } \\
\text { Diagramados } \\
\text { As Is } \\
\text { Empezar } \\
\text { Diagramado } \\
\text { To Be }\end{array}$ & $\begin{array}{l}\text { Joan Motta } \\
\text { Altamiran } \\
\text { o y } \\
\text { Sebastián } \\
\text { Neira } \\
\text { Medina }\end{array}$ & $\begin{array}{l}\text { Profesor } \\
\text { Gerente IT } \\
\text { consulting } \\
\text { y Cliente } \\
\text { Profesor }\end{array}$ & $\begin{array}{l}\text { Email(escrita) } \\
\text { y Oral }\end{array}$ & $\begin{array}{l}1.3 .1 .1 \\
1.3 .1 .2 \\
1.3 .2 .1 \\
1.3 .2 .2 \\
1.3 .2 .3 \\
1.3 .2 .4 \\
1.3 .3 .1 \\
1.3 .4 .1 \\
1.3 .4 .2 \\
1.3 .5 .1 \\
1.3 .5 .2 \\
1.3 .6 .1 \\
1.3 .6 .2 \\
1.3 .7 .1 \\
1.8 .1\end{array}$ \\
\hline
\end{tabular}




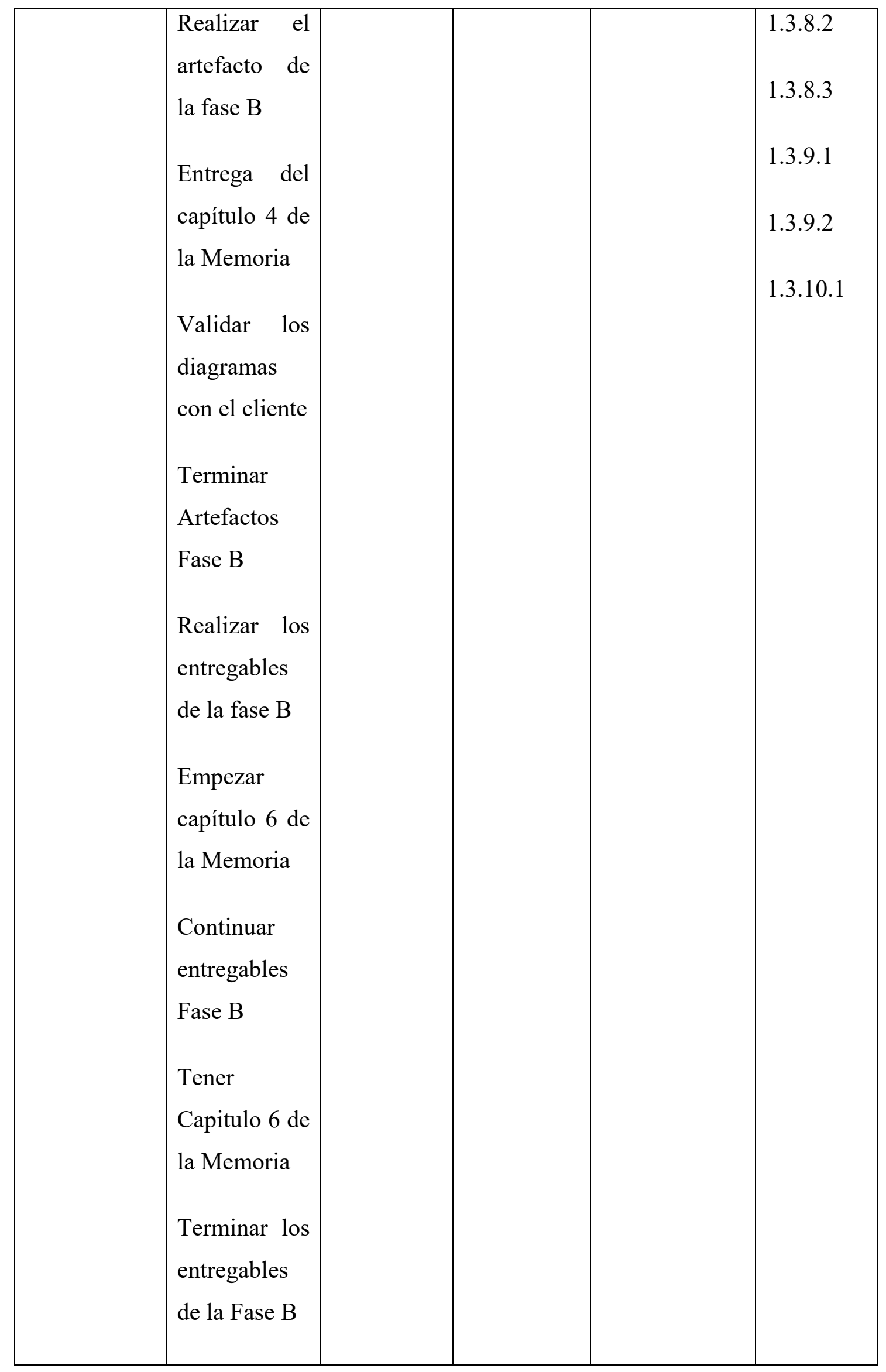




\begin{tabular}{|c|c|c|c|c|c|}
\hline & $\begin{array}{l}\text { Validar Fase } \\
\text { B con el } \\
\text { cliente } \\
\text { Ajustar } \\
\text { Entregables } \\
\text { Fase B } \\
\text { Levantar } \\
\text { observacione } \\
\text { s de la Fase B } \\
\text { Presentar } \\
\text { documentos } \\
\text { al comité } \\
\text { Exposición } \\
\text { con el comité }\end{array}$ & & & & \\
\hline Control & $\begin{array}{l}\text { Firmar Actas } \\
\text { de } \\
\text { Aprobación } \\
\text { de Todo. } \\
\text { Aprobación } \\
\text { del plan de } \\
\text { continuidad }\end{array}$ & $\begin{array}{l}\text { Joan Motta } \\
\text { Altamiran } \\
\text { o y } \\
\text { Sebastián } \\
\text { Neira } \\
\text { Medina }\end{array}$ & $\begin{array}{l}\text { Profesor } \\
\text { Gerente IT } \\
\text { consulting } \\
\text { y Cliente } \\
\text { Profesor }\end{array}$ & $\begin{array}{l}\text { Email(escrita) } \\
\text { y Oral }\end{array}$ & $\begin{array}{l}1.4 .1 \\
1.4 .1 .1 \\
1.4 .1 .2\end{array}$ \\
\hline Cierre & $\begin{array}{l}\text { Entregar } \\
\text { trabajo final } \\
\text { Exposición }\end{array}$ & $\begin{array}{l}\text { Joan Motta } \\
\text { Altamiran } \\
\text { o y } \\
\text { Sebastián } \\
\text { Neira } \\
\text { Medina }\end{array}$ & $\begin{array}{l}\text { Profesor } \\
\text { Gerente IT } \\
\text { consulting } \\
\text { y Cliente } \\
\text { Profesor }\end{array}$ & $\begin{array}{l}\text { Email(escrita) } \\
\text { y Oral }\end{array}$ & $\begin{array}{l}1.5 .1 \\
1.5 .1 .1 \\
1.5 .1 .2\end{array}$ \\
\hline
\end{tabular}


Fuente: Elaboración Propia

\section{Plan de Gestión de Riesgos}

A continuación, se muestra los riesgos considerados para el proyecto en ambos ciclos académicos durante el desarrollo de la tesis.

Tabla 2: Matriz de Riesgos

\begin{tabular}{|c|c|c|c|c|c|c|c|}
\hline $\begin{array}{l}\text { Descripci } \\
\text { ón del } \\
\text { Riesgo }\end{array}$ & $\begin{array}{l}\text { Dispar } \\
\text { ador }\end{array}$ & $\begin{array}{l}\text { Probabi } \\
\text { lidad }\end{array}$ & $\begin{array}{l}\text { Impa } \\
\text { cto }\end{array}$ & Estrategia & $\begin{array}{l}\text { Descripción } \\
\text { de la } \\
\text { estrategia } \\
\text { planteada }\end{array}$ & $\begin{array}{l}\text { Accion } \\
\text { es } \\
\text { realiza } \\
\text { das }\end{array}$ & $\begin{array}{l}\text { Plan de } \\
\text { Conting } \\
\text { encia }\end{array}$ \\
\hline $\begin{array}{l}\text { Cambio } \\
\text { en la } \\
\text { estructur } \\
\text { a de } \\
\text { Trabajo } \\
\text { (tanto por } \\
\text { la } \\
\text { universid } \\
\text { ad como } \\
\text { el equipo } \\
\text { de } \\
\text { trabajo) }\end{array}$ & $\begin{array}{l}\text { Cambi } \\
\text { o de la } \\
\text { estruct } \\
\text { ura }\end{array}$ & Media & $\begin{array}{l}\text { Med } \\
\text { ia }\end{array}$ & $\begin{array}{l}\text { Aceptar - } \\
\text { Activame } \\
\text { nte }\end{array}$ & $\begin{array}{l}\text { Comunicar } \\
\text { con el } \\
\text { profesor } \\
\text { competente } \\
\text { los cambios } \\
\text { para hacer } \\
\text { los arreglos } \\
\text { necesarios. }\end{array}$ & $\begin{array}{l}\text { Comun } \\
\text { icación } \\
\text { con el } \\
\text { profeso } \\
\mathrm{r} \\
\text { compet } \\
\text { ente } \\
\text { para } \\
\text { evitar } \\
\text { cambio } \\
\text { s no } \\
\text { comuni } \\
\text { cados. }\end{array}$ & $\begin{array}{l}\text { Reunión } \\
\text { con el } \\
\text { profesor } \\
\text { gerente } \\
\text { para } \\
\text { evitar } \\
\text { cambios } \\
\text { no } \\
\text { esperado } \\
\text { s, }\end{array}$ \\
\hline $\begin{array}{l}\text { Cambios } \\
\text { en el } \\
\text { gobierno } \\
\text { que } \\
\text { modifiqu } \\
\text { en la } \\
\text { estructur } \\
\text { a actual }\end{array}$ & $\begin{array}{l}\text { Cualqu } \\
\text { ier } \\
\text { momen } \\
\text { to }\end{array}$ & $\begin{array}{l}\text { Muy } \\
\text { alta }\end{array}$ & $\begin{array}{l}\text { Muy } \\
\text { alta }\end{array}$ & Mitigar & $\begin{array}{l}\text { Comunicar } \\
\text { inmediatam } \\
\text { ente a los } \\
\text { jefes de } \\
\text { proyecto } \\
\text { para ver el } \\
\text { posible } \\
\text { impacto en }\end{array}$ & $\begin{array}{l}\text { Se } \\
\text { quitaro } \\
n \quad \text { del } \\
\text { alcance } \\
\text { entrega } \\
\text { bles y/o } \\
\text { artefact } \\
\text { os que }\end{array}$ & $\begin{array}{l}\text { Se } \\
\text { convers } \\
\text { ó con el } \\
\text { cliente } \\
\text { para } \\
\text { reducir } \\
\text { ciertos } \\
\text { entregab }\end{array}$ \\
\hline
\end{tabular}




\begin{tabular}{|c|c|c|c|c|c|c|c|}
\hline $\begin{array}{l}\text { de } \\
\text { gobierno } \\
\text { de } \\
\text { EsSalud, } \\
\text { resultand } \\
\text { o en una } \\
\text { dificultad } \\
\text { para las } \\
\text { coordina } \\
\text { ciones }\end{array}$ & & & & & $\begin{array}{l}\text { el alcance a } \\
\text { nivel de } \\
\text { informació } \\
\text { n obtenible }\end{array}$ & $\begin{array}{l}\text { no se } \\
\text { pueden } \\
\text { realizar } \\
\text { debido } \\
\text { a la } \\
\text { falta de } \\
\text { inform } \\
\text { ación }\end{array}$ & $\begin{array}{l}\text { les del } \\
\text { alcance } \\
\text { que no } \\
\text { afectara } \\
\text { n la } \\
\text { visión } \\
\text { holística } \\
\text { del } \\
\text { proyecto }\end{array}$ \\
\hline $\begin{array}{l}\text { Problema } \\
\text { s con los } \\
\text { recursos } \\
\text { de QS/IT } \\
\text { Service }\end{array}$ & $\begin{array}{l}\text { Apoyo } \\
\text { de } \\
\text { Recurs } \\
\text { os }\end{array}$ & Media & Alta & Mitigar & $\begin{array}{l}\text { Plantear } \\
\text { actividades } \\
\text { sencillas } \\
\text { para los } \\
\text { recursos de } \\
\text { QS para no } \\
\text { ser } \\
\text { impactados }\end{array}$ & $\begin{array}{l}\text { Respon } \\
\text { sabilid } \\
\text { ades y } \\
\text { tareas } \\
\text { control } \\
\text { adas } \\
\text { median } \\
\text { te el } \\
\text { cronog } \\
\text { rama }\end{array}$ & $\begin{array}{l}\text { Los jefes } \\
\text { de } \\
\text { proyecto } \\
\text { realizara } \\
\text { n las } \\
\text { activida } \\
\text { des en } \\
\text { tiempo } \\
\text { extra }\end{array}$ \\
\hline $\begin{array}{l}\text { Falta de } \\
\text { disponibi } \\
\text { lidad del } \\
\text { profesor } \\
\text { cliente }\end{array}$ & $\begin{array}{l}\text { Falta } \\
\text { de } \\
\text { tiempo }\end{array}$ & Media & Alta & Evitar & $\begin{array}{l}\text { Planificar } \\
\text { mediante } \\
\text { horarios la } \\
\text { comunicaci } \\
\text { ón del } \\
\text { cliente. }\end{array}$ & $\begin{array}{l}\text { Correo } \\
\mathrm{s} \\
\text { electró } \\
\text { nicos } \\
\text { con } \\
\text { fechas } \\
\text { para } \\
\text { entrevi } \\
\text { stas }\end{array}$ & $\begin{array}{l}\text { Agendar } \\
\text { reunión } \\
\text { vía sky u } \\
\text { otros } \\
\text { medíos } \\
\text { de } \\
\text { comunic } \\
\text { ación }\end{array}$ \\
\hline
\end{tabular}




\begin{tabular}{|c|c|c|c|c|c|c|c|}
\hline $\begin{array}{l}\text { Conocim } \\
\text { ientos } \\
\text { insuficie } \\
\text { ntes en } \\
\text { los } \\
\text { miembro } \\
\text { s del } \\
\text { proyecto }\end{array}$ & $\begin{array}{l}\text { Proces } \\
\text { o de } \\
\text { prepara } \\
\text { ción }\end{array}$ & Media & $\begin{array}{l}\text { Med } \\
\text { ia }\end{array}$ & $\begin{array}{l}\text { Aceptar - } \\
\text { Activame } \\
\text { nte }\end{array}$ & $\begin{array}{l}\text { Realizar } \\
\text { capacitacio } \\
\text { nes al } \\
\text { personal } \\
\text { antes de } \\
\text { iniciar la } \\
\text { implementa } \\
\text { ción del } \\
\text { proyecto }\end{array}$ & $\begin{array}{l}\text { Estable } \\
\text { cer el } \\
\text { marco } \\
\text { de } \\
\text { conoci } \\
\text { miento } \\
\text { de cada } \\
\text { uno de } \\
\text { los } \\
\text { miemb } \\
\text { ros del } \\
\text { grupo }\end{array}$ & $\begin{array}{l}\text { As Istir a } \\
\text { clases de } \\
\text { gestión } \\
\text { de } \\
\text { proyecto } \\
\text { o } \\
\text { arquitect } \\
\text { ura } \\
\text { empresa } \\
\text { rial }\end{array}$ \\
\hline $\begin{array}{l}\text { Que } \\
\text { salga una } \\
\text { nueva } \\
\text { versión } \\
\text { de alguno } \\
\text { de los } \\
\text { marcos } \\
\text { de } \\
\text { trabajo o } \\
\text { metodolo } \\
\text { gías } \\
\text { elegidos }\end{array}$ & $\begin{array}{l}\text { Proces } \\
\text { o de } \\
\text { prepara } \\
\text { ción }\end{array}$ & Baja & $\begin{array}{l}\text { Muy } \\
\text { Baja }\end{array}$ & $\begin{array}{l}\text { Aceptar - } \\
\text { Activame } \\
\text { nte }\end{array}$ & $\begin{array}{l}\text { Conciliar si } \\
\text { es necesario } \\
\text { realizar } \\
\text { alguna } \\
\text { modificació } \\
\text { n }\end{array}$ & $\begin{array}{l}\text { Definir } \\
\text { estado } \\
\text { del } \\
\text { framew } \\
\text { ork }\end{array}$ & $\begin{array}{l}\text { Agendar } \\
\text { reunione } \\
\text { s para } \\
\text { solucion } \\
\text { ar el } \\
\text { problem } \\
\text { a }\end{array}$ \\
\hline $\begin{array}{l}\text { Informac } \\
\text { ión } \\
\text { inaccesib } \\
\text { le o } \\
\text { escasa } \\
\text { sobre el }\end{array}$ & $\begin{array}{l}\text { Proces } \\
\text { o de } \\
\text { prepara } \\
\text { ción }\end{array}$ & Alta & $\begin{array}{l}\text { Muy } \\
\text { Alta }\end{array}$ & Mitigar & $\begin{array}{l}\text { Realizar } \\
\text { otros } \\
\text { medios de } \\
\text { comunicaci } \\
\text { ón }\end{array}$ & $\begin{array}{l}\text { Definir } \\
\text { estados } \\
\text { y actas } \\
\text { de } \\
\text { reunión } \\
\text { para la } \\
\text { definici } \\
\text { ón de }\end{array}$ & $\begin{array}{l}\text { Agendar } \\
\text { reunione } \\
\mathrm{s} \quad \text { para } \\
\text { solucion } \\
\text { ar el } \\
\text { problem } \\
\text { a }\end{array}$ \\
\hline
\end{tabular}




\begin{tabular}{|c|c|c|c|c|c|c|c|}
\hline $\begin{array}{l}\text { proceso y } \\
\text { cliente, }\end{array}$ & & & & & & $\begin{array}{l}\text { requeri } \\
\text { miento } \\
\mathrm{S}\end{array}$ & \\
\hline $\begin{array}{l}\text { Cambio } \\
\text { en los } \\
\text { requerimi } \\
\text { entos del } \\
\text { cliente. }\end{array}$ & $\begin{array}{l}\text { Proces } \\
\text { o de } \\
\text { prepara } \\
\text { ción }\end{array}$ & Media & Alta & Mitigar & $\begin{array}{l}\text { Conciliar si } \\
\text { es necesario } \\
\text { realizar } \\
\text { alguna } \\
\text { modificació } \\
\text { n }\end{array}$ & $\begin{array}{l}\text { Realiza } \\
\mathrm{r} \\
\text { supervi } \\
\text { siones } \\
\text { del } \\
\text { avance } \\
\text { del } \\
\text { proyect } \\
\text { o }\end{array}$ & $\begin{array}{l}\text { Agendar } \\
\text { reunione } \\
\mathrm{s} \text { para } \\
\text { solucion } \\
\text { ar el } \\
\text { problem } \\
\text { a }\end{array}$ \\
\hline
\end{tabular}

Fuente: Elaboración Propia 


\section{Capítulo 2: Logros de los Resultados de los}

\section{Alumnos}

En este capítulo, se describe como se ha cumplido los "student outcomes" que propone la carrera de ingeniería de sistemas de información de UPC, el cual tiene como objetivo medir la calidad del servicio y rendimiento de los mismos frente a estándares que se maneja al aplicarlos al proyecto de tesis del profesional. 


\section{The Student Outcomes}

El objetivo del cumplimiento de los "Student Outcomes" es lograr que los estudiantes de ingeniería de sistemas de información sepan y sean capaces de cumplir los requisitos de la acreditación ABET para la carrera profesional. Estos se relacionan con los conocimientos, habilidades y comportamientos que los estudiantes adquieren a medida que avanzan a través de la vida universitaria.

\section{Criterios de Ingeniería de Sistemas de Información}

Tabla 3: Lista de Student Outcomes

\begin{tabular}{|l|l|}
\hline Student Outcome (a) & $\begin{array}{l}\text { Propone soluciones en sistemas de información aplicando } \\
\text { principios de matemática, ciencias, computación e ingeniería. }\end{array}$ \\
\hline Student Outcome (b) & $\begin{array}{l}\text { Diseña y conduce experimentos en base al análisis e } \\
\text { interpretación de datos relevantes en la implementación de } \\
\text { sistemas de información. }\end{array}$ \\
\hline Student Outcome (c) & $\begin{array}{l}\text { Diseña sistemas y componentes para la implementación de un } \\
\text { económicas, sociales, políticas, éticas y otras propias del } \\
\text { entorno empresarial. }\end{array}$ \\
\hline Student Outcome (d) & $\begin{array}{l}\text { Participa en equipos multidisciplinarios liderando o } \\
\text { desarrollando sus tareas eficientemente con profesionales de } \\
\text { diferentes especialidades o dominios de aplicación. }\end{array}$ \\
\hline Student Outcome (e) & $\begin{array}{l}\text { Identifica y analiza problemas de negocio o tecnológicos } \\
\text { dentro del ciclo de vida de un sistema de información con } \\
\text { alcance empresarial o inter empresarial. }\end{array}$ \\
\hline responsabilidad profesional y ética. \\
\hline
\end{tabular}




\begin{tabular}{|l|l|}
\hline Student Outcome $(\mathrm{g})$ & $\begin{array}{l}\text { Comunica ideas o resultados orales o escritos con claridad y } \\
\text { efectividad a públicos de diferentes especialidades y niveles } \\
\text { jerárquicos. }\end{array}$ \\
\hline Student Outcome (h) & $\begin{array}{l}\text { Identifica el impacto de las soluciones en sistemas de } \\
\text { información en el contexto global, económico y del entorno en } \\
\text { la sociedad. }\end{array}$ \\
\hline Student Outcome (i) & $\begin{array}{l}\text { Actualiza los conocimientos en metodologías, técnicas, } \\
\text { herramientas por ser necesarios para mantener la vigencia en } \\
\text { el desarrollo de sistemas de información. }\end{array}$ \\
\hline Student Outcome (j) & $\begin{array}{l}\text { Analiza hechos del mundo contemporáneo identificando el } \\
\text { impacto en el desempeño profesional del ingeniero de sistemas } \\
\text { de información. }\end{array}$ \\
\hline Student Outcome $(\mathrm{k})$ & $\begin{array}{l}\text { Utiliza técnicas y herramientas de última generación en el } \\
\text { desarrollo de sistemas de información. }\end{array}$ \\
\hline Student Outcome (J) & $\begin{array}{l}\text { Comprende y brinda soporte para el uso, entrega y gestión de } \\
\text { sistemas de información dentro de un entorno de sistemas de } \\
\text { información. }\end{array}$ \\
\hline
\end{tabular}

Fuente: UPC

\section{Cumplimiento de los Student Outcome}

A continuación, se mostrará cómo se llegó a cumplir cada "Student Outcome" para proyecto de tesis de arquitectura empresarial al proceso de prestación social de EsSalud.

Tabla 4: Resultado del Cumplimiento de los Student Outcomes

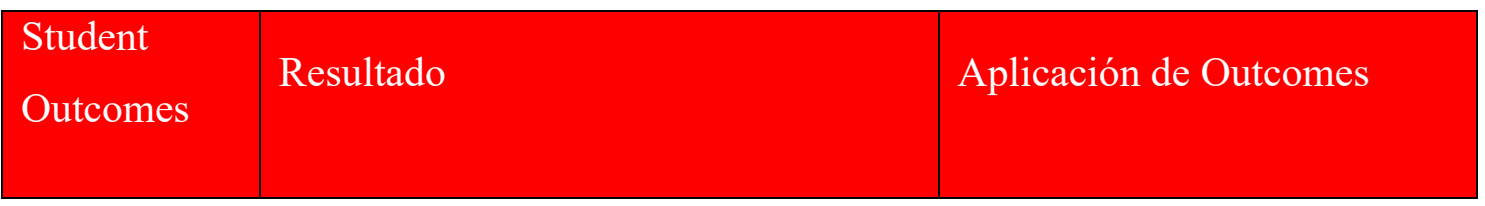




\begin{tabular}{|c|c|c|}
\hline $\begin{array}{l}\text { Student } \\
\text { Outcome (a) }\end{array}$ & $\begin{array}{l}\text { Se propone una solución que involucra } \\
\text { una infraestructura tecnológica que } \\
\text { soporte los dominios de negocio, datos } \\
\text { y aplicaciones del macro proceso de } \\
\text { prestación social. También una } \\
\text { aplicación hecha a medida, la cual } \\
\text { tendrá seis módulos que soporten los } \\
\text { procesos de gestionar atención del } \\
\text { CAM y CERP. Además de aplicar } \\
\text { cálculos matemáticos para la } \\
\text { elaboración de la factibilidad } \\
\text { financiera del proyecto y estimación } \\
\text { numérica de la simulación/variación. }\end{array}$ & $\begin{array}{l}\text {-Conocimiento de principios } \\
\text { arquitectura empresarial } \\
\text { (Zachman / TOGAF) y } \\
\text { gestión } \\
\text { proyectos(PMBOK) } \\
\text {-Conocimiento de redes, } \\
\text { sistemas operativos y base de } \\
\text { datos. } \\
\text {-Conocimiento de desarrollo } \\
\text { en lenguaje C++, C\# y Java. } \\
\text {-Conocimiento de matemática } \\
\text { básica, } \\
\text { computacional, finanzas y } \\
\text { contabilidad. }\end{array}$ \\
\hline $\begin{array}{l}\text { Student } \\
\text { Outcome (b) }\end{array}$ & $\begin{array}{l}\text { Se diseñó, ejecuto y ajusto las } \\
\text { simulaciones en repetidas ocasiones de } \\
\text { los procesos de gestionar atención del } \\
\text { CAM y CERP para lograr validar la } \\
\text { solución. Cabe mencionar que la } \\
\text { simulación se elaboró con información } \\
\text { real obtenida de primera fuente del } \\
\text { cliente del proyecto. }\end{array}$ & $\begin{array}{l}\text {-Conocimiento del curso de } \\
\text { medición y evaluación de } \\
\text { procesos. } \\
\text {-Conocimientos del curso } \\
\text { métricas, herramientas y } \\
\text { mejora de procesos. }\end{array}$ \\
\hline $\begin{array}{l}\text { Student } \\
\text { Outcome (c) }\end{array}$ & $\begin{array}{l}\text { Se creó un modelo de arquitectura } \\
\text { empresarial que presenta los cuatro } \\
\text { dominios (negocio, datos, aplicaciones } \\
\text { y tecnología), el cual solucione el } \\
\text { problema de prestación social y pueda } \\
\text { atender su público objetivo y su } \\
\text { trabajo interno correctamente. } \\
\text { También se desarrolló un sistema web }\end{array}$ & $\begin{array}{l}\text {-Conocimiento de notación } \\
\text { archimate. } \\
\text {-Conocimiento } \\
\text { diagramación } \\
\text { normalización de base de } \\
\text { datos. }\end{array}$ \\
\hline
\end{tabular}




\begin{tabular}{|c|c|c|}
\hline & $\begin{array}{l}\text { que sea soportado por la arquitectura } \\
\text { presentada. El modelo se diseñaro a } \\
\text { partir del análisis e interpretación de } \\
\text { información obtenida de los } \\
\text { documentos que presenta la web de } \\
\text { transparencia de EsSalud, pero } \\
\text { basándolo bajo las restricciones } \\
\text { económicas, sociales, políticas y éticas } \\
\text { propias de la entidad. La información } \\
\text { se refleja en los documentos de } \\
\text { organizational model for Enterprise } \\
\text { architecture, statement of architecture } \\
\text { work y visión architecture. }\end{array}$ & $\begin{array}{l}\text {-Prácticas pre profesionales } \\
\text { para decidir la correcta } \\
\text { decisión de solución }\end{array}$ \\
\hline $\begin{array}{l}\text { Student } \\
\text { Outcome (d) }\end{array}$ & $\begin{array}{l}\text { En el proyecto descrito se tuvo } \\
\text { comunicación, debate e interacción } \\
\text { con profesionales de diferentes } \\
\text { especialidades, como los siguientes: } \\
\text { Diseñador grafico } \\
\text { Software y sistemas } \\
\text { Finanzas } \\
\text { Doctores, enfermeras y técnicos de } \\
\text { salud. }\end{array}$ & $\begin{array}{l}\text {-Conocimiento básico de } \\
\text { finanzas para establecer } \\
\text { conversaciones de trabajo. } \\
\text {-Conocimiento de } \\
\text { bioingeniería para entender } \\
\text { términos de los especialistas } \\
\text { de salud. }\end{array}$ \\
\hline $\begin{array}{l}\text { Student } \\
\text { Outcome (e) }\end{array}$ & $\begin{array}{l}\text { Al inicio del proyecto se identificó y } \\
\text { analizo el principal problema del } \\
\text { macro proceso de prestación social de } \\
\text { acuerdo a las reuniones de trabajo con } \\
\text { el cliente y a las visitas a los centros } \\
\text { especializados. Posterior a ello se pasó }\end{array}$ & $\begin{array}{l}\text {-Conocimiento del curso de } \\
\text { requerimiento de sistemas de } \\
\text { información. }\end{array}$ \\
\hline
\end{tabular}




\begin{tabular}{|c|c|c|}
\hline & $\begin{array}{l}\text { a definir el alcance, los objetivos e } \\
\text { indicadores de éxito del proyecto. }\end{array}$ & \\
\hline $\begin{array}{l}\text { Student } \\
\text { Outcome (f) }\end{array}$ & $\begin{array}{l}\text { Se propuso una solución que } \\
\text { contempla un modelo de arquitectura } \\
\text { que satisfaga la expectativa del macro } \\
\text { proceso de prestación social. Teniendo } \\
\text { en consideración el profesionalismo } \\
\text { obtenido durante el tiempo de } \\
\text { prácticas pre profesional y } \\
\text { conocimiento por estudiar la carrera de } \\
\text { ingeniería de sistemas de información. }\end{array}$ & $\begin{array}{l}\text {-Cursos propios de la carrera } \\
\text { de ingeniería de sistemas de } \\
\text { información. } \\
\text {-Practicas pre profesional. }\end{array}$ \\
\hline $\begin{array}{l}\text { Student } \\
\text { Outcome (g) }\end{array}$ & $\begin{array}{l}\text { Se llegó a un entendimiento claro y } \\
\text { conciso en todas las reuniones de } \\
\text { trabajo. Además, superando las } \\
\text { expectativas propuestas al momento } \\
\text { de explicar la solución tecnología a los } \\
\text { especialistas de salud y a otros perfiles } \\
\text { profesionales. Cabe mencionar que la } \\
\text { comunicación fue presencial y vía } \\
\text { hangout con algunos especialistas. }\end{array}$ & $\begin{array}{l}\text {-Conocimiento de cursos de } \\
\text { emprendimiento para } \\
\text { proponer una idea/solución } \\
\text { atractiva para la empresa. }\end{array}$ \\
\hline $\begin{array}{l}\text { Student } \\
\text { Outcome (h) }\end{array}$ & $\begin{array}{l}\text { La solución de arquitectura } \\
\text { empresarial planteada para el macro } \\
\text { proceso de prestación social y los } \\
\text { procesos de gestionar atención del } \\
\text { CERP y CAM contempla la realidad } \\
\text { de EsSalud en aspectos legales, } \\
\text { proceso, económico y contexto de la } \\
\text { institución de salud. La solución en } \\
\text { mención tubo en consideraciones la }\end{array}$ & $\begin{array}{l}\text {-Aceptación del modelo de } \\
\text { arquitectura empresarial. }\end{array}$ \\
\hline
\end{tabular}




\begin{tabular}{|c|c|c|}
\hline & $\begin{array}{l}\text { realidad de infraestructura que maneja } \\
\text { el datacenter, posibilidades de } \\
\text { adquisitivas del macro proceso y } \\
\text { consideraciones legales y contextuales } \\
\text { que permite la entidad de salud en base } \\
\text { a las regulaciones que le impone el } \\
\text { MINSA. }\end{array}$ & \\
\hline $\begin{array}{l}\text { Student } \\
\text { Outcome (i) }\end{array}$ & $\begin{array}{l}\text { Durante el desarrollo del proyecto se } \\
\text { utilizó el framework TOGAF } 9.1 \text { y el } \\
\text { PMBOK 5, ambas metodologías } \\
\text { brindando documentación pertinente } \\
\text { para solución de cada hito del proyecto }\end{array}$ & $\begin{array}{l}\text {-Conocimiento de TOGAF } \\
9.1 \text { y PMBOK } 5 \text { por los cursos } \\
\text { de arquitectura empresarial y } \\
\text { gestión de proyectos } \\
\text { respectivamente. }\end{array}$ \\
\hline $\begin{array}{l}\text { Student } \\
\text { Outcome (j) }\end{array}$ & $\begin{array}{l}\text { En el proyecto en mención se analizó } \\
\text { procesos, tecnología, soluciones y } \\
\text { modelos de referencia de otros países } \\
\text { como Chile, Uruguay, Canadá y Suiza. } \\
\text { Llevando a un mayor análisis por no } \\
\text { encontrar un proceso de prestación } \\
\text { social de salud igual en objetivos a los } \\
\text { demás investigados. }\end{array}$ & $\begin{array}{l}\text {-Conocimiento de seminario } \\
\text { de investigación al momento } \\
\text { de buscar paper relacionados } \\
\text { al proceso. }\end{array}$ \\
\hline $\begin{array}{l}\text { Student } \\
\text { Outcome (k) }\end{array}$ & $\begin{array}{l}\text { Se utilizó técnicas actualizadas para el } \\
\text { modelado de proceso descriptivo bajo } \\
\text { el estándar de BPMN } 2.0 \text { y } \\
\text { diagramado de la arquitectura en } \\
\text { archimate. Además de la utilización de } \\
\text { las mejores prácticas para el desarrollo } \\
\text { de la solución de arquitectura } \\
\text { empresarial bajo el framework de } \\
\text { TOGAF. Cabe mencionar que es el } \\
\text { principal marco de trabajo del mercado } \\
\text { laboral por proponer soluciones que }\end{array}$ & $\begin{array}{l}\text {-Conocimiento de } \\
\text { metodologías y frameworks } \\
\text { que proporciona los cursos de } \\
\text { la carrera de ingeniería de } \\
\text { sistemas de información. }\end{array}$ \\
\hline
\end{tabular}




\begin{tabular}{|c|c|c|}
\hline & $\begin{array}{l}\text { abarquen los cuatro dominios de una } \\
\text { empresa. }\end{array}$ & \\
\hline $\begin{array}{l}\text { Student } \\
\text { Outcome (J) }\end{array}$ & $\begin{array}{l}\text { Proponer un plan de continuidad que } \\
\text { contenga acciones, información e } \\
\text { indicadores para que la arquitectura y } \\
\text { el sistema propuesto se mantengan en } \\
\text { el tiempo. Además, se brindará } \\
\text { diagramas del proceso As Is y To Be } \\
\text { para el mejor entendimiento y } \\
\text { solución. }\end{array}$ & $\begin{array}{l}\text {-Practicas pre profesional y } \\
\text { cocimientos propios. }\end{array}$ \\
\hline
\end{tabular}

Fuente: Elaboración Propia 


\section{Capítulo 3: Marco Teórico}

En este capítulo, se describe el marco teórico y definiciones involucradas a lo largo del desarrollo de la arquitectura empresarial al macro proceso de prestación social de ESSALUD. 


\section{Prestacion Social}

Es llamado como el desarrollo de programas y proyectos sociales que contribuyan a mejorar la calidad de vida de los adultos mayores y de las personas con discapacidad procurando la promoción y el desarrollo individual, social y de las instituciones vinculadas a esos colectivos (Instituto de seguro social - Uruguay, s.f.).

\section{Adulto Mayor}

La organización mundial de la salud (OMS) considera como adulto mayor a quien tienen una edad mayor o igual de 60 años en los países en vías de desarrollo y de 65 años o más a quienes viven en países desarrollados (Olmedo, 2003).

\section{Adulto Mayor Independiente}

Es aquella persona adulta mayor capaz de realizar las actividades básicas de la vida diaria.

\section{Adulto Mayor Independiente con Riesgo}

Persona con aumento de la susceptibilidad a la discapacidad, es decir aquella persona adulto mayor con alguna patológica crónica.

\section{Adulto Mayor Dependiente}

Persona con restricción o ausencia física o funcional que limita o impide el desempeño de las actividades de la vida diaria (Educar chile).

\section{Persona con Discapacidad}

Término genérico que abarca deficiencias, limitaciones de la actividad y restricciones a la participación de actividades. Además, se entiende por discapacidad la interacción entre las personas que padecen alguna enfermedad (por ejemplo, parálisis cerebral, síndrome de Down y depresión) y factores personales y ambientales (por ejemplo, actitudes negativas, transporte y edificios públicos inaccesibles y un apoyo social limitado) (Organización mundial de la salud (OMS), 2016).

\section{Reinserción / Rehabilitación Social}

Es el proceso mediante el cual, con el uso coordinado y combinado de medidas médicas, educativas y vocacionales, se ayuda a los individuos discapacitados (con limitaciones 
físicas, sensoriales o mentales) a alcanzar los más altos niveles funcionales posibles y a integrarse a la sociedad.

\section{Reinserción / Rehabilitación Laboral}

Se refiere a un proceso continuo y coordinado que comprende el suministro de servicios de evaluación, orientación profesional, formación profesional y colocación selectiva para que la persona con limitaciones pueda obtener, conservar y promoverse en un empleo, logrando así el reintegro de esta persona a la sociedad (Badilla, 1997)

\section{Project Management Body of Knowledge (PMBOK)}

La guía del PMBOK (Project Management Book Of Knowledge) es el que contiene el estándar para la dirección de proyectos del PMI (Project Management Institute), el cual integra los conocimientos de buenas prácticas para la ejecución de proyectos. El PMBOK también proporciona pautas, herramientas, técnicas y vocabulario para aumentar las posibilidades de éxito del proyecto a desarrollarse (PMI, 2013).

\section{Fases del PMBOK}

1. Inicio

Está fase de inicio está compuesto por aquellos procesos que definen un nuevo proyecto o una nueva fase de un proyecto existente al obtener la autorización para iniciar el proyecto o fase. Dentro del ámbito de inicio es donde se define el alcance inicial y se comprometen los recursos financieros iniciales. Además, se identifican los interesados internos y externos que van a participar y ejercer alguna influencia sobre el resultado global del proyecto. El principal propósito de esta fase es alinear las expectativas de los interesados con el propósito del proyecto, darles visibilidad sobre el alcance y los objetivos, y mostrar cómo su participación en el proyecto y sus fases asociadas puede asegurar el logro del proyecto.

\section{Planificación}

Está fase de planificación está compuesto por aquellos procesos que establecen el alcance total del proyecto, definir y refinar los objetivos, y desarrollar la línea de acción requerida para alcanzar los objetivos propuestos.

\section{Ejecución}


Esta fase de ejecución está compuesta por aquellos procesos que realizan el trabajo definido en el plan para la dirección del proyecto a fin de cumplir con las especificaciones del mismo. Este grupo de procesos implica coordinar personas, recursos, gestionar las expectativas de los interesados y realizar las actividades del proyecto conforme al plan para la dirección del proyecto. Durante la ejecución del proyecto se puede requerir una actualización de la planificación y una revisión de la línea base, lo que conlleva a cambios en la duración prevista de las actividades, cambios en la disponibilidad y productividad de los recursos, así como riesgos no previstos.

\section{Control y monitoreo}

Esta fase de control y monitoreo está compuesta por aquellos procesos requeridos para rastrear, analizar y dirigir el progreso con el desempeño del proyecto, para identificar áreas en las que el plan requiera cambios y para iniciar los cambios correspondientes.

\section{Cierre}

Esta fase de cierre está compuesta por aquellos procesos que finalizan todas las actividades de los grupos de la dirección de proyectos, a fin de completar formalmente el proyecto. Esta fase se centra en verificar que los procesos definidos se han completado dentro de todos los grupos de procesos a fin de cerrar el proyecto o una fase del mismo, según corresponda, y establece formalmente que el proyecto o fase del mismo ha finalizado (PMI, 2013). 
Ilustración 6: Interacciones entre Procesos de la Dirección de Proyectos

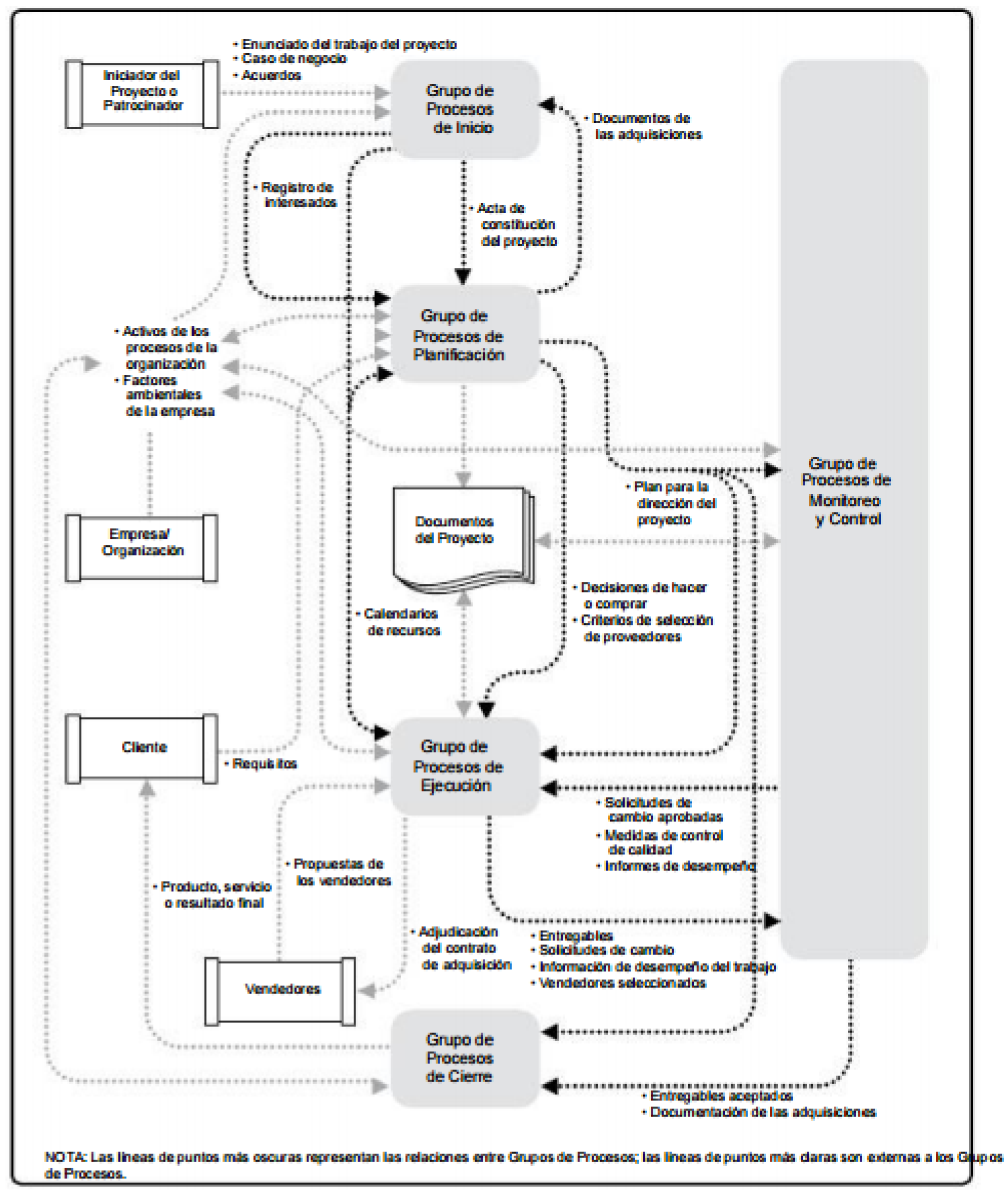

Fuente: Guía del PMBOK 5² Edición 


\section{Áreas del Conocimiento PMBOK}

1. Gestión de Integración de Proyectos

La gestión de la integración del proyecto incluye los procesos y actividades necesarios para identificar, definir, combinar, unificar y coordinar los diversos procesos $\mathrm{y}$ actividades de dirección del proyecto dentro de los grupos de procesos de la dirección de proyectos. En el contexto de la dirección de proyectos, la integración incluye características de unificación, consolidación, comunicación y acciones integradoras cruciales para que el proyecto se lleve a cabo de manera controlada.

\section{Gestión del Alcance del Proyecto}

La gestión del alcance del proyecto incluye los procesos necesarios para garantizar que tenga la definición y el control del trabajo requerido para completar el proyecto. Además de validar y controlar que el flujo del proyecto sea el adecuado y su éxito depende directamente de la participación activa de los interesados en el descubrimiento y la descomposición de las necesidades en requisitos y del cuidado que se tenga al determinar, documentar y gestionar los requisitos del producto, servicio o resultado del proyecto.

\section{Gestión de Tiempo del Proyecto}

La gestión de tiempo del proyecto describe los procesos requeridos para asegurar el proyecto en términos de tiempo. Esta consiste en la definición de las actividades, la secuencia de las actividades, estimación de la duración de las actividades, desarrollo del programa y control del programa.

\section{Gestión de Costos del Proyecto}

La gestión de costos del proyecto describe los procesos requeridos para planificar, estimar, presupuestar, financiar, obtener financiamiento, gestionar y controlar los costos de modo que se complete el proyecto dentro del presupuesto aprobado. La gestión de los costos del proyecto debería tener en cuenta los requisitos de los diversos interesados que medirán los costos del proyecto de diferentes maneras y en momentos diferentes. Este proceso se centra principalmente del costo de los recursos necesarios para completar las actividades del proyecto. También debería tener en cuenta el efecto de las decisiones tomadas en el proyecto sobre los costos recurrentes posteriores de utilizar, mantener y dar soporte al proyecto.

5. Gestión de Calidad del Proyecto 
La gestión de la calidad del proyecto incluye los procesos y actividades de la organización ejecutora que establecen las políticas de calidad, los objetivos y las responsabilidades de calidad para que el proyecto satisfaga las necesidades propuestas en la gestión de alcance. También utiliza políticas y procedimientos para implementar el sistema de gestión de la calidad de la organización en el contexto del proyecto y en la forma que resulte adecuada, apoya las actividades de mejora continua del proceso, tal y como las lleva a cabo la organización ejecutora.

\section{Gestión de Recursos Humanos del Proyecto}

La gestión de los recursos humanos del proyecto incluye los procesos que organizan, gestionan y conducen al equipo del proyecto. El equipo del proyecto está compuesto por las personas a las que se han asignado roles y responsabilidades para completar el proyecto. Los miembros del equipo del proyecto pueden tener diferentes conjuntos de habilidades, pueden estar asignados a tiempo completo o a tiempo parcial y se pueden incorporar o retirar del equipo conforme avanza el proyecto. También se puede referir a los miembros del equipo del proyecto como personal del proyecto. Si bien se asignan roles y responsabilidades específicos a cada miembro del equipo del proyecto, la participación de todos los miembros en la toma de decisiones y en la planificación del proyecto es beneficiosa para el éxito del proyecto.

\section{Gestión de Comunicaciones del Proyecto}

La gestión de las comunicaciones del proyecto incluye los procesos requeridos para asegurar que la planificación, recopilación, creación, distribución, almacenamiento, recuperación, gestión, control, monitoreo y disposición final de la información del proyecto sean oportunos y adecuados. Los interesados de proyecto emplean la mayor parte de su tiempo comunicándose con los miembros del equipo y otros interesados en el proyecto, tanto si son internos (en todos los niveles de la organización) como externos a la misma. Una comunicación eficaz crea un puente entre diferentes interesados que pueden tener diferentes antecedentes culturales y organizacionales, diferentes niveles de experiencia, y diferentes perspectivas e intereses, lo cual impacta o influye en la ejecución o resultado del proyecto.

\section{Gestión de Riesgos del Proyecto}

La gestión de los riesgos del proyecto incluye los procesos para llevar a cabo la planificación de la gestión de riesgos, así como la identificación, análisis, planificación 
de respuesta y control de los riesgos de un proyecto. Los objetivos de la gestión de los riesgos del proyecto consisten en aumentar la probabilidad y el impacto de los eventos positivos, y disminuir la probabilidad y el impacto de los eventos negativos en el proyecto.

9. Gestión de las Adquisiciones de Proyectos

La gestión de las adquisiciones del proyecto incluye los procesos necesarios para comprar o adquirir productos, servicios o resultados que es preciso obtener fuera del equipo del proyecto. La organización puede ser la compradora o vendedora de los productos, servicios o resultados de un proyecto. Además, incluye los procesos de gestión del contrato y de control de cambios requeridos para desarrollar y administrar contratos $\mathrm{u}$ órdenes de compra emitidos por miembros autorizados del equipo del proyecto.

\section{Arquitectura Empresarial}

La arquitectura empresarial según Gartner es el proceso de trasladar una visión y estrategia de negocio en un cambio efectivo, comunicando las capacidades actuales y repensando los principios y los modelos que describen el estado futuro de la empresa y facilitan su evolución (Gartner, s.f.).

TOGAF, framework de arquitectura empresarial proporcionado por Open group, proporciona los métodos y herramientas para ayudar a la aceptación, la producción, el uso y el mantenimiento de una arquitectura empresarial. Se basa en un modelo de proceso iterativo con el apoyo de las mejores prácticas y un reutilizable conjunto de activos existente.

No obstante, la arquitectura empresarial para TOGAF, se divide en cuatro dominios:

- Arquitectura de Negocios, la cual define la estrategia de negocios, la gobernabilidad, la estructura y los procesos clave de la organización.

- Arquitectura de Aplicaciones, la cual provee un plano para cada uno de los sistemas de aplicación que se requiere implantar, las interacciones entre estos sistemas y sus relaciones con los procesos de negocio centrales de la organización.

- Arquitectura de Datos, la cual describe la estructura de los datos físicos y lógicos de la organización, y los recursos de gestión de estos datos. 
- Arquitectura Tecnológica, la cual describe la estructura de hardware, software y redes requerida para dar soporte a la implantación de las aplicaciones principales, de misión crítica, de la organización.

El framework TOGAF agrupa en 3 categorías sus principales productos de la arquitectura empresarial:

\section{Entregable}

Es el producto que esta contractualmente definido y que es revisado, acordado y firmado por los actores. La unión de estos entregables forma un proyecto.

\section{Artefacto:}

Es un producto más granular que describe una arquitectura desde un punto de vista. Ejemplos: diagrama de red, especificación de un servidor, una especificación de un caso de uso. Se subdivide en: Catálogos (listas de cosas), Matrices (relaciones entre cosas) y Diagramas (pinturas de cosas)

\section{Bloque Constructivo:}

Representa un componente (potencialmente reusable) de negocios, de tecnología de información, o una capacidad arquitectural que combina otros bloques constructivos. Los bloques constructivos pueden ser definidos a varios niveles: ABBs (Architecture Building Blocks) típicamente describen la capacidad requerida en la forma de SBBs (Solution Building Blocks) que representan componentes que son usados para implementar una capacidad requerid.

La metodología de TOGAF es el Architecture Development Method (ADM) el cual maneja 9 fases para el desarrollo de la arquitectura empresarial (The Open group framework). Además, el ADM es el resultado de las contribuciones continuas a partir de un gran número de profesionales de la arquitectura. En él se describe un método para el desarrollo y gestión del ciclo de vida de una arquitectura empresarial, y constituye el núcleo de TOGAF y otros activos arquitectónicos disponibles, para cumplir con el negocio y las necesidades de TI de una organización (The Open group framework).

Ilustración 7: Ciclo del ADM 


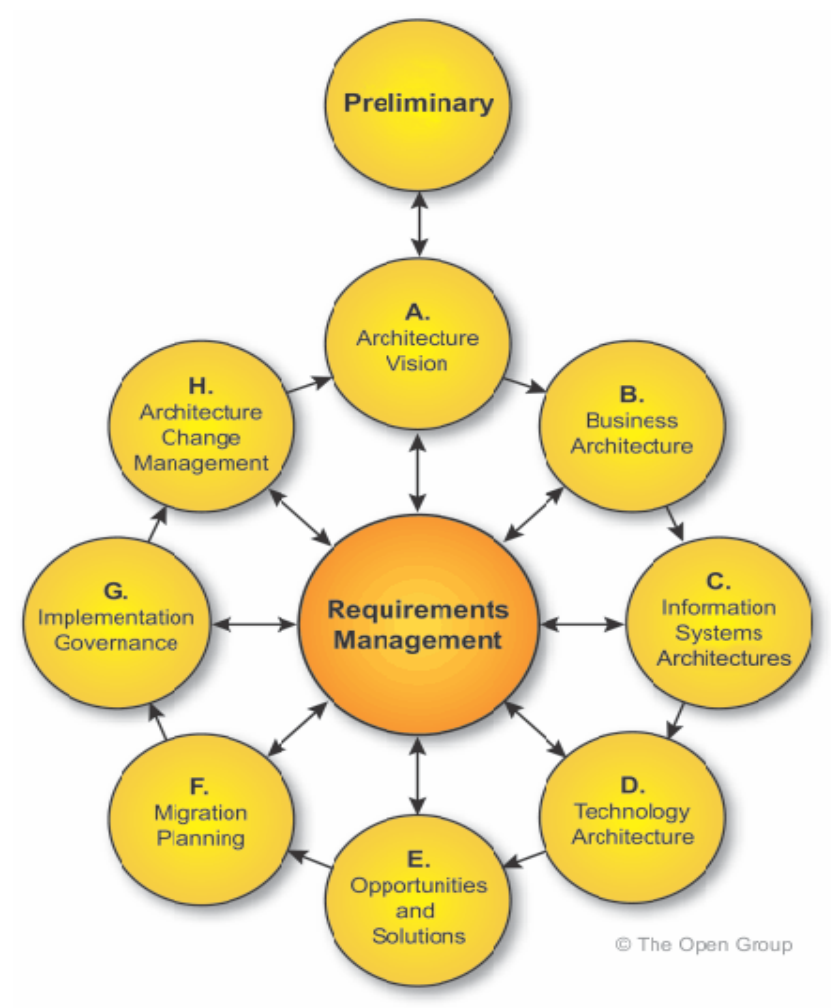

Fuente: OPENGROUP 


\section{Capítulo 4: Estado del Arte}

En este capítulo se detallará los estados de arte de las investigaciones científicas que sustentan la viabilidad del proyecto. Además, se mostrará investigaciones de metodologías de framework orientadas a salud y estudios relacionados al proceso de prestación social. 


\section{Investigación del Estado del Arte}

La propuesta de solución de la arquitectura empresarial para el proceso de prestación social de EsSalud se basa en la búsqueda de artículos científicos que aportan beneficios de usar una arquitectura empresarial como solución a un problema. El framework escogido es TOGAF con la metodología ADM, y el BPM para la fase de negocio. Por tal fin solo se escogieron artículo que tienen fecha de publicación desde el 2013 al 2017 y fuente origen de publicación de los bancos de información de la universidad Peruana de Ciencias Aplicadas(UPC) como ACM Digital Library DL, IEEE Xplore, Computer Applied Sciences Complete, Springer y Proquest.

\section{Revisión de la Literatura}

Durante la búsqueda de artículos científicos se identificó que cada investigación aporta consistencia y valor para el desarrollo del metamodelo de una arquitectura empresarial con los cuatro dominios de negocio, datos, aplicaciones y tecnología para el proceso de prestación social de EsSalud.

\section{Beneficios de una Arquitectura Empresarial}

Esta sección muestra un artículo que aporta los beneficios de usar una arquitectura empresarial como solución de cualquier empresa que tenga problemas de negocio y la cual busca resultados con el apoyo de los sistemas de información (software) e infraestructura tecnológica (hardware).

La arquitectura empresarial según Daniel Simon, Kai Fischbach y Detlef Schoder es un modelo de solución adaptada a una organización que esencialmente busca la mejora del negocio, pero basándose en la tecnología que tiene o va a adquirir en software o hardware (Daniel Simon, 2013). Entre los principales beneficios de una arquitectura mencionan lo siguiente:

- Analiza el negocio a nivel interno de estructura organizativa y externa con sus competidores.

- Reduce el costo de operaciones y proyectos futuros de TI.

- Facilita la elección de estrategia en el análisis de modelos de negocio y la ejecución del diseño. 
- Ayuda a la evaluación del estado que esta la organización a nivel de tecnología hardware y software.

- Apoya en la toma de decisión con respecto a la estrategia de implementación de la solución de la organización.

- Desarrolla el diseño del plan de mantención de la solución.

- Facilita la gestión estratégica corporativa y el gobierno que TI de la empresa.

\section{Beneficios de una Arquitectura Empresarial con TOGAF}

Esta sección muestra artículos que aporta beneficios de adoptar una arquitectura empresarial con marco de trabajo de TOGAF, gobierno de TI y sub investigaciones que aportar valor para el presente trabajo.

Los investigadores Jam L. G. Dietz y Jam A.P. Hoogervorst sostienen que para buscar un framework de arquitectura empresarial sea adecuado para una organización, este debe de alinearse a los objetivos de la empresa y al equipo de trabajo de TI que va a desarrollar el proyecto de arquitectura empresarial. Además, sostienen que The Open Group Architecture Framework (TOGAF) se integra con facilidad a una empresa y a los sistemas de software de TI que tiene en funcionamiento. También al momento de aplicar TOGAF a una organización se garantiza cambios favorables de rentabilidad, unificación e integración una empresa. Una solución por parte de Dietz y Hoogervorst es crear como primera instancia la interconexión de la empresa y de allí en adelante desarrollar el Roadmap del proyecto de la arquitectura. No obstante, estos autores proponen cuatro dominios basados en los de TOGAF. Los dos primeros dominios de Negocio y tecnología con un mismo enfoque respecto a los de Open Group, el de información que engloba los dominios de datos y aplicación. Y por último el dominio de organización con un enfoque de estandarizar los roles y organigramas de una empresa (Hoogervorst, 2013).

Otro estudio que apoya la propuesta de estos autores son las investigaciones de Tobias Mueller, Denis Schuldt, Birgit Sewald y Marcel Morisse del departamento de informática de la universidad de Hamburgo - Alemania donde ellos analizaron 24 investigaciones y 37 desafíos de proyectos relacionados con TOGAF, llegando a la conclusión que este framework ayuda a integrar los procesos, datos, infraestructura y aplicaciones de una 
organización. Además, brinda una visión genérica y holística de los diferentes puntos que tienen los stakeholder de una empresa. Cabe mencionar del análisis de los autores es que si se tiene una arquitectura de TI de diferente framework o sistemas ad hoc se puede adaptar con TOGAF para desarrollar un modelo de solución y mejorar la organización. El gobierno de TI de TOGAF ayuda a identificar las partes interesas que no se tenían mapeadas, las funciones de control faltantes y evaluación de riesgos (Tobias Mueller, 2013).

\section{Procesos BPM Alineados a la Fase de Negocio de TOGAF}

Esta categoría muestra un artículo que apoya el uso de BPMN como solución a la capa de negocio de una empresa usando el marco de trabajo de TOGAF.

Un estudio por parte de Ramtín Mesbahipour, André Nursinsky y Michael Spiller sostienen que por ser TOGAF un framework basado en la ISO 42010 maneja herramientas para el desarrollo de soluciones como el lenguaje de modelamiento Archimate, esquemas de clasificación y una metodología. También mencionan que por ser un framework con estas características es adaptable con otros modelos de solución como con el Subject Business Process Model (S-BPM) porque permite obtener una visión grafica de los procesos AS IS de la organización (capa negocio) desde un nivel de macro proceso hasta el nivel proceso con actividades con el fin de emular una solución TO BE. Cabe mencionar que unas de las deficiencias de este marco de trabajo mencionado por el estudio de los Sr's Mueller, Schuldt, Seweld y Morisse es que el framework de TOGAF no soporta una arquitectura para un grupo corporativo, pero brinda recomendaciones para el diseño de una arquitectura empresarial de este tipo (Ramtín Mesbahipour, 2014). 
Ilustración 8: Integración BPM CON ADM

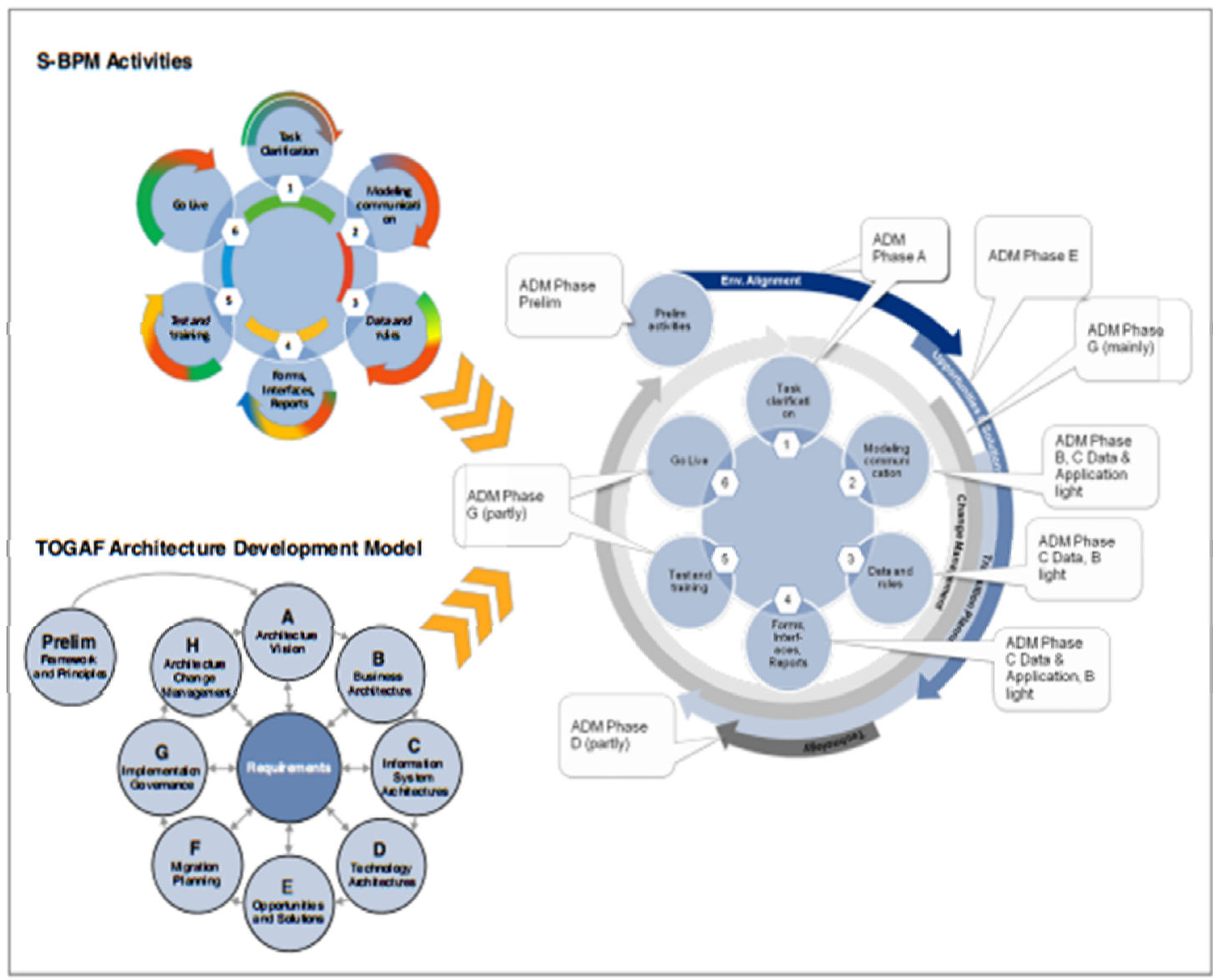

Fuente: Paper R. Mesbahipour

\section{Arquitectura Empresarial en Hospitales}

\section{Solución Viable de Implementar una Arquitectura a un Hospital Europeo}

Esta categoría muestra un artículo que sostiene el éxito de implementar una arquitectura empresarial con TOGAF a un hospital de Europa.

Las organizaciones de salud pública y privadas presentan problemas de integración de sus sistemas por la gran información que se maneja y por consecuencia generan una baja calidad de información como lo son los datos de los pacientes según menciona el estudio realizado por los autores Muhammad Sajid y Kamran Ahsan. He allí que radica la necesidad de crear una solución por medio una arquitectura empresarial para este problema común. Por un lado, los autores analizan el framework Zachman, pero la 
deficiencia de este es que no desarrolla la creación completa de una arquitectura empresarial sino la de un sistema que satisfaga la necesidad de un centro médico, pero no soluciona completamente el problema. Sin embargo, TOGAF por la división de sus cuatro dominios de negocio, aplicación, datos y tecnología apoya de una manera directa para una organización de salud y la integración incluso con otras redes médicas. Aplicar TOGAF ayudaría a crear información estandarizada de las diferentes áreas, proveer métodos entre los médicos y compartir vocabularios que se entiendan en la organización sin ningún problema entre el diferente tipo de personal. Además, que propone soluciones viables y de fácil mantención para cualquier profesional que quiera mejorar la arquitectura en un futuro (Ahsan, 2016).

La arquitectura empresarial para un hospital europeo, como Portugal según los autores Rui Rijo, Ricardo Martinho y Diego Ermida es que presentan problemas en el internado de pacientes por falta de camas para los centenares de habitantes que tienen, también en los procesos de atención a los pacientes y citas médicas. Es por ello que estos autores buscan un enfoque en una arquitectura empresarial que soporte una infraestructura tecnológica, Cabe mencionar que para medir el éxito de la A.E. se definió indicadores de desempeño para los procesos existentes de este centro médico. Además, se encontraron que no existe una herramienta de TI que soporte completamente su modelo de diseño de arquitectura, ya que dicha herramienta debería adaptarse a los objetivos estratégicos del proyecto y no vice versa.

Ilustración 9: Propuesta de Trabajo de AE 


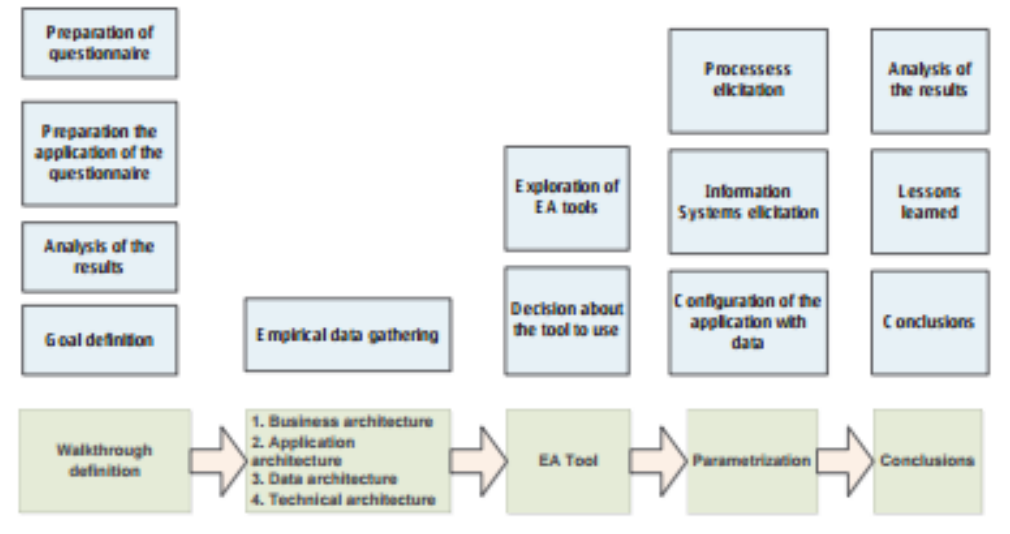

Fuente: Paper Rui Rijo

Por parte de la mejorara del proceso de citas médicas que menciona el autor, consiste en el análisis de flujo de datos de entrada y salida necesarios para cada tarea. Por tal se eliminó actividades innecesarias y se automatizo de actividades. Y para la mejora del proceso de atención médica se necesitó una reestructuración física de los ambientes y contratación de mayor cantidad de especialistas que sepan el uso de la tecnología propuesta y sepan manipular los aplicativos y maquinas del hospital con nivel esperado por los pacientes (Rui Rijo, 2015).

\section{Solución Viable de Implementar una Arquitectura a un Centro Médico en América Latina}

Esta sección muestra un artículo que sostiene el éxito de implementar una arquitectura empresarial con TOGAF a un centro médico de américa latina.

Otro autor analizo las organizaciones de salud pública y privada en un país de Latinoamérica, Ecuador, Andrés Santiago Fuseau menciona que, en la actualidad, los centros hospitalarios enfrentan el reto de intercambiar información de manera precisa, confiable y segura al momento de la atención a los pacientes. Una solución para este problema es la aplicación de una arquitectura orientada a servicios (SOA) y TOGAF que permitirá a las organizaciones integrarse con plataformas tecnológicas, puesto que un centro médico tiene un crecimiento acelerado de volúmenes de información por cada día de trabajo. Otra forma de apoyar a la solución según el autor es aplicando una gestión de BPMN permitiendo modelar los procesos de negocio de una manera gráfica de flujos de trabajo. Para el diseño de S.O.A. alineado a TOGAF se menciona que se debe de realizar 
una selección y análisis de capas necesarias para el hospital con pruebas de servicios bajo una administración de gobierno de TI. Aplicando una arquitectura empresarial de este tipo es favorable para el flujo de intercambio de información, asimismo reduce los costos de integración de aplicaciones complejas y del desarrollo de estas (García, 2015).

Ilustración 10: Integración de Servicios y Áreas.

\begin{tabular}{|c|c|c|c|c|c|c|c|c|c|c|c|c|c|c|c|c|c|}
\hline \multirow[b]{2}{*}{$\begin{array}{l}\text { Línea de } \\
\text { Negocio }\end{array}$} & \multirow[t]{2}{*}{ Servicios } & \multicolumn{5}{|c|}{ Especificos de salud } & \multicolumn{5}{|c|}{ Negocio } & \multicolumn{6}{|c|}{ Infraestructura } \\
\hline & & 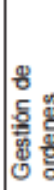 & 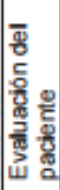 & 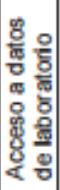 & 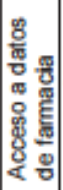 & 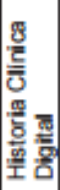 & 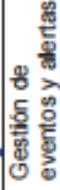 & 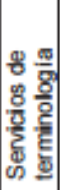 & 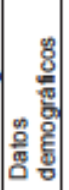 & 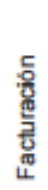 & 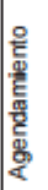 & $\begin{array}{l}\frac{\pi}{5} \\
\frac{12}{5} \\
\frac{3}{4}\end{array}$ & 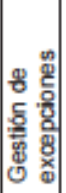 & 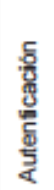 & 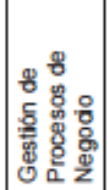 & 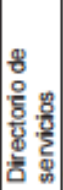 & 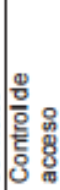 \\
\hline \multicolumn{2}{|l|}{ Farmacia } & $\mathrm{X}$ & $\mathrm{X}$ & & $\mathrm{x}$ & $\mathrm{X}$ & $\mathrm{X}$ & $\mathrm{X}$ & $\mathrm{X}$ & $\mathrm{X}$ & & $\mathrm{X}$ & $\mathrm{X}$ & $\mathrm{X}$ & $\mathrm{X}$ & & $\mathrm{X}$ \\
\hline \multicolumn{2}{|l|}{ Laboratorio } & $\mathrm{X}$ & $\mathrm{X}$ & $\mathrm{X}$ & & $\mathrm{X}$ & $\mathrm{X}$ & $\mathrm{x}$ & $\mathrm{X}$ & $\mathrm{X}$ & $\mathrm{X}$ & $\mathrm{X}$ & $\mathrm{X}$ & $\mathrm{x}$ & $\mathrm{X}$ & & $\mathrm{X}$ \\
\hline \multicolumn{2}{|c|}{ Administración de pacientes } & & & & & & $\mathrm{X}$ & & $\mathrm{X}$ & $\mathrm{X}$ & & $\bar{x}$ & $\mathrm{X}$ & $\mathrm{x}$ & & $\mathrm{X}$ & $\mathrm{X}$ \\
\hline \multicolumn{2}{|c|}{ Gestión de órdenes } & $\mathrm{X}$ & & & & $\mathrm{X}$ & $\mathrm{X}$ & $\mathrm{X}$ & $\mathrm{X}$ & $\mathrm{X}$ & $\mathrm{X}$ & $\mathrm{X}$ & $\mathrm{X}$ & $\mathrm{X}$ & $\mathrm{X}$ & $\mathrm{X}$ & $\mathrm{X}$ \\
\hline \multicolumn{2}{|c|}{ Agendamiento } & & & & & & $\mathrm{X}$ & & $\mathrm{X}$ & & $\mathrm{X}$ & $\mathrm{X}$ & $\mathrm{X}$ & $\mathrm{X}$ & $\mathrm{X}$ & $\mathrm{X}$ & $\bar{X}$ \\
\hline \multicolumn{2}{|c|}{ Admisión y registro } & & & & & & $\mathrm{X}$ & & $\mathrm{X}$ & $\mathrm{X}$ & $\mathrm{X}$ & $\mathrm{X}$ & $\mathrm{X}$ & $\mathrm{X}$ & $\mathrm{X}$ & & $\bar{x}$ \\
\hline \multicolumn{2}{|c|}{ Gestión de los cuidados } & $\mathrm{x}$ & $\mathrm{x}$ & $\mathrm{X}$ & $\mathrm{X}$ & $\mathrm{X}$ & $\mathrm{X}$ & $\mathrm{X}$ & $\bar{x}$ & $\mathrm{X}$ & $\mathrm{x}$ & $\mathrm{x}$ & $\mathrm{X}$ & $\mathrm{x}$ & $\mathrm{X}$ & $\mathrm{X}$ & $\bar{x}$ \\
\hline \multicolumn{2}{|c|}{ Gestión de las referencias } & $\mathrm{X}$ & $\mathrm{X}$ & $\mathrm{X}$ & $\mathrm{X}$ & $\mathrm{X}$ & $\mathrm{X}$ & $\mathrm{X}$ & $\mathrm{X}$ & $\mathrm{X}$ & $\mathrm{X}$ & $\mathrm{X}$ & $\mathrm{X}$ & $\mathrm{x}$ & $\mathrm{X}$ & $\mathrm{X}$ & $\mathrm{X}$ \\
\hline \multicolumn{2}{|l|}{ Enfermería } & $\mathrm{X}$ & $\mathrm{X}$ & $\mathrm{X}$ & $\mathrm{X}$ & $\mathrm{X}$ & $\mathrm{X}$ & $\mathrm{X}$ & $\mathrm{X}$ & $\mathrm{X}$ & $\mathrm{X}$ & $\mathrm{X}$ & $\mathrm{X}$ & $\mathrm{X}$ & $\mathrm{X}$ & $\mathrm{X}$ & $\mathrm{X}$ \\
\hline \multicolumn{2}{|c|}{ Servicios de emergencias } & $\mathrm{X}$ & $\mathrm{x}$ & $X$ & $x$ & 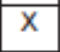 & $\mathrm{X}$ & $\mathrm{x}$ & $\mathrm{x}$ & $\mathrm{X}$ & $\mathrm{x}$ & $\mathrm{X}$ & $\mathrm{x}$ & $\mathrm{x}$ & $\mathrm{X}$ & $\mathrm{X}$ & $\mathrm{X}$ \\
\hline \multicolumn{2}{|l|}{ Facturación } & $\mathrm{X}$ & & $\mathrm{X}$ & $\mathrm{X}$ & $\mathrm{X}$ & $\mathrm{X}$ & & $\mathrm{X}$ & $\mathrm{X}$ & & $\mathrm{X}$ & $\mathrm{x}$ & $\mathrm{X}$ & $\mathrm{X}$ & & $\mathrm{X}$ \\
\hline \multicolumn{2}{|c|}{ magen y radiologia } & $\mathrm{X}$ & & & & $\mathrm{X}$ & $\mathrm{X}$ & $\mathrm{X}$ & $\mathrm{X}$ & $\mathrm{X}$ & $\mathrm{X}$ & $\bar{X}$ & $\mathrm{X}$ & $X$ & $\mathrm{X}$ & $\mathrm{X}$ & $\bar{x}$ \\
\hline \multicolumn{2}{|c|}{ Apoyo a toma de decisiones } & & $\mathrm{x}$ & $\mathrm{X}$ & $\mathrm{X}$ & $\mathrm{X}$ & $\mathrm{X}$ & $\mathrm{X}$ & $\mathrm{X}$ & & & $\mathrm{x}$ & $\mathrm{x}$ & $\mathrm{x}$ & & & $\mathrm{X}$ \\
\hline
\end{tabular}

Fuente: Paper A. Santiago Fuseau 


\section{Capítulo 5: Desarrollo del Proyecto}

En este capítulo se describe en detalle el trabajo realizado para el desarrollo de la arquitectura empresarial al macro proceso de prestación social de EsSalud. Asimismo se explica las actividades realizadas para el cumplimiento del proyecto. 


\section{Benchmarking Arquitectura Empresarial}

Para poder realizar el trabajo de arquitectura empresarial con éxito, se necesita elegir un Framework y una metodología de trabajo. Para ellos se basó en el artículo de investigación de Microsoft (Microsoft, 2007), el cual categorizo y separo su análisis de benchmarking en:

- Exhaustividad taxonómica

- Proceso de integridad

- Guía de referencia modelo

- Orientación práctica

- Modelo de madurez

- Enfoque de negocio

- Orientación gubernamental

- Participación orientada

- Catálogo prescriptivo

- Neutralidad de proveedor

- Disponibilidad de información

- Tiempo de valoración

Tabla 5: Benchmarking de Framework de Arquitectura Empresarial

\begin{tabular}{|l|l|l|l|l|}
\hline Categoria & ZACHMAN & TOGAF & FEA & GARTNER \\
\hline Taxonomía & 4 & 2 & 2 & 1 \\
\hline Procesos & 1 & 4 & 2 & 3 \\
\hline Modelos de Referencia & 1 & 3 & 4 & 1 \\
\hline
\end{tabular}




\begin{tabular}{|l|l|l|l|l|}
\hline Practica & 1 & 2 & 2 & 4 \\
\hline Modelo de Madurez & 1 & 1 & 3 & 2 \\
\hline Centro de Negocio & 1 & 2 & 1 & 4 \\
\hline Guía de Gobierno & 1 & 2 & 3 & 3 \\
\hline Guía de Partición & 1 & 2 & 4 & 3 \\
\hline Catálogo de Rehusó & 1 & & & \\
\hline Vendedor & & 2 & 4 & 2 \\
\hline Información & 2 & 4 & 3 & 1 \\
\hline Tiempo de Evaluación & 1 & 4 & 2 & 1 \\
\hline TOTAL & & & & \\
\hline
\end{tabular}

Fuente: MSDN Microsoft

Resultando como un empate entre TOGAF y FEA como rotundos ganadores de arquitectura empresarial. En este caso la elección fue TOGAF, ya que es una arquitectura empresarial aprendida y enseñada por cursos de la carrera de ingeniería de sistemas de información y por los cuales tenemos un mayor dominio para desarrollarlo.

\section{Analisis de Soluciones de Sistemas de Informacion para Seguros}

Durante el desarrollo del proyecto se analizó diferentes soluciones existentes en el ámbito de seguros por la razón si es posible adaptar alguna a la realidad de EsSalud y al macro proceso de prestación social.

\section{Guidewire}

Esta suiete empresarial proporciona un software que permite a las empresas del rubro de seguros reemplacen los ambientes de sistemas centrales preexistente. Su estructura de gestión de datos moderna permite mejorar el tiempo, costos y minimizar riesgos (Guidewire, 2016). 
- Empresa que lo desarrolló: Guidewire Software, Inc.

- Año de lanzamiento: 2001

- Módulos:

- Policy Center

- Mejorar y optimizar los procesos operativos de una empresa.

- Crear y actualizar los productos nuevos de cada empresa.

- Gestionar la cartera de productos.

- Optimizar el flujo de las renovaciones de pólizas.

- Billing Center

- Automatizar el ciclo de vida de facturación y cuotas.

- Proporciona, opciones de facturación de terceros granulares

- Entrega, tramitación de comisiones transparente rápida

- Proporciona un acceso fácil a la información que los equipos de facturación tienen que ofrecer un servicio rápido y preciso a los clientes y agentes

- Asegura prácticas de facturación de sonido con advertencias de renta variable definidos por el usuario

- Equipa a los usuarios finales con la configuración de negocios

- Activar el servicio digital a los asegurados y agentes a través de la integración con Guidewire Portales Digital.

- Proporciona inteligencia de negocios de autoservicio a través de la integración con Guidewire InfoCenter.

- Clain Center

- Ingesta deficitaria informe intuitiva 
- Procesos de adjudicación avanzada

- Informes operativos integrada

- Seguimiento de todas las reclamaciones necesarias relacionadas con los datos financieros

- Precio, Requerimiento mínimos, Hardware y Software

- Precio: No se detalla en la web oficial.

- Requerimientos Mínimos: No se detalla en la web oficial.

- Hardware: No se detalla en la web oficial.

- Software: No se detalla en la web oficial.

- Principales ventajas

- Optimizar el aseguramiento de las pólizas creadas por su diversidad de módulos.

- Guidewire permite a adaptarse al cambio de los seguros por las regulaciones de cada país.

- Automatizar el ciclo de vida de los aplicativos asociados a Guidewire.

- Impulsar la innovación de TI.

- Entrar con facilidad a nuevos mercados con agilidad.

- Permite a las aseguradoras a darse cuenta de una visión analítica y una verdadera experiencia en todos los canales de distribución y todas las líneas de negocio.

- Permite el crecimiento rentable y la capacidad para aprovechar las oportunidades y tendencias del mercado de hoy en día.

\section{Axcel /x}

Es una solución integral, diseñada para empresas de seguros y tecnología para manejar los procesos de la cadena de valor. Tiene un alto grado de parametrización en productos y procesos. Además, permite disponer de un robusto core-system para administrar la administración de la empresa y la gestión de ventas (Accuys, 2009). 
- Empresa que lo desarrolló: ACCUSYS TECNOLOGY

- Año de lanzamiento: 2000

- Módulos:

- Módulo de clientes

- El sistema contempla el manejo de cualquier tipo de persona natural o jurídica y su clasificación al nivel de empresas y grupos corporativos. La información financiera y de mercadeo son los principales roles que desempeñan en los procesos de la cadena de valor.

- Configurador de Líneas de Negocios y Productos:

- Maneja políticas y reglas de negocio a través de diversos parámetros y configuradores para definir los componentes asociados al producto, tales como: coberturas, riesgos, planes, anexos, cláusulas, recargos, descuentos, conceptos a cobrar o descontar de la prima, tipos de beneficiarios del pago de reclamos, conceptos a indemnizar, deducibles, franquicias, reaseguros, etc.

- Contratos de Reaseguro:

- Define y configura los tipos, grupos y condiciones de los contratos para manejar todas las operaciones y administración de Reaseguro tanto aceptado como cedido contemplando la distribución automática de los contratos y sus participantes. Incluye contratos proporcionales y no proporcionales.

- Coaseguro:

- Maneja tanto el coaseguro aceptado como cedido, incluyendo las condiciones y comisiones de cada participante dentro de la administración de cada operación.

- Administración de Reclamos:

- Control y manejo de las operaciones administrativas y técnicas de reclamos, desde la notificación, hasta la constitución de reservas, modificaciones, pagos y recuperaciones o salvamentos.

- Área administrativa y Financiera: 
- Configuración de Acreencias y Egresos, grupos y relaciones de conceptos, facturación, financiamiento de primas, recaudación y cobranza, manejo de ingresos y caja, cuentas por pagar, tesorería, Mayorización de asientos y Contabilidad.

- Mantenimiento y Seguridad:

- Configura todas las opciones de acceso y autorización por roles de usuarios y escalamiento por diferentes niveles. Los niveles y criterios son muy amplios para detalles tan específicos como: un usuario puede autorizar por rangos de fechas o por límites de montos; o puede trabajar en otra moneda; o puede solo hacer pagos parciales y no totales, etc. Así mismo existen configuradores para definir los parámetros locales al país (moneda, tiempo-zona, lenguaje, etc.) interfaces con otros sistemas, etc.

- Comercialización y Canales de Ventas:

- Configurar los diferentes canales de ventas y sus condiciones con posibilidad de combinatoria de múltiples canales en un mismo negocio, estado de cuentas de comisiones y movimientos, liquidación de comisiones, traspasos de cartera.

- Reportes:

- El sistema viene acompañado por un grupo básico de reportes, entre los cuales se encuentran: Emisión (cuadro-póliza, clausulado, recibos, facturas, primas emitidas) recaudación y cobranzas, primas pendientes de cobro, reclamos, coaseguro, reaseguro cuentas por pagar, egresos y listados contables.

- Administración de Primas y Pólizas:

- Operaciones de suscripción y emisión de nuevos negocios, endosos, renovaciones, modificaciones, devoluciones, cambios sin movimientos de prima, etc.

- Interfaces:

- El sistema contempla interfaces listas a Oracle financieros, Oracle EBS, SAP GL, SunSystem (Contabilidad). Gracias a su integración con Web Services, el proceso de interfaz es relativamente simple.

- Precio, Requerimiento mínimos, Hardware y Software: 
- Precio: No se detalla en la web oficial.

- Requerimientos Mínimos: No se detalla en la web oficial.

- Software: No se detalla en la web oficial.

- Principales ventajas:

- Protege la inversión tecnológica, ya que es una solución completa y escalable sobre ORACLE, con un modelo tecnológico permanente y orientado a estándares.

- Contiene los costos y optimiza la productividad del recurso humano, evitando crecimientos desproporcionados en los mismos y gastos asociados al aumentar la empresa el market-share.

- Dispone de una administración controlada y efectiva día tras día, así como manejar sus informes financieros al cierre, sin mayores traumas ni inconsistencias de cifras, lo cual le permite oportunamente reaccionar ante cualquier necesidad.

- Otorgarle mayor competitividad a la empresa en time-to-market y benchmarking, al disponer de una herramienta competitiva, integral y de fácil acceso.

- Cubre la gestión aseguradora en toda su operatividad y líneas de negocios.

- Permite integrarse a servicios Web e interfaces externas para conformar redes de valor agregado con canales de ventas y proveedores asociados.

- Arquitectura robusta basada en Oracle y totalmente Web.

- Es muy sencillo de manejar y dispone de una interfaz intuitiva que los usuarios estarán encantados de manejar y operar.

- El área de sistemas dispone de mecanismos y procesos que facilitan su integración y mantenimiento.

- Visión global, por su diseño multi: empresa, idioma, moneda.

- El éxito en la implantación está garantizado por la metodología y el equilibrio de destrezas que se conjugan en el equipo de consultores. 


\section{Sage 300 - ERP for Hospitals and Healthcare}

Sage ERP Solution para Hospitales y Salud, impulsado por MIMSys, proporciona a las empresas de salud una arquitectura técnica en módulos, seguridad robusta y la integración entre todos los departamentos que tenga la empresa (Sage, 2013).

- Módulos:

- System Manager:

- Mantenimiento de la aplicación y configuración general

- Patient Appointment:

- Este módulo permite registrar citas, según disponibilidad de los doctores.

- Electronic Health Record (HRE):

- Modulo qué sirve a los médicos a hacer el seguimiento de pacientes, en general mantenimiento de la historia clínica.

- Admission, Transfer and Discharge (ATD):

- Modulo qué se encarga de revisar y darle seguimiento a las admisiones del hospital / clínica, control de camas y cuartos.

- Nursing Station \& Assessment:

- Modulo para dar seguimiento a la asignación de pacientes del ATD.

- Nursing Protocols (Integrated Care Plan)

- Modulo para qué las enfermeras tengan un acceso al tratamiento y diagnóstico de los doctores a los pacientes.

- Care Provider Forms:

- Modulo para solicitar servicios especiales, como atención a recién nacidos, o transfusiones de sangre.

- Triage \& Emergency: 
- Modulo para manejar las emergencias qué llegan al hospital / clínica.

- Laboratory:

- Modulo qué recibe solicitudes para exámenes en laboratorio.

- Radiology:

- Módulo especial para el área de cardiología.

- Insurance \& Claims management:

- Modulo para manejar la integración con los seguros locales.

- Evaluation \& Management:

- Módulo usado por los doctores para justificar su diagnóstico.

- Out-Patient Billing:

- Módulo de cobro para pacientes qué no son atendidos en el hospital / clínica.

- Módulo de finanzas:

- Módulo que contiene toda la aplicación necesaria para el control y seguimiento administrativo.

- Precio, Requerimiento mínimos, Hardware y Software

- Precio: No se detalla en la web oficial.

- Requerimientos Mínimos: No se detalla en la web oficial.

- Hardware: No se detalla en la web oficial.

- Software: No se detalla en la web oficial.

- Principales ventajas

- No se específica, la web oficial menciona que son líderes en el medio oriente. 


\section{SIS.NET (SISTEMA INTEGRAL DE SEGUROS 10)}

Plataforma integral para rubros de empresas aseguradoras, el cual brinda escalabilidad y fusión con sistemas transaccionales (Axxis systems, 2015).

- Módulos:

- Pólizas

- Contiene suscripción, endoso, renovaciones, colectivos, reservas y cotizaciones.

- Siniestros

- Contiene administración de siniestro, recaudos, pagos, órdenes de servicios, reservas, recobros, siniestralidad e inspecciones.

- Reaseguro

- Contiene taller de contratos, operativo, gestión de contrato, analítico y coaseguro.

- Comisiones

- Contiene configuración, operativo, metas y liquidaciones.

- Administrativos

- Contiene facturación, morosidad, caja ingresos, cobranza, tesorería y egresos.

- Contabilidad

- Contiene catálogo, asientos, transacciones, cuentas corrientes, estados financieros y entidad reguladora.

- Contacto CRM

- Contiene administración de contactos, correspondencia e interfaces.

- Inteligencia Negocio BI

- Contiene estadística, cuadros de Mando y reportes Operativos.

- Operaciones Masivas 
- Contiene carga masiva, remesas, exportación, planillas y endosos masivos.

- Auxiliares

- Contiene líneas de comandos SISOS, motor de búsquedas, gestor de documentos, seguridad, configuraciones y auditoría de accesos.

- Precio, Requerimiento mínimos, Hardware y Software

- Precio: No se detalla en la web oficial.

- Requerimientos Mínimos: No se detalla en la web oficial.

- Hardware: No se detalla en la web oficial.

- Software:

- Capa de Presentación: HTML 5

- Capa de Servicio: APIs REST (SOA)

- Capa de Lógica de Negocio: C\# .NET 4.5

- Capa de Acceso a Datos: Entity Framework 6 con Code First

- Capa de Base de Datos: SQLServer, Oracle, DB2

- Principales ventajas:

- Navegar mediante una web desde cualquier dispositivo

- Gestionar el proceso de actuarial completa del ciclo de vida de productos.

- Importación masiva de pólizas y gestión completo de su ciclo de vida.

- Gestiona por módulo para cada departamento de la compañía de seguros.

- Entrega de código fuente, implementación parcial y contratos de soporte.

- Interconexión inmediata con otros sistemas y orquestación de servicios mediante el API REST. 


\section{SPG-AIT (Software para Geriátricos)}

Software especializado para geriátricos en residencias y centros geriátricos para el cuidado del adulto mayores (AIT, 2015).

- Módulos:

- Urgencias:

- Imprime de forma inmediata todos los documentos necesarios para atender a una urgencia de ese residente (datos personales, datos familiares, pauta médica actual, historial médico, etc.).

- Almacén Digital de Documentos:

- Mediante un escáner podrá digitalizar todo tipo de documentos clínicos y de cualquier otra índole e integrarlos en el expediente de un residente. Para cada documento podrá indicar si lo desea imprimir en caso de urgencia.

- Gestión de empleados:

- Permite controlar su ausentismo, vacaciones, contrato, dedicación, remuneración, datos básicos de las nóminas, etc.

- Gestión de farmacia Control de stocks:

- El módulo de farmacia controla automáticamente el stock de los medicamentos suministrados a los residentes a partir de las pautas de los mismos.

- Listados y mailings:

- La integración con Microsoft Word le permitirá editar mailings y todo tipo de documentos dirigidos a los residentes o familiares de los mismos. Incluye además un potente gestor de listados, además de enviar la información solicitada por el solicitante.

- Información Financiera y Contable:

- Caja

- Bancos 
- Cuentas por Cobrar (Residentes y otras)

- Cuentas por Pagar (Proveedores)

- Balance de Sumas y Saldos

- Libros de IVA

- Confección automática de Asientos Contables

- Gráficos estadísticos

- Precio, Requerimiento mínimos, Hardware y Software

- Precio: No se detalla en la web oficial.

- Requerimientos Mínimos: No se detalla en la web oficial.

- Hardware: No se detalla en la web oficial.

- Software: No se detalla en la web oficial

- Principales ventajas

- Reduzca al mínimo el tiempo dedicado a la gestión administrativa y económica.

- Automatización de la digitalización y edición de documentos.

- Adaptable con otras plataformas Windows.

- Intuitivo y fácil de usar para el usuario.

\section{Greengeriatric}

El software permite gestionar fácilmente todas las áreas de un negocio, organizar los turnos de trabajo de la persona y realiza de una forma sencilla todas las gestiones relativas a: administración, facturación, almacén, compras y producción (Greengeriatric, 2016).

- Módulos:

- Gestión de Residentes

- Datos de contacto del residente: ingreso, contrato, tipología y reseñas familiares. 
- Datos administrativos: seguro médico, cuotas de facturación y pertenencias

- Evoluciones temporales

- Gestión de visitas

- Área Médica

- Seguimiento del residente: exploración, patologías, antecedentes, tratamientos, escalas de valoración, alergias, etc.

- Diario médico y alertas

- Ficha ingreso hospital, informe clínico y listados

- Área de Enfermería

- Seguimiento del residente: planificación, controles, cuidados, caídas, consultas externas, medicación, etc.

- Listados: tratamientos, tareas a realizar, dietas, alergias, etc.

- Equipo Interdisciplinar

- Trabajador social, dietista, animador, psicólogo, fisioterapeuta, terapeuta ocupacional, supervisora

- Listados

- Informe P.I.A.

- Área de Personal

- Registro de los datos del personal

- Organización del personal en grupos y turnos

- Gestión de cuadrantes y del cálculo de personal

- Facturación

- Registro de los datos del personal 
- Organización del personal en grupos y turnos

- Gestión de cuadrantes y del cálculo de personal

- Almacenes

- Multi-almacén

- Pedidos, entradas, facturación, previsión y pagos

- Control de stocks, traspasos entre almacenes y salidas de mercancía

- Pedidos de reposición, inventarios, consumos, etc.

- Dirección

- Datos de facturación: Listados de IVA y facturación por conceptos

- Datos de producción: Resultados actuales y comparativas

- Auditoría interna: registro anulaciones y modificaciones

- Mantenimiento y limpieza

- Gestión de reparaciones y averías

- Control de limpieza

- Objetos perdidos

- Precio, Requerimiento mínimos, Hardware y Software

- Precio: No se detalla en la web oficial.

Ilustración 11: Requerimiento Minimo de Greengeriatric

\begin{tabular}{|l|l|l|l|}
\hline & Menos de 6 puestos de trabajo & 6 o más puestos de trabajo & \\
\hline & Ordenador & Servidor & Cliente \\
\hline Procesador & Procesador PIV a 3Ghz. & Procesador PIV a 3Ghz. & Procesador PIV a 3Ghz. \\
\hline Memoria & 2Gb. RAM & 2Gb. RAM & 2Gb. RAM \\
\hline Tarjeta Vídeo & Tarjeta gráfica de 256Mb. RAM & Tarjeta gráfica de 256Mb. RAM & Tarjeta gráfica de 256Mb. RAM \\
\hline Disco duro & 5 Gb libres en disco & 5 Gb libres en disco & \\
\hline Resolución & $1024 \times 768$ & $1024 x 768$ & 1024x768 \\
\hline S.O. & Windows 7 o superior & Windows 2003 server & Windows 7o superior \\
\hline BB.DD. & Pervasive. SQL V10 Workgroup ó superior & Pervasive. SQL V10 Cliente/Servidor ó superior \\
\hline
\end{tabular}


Fuente: Web Oficial

- Principales ventajas

- Integración con otras soluciones de la misma compañía: Greenrestaurant, Greenspa y Greenchennel.

- Instalaciones en varios reconocidos geriátricos.

- Facilidad de uso del As Is de alguna aplicación core

- Maneja herramientas de Microsoft como nativas.

- Base de instalación rápida.

- Manejo de soporte integrado en varios países.

En análisis a todas las plataformas mencionadas, puede resaltar que no se adaptan a la realidad de EsSalud, por el dimensionamiento actual que presenta la entidad se seguro social, pero cabe mencionar que el módulo de las mencionadas soluciones seria escalable y adaptable para el macro proceso de prestación social en momento de la conexión al sistema actual de EsSalud.

\section{Descripcion del Proyecto y Alcance}

El marco de trabajo utilizado es TOGAF con la metodología ADM, centrándonos en los cuatro dominios (negocio, datos, aplicación y tecnología) para el desarrollo del macro proceso de prestación social de EsSalud. El proyecto abarcará hasta la fase de arquitectura de tecnología del ADM, es decir se tomará en cuenta las fases Preliminar, Visión de 
Arquitectura, Arquitectura de Negocios, Arquitectura de Sistemas de Información y Arquitectura de Tecnología.

Las soluciones serán basadas en mejores prácticas, sugerencias personales, y la visión de la empresa con aspectos del negocio, aplicaciones e infraestructura.

\section{Activiades y Entregables}

\section{Preliminar}

- Actividades

- Reunión con el Profesor Gerente

- Reunión con el Cliente

- Definición del Alcance

- Definir los Entregables de TOGAF (ADM)

- Validación del Charter con el Profesor Gerente (Alcance)

- Validación con el Cliente del Alcance y entregables

- Validación del Charter con el Profesor Gerente (Entregables)

- Elaboración del Plan de Trabajo

- Presentación del Project Charter

- Presentación del Plan de Trabajo

- Aprobación del Project Charter

- Acuerdo de Entregables con el representante del comité

- Elaborar el Organizational Model for Enterprise Architecture

- Elaborar el Principles catalog

- Elaboración de encuestas a usuarios 
- Diagrama de Gantt del Proyecto

- Iniciar los documentos de Gestión

- Entregables

- Organizational Model for Enterprise Architecture

- Principles catalog

\section{Arquitectura Visión}

- Actividad

- Iniciar el Architecture Statement

- Iniciar el Architecture Vision

- Empezar el Capítulo 1 de la Memoria

- Entrega de documentos para la primera revisión al comité

- Terminar el Architecture Statement

- Empezar los Artefactos de Fase A

- Primera Revisión de QS

- Exposición con el comité

- Terminar los documentos de gestión

- Cerrar las observaciones de QS

- Validar la Fase A con el cliente

- Segunda Revisión de QS

- Levantar observaciones de la Fase A

- Entregar el Capítulo 1 de Memoria

- Entregables 
- Statement of Architecture Work

- Architecture Vision

- Architecture Definition Document (Alto Nivel)

Arquitectura de Negocio

- Actividad

- Iniciar los diagramas

- Empezar el Capítulo 3 de la Memoria

- Entregar el capítulo 3

- Empezar el capítulo 4 memoria

- Validación de Diagramados As Is

- Empezar Diagramado To Be

- Realizar el artefacto

- Entrega del capítulo 4 de la Memoria

- Validar los diagramas con el cliente

- Terminar Artefactos Fase B

- Realizar los entregables

- Empezar capítulo 6 de la Memoria

- Continuar entregables Fase B

- Tener Capítulo 6 de la Memoria

- Terminar los entregables de la Fase B

- Validar Fase B con el cliente

- Entregables Fase B 
- Levantar observaciones de la Fase B

- Presentar documentos al comité

- Exposición con el comité

- Entregables

- Architecture Definition Document (Negocio)

- Architecture Requirements Specification (Negocio)

- Architecture Roadmap (Negocio)

- Role catalog

- Business Service/Funcion Catalog

\section{Arquitectura de Sistema de Información}

- Actividad

- Empezar Levantamiento de Información para las fases C

- Empezar Architecture Definition con la Información de la Fase C (As Is)

- Continuar Architecture Definition con la Información de la Fase C (As Is)

- Empezar Architecture Requirements Specification con la Información de la Fase C (As Is)

- Empezar el Diagrama en Archivo de Fase C (As Is)

- Continuar Architecture Definition con la Información de la Fase C (As Is)

- Continuar Architecture Requirements Specification con la Información de la Fase C (As Is)

- Terminar Diagrama As Is de fase C

- Empezar Architecture Requirements Specification con la Información de la Fase C (To $\mathrm{Be})$ 
- Continuar Architecture Definition con la Información de la Fase C (To Be)

- Continuar Architecture Requirements Specification con la Información de la Fase C (To $\mathrm{Be})$

- Entregables

- Architecture Definition Document (Datos y Aplicaciones)

- Architecture Requirements Specification (Datos y Aplicaciones)

- Architecture Roadmap (Datos y Aplicaciones)

- Application Portfolio Catalog (Datos y Aplicaciones

\section{Arquitectura de la Tecnología}

- Actividades

- Empezar Levantamiento de Información para las fases D

- Empezar Architecture Definition con la Información de la Fase D (As Is)

- Continuar Architecture Definition con la Información de la Fase D(As Is)

- Empezar Architecture Requirements Specification con la Información de la Fase D (As Is)

- Empezar el Diagrama en Archivo de Fase D (As Is)

- Continuar Architecture Definition con la Información de la Fase D (As Is)

- Continuar Architecture Requirements Specification con la Información de la Fase D (As Is)

- Terminar Diagrama As Is de fase D

- Empezar Architecture Requirements Specification con la Información de la Fase D (To $\mathrm{Be})$

- Continuar Architecture Definition con la Información de la Fase D (To Be) 
- Terminar Capítulos de la Memoria

- Continuar Architecture Requirements Specification con la Información de la Fase D (To $\mathrm{Be})$

- Entregables

- Architecture Definition Document (Infraestructura)

- Architecture Requirements Specification (Infraestructura)

- Technology Portafolio Catalog (Infraestructura)

- Architecture Roadmap (Infraestructura)

\section{Desarrollo del Proyecto}

\section{Inicio y Análisis}

El proyecto inicio con reuniones de trabajo con el Cliente Jorge Sánchez para contextualizar la realidad de EsSalud y entender los dos grandes grupos de gestión que son IAFAS e IPRESS (EsSalud - Reglamento de organización y funciones del seguro social de salud, 2014).

El siguiente paso fue definir el alcance, restricciones, supuestos y las variables que pudieran afectar el desarrollo del trabajo de arquitectura (Adjunto documento: Gestión de Alcance PMBOK).

Tabla 6: Ficha de Definición, Alcance y Bosquejo del Proyecto 


\begin{tabular}{|c|c|c|c|}
\hline Código y Nombre del Proyecto & $\begin{array}{l}\text { Fecha de } \\
\text { reunión }\end{array}$ & $\begin{array}{l}\text { Hora } \\
\text { inicio }\end{array}$ & Hora fin \\
\hline $\begin{array}{l}\text { Arquitectura Empresarial del proceso de } \\
\text { prestación social de EsSalud }\end{array}$ & $20 / 08 / 2016$ & 10:00 am & $13: 00 \mathrm{pm}$ \\
\hline \multicolumn{4}{|l|}{ Elaborado por: } \\
\hline Joan Motta Altamirano & \multicolumn{3}{|c|}{ Sebastián Neira Medina } \\
\hline \multicolumn{4}{|l|}{ Apertura del proyecto } \\
\hline \multicolumn{4}{|c|}{ ¿Cómo funciona el proceso de prestación social con respecto a EsSalud? } \\
\hline \multicolumn{4}{|c|}{$\begin{array}{l}\text {-Prestación social es el proceso dentro de las IPRESS, el cual ve la mejora de la } \\
\text { actividad física al adulto mayor y rehabilitación profesional de un discapacitado. }\end{array}$} \\
\hline \multicolumn{4}{|c|}{ ¿Qué son las CAM y CERP dentro de prestación social? } \\
\hline \multicolumn{4}{|c|}{$\begin{array}{l}\text {-Los CAM son los Centro del adulto mayor y los CERP son los Centro de } \\
\text { especializados de rehabilitación profesional, las cuales estos dos son los centros que } \\
\text { integra el proceso de prestación social. }\end{array}$} \\
\hline \multicolumn{4}{|l|}{ ¿El proceso presenta algún sistema definido? } \\
\hline \multicolumn{4}{|c|}{-Actualmente no se tiene un sistema, el control y trabajo se lleva en tablas de Excel. } \\
\hline \multicolumn{4}{|c|}{ ¿El proceso presenta indicadores de éxito para su monitoreo? } \\
\hline \multicolumn{4}{|c|}{-No presenta indicadores, por ser un proceso nuevo y en reestructuración. } \\
\hline Objetivos & & & Resolución \\
\hline Diseño y bosquejo del proceso de prestac & ión social de Es & Salud & SI \\
\hline Definir alcance del proyecto de tesis & & & SI \\
\hline
\end{tabular}


Para desarrollar correctamente los lineamientos de la arquitectura a proponer se elaboró los siguientes principios:

Principios de arquitectura

Tabla 7: Principios de Arquitectura

\begin{tabular}{|c|c|c|}
\hline ID & Nombre & Descripción \\
\hline PRN_ARC_01 & $\begin{array}{l}\text { Definir los objetivos } \\
\text { estratégicos de la empresa }\end{array}$ & $\begin{array}{l}\text { Los objetivos estratégicos, objetivos y } \\
\text { metas de la empresa (EsSalud) deben } \\
\text { estar definidos antes de comenzar el } \\
\text { proyecto de arquitectura empresarial. }\end{array}$ \\
\hline PRN_ARC_02 & Cumplimiento de la ley & $\begin{array}{l}\text { El cumplimiento de las leyes, } \\
\text { regulaciones dadas por el MINSA y } \\
\text { ministerios del Perú. }\end{array}$ \\
\hline PRN_ARC_03 & Continuidad del negocio & $\begin{array}{l}\text { La empresa será resistente a las amenazas } \\
\text { internas y externas. }\end{array}$ \\
\hline PRN_ARC_04 & Alineación de negocio & $\begin{array}{l}\text { Cada proyecto de TI deberá estar alineada } \\
\text { con los objetivos estratégicos y metas del } \\
\text { negocio. }\end{array}$ \\
\hline PRN_ARC_05 & Re uso de soluciones & $\begin{array}{l}\text { Los proyectos de TI deberán reutilizar } \\
\text { soluciones de fábrica y equipos existen } \\
\text { dentro del inventario. }\end{array}$ \\
\hline PRN_ARC_06 & $\begin{array}{l}\text { Ver los componentes que se } \\
\text { pueden reutilizar antes de } \\
\text { comprar una solución }\end{array}$ & $\begin{array}{l}\text { Se debe verificar si algún componente se } \\
\text { puede reutilizar. En caso de que el } \\
\text { requerimiento no pueda ser alcanzado con } \\
\text { ningún componente existente, se optará } \\
\text { por comprar la solución. }\end{array}$ \\
\hline PRN_ARC_07 & Calidad de TI & $\begin{array}{l}\text { Se deberá tener un mínimo de calidad a } \\
\text { pesar de tiempos cortos de entrega. }\end{array}$ \\
\hline
\end{tabular}




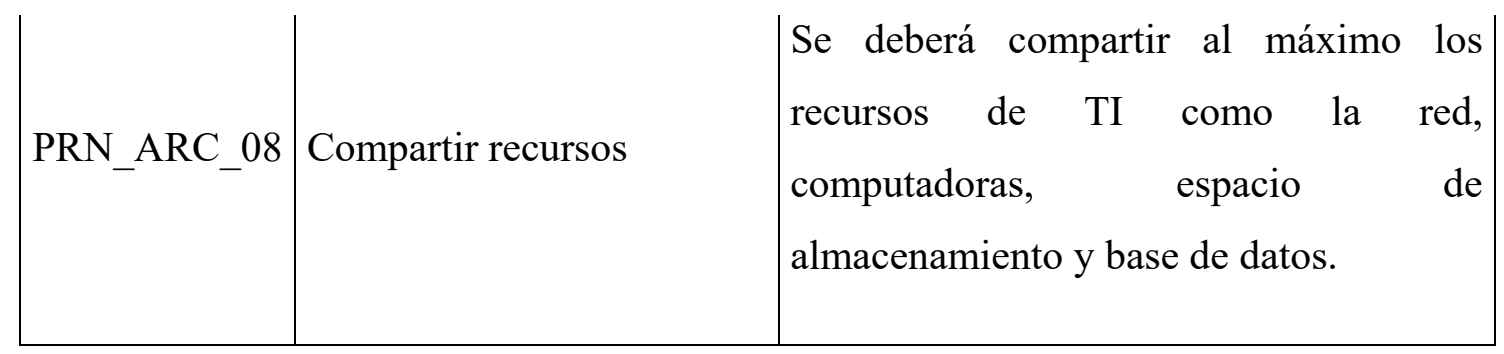

Fuente: Elaboración Propia

Principios de datos

Tabla 8: Principios de Datos

\begin{tabular}{|l|l|l|}
\hline ID & Nombre & Descripción \\
\hline PRN_IN_01 & Libertad de información & $\begin{array}{l}\text { La información deberá estar disponible } \\
\text { para apoyar la productividad y la } \\
\text { innovación. }\end{array}$ \\
\hline PRN_IN_02 & Compartir activos & $\begin{array}{l}\text { Los datos de información son activos de la } \\
\text { empresa compartida y no son de propiedad } \\
\text { de un departamento o área. }\end{array}$ \\
\hline PRN_IN_03 & Relevancia de información & $\begin{array}{l}\text { Los datos deben tener valor y relevante del } \\
\text { negocio. }\end{array}$ \\
\hline PRN_IN_04 & $\begin{array}{l}\text { Concurrencia } \\
\text { información }\end{array}$ & de \\
PRN_IN_06 & Interpretación de datos & $\begin{array}{l}\text { La información debe ser oportuna } \\
\text { interpretados en todo momento por las } \\
\text { personas de la empresa. }\end{array}$ \\
\hline PRN_IN_05 & Manejo de datos & $\begin{array}{l}\text { La información de datos debe tener un } \\
\text { gestor (administrador) designado que sea } \\
\text { responsable de la calidad de los datos. }\end{array}$ \\
\hline
\end{tabular}


\begin{tabular}{|l|l|l|l|l} 
PRN_IN_08 & $\begin{array}{l}\text { Política de retención de } \\
\text { datos. }\end{array}$ & $\begin{array}{l}\text { Los repositorios mantendrán políticas de } \\
\text { retención de datos que estén alineados con } \\
\text { la empresa. }\end{array}$ \\
\hline
\end{tabular}

Fuente: Elaboración Propia

Principios de negocio

Tabla 9: Principios de Negocio

\begin{tabular}{|l|l|l|}
\hline ID & Nombre & Descripción \\
\hline PRN_BU_01 & Enfocarse en el cliente & $\begin{array}{l}\text { Decisiones de la arquitectura empresarial } \\
\text { buscarán maximizar el valor para el cliente. }\end{array}$ \\
\hline PRN_BU_02 & Operaciones simplificadas & $\begin{array}{l}\text { Decisiones de la arquitectura empresarial } \\
\text { buscarán simplificar las operaciones. }\end{array}$ \\
\hline PRN_BU_03 & Respuestas a los clientes & $\begin{array}{l}\text { Solicitudes de los clientes serán tratados de } \\
\text { manera oportuna. }\end{array}$ \\
\hline PRN_BU_04 & Enfoque a largo plazo & $\begin{array}{l}\text { Las decisiones se basan en la estrategia a largo } \\
\text { plazo. }\end{array}$ \\
\hline PRN_BU_05 & Time to market & $\begin{array}{l}\text { Las áreas de negocio responderán a las } \\
\text { oportunidades de manera oportuna. }\end{array}$ \\
\hline PRN_BU_07 & $\begin{array}{l}\text { Personalización de atención } \\
\text { cliente }\end{array}$ & $\begin{array}{l}\text { Toda atención se realizará a la necesidad del } \\
\text { paciente de EsSalud. }\end{array}$ \\
\hline PRN_BU_08 & Separación de funciones & $\begin{array}{l}\text { Detección de amenazas } \\
\text { amenazas internas y externas de manera } \\
\text { oportuna. }\end{array}$ \\
\hline
\end{tabular}


\begin{tabular}{|l|l|l|} 
PRN_BU_09 & Eficiencia en el proceso & $\begin{array}{l}\text { Desarrollar un proceso de correcto y flujo bajo } \\
\text { estándares de calidad. }\end{array}$ \\
\hline
\end{tabular}

Fuente: Elaboración Propia

Principios de aplicación

Tabla 10: Principios de Aplicación

\begin{tabular}{|c|c|c|}
\hline ID & Nombre & Descripción \\
\hline PRN_AP_01 & Seguimiento y medición & $\begin{array}{l}\text { Las aplicaciones deberán diseñarse para } \\
\text { soportar monitoreos y medición. }\end{array}$ \\
\hline PRN_AP_02 & Plataformas independientes & $\begin{array}{l}\text { Las aplicaciones deberán diseñarse para } \\
\text { soportar diferentes plataformas y } \\
\text { periféricos. }\end{array}$ \\
\hline PRN_AP_03 & $\begin{array}{l}\text { SLA de solicitudes de } \\
\text { aplicaciones }\end{array}$ & $\begin{array}{l}\text { Todas las solicitudes tendrán un SLA que } \\
\text { se ha acordado con EsSalud. }\end{array}$ \\
\hline PRN_AP_04 & $\begin{array}{l}\text { Alta disponibilidad de } \\
\text { aplicaciones }\end{array}$ & $\begin{array}{l}\text { Todas las aplicaciones tendrán una } \\
\text { disponibilidad acordada por EsSalud. }\end{array}$ \\
\hline PRN_AP_05 & $\begin{array}{l}\text { Documentación } \\
\text { aplicaciones }\end{array}$ & $\begin{array}{l}\text { Las aplicaciones deben tener la } \\
\text { arquitectura, el diseño y la documentación } \\
\text { necesaria definida por EsSalud. }\end{array}$ \\
\hline PRN_AP_06 & Reusó de aplicaciones & $\begin{array}{l}\text { Cuando sea posible previo análisis se debe } \\
\text { reutilizar las aplicaciones existentes. }\end{array}$ \\
\hline
\end{tabular}

Fuente: Elaboración Propia

Principios de tecnología

Tabla 11: Principios de Tecnología 


\begin{tabular}{|c|c|c|}
\hline PRN_TI_01 & $\begin{array}{l}\text { Definir el control de la } \\
\text { tecnología }\end{array}$ & $\begin{array}{l}\text { Las diversidades tecnológicas estarán } \\
\text { controladas con el fin de reducir la } \\
\text { complejidad futura de la infraestructura de } \\
\text { TI. }\end{array}$ \\
\hline PRN_TI_02 & $\begin{array}{l}\text { Necesidades de la } \\
\text { organización de TI }\end{array}$ & $\begin{array}{l}\text { Los cambios de tecnología deben ser } \\
\text { manejados y requeridos a la necesidad de } \\
\text { EsSalud. }\end{array}$ \\
\hline PRN_TI_03 & $\begin{array}{l}\text { Actualización } \quad \text { de } \quad \text { la } \\
\text { tecnología }\end{array}$ & $\begin{array}{l}\text { Los cambios de versiona miento y } \\
\text { actualización se debe manejar según el } \\
\text { ciclo de vida de hardware y software. }\end{array}$ \\
\hline PRN_TI_04 & Uso de nueva tecnología & $\begin{array}{l}\text { El uso de nueva tecnología es solo la } \\
\text { experimentada y con referencias de buen } \\
\text { funcionamiento críticos por otras empresas. }\end{array}$ \\
\hline PRN_TI_05 & $\begin{array}{l}\text { Declaración de ciclo de vida } \\
\text { de la tecnología }\end{array}$ & $\begin{array}{l}\text { El ciclo de vida de la tecnología de EsSalud } \\
\text { deberá comprender toda lo comprado por la } \\
\text { misma y los terceros que se tenga } \\
\text { monitoreo. }\end{array}$ \\
\hline
\end{tabular}

Fuente: Elaboración Propia

Principios de seguridad

Tabla 12: Principios de Seguridad

\begin{tabular}{|l|l|l|}
\hline ID & Nombre & Descripción \\
\hline PRN_SE_01 & Protección de datos & $\begin{array}{l}\text { Los datos son un activo que deben ser } \\
\text { protegidos. }\end{array}$ \\
\hline PRN_SE_02 & Confidencialidad de datos & $\begin{array}{l}\text { Los datos de alto impacto tienen que ser } \\
\text { confidenciales. }\end{array}$ \\
\hline
\end{tabular}




\begin{tabular}{|c|c|c|}
\hline PRN_SE_03 & Segregación de tareas & $\begin{array}{l}\text { La segregación de actividades y tareas para } \\
\text { los roles de EsSalud deben estar definidos } \\
\text { y aprobados por el encargado. }\end{array}$ \\
\hline PRN_SE_04 & $\begin{array}{l}\text { Seguridad en el diseño de la } \\
\text { arquitectura empresarial }\end{array}$ & $\begin{array}{l}\text { El diseño de la arquitectura empresarial } \\
\text { deberá estar alineado a la seguridad actuad } \\
\text { de EsSalud y cumplir con los estándares y } \\
\text { buenas prácticas de seguridad informática. }\end{array}$ \\
\hline PRN_SE_05 & Permisos & $\begin{array}{l}\text { El privilegio de seguridad en permisos a las } \\
\text { actividades requeridas deberá ser analizada } \\
\text { para su aceptación. }\end{array}$ \\
\hline PRN_SE_06 & $\begin{array}{l}\text { Responsabilidades de } \\
\text { seguridad externa }\end{array}$ & $\begin{array}{l}\text { EsSalud tiene la responsabilidad de } \\
\text { seguridad de la información de sus clientes, } \\
\text { socios y reguladores. }\end{array}$ \\
\hline PRN_SE_07 & Propietario de información & $\begin{array}{l}\text { El usuario como responsable y dueño de un } \\
\text { activo es el responsable de su custodia y } \\
\text { compartir su información bajo su } \\
\text { responsabilidad. }\end{array}$ \\
\hline PRN_SE_08 & Auditoria de TI & $\begin{array}{l}\text { Auditoria tiene control total y acceso para } \\
\text { el estudio de vulnerabilidades de EsSalud. }\end{array}$ \\
\hline
\end{tabular}

Fuente: Elaboración Propia

Posterior a ello se aterrizó la información del macro proceso con los procesos gestionar atención del CERP y CAM. Pasando a la realización de la cadena de valor a partir de la información de la resolución Macroprocesos_EsSalud_Res127GG2016.

Ilustración 12: Cadena de Valor EsSalud 


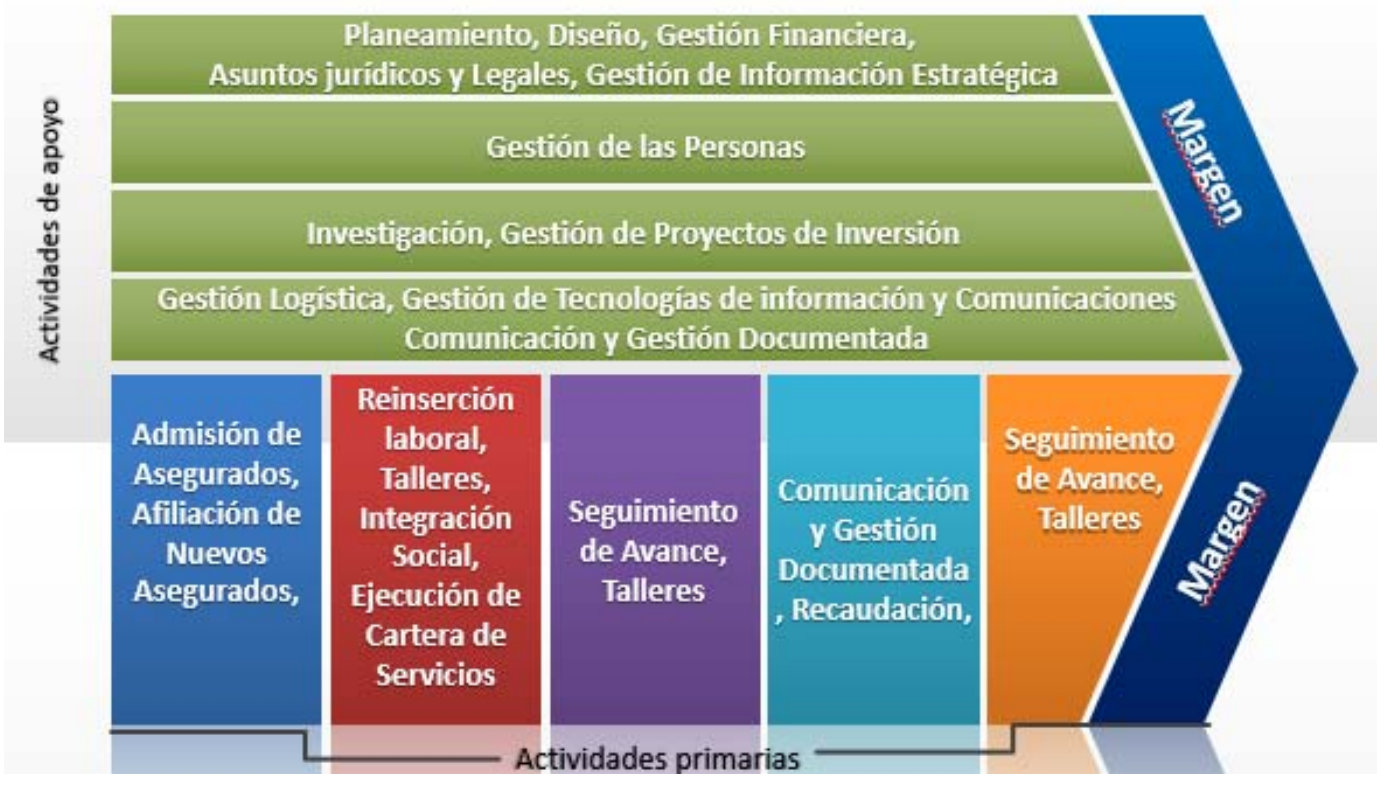

Fuente: Resolución Macroprocesos_EsSalud_Res127GG2016

A partir del análisis de información de las reuniones de trabajo y del portal de transparencia de EsSalud se logró plasmar los procesos misiones, estratégicos y soporte (EsSalud, 2015). Ubicando al macro proceso de prestación social dentro de la categoría de misionales. 
Ilustración 13: Mapa de Procesos de EsSalud As Is

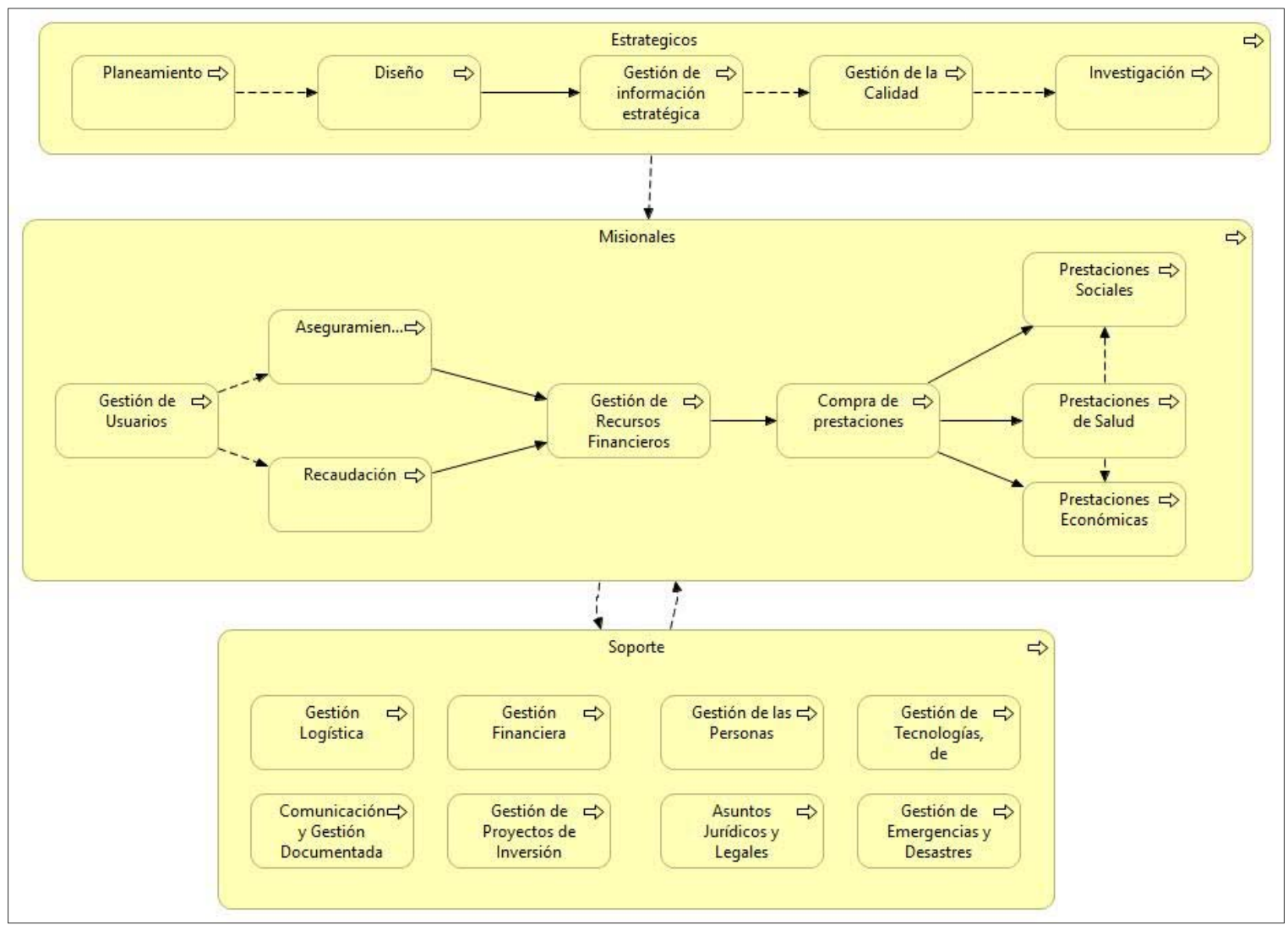

Fuente: Macroprocesos_EsSalud_Res127GG2016

Con esta información recolectada se pudo identificar que es un proceso misional que no está conectado a nivel de negocio con ningún otro macro proceso de la empresa, pero si tiene un flujo de información del proceso core y central de "Prestación de Salud". Descubriendo que los procesos de negocio estaban vagamente definidos y no cuentan con soporte de sistemas.

La información quedo documentada en los siguientes entregables de TOGAF:

- Statement of Architecture Work

- Architecture Vision

- Architecture Definition Document

- Value Chain diagram

Dentro del macro proceso a un nivel As Is se divide en los procesos de gestionar atención del CERP y gestionar atención del CAM. Para un mayor detalle se graficaron los procesos con sus funciones de negocio en archimate. 
Ilustración 14: Gestionar Atención en el CAM As Is

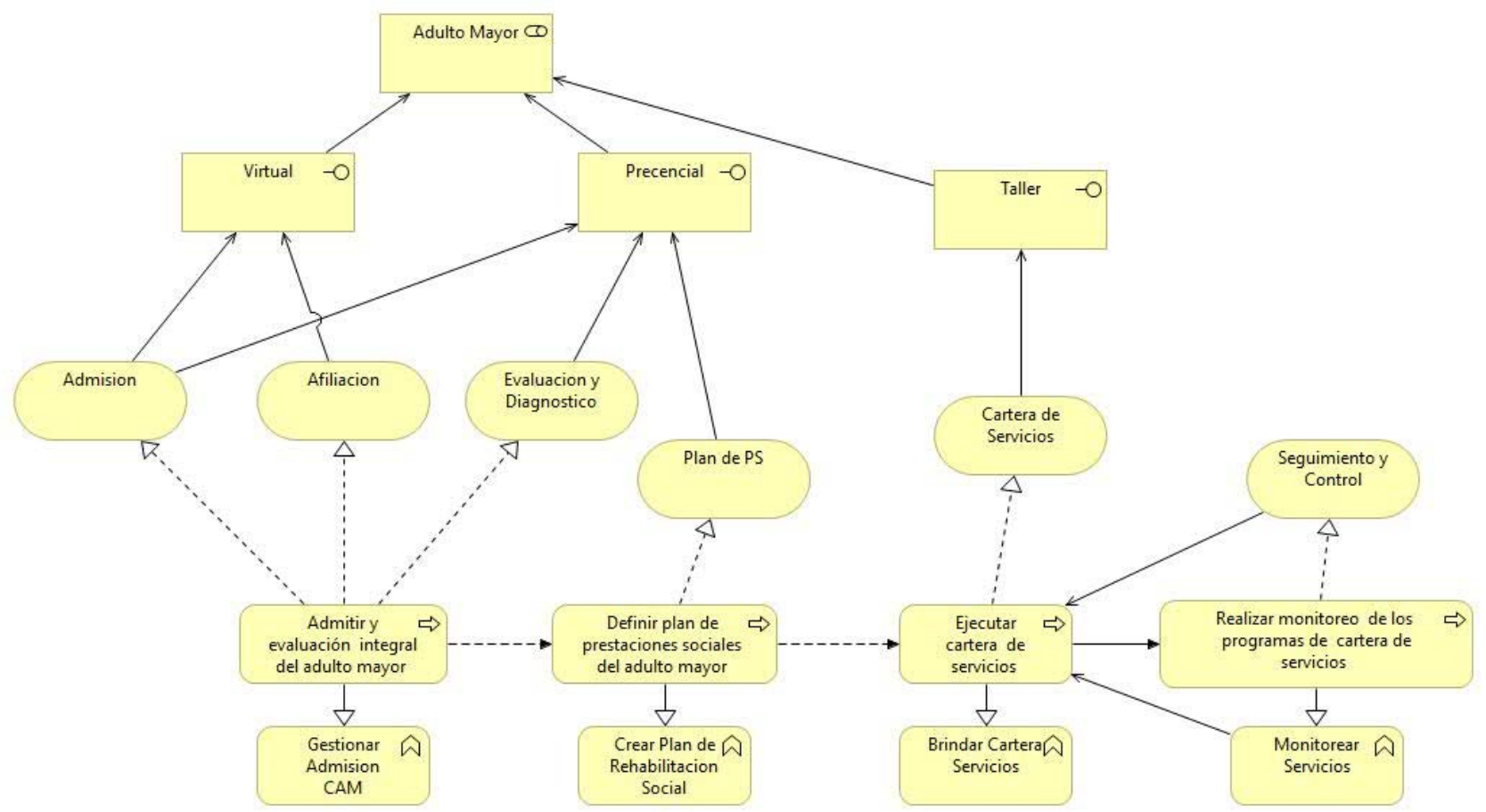

Fuente: Manual de Operaciones del Centro del Adulto Mayor

Ilustración 15: Gestionar Atención en el CERP As Is

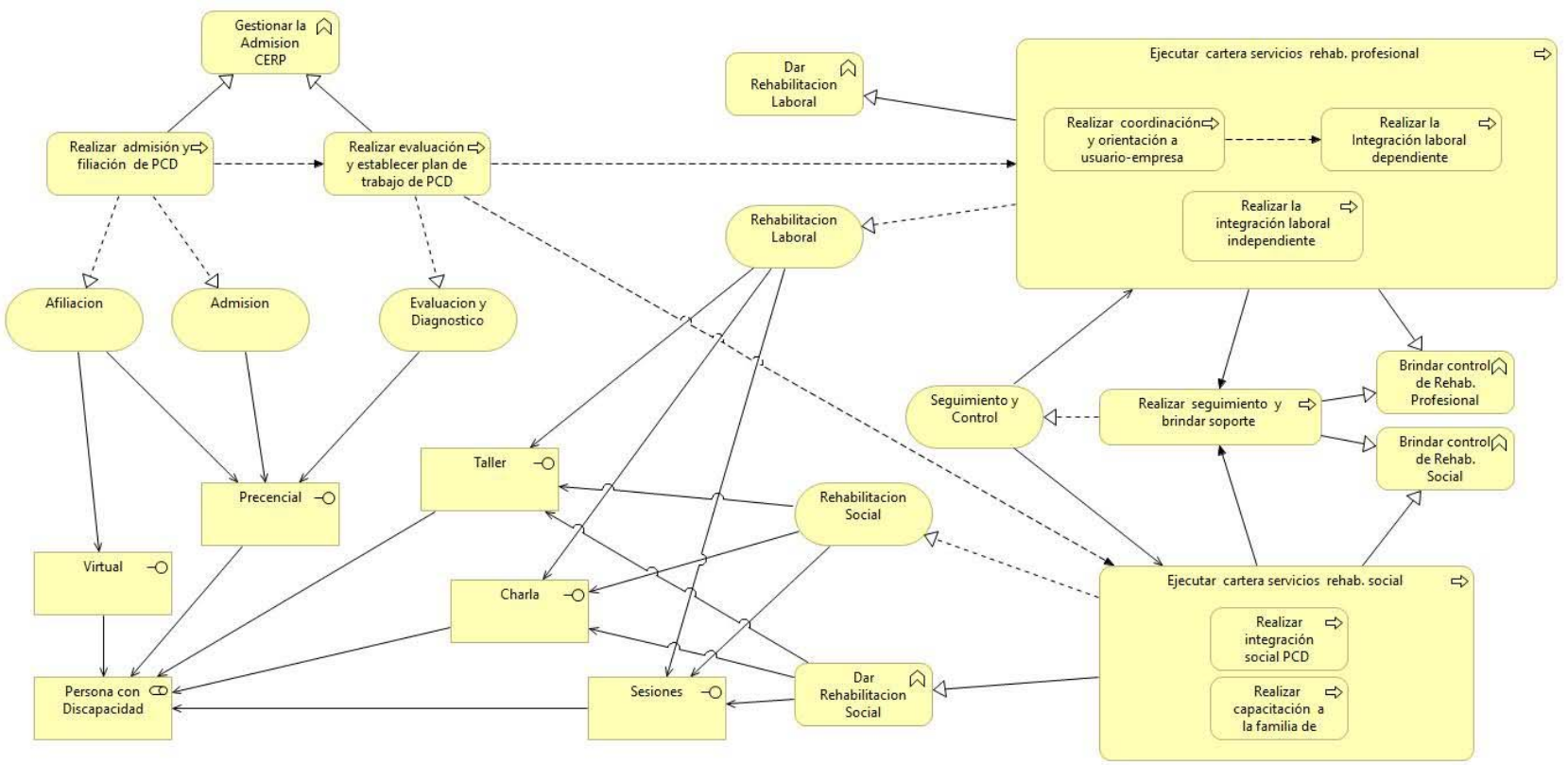

Fuente: Manual de Operaciones del Centro de Rehabilitación Profesional y Social (CERP) 


\section{Ilustración 16: Relación de Arquitectura entre CERP y CAM As Is}

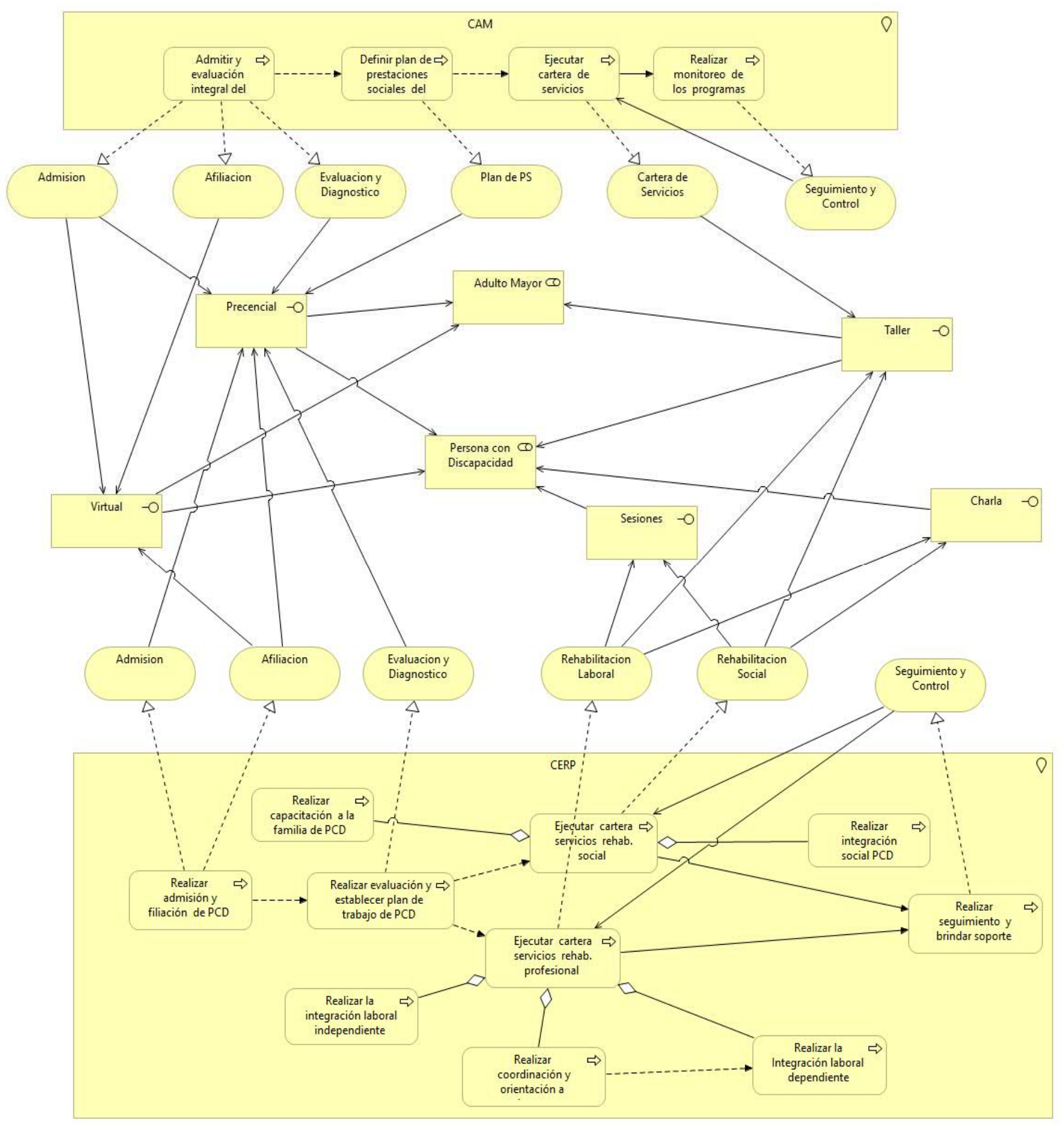

Fuente: Elaboración Propia 


\section{Desarrollo}

Al obtener información recabada en la fase inicial y análisis se elaboró los procesos, actividades, metas, objetivos, roles, funciones y servicios. Posterior a ello se identificó cuáles serían las posibles mejoras o problemas actuales.

\section{Metas de Negocio y Tecnológicas}

- Extender la cobertura de la seguridad social, incluyendo a los trabajadores independientes e informales

- Brindar atención integral a los asegurados, con los más altos estándares de calidad, en el marco de un fuerte compromiso del Estado con el bienestar de los asegurados; mejorar el trato a los asegurados, cambiar el modelo de atención por uno basado en la atención primaria y actuar sobre los determinantes sociales de la salud, con los aspectos preventivo-promocionales, contando para ello con el apoyo técnico de la OPS/OMS

- Garantizar la sostenibilidad financiera de la seguridad social en salud

- Implementar una gestión transparente basada en el mérito y la capacidad, con personal calificado y comprometido

\section{Objetivos Derivados de las Metas}

- Extender la cobertura de la seguridad social incorporando a segmentos poblacionales excluidos, hacia una seguridad social para todos.

- Mejorar la gestión de seguros, orientándola al logro de altos estándares de calidad.

- Establecer alianzas estratégicas a nivel regional y local para el intercambio y complementariedad de servicios y recursos orientados a la universalización de la seguridad social.

- Promover la seguridad social para todos en foros internacionales.

- Mejorar la calidad de los servicios de salud logrando un alto nivel de satisfacción de los usuarios.

- Implementar un sistema de atención integral basado en la atención primaria de salud y las prioridades sanitarias, gestión por procesos y gestión de la enfermedad. 
- Organizar redes integrales de servicios que garanticen la continuidad de la atención desde el primer al tercer nivel.

- Mejorar el impacto de las prestaciones sociales y económicas en el bienestar de los asegurados.

- Mejorar la gestión de la siniestralidad y de la administración de riesgos.

- Mejorar la gestión del gasto orientándolo a financiar resultados a través de intervenciones costo-efectivas.

- Mejorar la gestión de ingresos tributarios y no tributarios, procurando preservar o incrementar el valor del capital del portafolio de inversiones que respalda la reserva técnica institucional.

- Fortalecer la lucha contra la corrupción a través de mecanismos de transparencia, vigilancia ciudadana, rendición de cuentas y recepción de denuncias.

- Desarrollar una gestión eficiente basada en resultados, incorporando tecnologías modernas de gestión.

Tabla 13: Capacidades del Proceso de Gestionar Atención del CAM y CERP

\begin{tabular}{|l|l|}
\hline CAM & CERP \\
\hline Admitir Afiliado & Admitir Afiliado \\
\hline Afiliar Prospecto & Afiliar Prospecto \\
\hline Evaluar de Estado de Salud del Afiliado & Evaluar de Estado de Salud del Afiliado \\
\hline Realizar Plan de Rehabilitación & $\begin{array}{l}\text { Evaluar de Estado de Psicológico del } \\
\text { Afiliado }\end{array}$ \\
\hline Ejecutar Talleres & Talleres de Rehabilitación Profesional \\
\hline Monitorear Servicios & $\begin{array}{l}\text { Realizar Plan de Rehabilitación } \\
\text { Profesional }\end{array}$ \\
\hline & Realizar Plan de Rehabilitación Social \\
\hline
\end{tabular}




\begin{tabular}{|l|l|}
\hline & Talleres de Rehabilitación \\
\hline & Monitorear Servicios \\
\hline
\end{tabular}

Fuente: Elaboración Propia

Toda la documentación referente a esta fase se encuentra en los entregables TOGAF:

- Architecture Definition Document

- Architecture Requirements Specification

- Architecture Roadmap

- Role catalog

- Business Service/Function catalog

Se pasó al diagramado de los procesos de gestionar atención del CERP y CAM AS Is en Bizagi con notación BPMN 2.0 para un mayor detalle y entendimiento.

Ilustración 17: Gestionar Atención del CAM - As Is

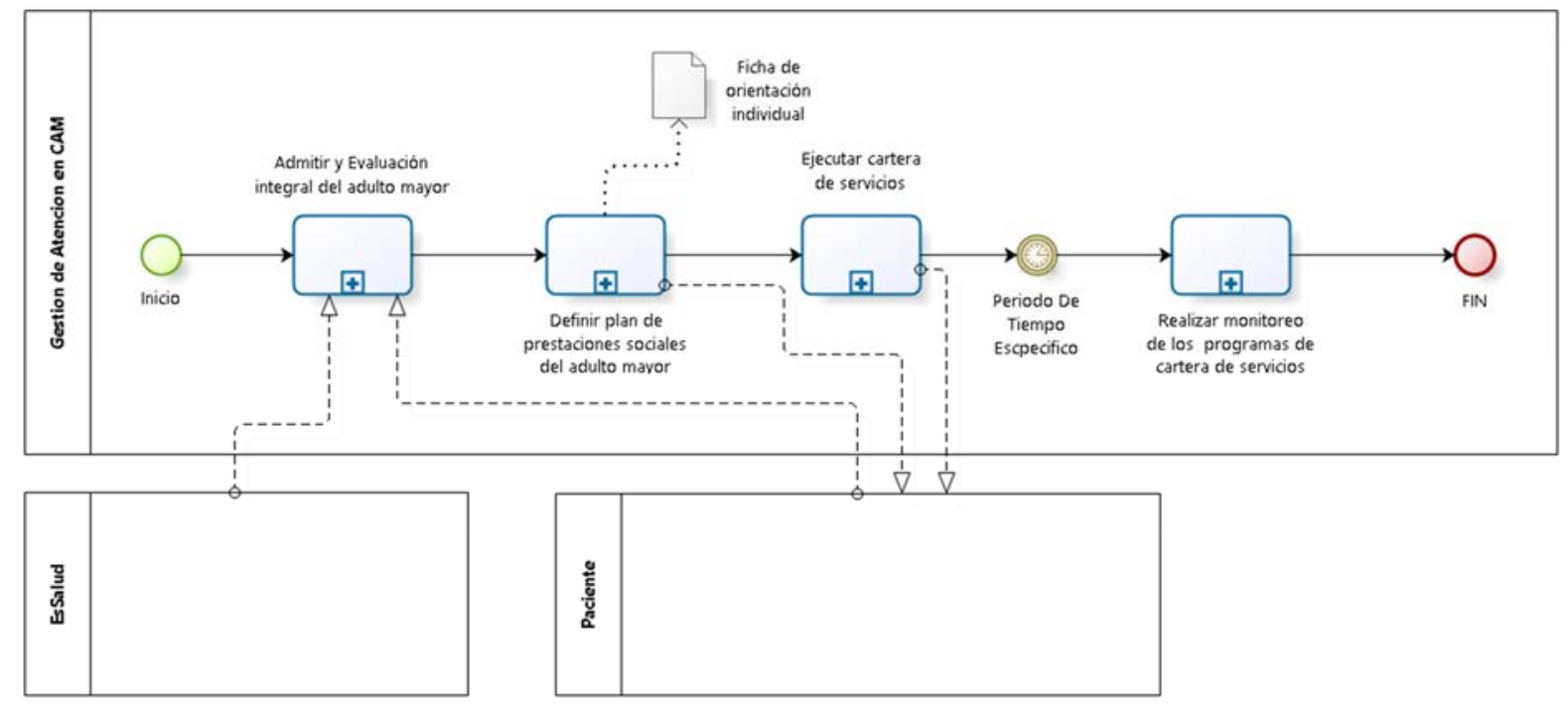

Fuente: Elaboración Propia 
Sub proceso:

- Admitir y evaluación integral al adulto mayor.

- Definir plan de prestaciones sociales del adulto mayor

- Ejecutar cartera de servicios

- Realizar monitoreo de los programas de cartera de servicios

Ilustración 18: Admitir y Evaluación Integral del Adulto Mayor

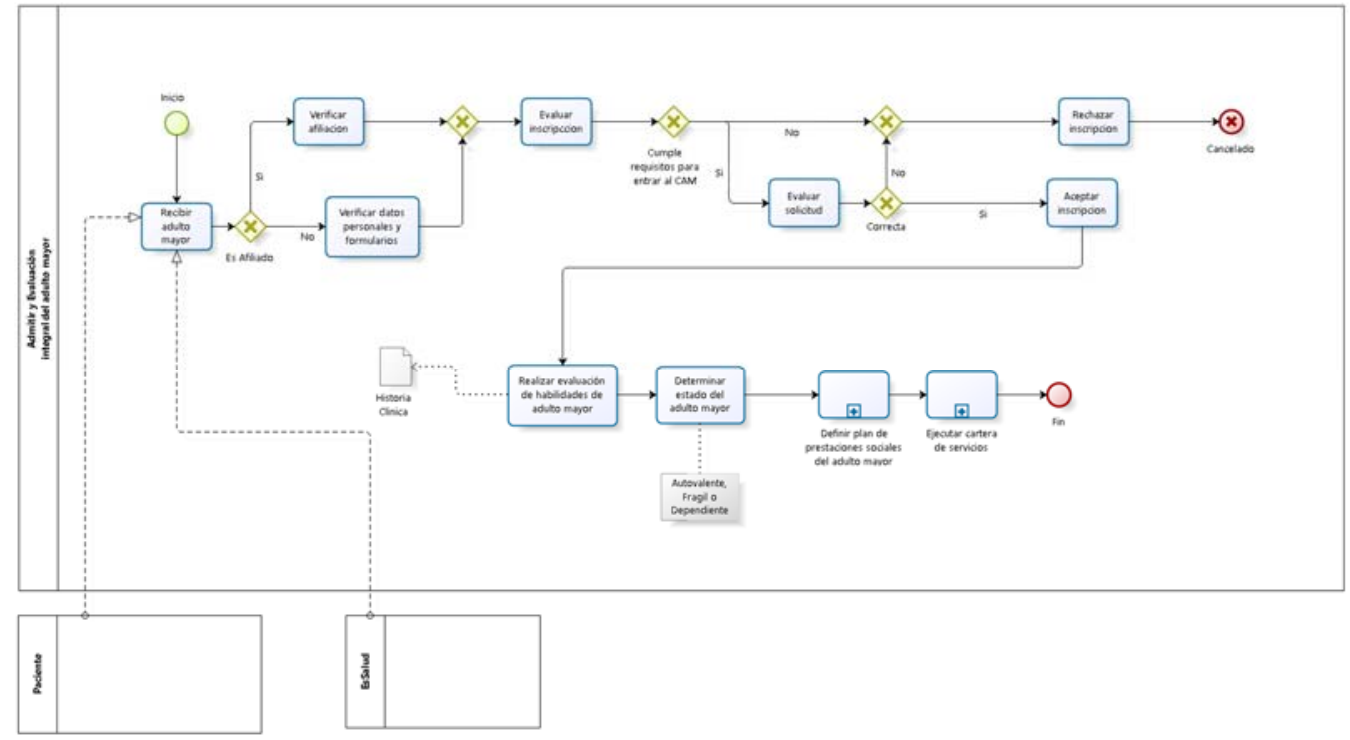

Fuente: Elaboración Propia

Actividad: 
- Recibir adulto mayor

- Verificar datos personales y formularios

- Verificar afíliación

- Evaluar inscripción

- Evaluar solicitud

- Rechazar inscripción

- Aceptar inscripción

- Realizar evaluación de habilidades del adulto mayor

- Determinar estado del adulto mayor

Sub proceso:

- Definir plan de prestaciones sociales del adulto mayor

- Ejecutar cartera de servicios

Ilustración 19: Definir Plan de Prestaciones Sociales del Adulto Mayor

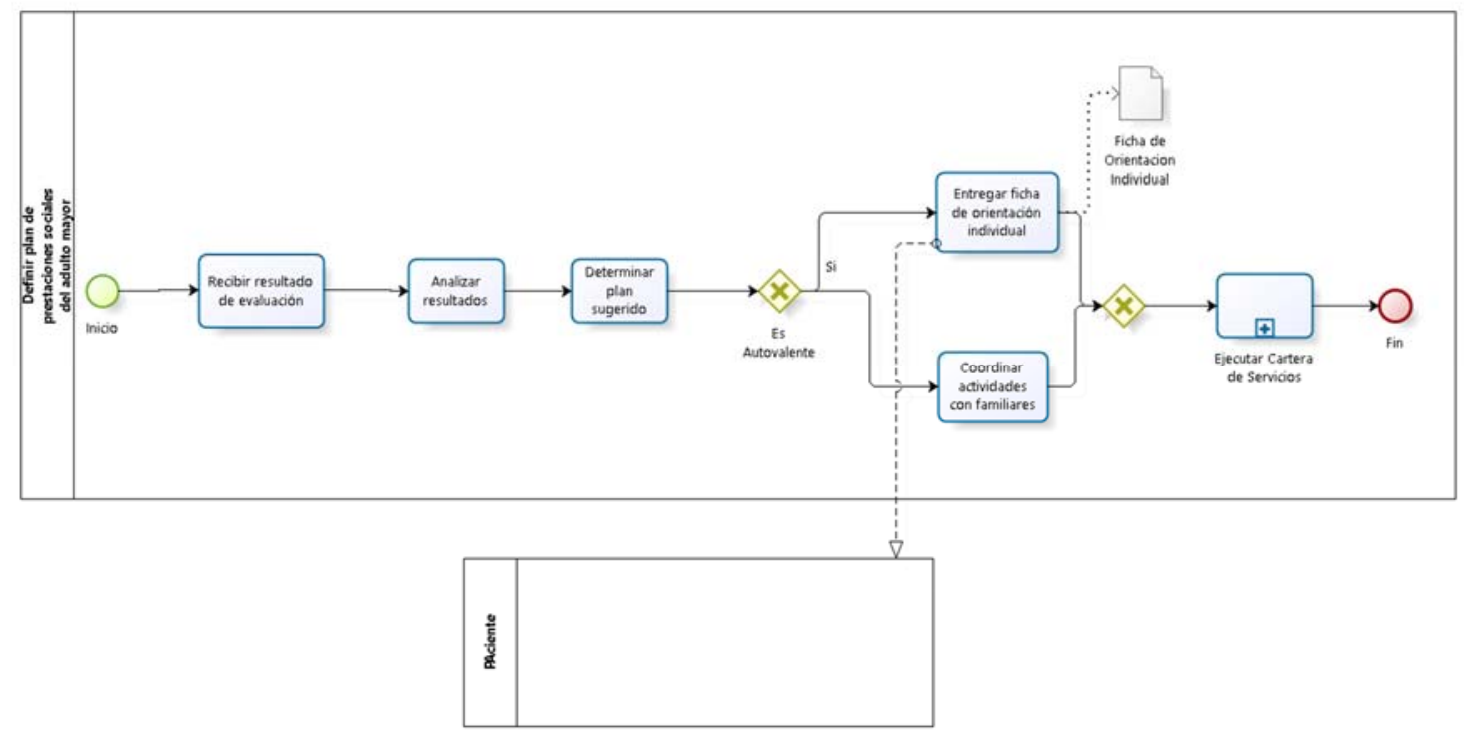

Fuente: Elaboración Propia

Actividad: 
- Recibir resultado de evaluación

- Analizar resultados

- Determinar plan sugerido

- Entregar ficha de orientación individual

- Coordinar actividades con familiares

Sub proceso:

- Ejecutar Cartera de Servicios

Ilustración 20: Ejecutar Cartera de Servicios

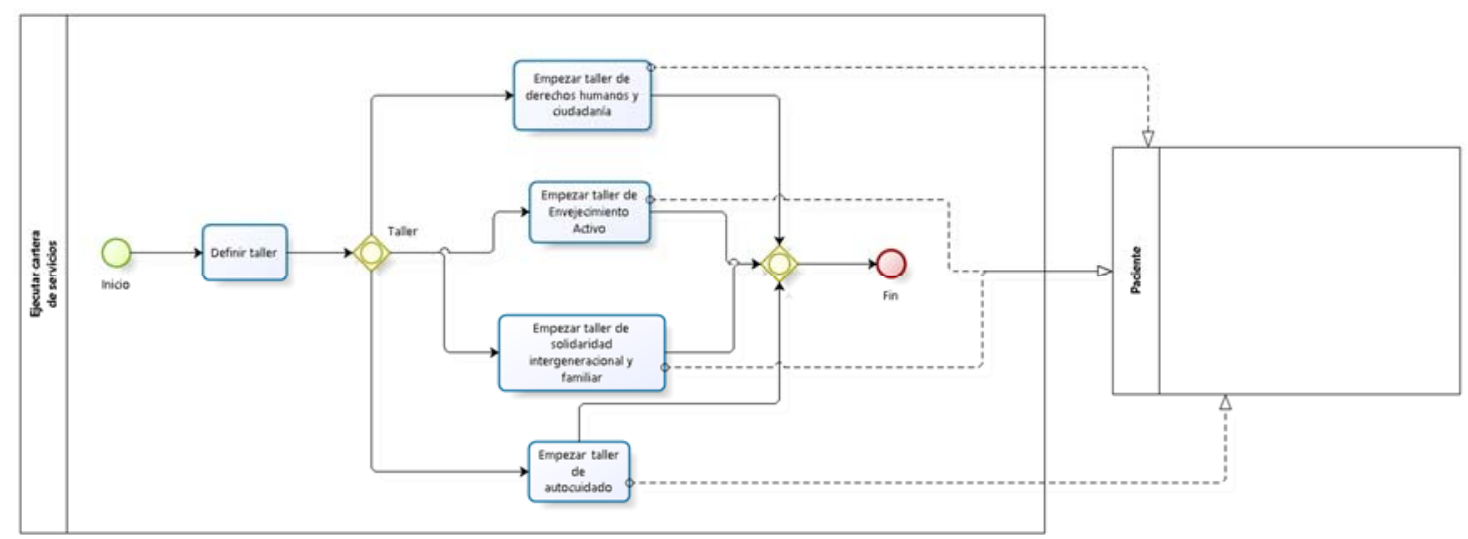

Fuente: Elaboración Propia

Actividad:

- Definir taller

- Empezar taller de autocuidado 
- Empezar taller de solidaridad intergeneracional y familiar

- Empezar taller de Envejecimiento Activo

- Empezar taller de derechos humanos y ciudadanía

Ilustración 21: Gestionar atención del CERP - As Is

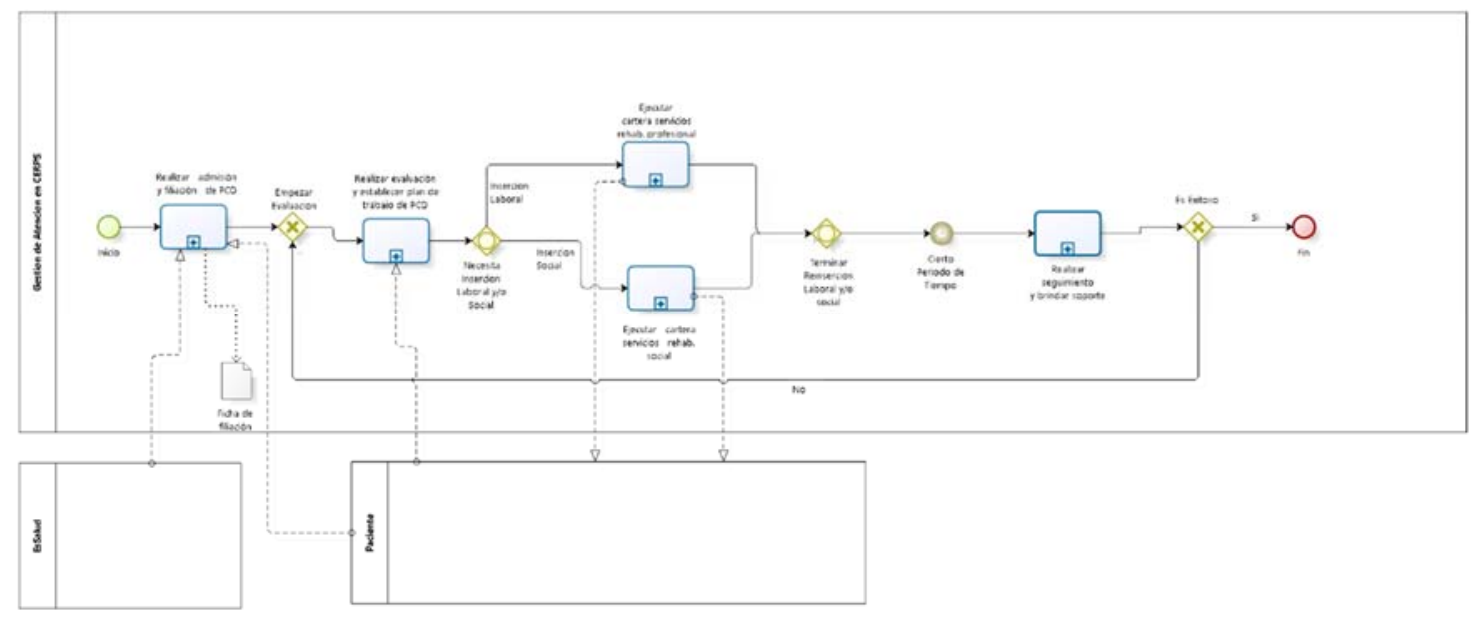

Fuente: Elaboración Propia

Sub proceso:

- Realizar admisión y afiliación de PCD

- Realizar evaluación y establecer plan de trabajo de PCD

- Ejecutar cartera se servicios de rehabilitación profesional

- Ejecutar cartera se servicios de rehabilitación social

- Realizar seguimiento y brindar soporte

Ilustración 22: Realizar Admisión y Afiliación de PCD 


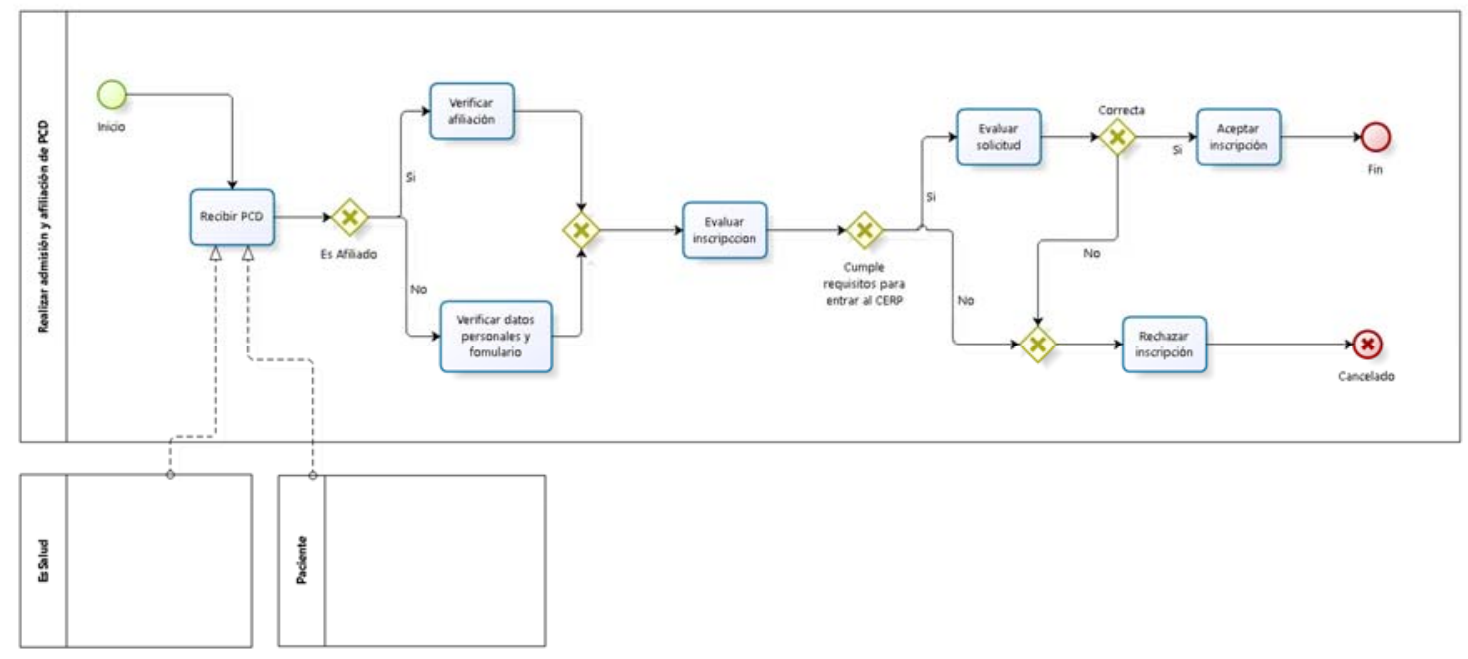

Fuente: Elaboración Propia

Actividad:

- Recibir PCD

- Verificar datos personales y formulario

- Verificar afiliación

- Evaluar inscripción

- Evaluar solicitud

- Aceptar inscripción

- Rechazar inscripción

Ilustración 23: Realizar Evaluación y Establecer Plan de Trabajo de PCD 


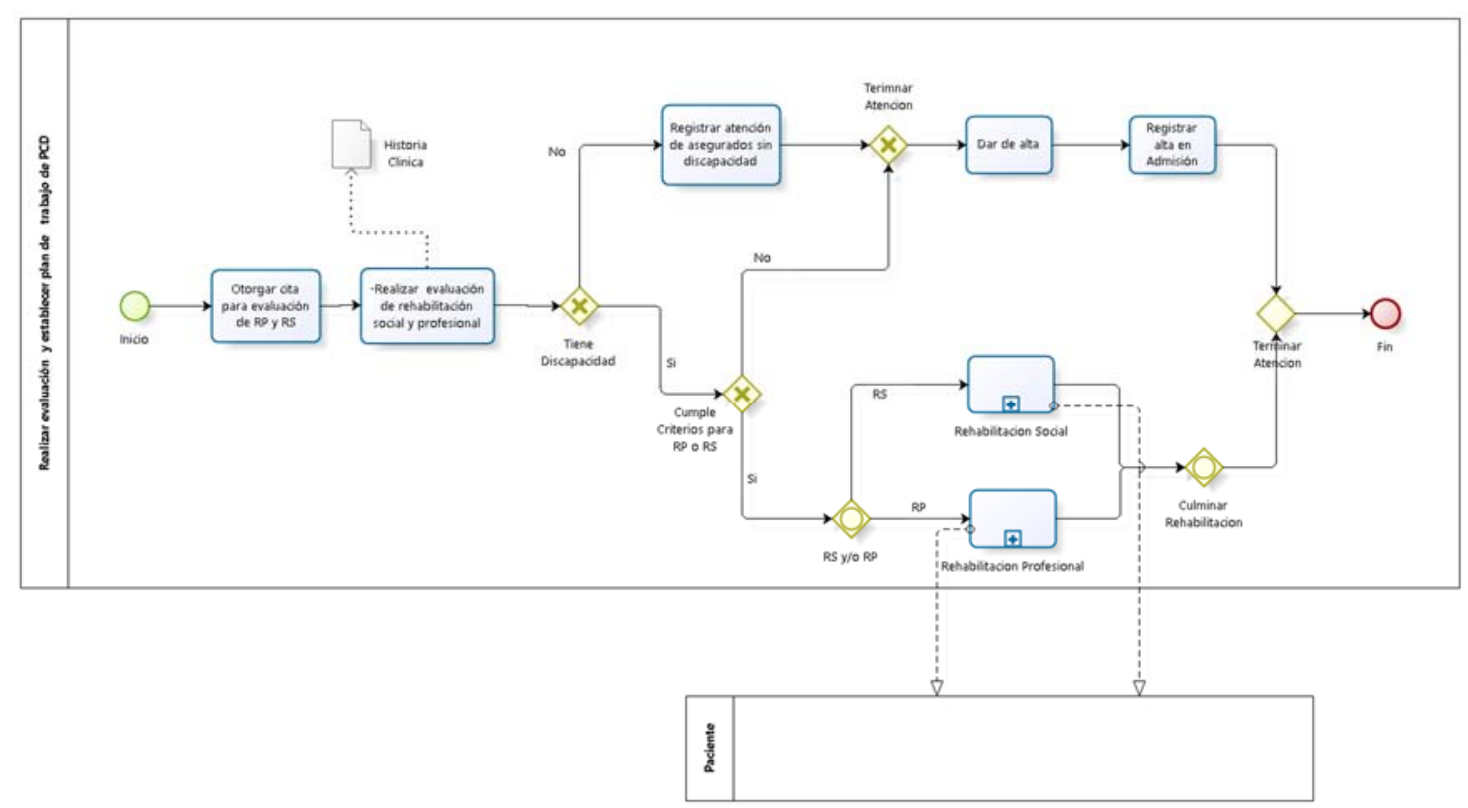

Fuente: Elaboración Propia

Sub proceso:

- Rehabilitación social

- Rehabilitación profesional

Actividad:

- Otorgar cita para evaluación de RP y RS

- Realizar evaluación de rehabilitación social y profesional

- Registrar atención de asegurados sin discapacidad

- Dar de alta

- Registrar alta en Admisión

Ilustración 24: Ejecutar Cartera Servicios Rehab. Profesional 


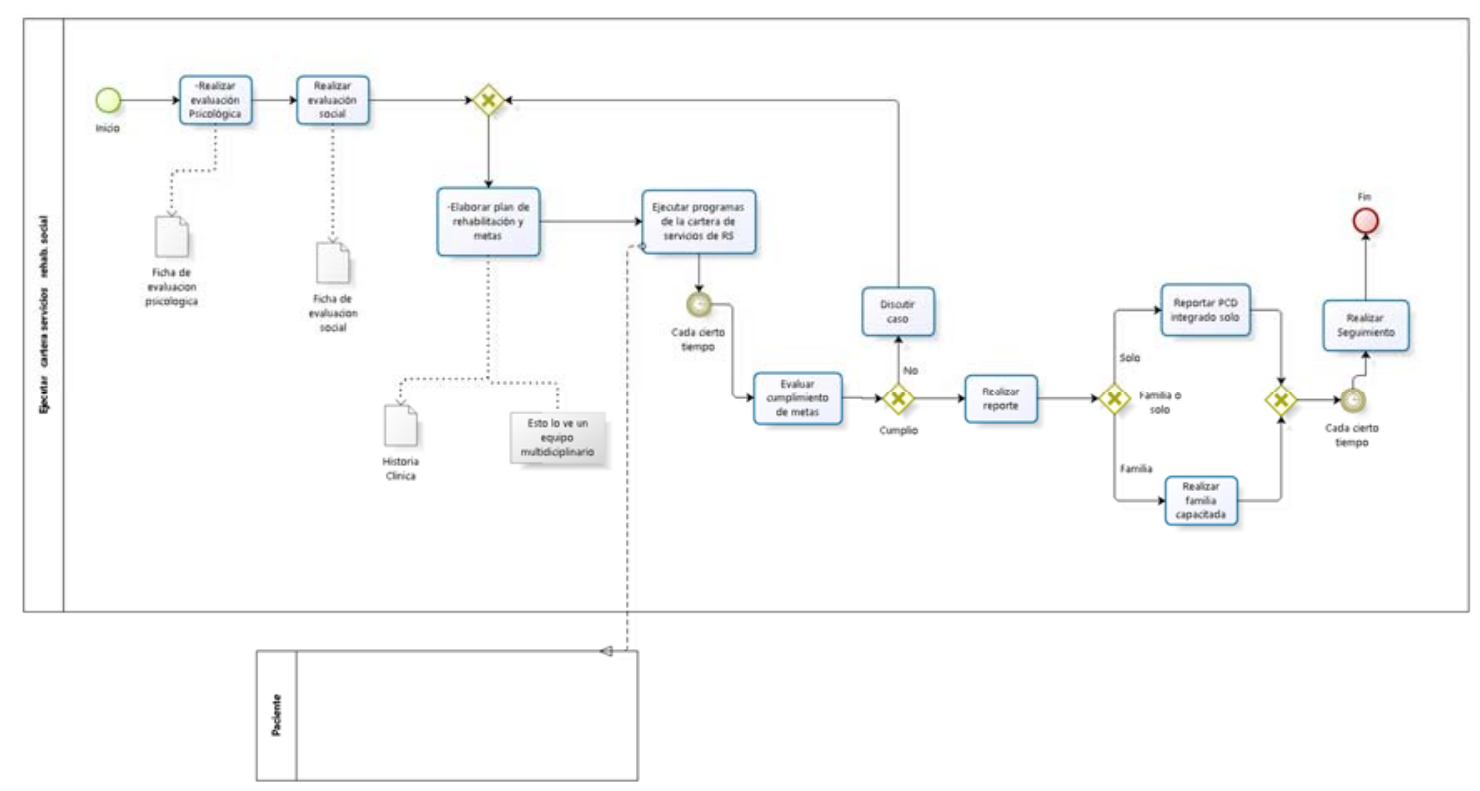

Fuente: Elaboración Propia

Sub proceso:

- Realizar proceso de IL independiente

- Realizar proceso de IL dependiente con vinculo

- Realizar proceso de IL dependiente sin vinculo

Actividad:

- Realizar coordinación y orientación a usuario-empresa

Ilustración 25: Realizar Proceso de IL Independiente 


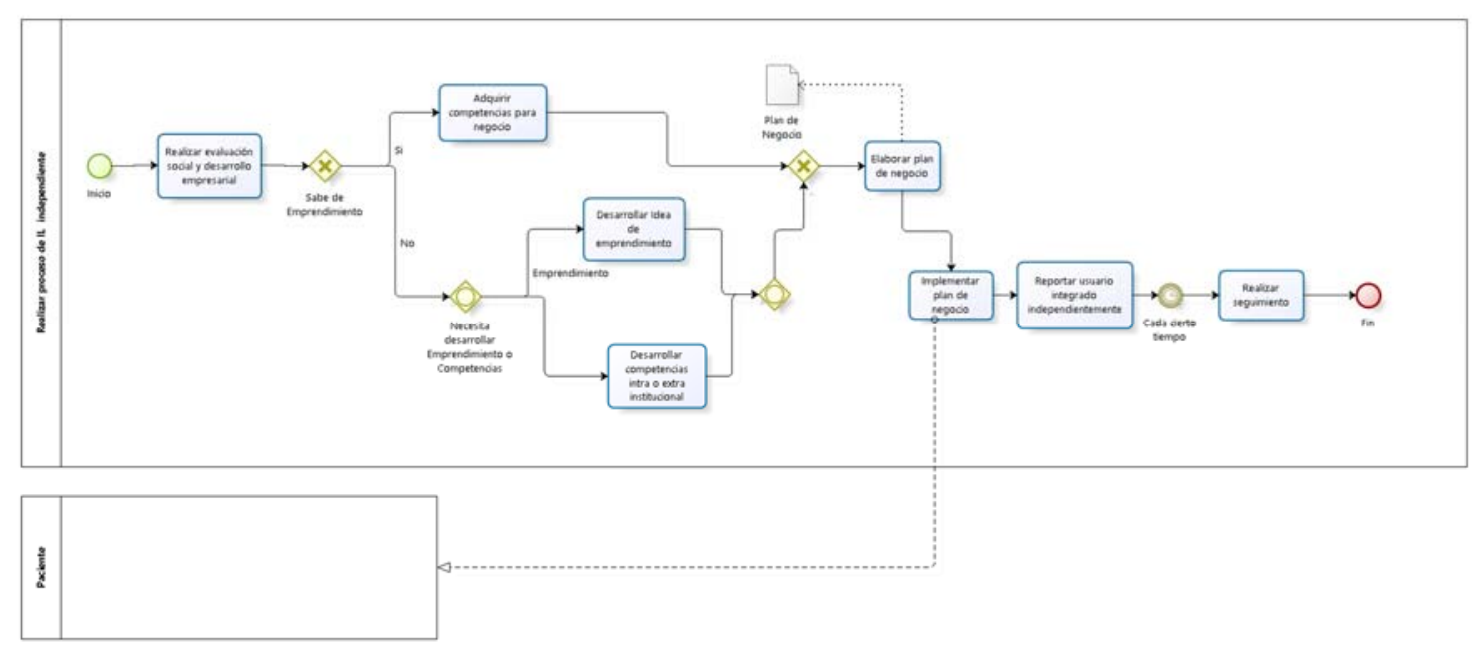

Fuente: Elaboración Propia

Actividad:

- Realizar evaluación social y desarrollo empresarial

- Adquirir competencias para negocio

- Desarrollar Idea de emprendimiento

- Desarrollar competencias intra o extra institucional

- Elaborar plan de negocio

- Implementar plan de negocio

- Reportar usuario integrado independientemente

- Realizar seguimiento 
Ilustración 26: Realizar Proceso de IL Dependiente con Vínculo

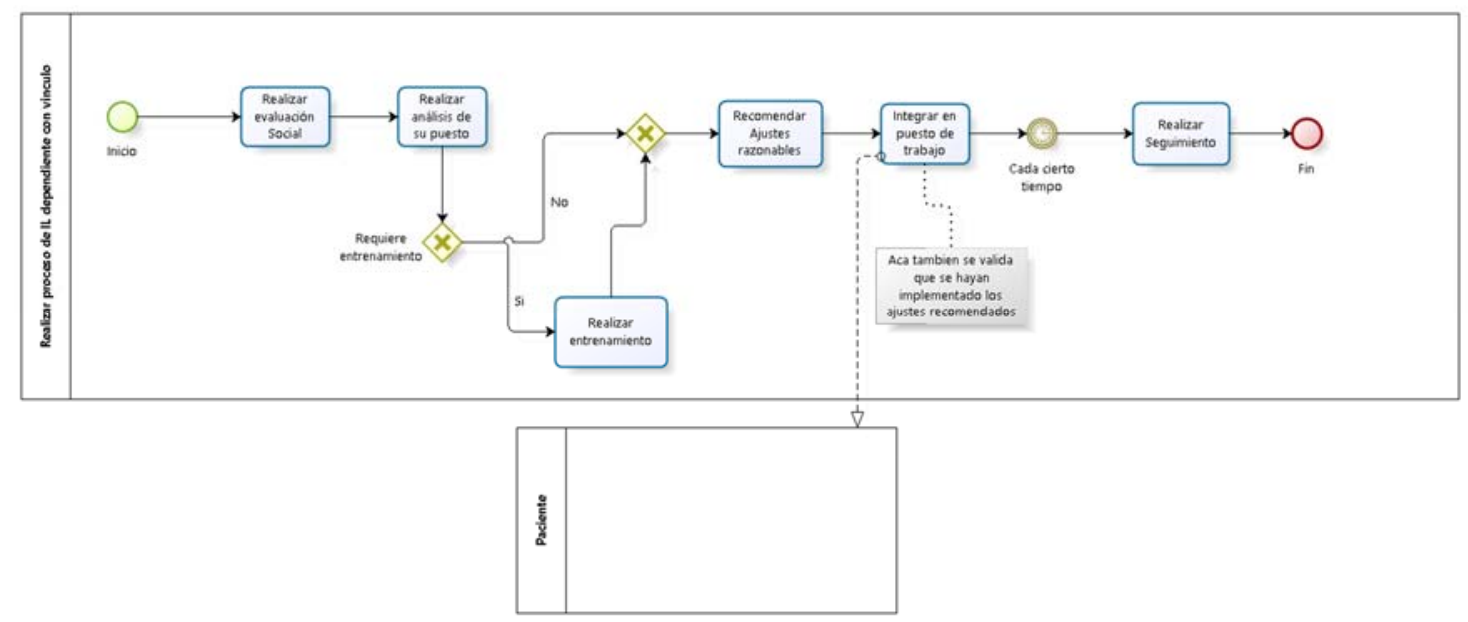

Fuente: Elaboración Propia

Actividad:

- Realizar evaluación Social

- Realizar análisis de su puesto

- Realizar entrenamiento

- Recomendar Ajustes razonables

- Integrar en puesto de trabajo

- Realizar Seguimiento 
Ilustración 27: Realizar Proceso de IL Dependiente sin Vínculo

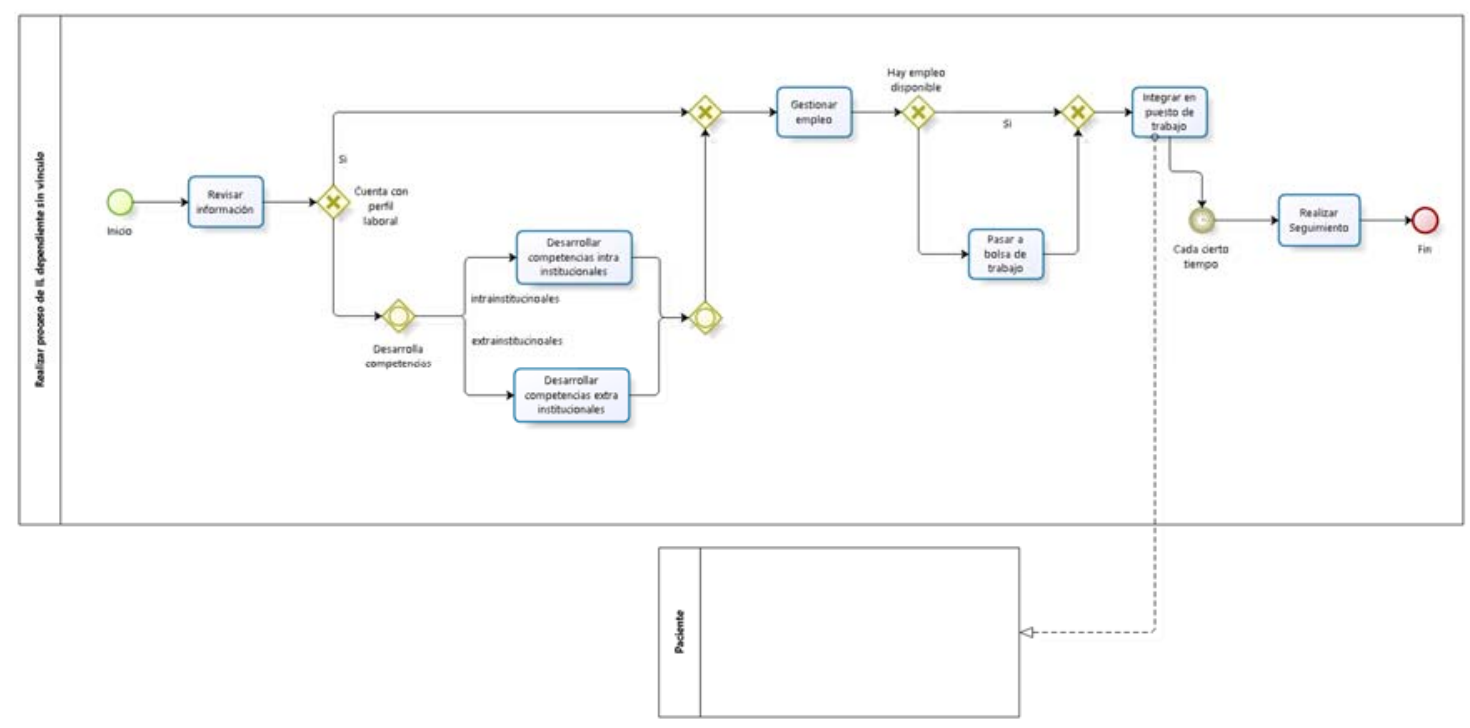

Fuente: Elaboración Propia

Actividad:

- Revisar información

- Desarrollar competencias extra institucionales

- Desarrollar competencias intra institucionales

- Gestionar empleo

- Pasar a bolsa de trabajo

- Integrar en puesto de trabajo

- Realizar Seguimiento 
Ilustración 28: Ejecutar Cartera Servicios Rehab. Social

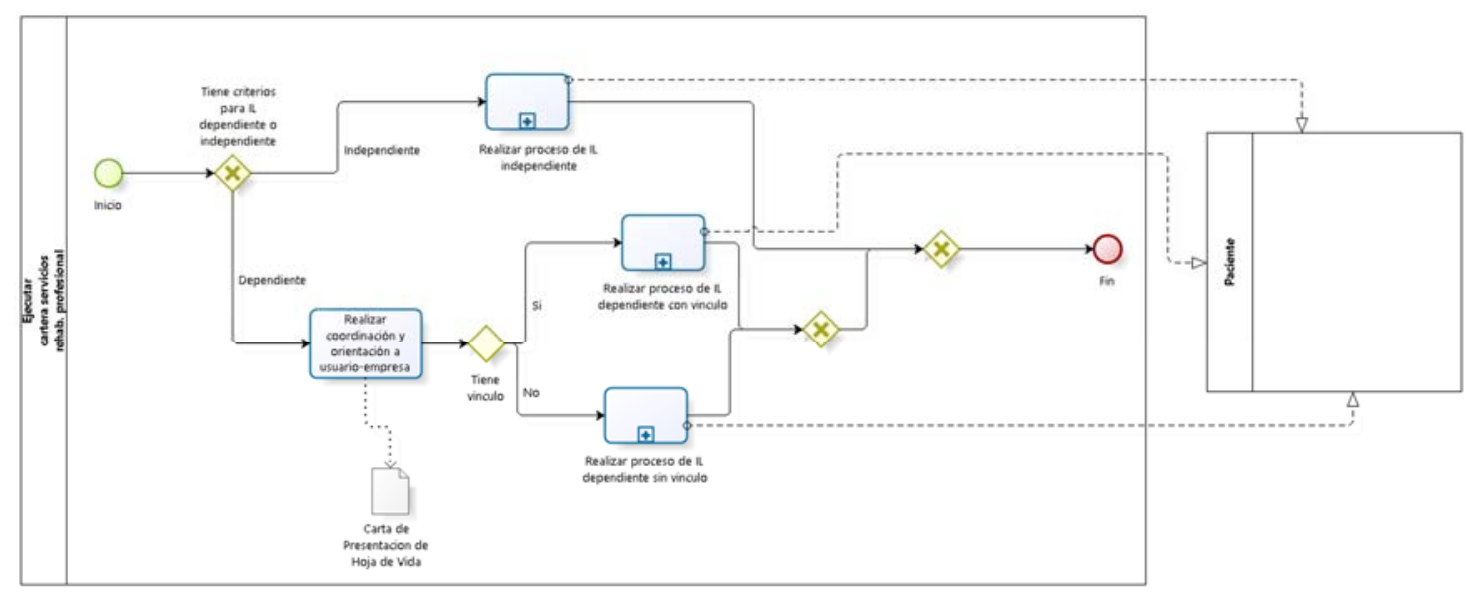

Fuente: Elaboración Propia

Actividad:

- Realizar evaluación Psicológica

- Realizar evaluación social

- Elaborar plan de rehabilitación y metas

- Ejecutar programas de la cartera de servicios de RS

- Discutir caso

- Evaluar cumplimiento de metas

- Realizar reporte

- Reportar PCD integrado solo

- Realizar familia capacitada

- Realizar Seguimiento

Luego del diseño y entender la realidad del proceso, se elaboró la arquitectura empresarial As Is abarcado los procesos, funciones y los sistemas actuales de EsSalud. 
Ilustración 29: Macro Proceso de Prestación Social Versus los Sistemas TI As Is

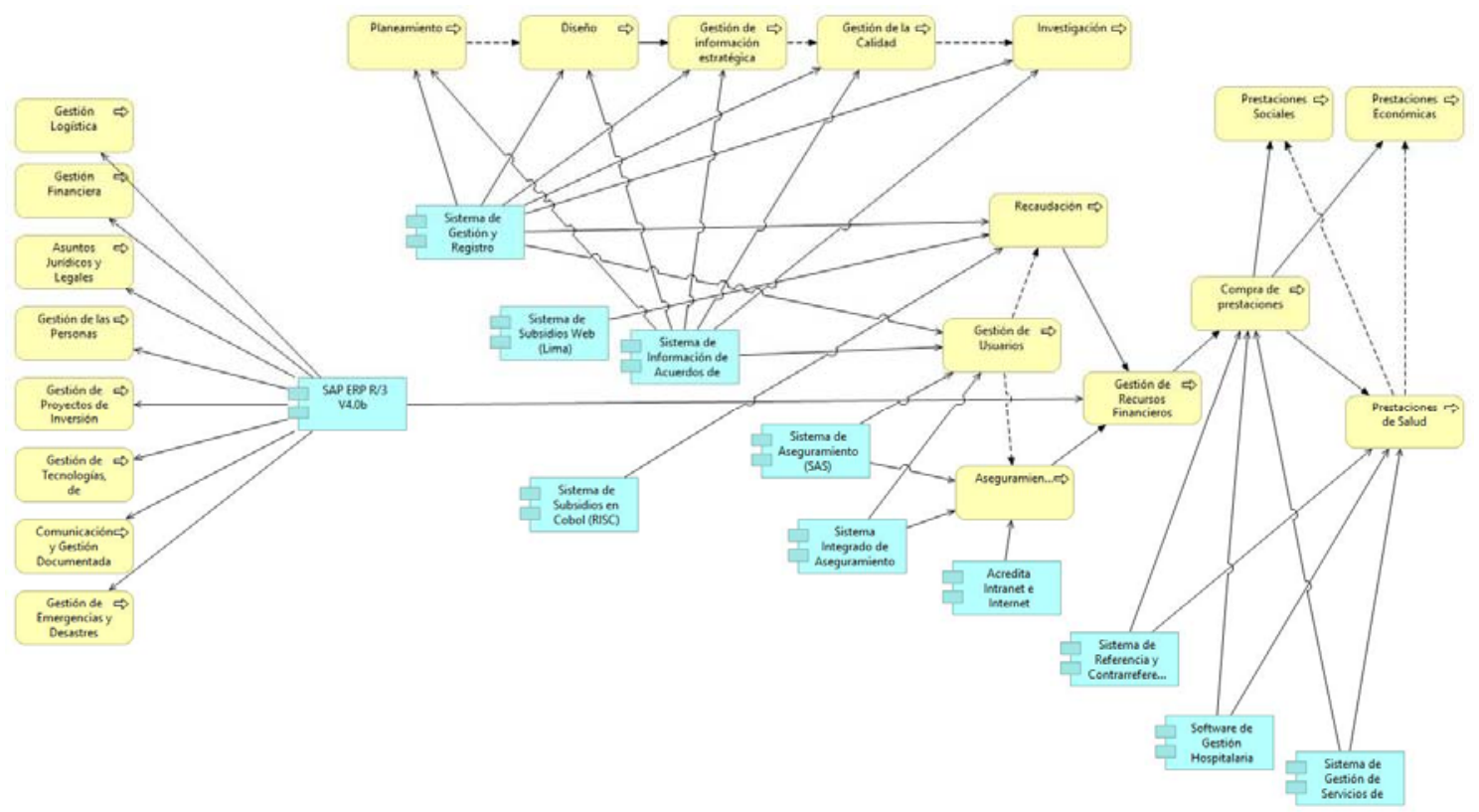

Fuente: Elaboración Propia

Posterior a la vista macro y la información del manual de operaciones, se logró mapear las relaciones entre los procesos misionales y los sistemas TI. Apreciando a simple vista que el macro proceso de prestación social no tiene una relación directa a algún sistema.

Ilustración 30: Procesos Misionales Versus Sistemas TI As Is

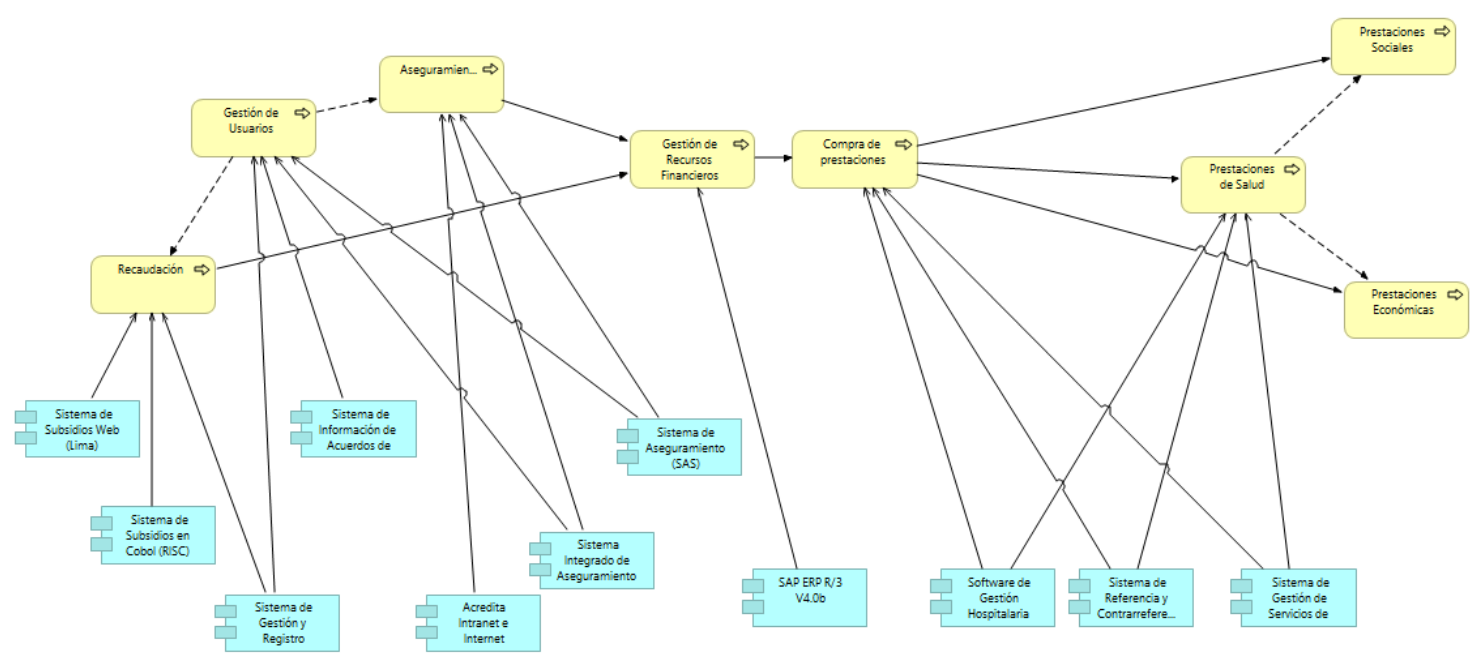

Fuente: Elaboración Propia 
El proceso presenta escasa documentación de ambos centros (CAM y CERP), sin estandarización. También se notó que había fallas en el proceso, ya que algunos flujos no eran óptimos y el proceso era simple (no soportaba errores o flujos alternos). Además, el proceso debería estar relacionado con prestación de salud, pero la única conexión es por información, cuando ambos procesos podrían beneficiarse si hubiera una derivación entre ambos.

A partir del As Is de los procesos y modelo de arquitectura, se pasó a reunirse para validar los diagramas y los modelos con el cliente y los profesionales del proceso en mención. En conclusión, de las reuniones de trabajo y la percepción al visitar los centros de salud se elaboró los siguientes requerimientos:

Tabla 14: Requerimiento de Negocios

\begin{tabular}{|l|l|l|}
\hline \multicolumn{2}{|l|}{ Dominio Negocio } \\
\hline R1 & $\begin{array}{l}\text { Reordenamiento del proceso de evaluación y } \\
\text { creación del plan de rehabilitación tanto del CAM y } \\
\text { CERP para agilizar la atención. }\end{array}$ & \\
\hline R2 & $\begin{array}{l}\text { Implementar programa de rehabilitación con } \\
\text { tecnología. }\end{array}$ & $\begin{array}{l}\text { específico para cada centro (CAM y CERP) } \\
\text { R3 }\end{array}$ \\
\hline R4 & $\begin{array}{l}\text { Ses CAM o CERP, para esto se establecerán dos } \\
\text { nuevos procesos de gestionar atención del CAM y } \\
\text { CERP. }\end{array}$ & Derivar pacientes \\
\hline R5 & $\begin{array}{l}\text { Se va a mantener la historia clínica y de mejora de los } \\
\text { pacientes de forma electrónica. }\end{array}$ & necepcionar \\
\hline
\end{tabular}




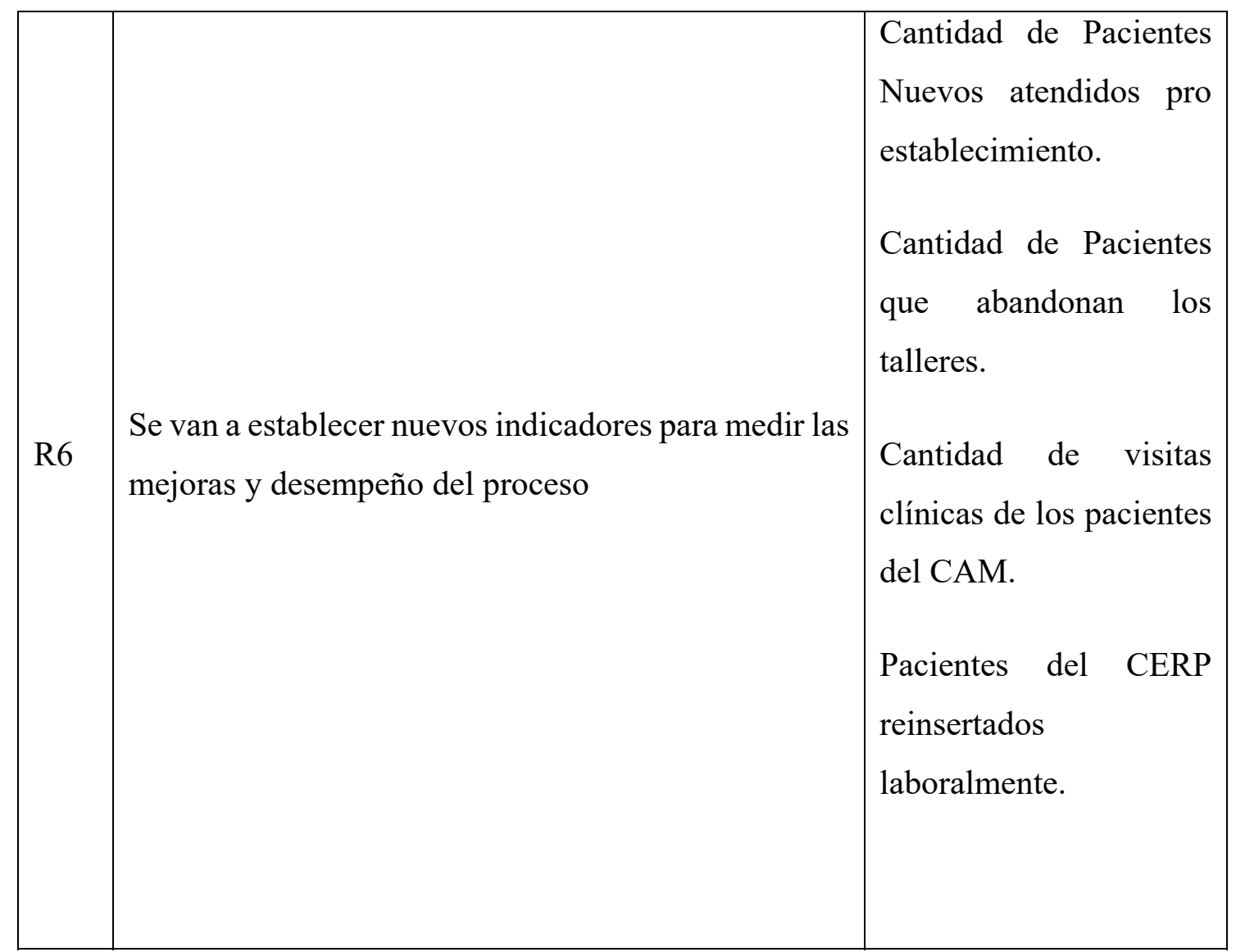

Fuente: Elaboración Propia

Tabla 15: Dominio de Aplicaciones

\section{Dominio de Aplicaciones}

\begin{tabular}{|c|c|c|}
\hline R7 & $\begin{array}{l}\text { Implementar una solución Ad-hoc que } \\
\text { contemple módulos para cubrir las } \\
\text { capacidades del proceso del CAM y CERP. }\end{array}$ & $\begin{array}{l}\text { Admisión } \\
\text { Evaluación psicológica } \\
\text { Evaluación medica } \\
\text { Mantenimiento historia clínica } \\
\text { Registro de talleres } \\
\text { Control de mejora }\end{array}$ \\
\hline R8 & $\begin{array}{l}\text { El sistema Ad-Hoc debe estar integrado al } \\
\text { sistema actual, para poder obtener la }\end{array}$ & \\
\hline
\end{tabular}




\begin{tabular}{|l|l|l|}
\hline $\begin{array}{l}\text { información de los afiliados a EsSalud y sus } \\
\text { historias clínicas. }\end{array}$ & \\
\hline
\end{tabular}

Fuente: Elaboración Propia

Tabla 16: Dominio de Datos

\section{Dominio de Datos}

\begin{tabular}{|l|l|l|}
\hline R9 & Se necesitará una base de datos Oracle 11g & \\
\hline R10 & $\begin{array}{l}\text { Se necesita grabar la información de pacientes, } \\
\text { talleres e historia clínica en tablas de base de } \\
\text { datos. }\end{array}$ & \\
\hline R11 & $\begin{array}{l}\text { Se debe actualizar la información de la atención } \\
\text { del paciente en cualquier CAS }\end{array}$ & \\
\hline
\end{tabular}

Fuente: Elaboración Propia

Tabla 17: Dominio de Tecnología

\section{Dominio de tecnología}

R12 Se montará la solución sobre la infraestructura actual de EsSalud 


\begin{tabular}{|l|l|l|}
\hline R13 & $\begin{array}{l}\text { Reutilización en lo posible las redes actuales, } \\
\text { servidores y Pcs. }\end{array}$ & \\
\hline
\end{tabular}

Fuente: Elaboración Propia

Luego se pasó a elaborar la propuesta de solución (To Be) en base a los requerimientos planteados. Se diseñó los procesos en mención bajo los estándares de BPMN 2.0 considerando un flujo óptimo, dando hincapié en el proceso de evaluación con integridad a la Prestación de Salud y los protocoles de atención.

Ilustración 31: Gestionar Atención del CAM To Be

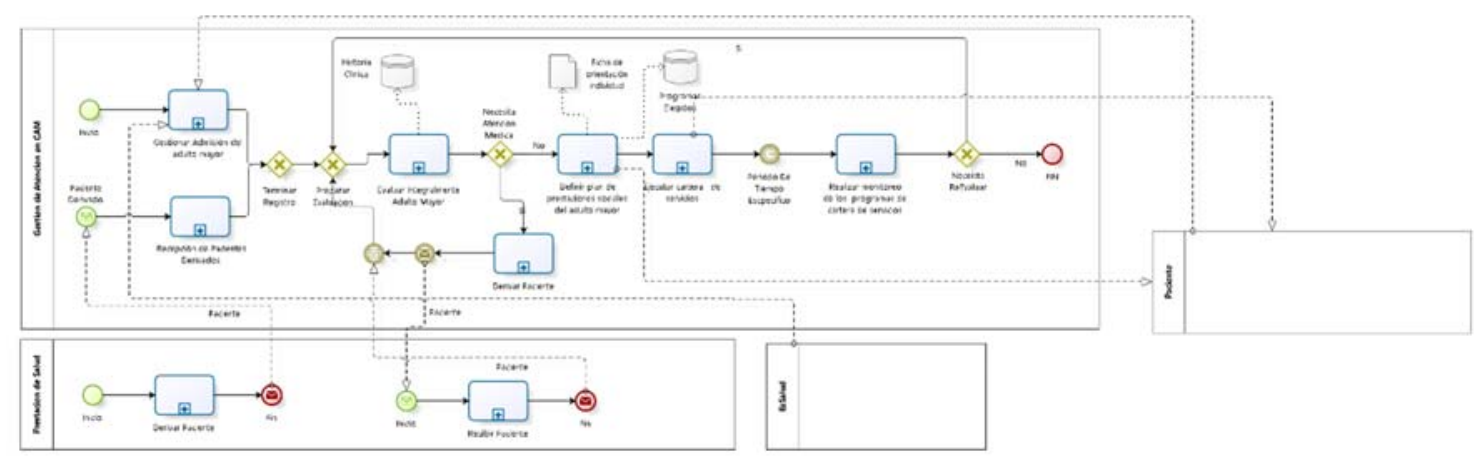

Fuente: Elaboración Propia

Sub proceso:

- Gestionar admisión del adulto mayor

- Recepción del paciente derivado

- Evaluar integralmente al adulto mayor

- Derivar paciente

- Definir plan de prestaciones sociales del adulto mayor

- Ejecutar cartera de servicios

- Realizar monitoreo de los programas de cartera de servicios

Caracterización:

Tabla 18: Caracterización de Gestión de Atención en CAM 


\begin{tabular}{|c|c|c|c|}
\hline \multicolumn{4}{|c|}{ Gestión de Atención en CAM } \\
\hline Input & Actividad & Output & Descripción \\
\hline $\begin{array}{l}\text { Adulto Mayor } \\
\text { sin Inscribir }\end{array}$ & $\begin{array}{l}\text { Gestionar Admisión del } \\
\text { adulto mayor }\end{array}$ & $\begin{array}{l}\text { Adulto Mayor } \\
\text { Inscrito }\end{array}$ & $\begin{array}{l}\text { Se genera la inscripción } \\
\text { del adulto mayor }\end{array}$ \\
\hline $\begin{array}{l}\text { Adulto Mayor } \\
\text { sin Inscribir }\end{array}$ & $\begin{array}{l}\text { Recepción de Pacientes } \\
\text { Derivados }\end{array}$ & $\begin{array}{l}\text { Adulto Mayor } \\
\text { Inscrito }\end{array}$ & $\begin{array}{l}\text { Se recibe a los adultos } \\
\text { mayores y se les inscribe }\end{array}$ \\
\hline $\begin{array}{l}\text { Adulto Mayor } \\
\text { Inscrito }\end{array}$ & $\begin{array}{l}\text { Evaluar Integralmente } \\
\text { Adulto Mayor }\end{array}$ & $\begin{array}{l}\text { Adulto Mayor } \\
\text { Evaluado, } \\
\text { Evaluación }\end{array}$ & $\begin{array}{l}\text { Se evalúa al adulto mayor } \\
\text { físicamente }\end{array}$ \\
\hline $\begin{array}{l}\text { Adulto Mayor } \\
\text { Evaluado, } \\
\text { Evaluación }\end{array}$ & Derivar Paciente & $\begin{array}{l}\text { Paciente } \\
\text { Derivado }\end{array}$ & $\begin{array}{l}\text { Según el plan se deriva si } \\
\text { fuera necesario a alguna } \\
\text { especialidad }\end{array}$ \\
\hline $\begin{array}{l}\text { Adulto Mayor } \\
\text { Evaluado, } \\
\text { Evaluación }\end{array}$ & $\begin{array}{l}\text { Definir plan de } \\
\text { prestaciones } \\
\text { adulto mayor }\end{array}$ & $\begin{array}{l}\text { Paciente con } \\
\text { Plan echo }\end{array}$ & $\begin{array}{l}\text { Según el plan se define el } \\
\text { plan a seguir del adulto } \\
\text { mayor }\end{array}$ \\
\hline $\begin{array}{l}\text { Paciente con } \\
\text { Plan echo }\end{array}$ & $\begin{array}{l}\text { Ejecutar cartera de } \\
\text { servicios }\end{array}$ & $\begin{array}{l}\text { Paciente en } \\
\text { Rehabilitación }\end{array}$ & $\begin{array}{l}\text { Se sigue el plan según lo } \\
\text { establecido }\end{array}$ \\
\hline $\begin{array}{l}\text { Paciente en } \\
\text { Rehabilitación }\end{array}$ & $\begin{array}{l}\text { Realizar monitoreo de los } \\
\text { programas de cartera de } \\
\text { servicios }\end{array}$ & $\begin{array}{l}\text { Paciente } \\
\text { Controlado }\end{array}$ & $\begin{array}{lll}\text { Se monitorea que } & \text { el } \\
\text { servicio se } & & \text { dé } \\
\text { correctamente } & & \end{array}$ \\
\hline
\end{tabular}

Fuente: Elaboración Propia 
Ilustración 32: Gestionar Admisión del Adulto Mayor

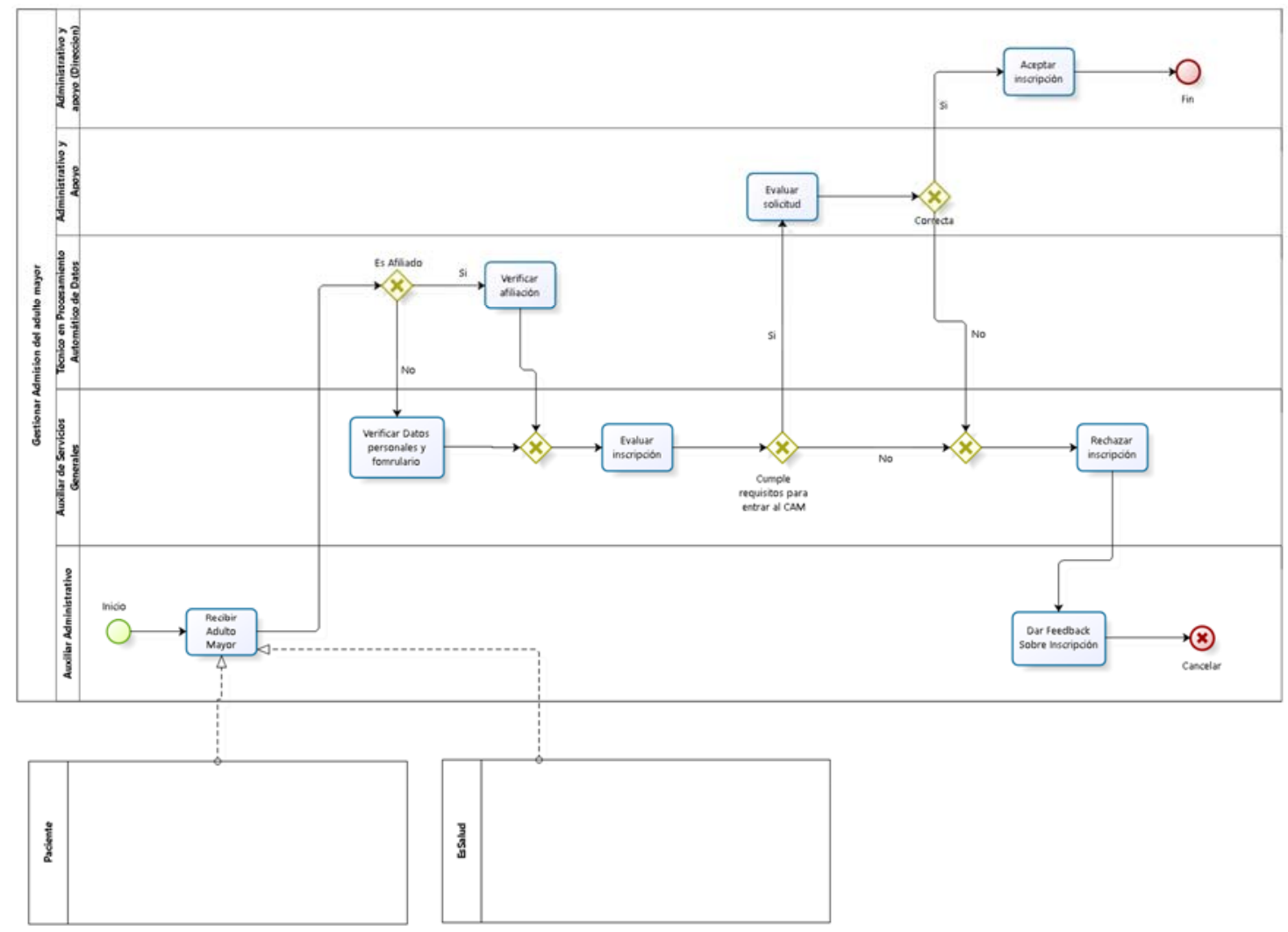

Fuente: Elaboración Propia

Actividades

- Recibir adulto mayor

- Verificar afiliación

- Verificar datos personales y formulario

- Evaluar inscripción

- Evaluar solicitud

- Aceptar inscripción

- Rechazar inscripción

- Dar feedback sobre inscripción 
Caracterización:

Tabla 19: Caracterización de Gestionar Admisión del Adulto Mayor

\begin{tabular}{|c|c|c|c|}
\hline \multicolumn{4}{|c|}{ Gestionar Admisión del Adulto Mayor } \\
\hline Input & Actividad & Output & Descripción \\
\hline $\begin{array}{l}\text { Adulto Mayor sin } \\
\text { Inscribir }\end{array}$ & $\begin{array}{l}\text { Recibir Adulto } \\
\text { Mayor }\end{array}$ & $\begin{array}{l}\text { Adulto Mayor } \\
\text { recibido }\end{array}$ & Se recibe al adulto mayor \\
\hline $\begin{array}{l}\text { Adulto Mayor } \\
\text { recibido que no es } \\
\text { afiliado }\end{array}$ & $\begin{array}{lr}\text { Verificar } & \text { Datos } \\
\text { personales } & \mathrm{y} \\
\text { formulario } & \end{array}$ & $\begin{array}{l}\text { Adulto Mayor } \\
\text { Verificado }\end{array}$ & $\begin{array}{l}\text { Se verifican los daos del } \\
\text { adulto mayor }\end{array}$ \\
\hline $\begin{array}{l}\text { Adulto Mayor } \\
\text { recibido que es } \\
\text { afiliado }\end{array}$ & $\begin{array}{l}\text { Verificar } \\
\text { afiliación }\end{array}$ & $\begin{array}{l}\text { Adulto Mayor } \\
\text { Verificado }\end{array}$ & $\begin{array}{l}\text { Se verifica si es afiliado a } \\
\text { EsSalud o no }\end{array}$ \\
\hline $\begin{array}{l}\text { Adulto Mayor } \\
\text { Verificado }\end{array}$ & $\begin{array}{l}\text { Evaluar } \\
\text { inscripción }\end{array}$ & $\begin{array}{l}\text { Adulto Mayor con } \\
\text { inscripción }\end{array}$ & $\begin{array}{l}\text { Se evalúa los datos de su } \\
\text { inscripción }\end{array}$ \\
\hline $\begin{array}{l}\text { Adulto Mayor con } \\
\text { inscripción }\end{array}$ & Evaluar solicitud & $\begin{array}{l}\text { Adulto Mayor con } \\
\text { inscripción } \\
\text { evaluada }\end{array}$ & $\begin{array}{l}\text { Se evalúa si la inscripción } \\
\text { es correcta }\end{array}$ \\
\hline $\begin{array}{l}\text { Adulto Mayor con } \\
\text { inscripción } \\
\text { correcta }\end{array}$ & $\begin{array}{l}\text { Aceptar } \\
\text { inscripción }\end{array}$ & $\begin{array}{l}\text { Adulto Mayor } \\
\text { Inscrito }\end{array}$ & Se acepta la inscripción \\
\hline $\begin{array}{l}\text { Adulto Mayor con } \\
\text { inscripción } \\
\text { incorrecta }\end{array}$ & $\begin{array}{l}\text { Rechazar } \\
\text { inscripción }\end{array}$ & $\begin{array}{l}\text { Adulto Mayor con } \\
\text { inscripción } \\
\text { rechazada }\end{array}$ & Se rechaza la inscripción \\
\hline
\end{tabular}




\begin{tabular}{|c|c|c|c|c|}
\hline $\begin{array}{l}\text { Adulto Mayor con } \\
\text { inscripción } \\
\text { rechazada }\end{array}$ & $\begin{array}{l}\text { Dar Feedback } \\
\text { Sobre Inscripción }\end{array}$ & $\begin{array}{l}\text { Adulto } \\
\text { rechazado }\end{array}$ & Mayor & $\begin{array}{l}\text { Se le indica al paciente } \\
\text { porque no se aceptó la } \\
\text { solicitud }\end{array}$ \\
\hline
\end{tabular}

Fuente: Elaboración Propia

Ilustración 33: Recepción de Pacientes Derivados 


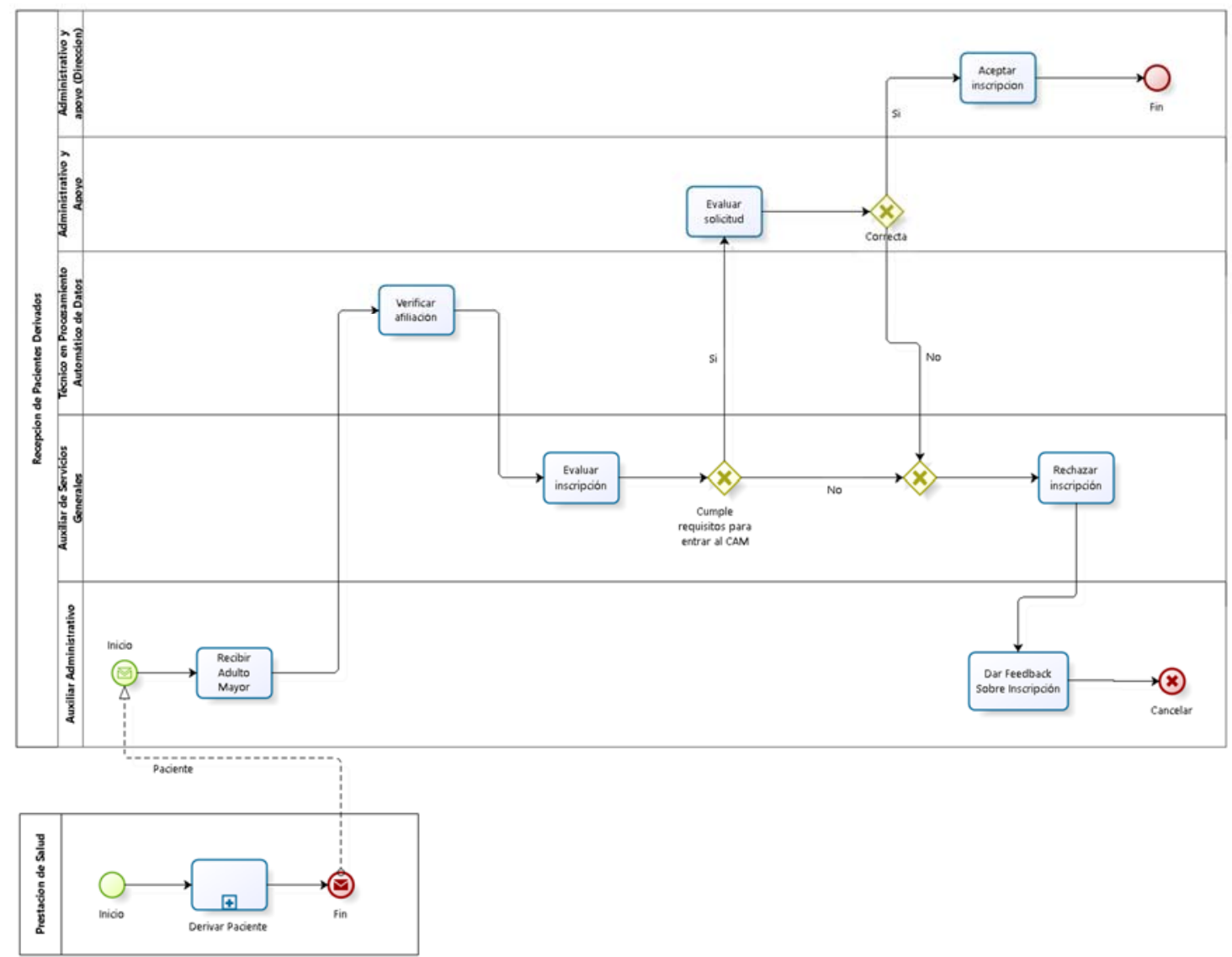

Fuente: Elaboración Propia

Actividad

- Recibir adulto mayor

- Verificar afiliación

- Evaluar inscripción

- Evaluar solicitud

- Aceptar inscripción

- Rechazar inscripción

- Dar feedback sobre inscripción

Caracterización: 
Tabla 20: Caracterización de Recepción de Pacientes Derivados

\begin{tabular}{|c|c|c|c|}
\hline \multicolumn{4}{|c|}{ Recepción de Pacientes Derivados } \\
\hline Input & Actividad & Output & Descripción \\
\hline $\begin{array}{l}\text { Adulto Mayor sin } \\
\text { Inscribir }\end{array}$ & $\begin{array}{l}\text { Recibir Adulto } \\
\text { Mayor }\end{array}$ & $\begin{array}{ll}\text { Adulto } & \text { Mayor } \\
\text { recibido } & \end{array}$ & Se recibe al adulto mayor \\
\hline $\begin{array}{l}\text { Adulto Mayor } \\
\text { recibido }\end{array}$ & $\begin{array}{l}\text { Verificar } \\
\text { afiliación }\end{array}$ & \begin{tabular}{|ll} 
Adulto & Mayor \\
Verificado &
\end{tabular} & $\begin{array}{l}\text { Se verifica si es afiliado a } \\
\text { EsSalud o no }\end{array}$ \\
\hline $\begin{array}{ll}\text { Adulto } & \text { Mayor } \\
\text { Verificado } & \end{array}$ & $\begin{array}{l}\text { Evaluar } \\
\text { inscripción }\end{array}$ & $\begin{array}{l}\text { Adulto Mayor con } \\
\text { inscripción }\end{array}$ & $\begin{array}{l}\text { Se evalúa los datos de su } \\
\text { inscripción }\end{array}$ \\
\hline $\begin{array}{l}\text { Adulto Mayor con } \\
\text { inscripción }\end{array}$ & $\begin{array}{l}\text { Evaluar } \\
\text { solicitud }\end{array}$ & $\begin{array}{l}\text { Adulto Mayor con } \\
\text { inscripción } \\
\text { evaluada }\end{array}$ & $\begin{array}{l}\text { Se evalúa si la inscripción } \\
\text { es correcta }\end{array}$ \\
\hline $\begin{array}{l}\text { Adulto Mayor con } \\
\text { inscripción correcta }\end{array}$ & $\begin{array}{l}\text { Aceptar } \\
\text { inscripción }\end{array}$ & $\begin{array}{ll}\text { Adulto } \quad \text { Mayor } \\
\text { Inscrito }\end{array}$ & Se acepta la inscripción \\
\hline $\begin{array}{l}\text { Adulto Mayor con } \\
\text { inscripción } \\
\text { incorrecta }\end{array}$ & $\begin{array}{l}\text { Rechazar } \\
\text { inscripción }\end{array}$ & $\begin{array}{l}\text { Adulto Mayor con } \\
\text { inscripción } \\
\text { rechazada }\end{array}$ & Se rechaza la inscripción \\
\hline $\begin{array}{l}\text { Adulto Mayor con } \\
\text { inscripción } \\
\text { rechazada }\end{array}$ & $\begin{array}{l}\text { Dar Feedback } \\
\text { Sobre } \\
\text { Inscripción }\end{array}$ & $\begin{array}{ll}\text { Adulto } & \text { Mayor } \\
\text { rechazado } & \end{array}$ & $\begin{array}{l}\text { Se le indica al paciente } \\
\text { porque no se aceptó la } \\
\text { solicitud }\end{array}$ \\
\hline
\end{tabular}

Fuente: Elaboración Propia

Ilustración 34: Evaluar Integralmente el Adulto Mayor 


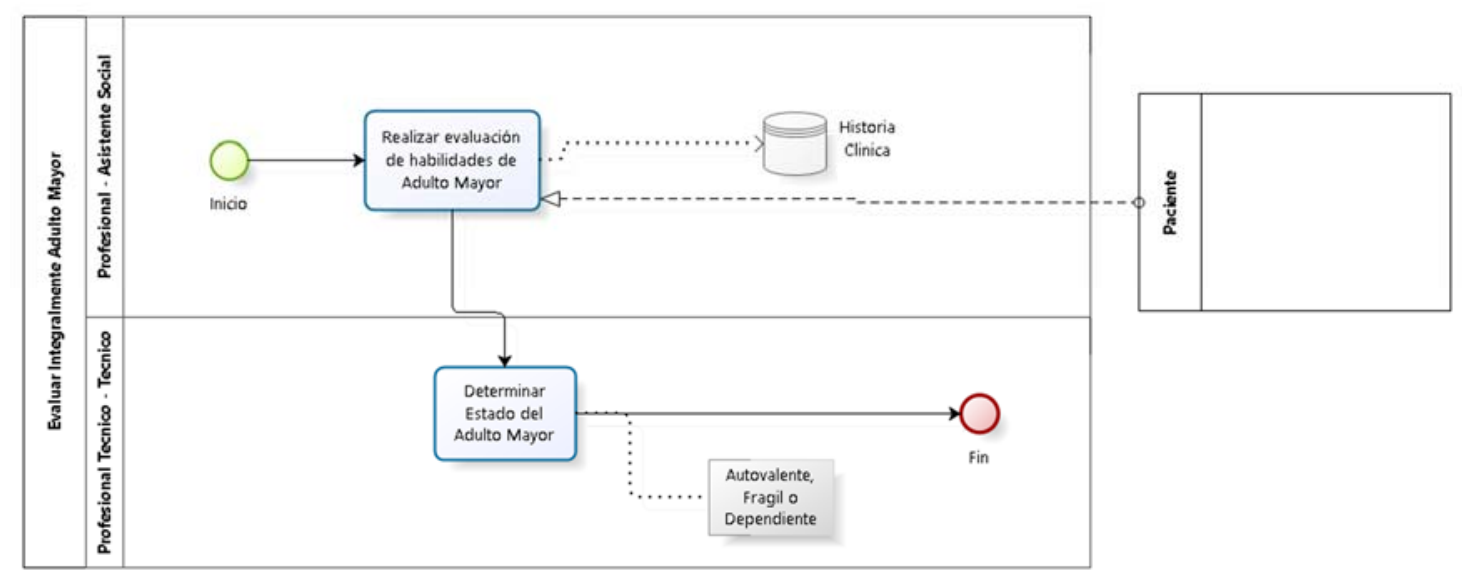

Fuente: Elaboración Propia

Actividad:

- Realizar evaluación de habilidades del adulto mayor

- Determinar estado del adulto mayor

Caracterización:

Tabla 21: Caracterización de Evaluar Integralmente el Adulto Mayor

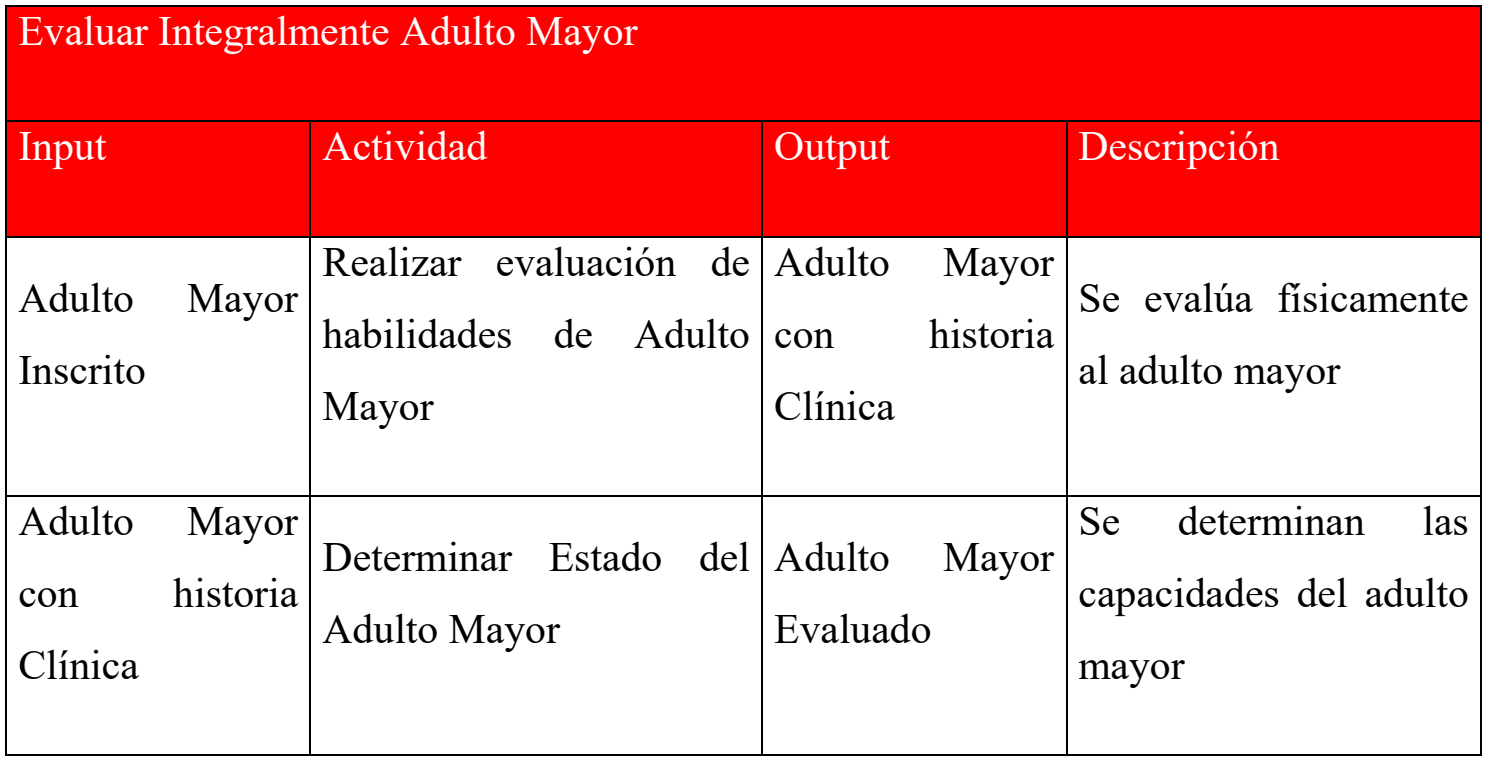

Fuente: Elaboración Propia

Ilustración 35: Derivar Paciente 


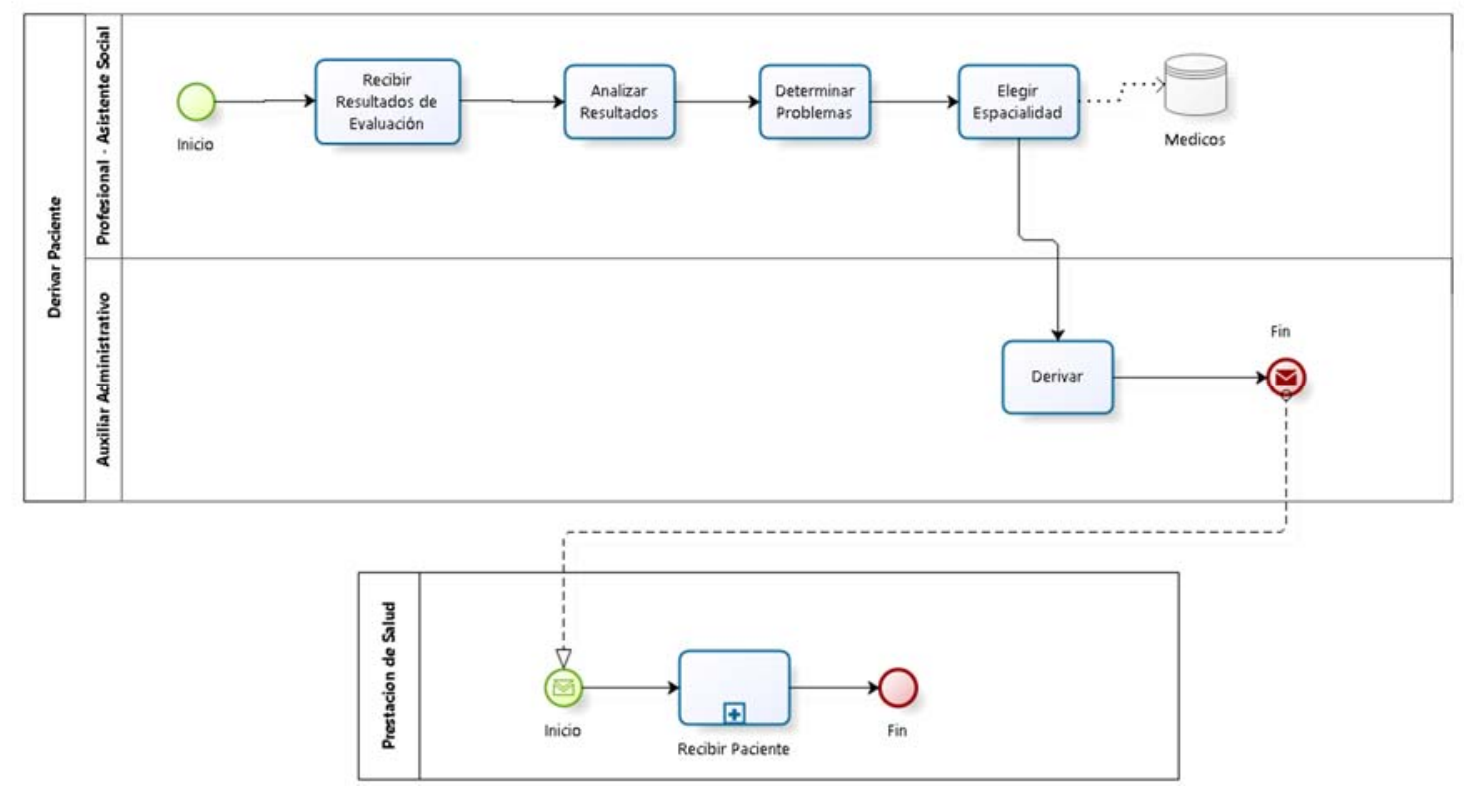

Fuente: Elaboración Propia

Actividades:

- Recibir resultados de evaluación

- Analizar resultados

- Determinar problemas

- Elegir especialidad

- Derivar

Caracterización:

Tabla 22: Caracterización de Derivar Paciente

\begin{tabular}{|c|c|c|c|}
\hline \multicolumn{4}{|l|}{ Derivar Paciente } \\
\hline Input & Actividad & Output & Descripción \\
\hline $\begin{array}{l}\text { Adulto Mayor } \\
\text { Evaluado, } \\
\text { Evaluación }\end{array}$ & $\begin{array}{l}\text { Recibir } \\
\text { Resultados de } \\
\text { Evaluación }\end{array}$ & $\begin{array}{l}\text { Evaluación } \\
\text { recibida }\end{array}$ & $\begin{array}{l}\text { Se reciben los resultados de la } \\
\text { evaluación }\end{array}$ \\
\hline
\end{tabular}




\begin{tabular}{|l|l|l|l|}
$\begin{array}{l}\text { Evaluación } \\
\text { recibida }\end{array}$ & $\begin{array}{l}\text { Analizar } \\
\text { Resultados }\end{array}$ & $\begin{array}{l}\text { Evaluación } \\
\text { Analizada }\end{array}$ & $\begin{array}{l}\text { Se analizan los resultados de } \\
\text { capacidades del adulto mayor }\end{array}$ \\
\hline $\begin{array}{l}\text { Evaluación } \\
\text { Analizada }\end{array}$ & $\begin{array}{l}\text { Determinar } \\
\text { Problemas }\end{array}$ & $\begin{array}{l}\text { Problemas } \\
\text { detectados }\end{array}$ & $\begin{array}{l}\text { Se determinan los problemas de } \\
\text { salud que tiene el adulto mayor }\end{array}$ \\
\hline $\begin{array}{l}\text { Problemas } \\
\text { detectados }\end{array}$ & $\begin{array}{l}\text { Elegir } \\
\text { Espacialidad }\end{array}$ & $\begin{array}{l}\text { Especialida } \\
\text { des elegida }\end{array}$ & $\begin{array}{l}\text { Se eligen que especialistas deben } \\
\text { atender al paciente }\end{array}$ \\
\hline $\begin{array}{l}\text { Especialidades } \\
\text { elegida }\end{array}$ & Derivar & Paciente & Se deriva al paciente \\
\hline
\end{tabular}

Fuente: Elaboración Propia

Ilustración 36: Definir Plan de Prestaciones Sociales del Adulto Mayor

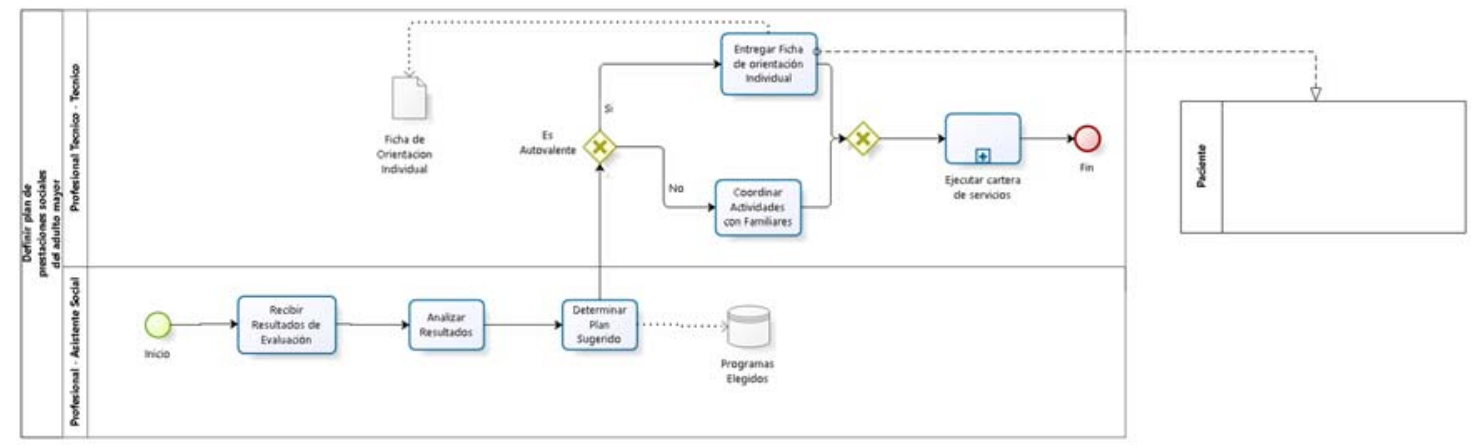

Fuente: Elaboración Propia

Proceso:

- Ejecutar cartera de servicios

Actividades:

- Recibir resultados de evaluación

- Analizar resultados

- Determinar plan sugerido

- Entregar ficha de orientación individual

- Coordinar actividades con familiares

- Ejecutar cartera de servicios 
Caracterización:

Tabla 23: Caracterización de Definir Plan de Prestaciones Sociales del Adulto Mayor

\begin{tabular}{|c|c|c|c|}
\hline \multicolumn{4}{|c|}{ Definir Plan de Prestaciones Sociales del Adulto Mayor } \\
\hline Input & Actividad & Output & Descripción \\
\hline $\begin{array}{l}\text { Adulto Mayor } \\
\text { Evaluado, } \\
\text { Evaluación }\end{array}$ & $\begin{array}{l}\text { Recibir Resultados } \\
\text { de Evaluación }\end{array}$ & $\begin{array}{l}\text { Evaluación } \\
\text { recibida }\end{array}$ & $\begin{array}{l}\text { Se reciben los resultados de la } \\
\text { evaluación }\end{array}$ \\
\hline $\begin{array}{l}\text { Evaluación } \\
\text { recibida }\end{array}$ & Analizar Resultados & $\begin{array}{l}\text { Evaluación } \\
\text { Analizada }\end{array}$ & $\begin{array}{l}\text { Se analizan los resultados de } \\
\text { capacidades del adulto mayor }\end{array}$ \\
\hline $\begin{array}{l}\text { Evaluación } \\
\text { Analizada }\end{array}$ & $\begin{array}{l}\text { Determinar Plan } \\
\text { Sugerido }\end{array}$ & Plan Creado & $\begin{array}{l}\text { Se crea el plan para mejorar las } \\
\text { capacidades del adulto mayor }\end{array}$ \\
\hline Plan Creado & $\begin{array}{l}\text { Entregar Ficha de } \\
\text { orientación } \\
\text { Individual }\end{array}$ & $\begin{array}{l}\text { Ficha de } \\
\text { Orientación }\end{array}$ & $\begin{array}{l}\text { Se crea la ficha de orientación } \\
\text { y se le explica al paciente }\end{array}$ \\
\hline $\begin{array}{l}\text { Ficha } \\
\text { Orientación }\end{array}$ & $\begin{array}{l}\text { Coordinar } \\
\text { Actividades con } \\
\text { Familiares }\end{array}$ & \begin{tabular}{|l|} 
Familiares \\
Coordinado \\
$\mathrm{s}$
\end{tabular} & $\begin{array}{l}\text { Se coordina con los familiares } \\
\text { el plan de rehabilitación }\end{array}$ \\
\hline $\begin{array}{l}\text { Familiares } \\
\text { Coordinados }\end{array}$ & $\begin{array}{l}\text { Ejecutar cartera de } \\
\text { servicios }\end{array}$ & \begin{tabular}{|l|}
\multicolumn{2}{|l|}{ Paciente } \\
con Plan \\
echo
\end{tabular} & $\begin{array}{l}\text { Se sigue el plan según lo } \\
\text { establecido }\end{array}$ \\
\hline
\end{tabular}

Fuente: Elaboración Propia

Ilustración 37: Ejecutar Cartera de Servicios 


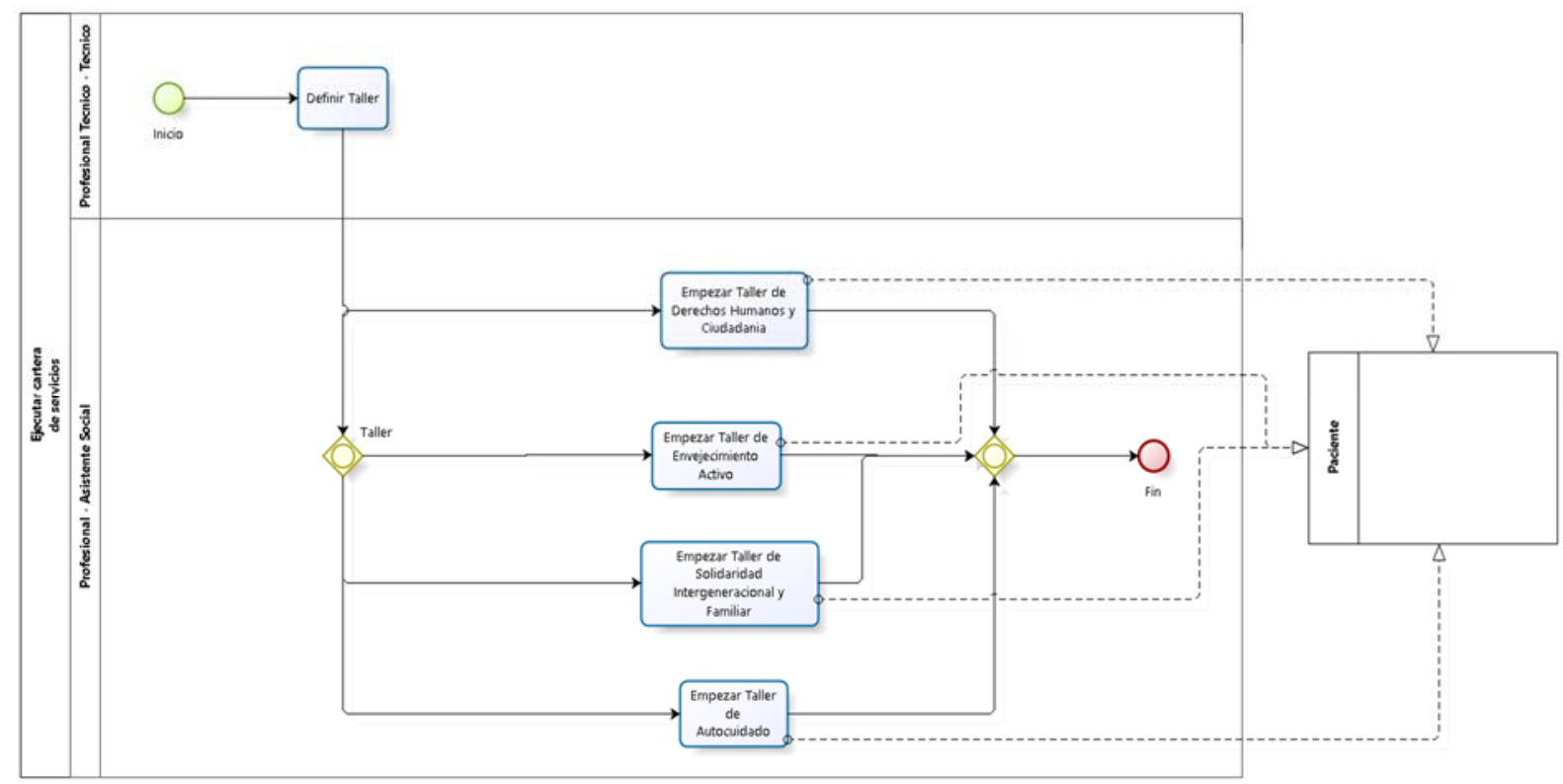

Fuente: Elaboración Propia

Actividad:

- Definir taller

- Empezar taller de autocuidado

- Empezar taller de solidaridad intergeneracional y familiar

- Empezar taller de envejecimiento activo

- Empezar taller de derecho humano y ciudadano

Caracterización: 
Tabla 24: Caracterización de Ejecutar Cartera de Servicios

\begin{tabular}{|c|c|c|c|}
\hline \multicolumn{4}{|c|}{ Ejecutar Cartera de Servicios } \\
\hline Input & Actividad & Output & Descripción \\
\hline $\begin{array}{l}\text { Paciente con } \\
\text { Plan echo }\end{array}$ & Definir Taller & $\begin{array}{l}\text { Taller } \\
\text { Definido }\end{array}$ & $\begin{array}{l}\text { Se definen los } \\
\text { talleres del paciente }\end{array}$ \\
\hline $\begin{array}{l}\text { Taller } \\
\text { Definido }\end{array}$ & $\begin{array}{l}\text { Empezar Taller de Derechos } \\
\text { Humanos y Ciudadanía }\end{array}$ & $\begin{array}{l}\text { Paciente en } \\
\text { Rehabilitación }\end{array}$ & Se empieza el taller \\
\hline \begin{tabular}{|l|} 
Taller \\
Definido
\end{tabular} & $\begin{array}{l}\text { Empezar Taller de Envejecimiento } \\
\text { Activo }\end{array}$ & $\begin{array}{l}\text { Paciente en } \\
\text { Rehabilitación }\end{array}$ & Se empieza el taller \\
\hline \begin{tabular}{|l|} 
Taller \\
Definido
\end{tabular} & $\begin{array}{l}\text { Empezar Taller de Solidaridad } \\
\text { Intergeneracional y Familiar }\end{array}$ & $\begin{array}{l}\text { Paciente en } \\
\text { Rehabilitación }\end{array}$ & Se empieza el taller \\
\hline $\begin{array}{l}\text { Taller } \\
\text { Definido }\end{array}$ & Empezar Taller de Autocuidado & $\begin{array}{l}\text { Paciente en } \\
\text { Rehabilitación }\end{array}$ & Se empieza el taller \\
\hline
\end{tabular}

Fuente: Elaboración Propia

Ilustración 38: Gestionar Atención del CERP

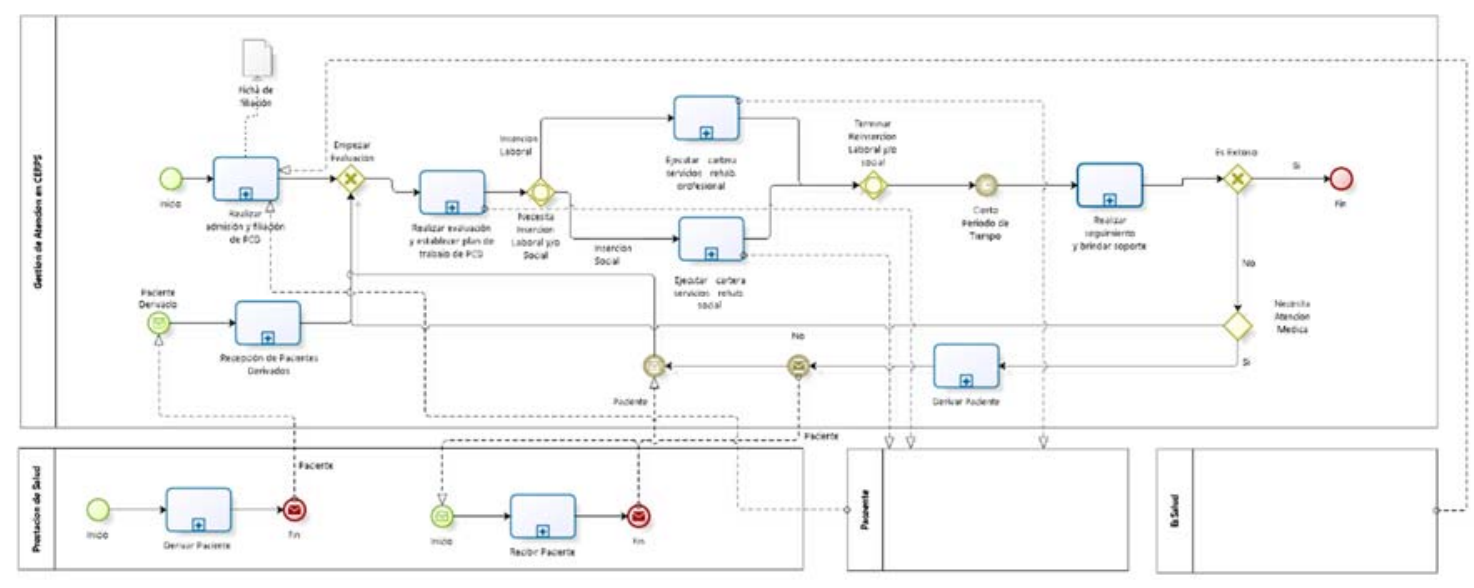

Fuente: Elaboración Propia

Proceso: 
- Realizar admisión y afiliación de PCD

- Recepción de pacientes derivados

- Realizar evaluación y establecer plan de trabajo de PCD

- Ejecutar cartera de servicios rehab. Profesional

- Ejecutar cartera de servicios de rehab. Social

- Realizar seguimiento y brindar soporte

- Derivar paciente

Caracterización:

Tabla 25: Caracterización Gestión de Atención en CERPS

\begin{tabular}{|c|c|c|c|}
\hline \multicolumn{4}{|c|}{ Gestión de Atención en CERPS } \\
\hline Input & Actividad & Output & Descripción \\
\hline $\begin{array}{l}\text { PCD } \quad \text { sin } \\
\text { Inscribir }\end{array}$ & $\begin{array}{l}\text { Realizar admisión y filiación } \\
\text { de PCD }\end{array}$ & $\begin{array}{l}\text { PCD } \\
\text { Inscrito }\end{array}$ & $\begin{array}{l}\text { Se genera la inscripción } \\
\text { del PCD }\end{array}$ \\
\hline $\begin{array}{l}\text { PCD } \quad \sin \\
\text { Inscribir }\end{array}$ & $\begin{array}{l}\text { Recepción de Pacientes } \\
\text { Derivados }\end{array}$ & $\begin{array}{l}\mathrm{PCD} \\
\text { Inscrito }\end{array}$ & $\begin{array}{l}\text { Se recibe a las PCD y se } \\
\text { les inscribe }\end{array}$ \\
\hline PCD Inscrito & $\begin{array}{l}\text { Realizar evaluación } y \\
\text { establecer plan de trabajo de } \\
\text { PCD }\end{array}$ & $\begin{array}{l}\text { PCD } \\
\text { Evaluado }\end{array}$ & $\begin{array}{l}\text { Se evalúa físicamente al } \\
\text { PCD y se hace su plan }\end{array}$ \\
\hline $\begin{array}{l}\text { PCD } \\
\text { Evaluado, } \\
\text { Evaluación }\end{array}$ & $\begin{array}{l}\text { Ejecutar cartera servicios } \\
\text { rehab. Profesional }\end{array}$ & $\mid \begin{array}{l}\text { Paciente en } \\
\text { Post-Rehab }\end{array}$ & $\begin{array}{l}\text { Se empieza } \\
\text { rehabilitación } \\
\text { Profesional }\end{array}$ \\
\hline $\begin{array}{l}\text { PCD } \\
\text { Evaluado, } \\
\text { Evaluación }\end{array}$ & $\begin{array}{l}\text { Ejecutar cartera servicios } \\
\text { rehab. social }\end{array}$ & $\begin{array}{l}\text { Paciente en } \\
\text { Post-Rehab }\end{array}$ & $\begin{array}{l}\text { Se empieza la } \\
\text { rehabilitación Social }\end{array}$ \\
\hline
\end{tabular}




\begin{tabular}{|l|l|l|l|l|}
$\begin{array}{l}\text { Paciente en } \\
\text { Rehabilitació }\end{array}$ & $\begin{array}{l}\text { Realizar seguimiento } \\
\text { brindar soporte }\end{array}$ & $\mathrm{y}$ & $\begin{array}{l}\text { Paciente } \\
\text { Controlado } \\
\text { servicio } \\
\text { correctamente }\end{array}$ \\
\hline $\begin{array}{l}\text { Paciente en } \\
\text { Rehabilitació } \\
\mathrm{n}\end{array}$ & Derivar Paciente & $\begin{array}{l}\text { Paciente } \\
\text { Derivado }\end{array}$ & $\begin{array}{l}\text { Se Deriva al PCD a la } \\
\text { especialidad necesaria }\end{array}$ \\
\hline
\end{tabular}

Fuente: Elaboración Propia

Ilustración 39: Realizar Admisión y Filiación de PCD 


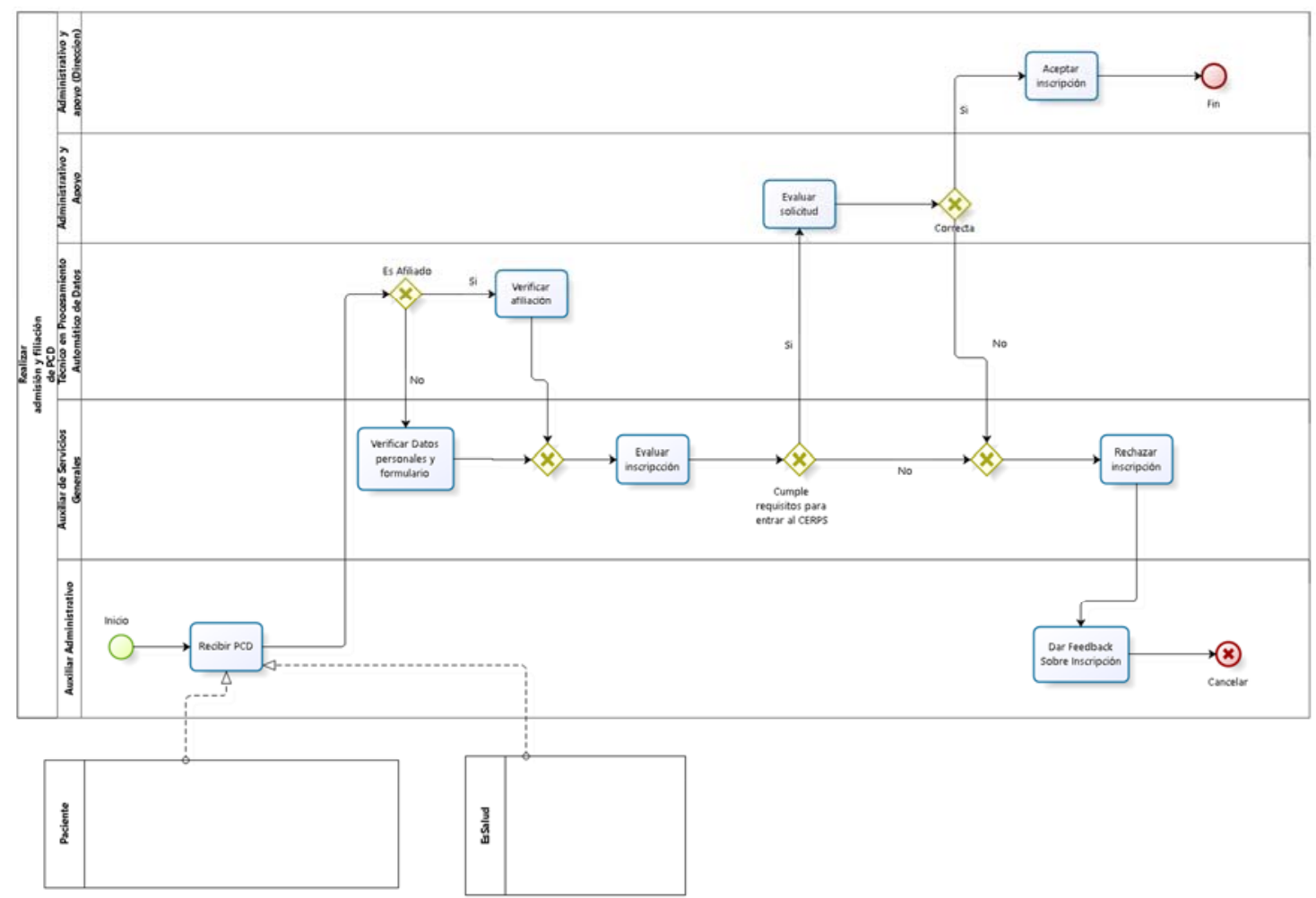

Fuente: Elaboración Propia

Actividad:

- Recibir PCD

- Verificar datos personales y formulario

- Verificar afiliación

- Evaluar inscripción

- Evaluar solicitud

- Aceptar inscripción

- Rechazar inscripción

- Dar feedback sobre inscripción

Caracterización: 
Tabla 26: Caracterización de Realizar Admisión y Afiliación de PCD

\begin{tabular}{|c|c|c|c|}
\hline \multicolumn{4}{|c|}{ Realizar Admisión y Afiliación de PCD } \\
\hline Input & Actividad & Output & Descripción \\
\hline $\begin{array}{ll}\text { PCD } & \text { sin } \\
\text { Inscribir } & \end{array}$ & Recibir PCD & PCD recibido & Se recibe al PCD \\
\hline 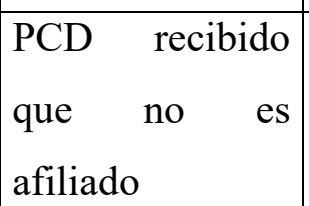 & $\begin{array}{|lr|}\text { Verificar } & \text { Datos } \\
\text { personales } & \mathrm{y} \\
\text { formulario } & \\
\end{array}$ & PCD Verificado & $\begin{array}{l}\text { Se verifican los daos del } \\
\text { PCD }\end{array}$ \\
\hline $\begin{array}{l}\text { PCD recibido } \\
\text { que es afiliado }\end{array}$ & Verificar afiliación & PCD Verificado & $\begin{array}{l}\text { Se verifica si es afiliado a } \\
\text { Essalud o no }\end{array}$ \\
\hline PCD Verificado & Evaluar inscripción & $\begin{array}{l}\text { PCD con } \\
\text { inscripción }\end{array}$ & $\begin{array}{l}\text { Se evalúa los datos de su } \\
\text { inscripción }\end{array}$ \\
\hline $\begin{array}{ll}\text { PCD } & \text { con } \\
\text { inscripción } & \end{array}$ & Evaluar solicitud & $\begin{array}{l}\text { PCD con } \\
\text { inscripción } \\
\text { evaluada }\end{array}$ & $\begin{array}{l}\text { Se evalúa si la inscripción es } \\
\text { correcta }\end{array}$ \\
\hline 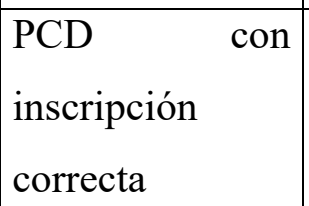 & Aceptar inscripción & PCD Inscrito & Se acepta la inscripción \\
\hline 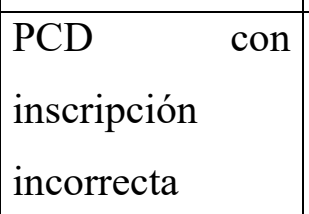 & $\begin{array}{l}\text { Rechazar } \\
\text { inscripción }\end{array}$ & $\begin{array}{l}\text { PCD con } \\
\text { inscripción } \\
\text { rechazada }\end{array}$ & Se rechaza la inscripción \\
\hline 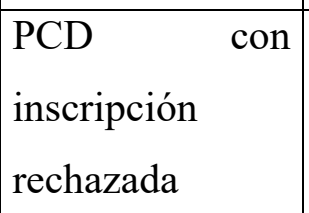 & $\begin{array}{l}\text { Dar Feedback Sobre } \\
\text { Inscripción }\end{array}$ & PCD rechazado & $\begin{array}{l}\text { Se le indica al paciente } \\
\text { porque no se aceptó la } \\
\text { solicitud }\end{array}$ \\
\hline
\end{tabular}

Fuente: Elaboración Propia 
Ilustración 40: Recepción de Pacientes Derivados

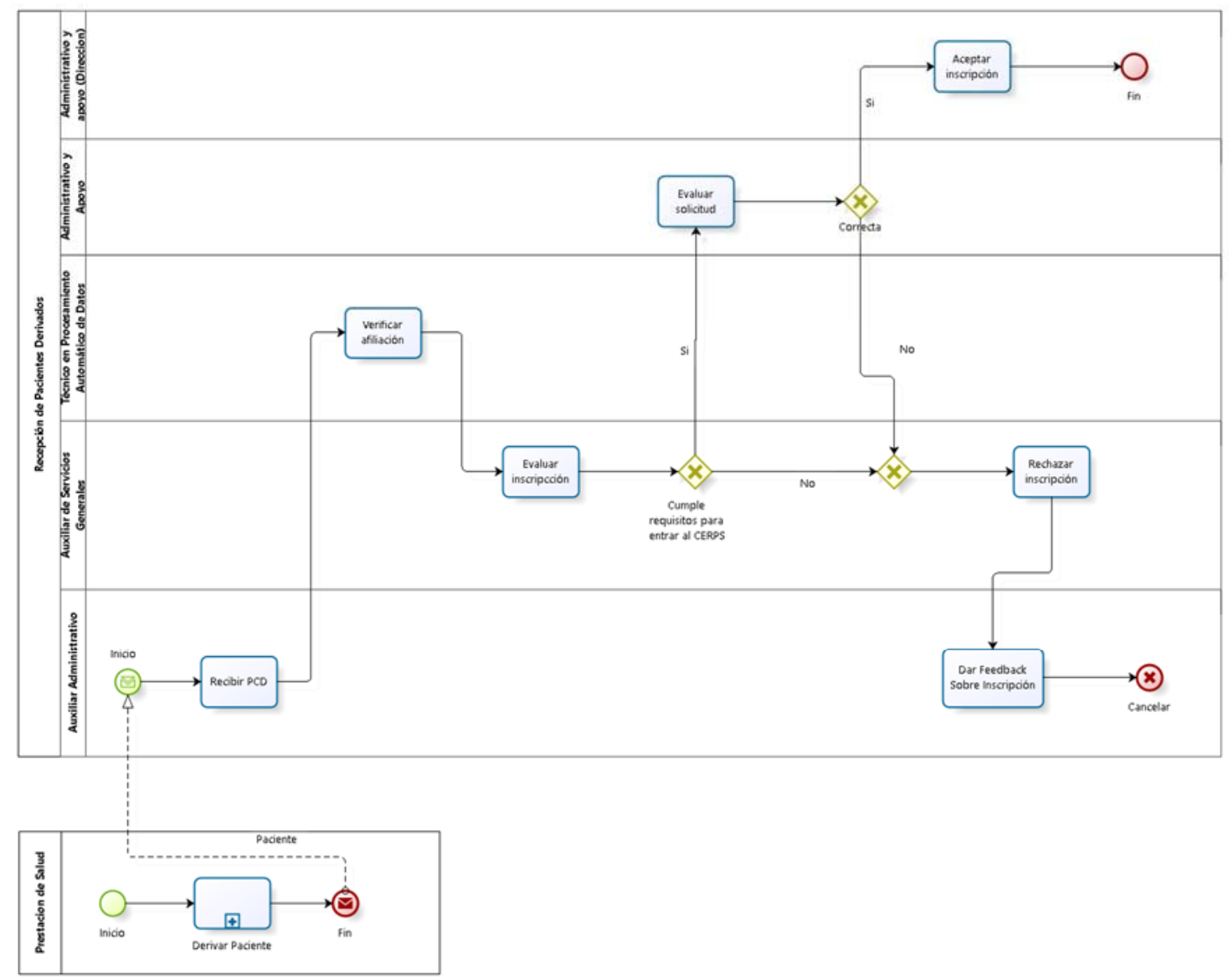

Fuente: Elaboración Propia

Actividades: 
- Recibir PCD

- Verificar afiliación

- Evaluar inscripción

- Evaluar solicitud

- Aceptar inscripción

- Rechazar inscripción

- Dar feedback sobre inscripción

Caracterización:

Tabla 27: Caracterización de Recepción de Pacientes Derivados

\begin{tabular}{|l|l|l|l|}
\hline \multicolumn{2}{|l|}{ Recepción de Pacientes Derivados } \\
\hline Input & Actividad & Output & \multicolumn{2}{l|}{ Descripción } \\
\hline PCD sin Inscribir & Recibir PCD & PCD recibido & Se recibe al PCD \\
\hline $\begin{array}{l}\text { PCD recibido } \\
\text { que es afiliado }\end{array}$ & $\begin{array}{l}\text { Verificar } \\
\text { afiliación }\end{array}$ & PCD Verificado & $\begin{array}{l}\text { Se verifica si es afiliado a } \\
\text { EsSalud o no }\end{array}$ \\
\hline PCD Verificado & $\begin{array}{l}\text { Evaluar } \\
\text { inscripción }\end{array}$ & $\begin{array}{l}\text { PCD } \\
\text { inscripción }\end{array}$ & $\begin{array}{l}\text { Se evalúa los datos de su } \\
\text { inscripción }\end{array}$ \\
\hline $\begin{array}{l}\text { PCD } \\
\text { inscripción }\end{array}$ & Evaluar solicitud & $\begin{array}{l}\text { PCD } \\
\text { inscripción } \\
\text { evaluada }\end{array}$ & $\begin{array}{l}\text { Se evalúa si la inscripción es } \\
\text { correcta }\end{array}$ \\
\hline $\begin{array}{l}\text { PCD } \\
\text { inscripción } \\
\text { correcta }\end{array}$ & $\begin{array}{l}\text { Aceptar } \\
\text { inscripción }\end{array}$ & PCD Inscrito & Se acepta la inscripción \\
\hline
\end{tabular}




\begin{tabular}{|ll|l|l|l|}
$\begin{array}{l}\text { PCD } \\
\text { inscripción } \\
\text { incorrecta }\end{array}$ & con & $\begin{array}{l}\text { Rechazar } \\
\text { inscripción }\end{array}$ & $\begin{array}{l}\text { PCD } \\
\text { inscripción } \\
\text { rechazada }\end{array}$ & Se rechaza la inscripción \\
\hline $\begin{array}{l}\text { PCD } \\
\text { inscripción } \\
\text { rechazada }\end{array}$ & $\begin{array}{l}\text { con } \\
\text { Sobre Inscripción }\end{array}$ & Feedback & PCD rechazado & $\begin{array}{l}\text { Se le indica al paciente porque } \\
\text { no se aceptó la solicitud }\end{array}$ \\
\hline
\end{tabular}

Fuente: Elaboración Propia

Ilustración 41: Realizar Evaluación y Establecer Plan de Trabajo de PCD

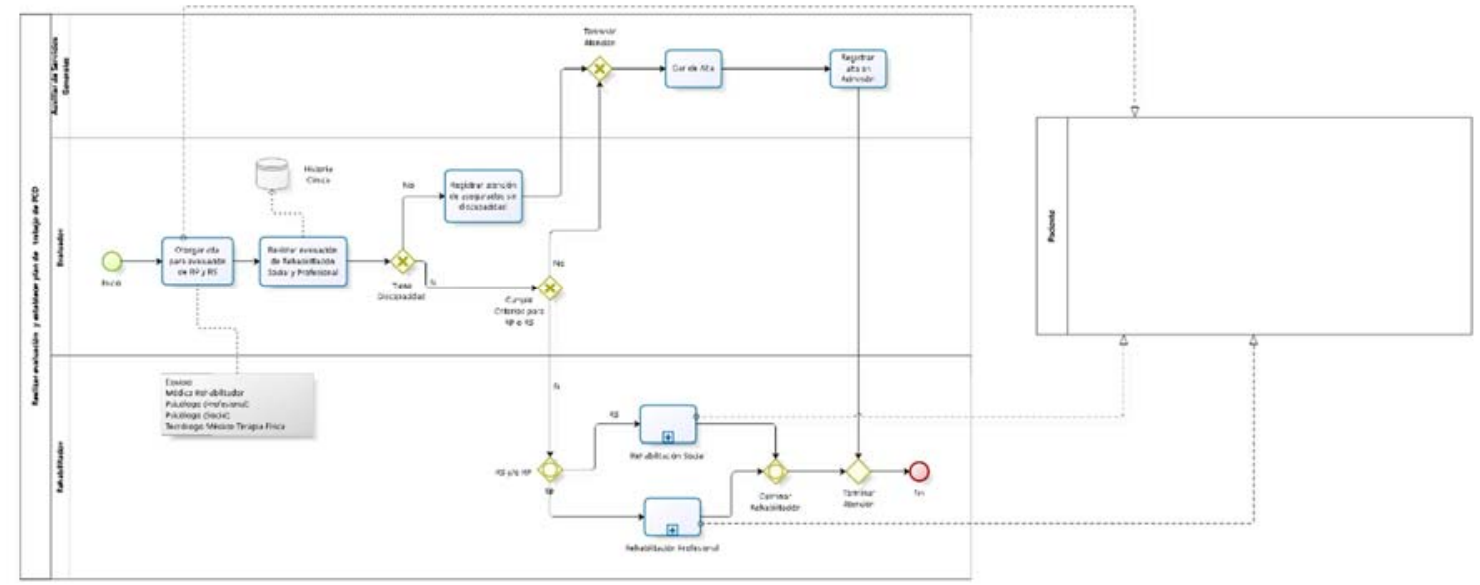

Fuente: Elaboración Propia

Sub Proceso:

- Rehabilitación Social

- Rehabilitación profesional

Actividad:

- Otorgar cita para evaluación de RP y RS

- Realizar evaluación de rehabilitación social y profesional

- Registrar atención de asegurado sin discapacidad

- Dar de alta 
- Registrar alta en admisión

Caracterización:

Tabla 28: Caracterización de Realizar Evaluación y Establecer Plan de Trabajo de PCD

\begin{tabular}{|c|c|c|c|}
\hline \multicolumn{4}{|c|}{ Realizar Evaluación y Establecer Plan de Trabajo de PCD } \\
\hline Input & Actividad & Output & Descripción \\
\hline PCD Inscrito & $\begin{array}{l}\text { Otorgar cita para } \\
\text { evaluación de RP y RS }\end{array}$ & $\begin{array}{l}\text { PCD con cita } \\
\text { de evaluación }\end{array}$ & $\begin{array}{l}\text { Se programa la cita del } \\
\text { PCD }\end{array}$ \\
\hline $\begin{array}{l}\text { PCD con cita } \\
\text { de evaluación }\end{array}$ & $\begin{array}{l}\text { Realizar evaluación de } \\
\text { Rehabilitación Social y } \\
\text { Profesional }\end{array}$ & PCD evaluado & $\begin{array}{l}\text { Se hace la evaluación } \\
\text { física del PCD }\end{array}$ \\
\hline $\begin{array}{l}\text { PCD evaluado } \\
\sin \\
\text { discapacidad }\end{array}$ & $\begin{array}{lr}\text { Registrar atención } & \text { de } \\
\text { asegurados } & \text { sin } \\
\text { discapacidad } & \end{array}$ & $\begin{array}{l}\text { PCD sin } \\
\text { discapacidad } \\
\text { atendido }\end{array}$ & $\begin{array}{l}\text { Se registra la atención si } \\
\text { se va a dar de alta al } \\
\text { paciente }\end{array}$ \\
\hline $\begin{array}{l}\text { PCD sin } \\
\text { discapacidad } \\
\text { atendido }\end{array}$ & Dar de Alta & $\begin{array}{l}\text { PCD dado de } \\
\text { Alta }\end{array}$ & Se da de alta al paciente \\
\hline $\begin{array}{l}\text { PCD dado de } \\
\text { Alta }\end{array}$ & Registrar alta en Admisión & $\begin{array}{l}\text { Alta } \\
\text { Registrada }\end{array}$ & Se registra el alta \\
\hline $\begin{array}{l}\text { PCD evaluado } \\
\text { con } \\
\text { discapacidad }\end{array}$ & Rehabilitación Social & $\begin{array}{l}\text { Paciente en } \\
\text { Post-Rehab }\end{array}$ & $\begin{array}{l}\text { Se rehabilita socialmente } \\
\text { al paciente }\end{array}$ \\
\hline $\begin{array}{l}\text { PCD evaluado } \\
\text { con } \\
\text { discapacidad }\end{array}$ & Rehabilitación Profesional & $\begin{array}{l}\text { Paciente en } \\
\text { Post-Rehab }\end{array}$ & $\begin{array}{l}\text { Se rehabilita } \\
\text { psicológicamente al } \\
\text { paciente }\end{array}$ \\
\hline
\end{tabular}

Fuente: Elaboración Propia 
Ilustración 42: Ejecutar Cartera Servicios Rehab. Profesional

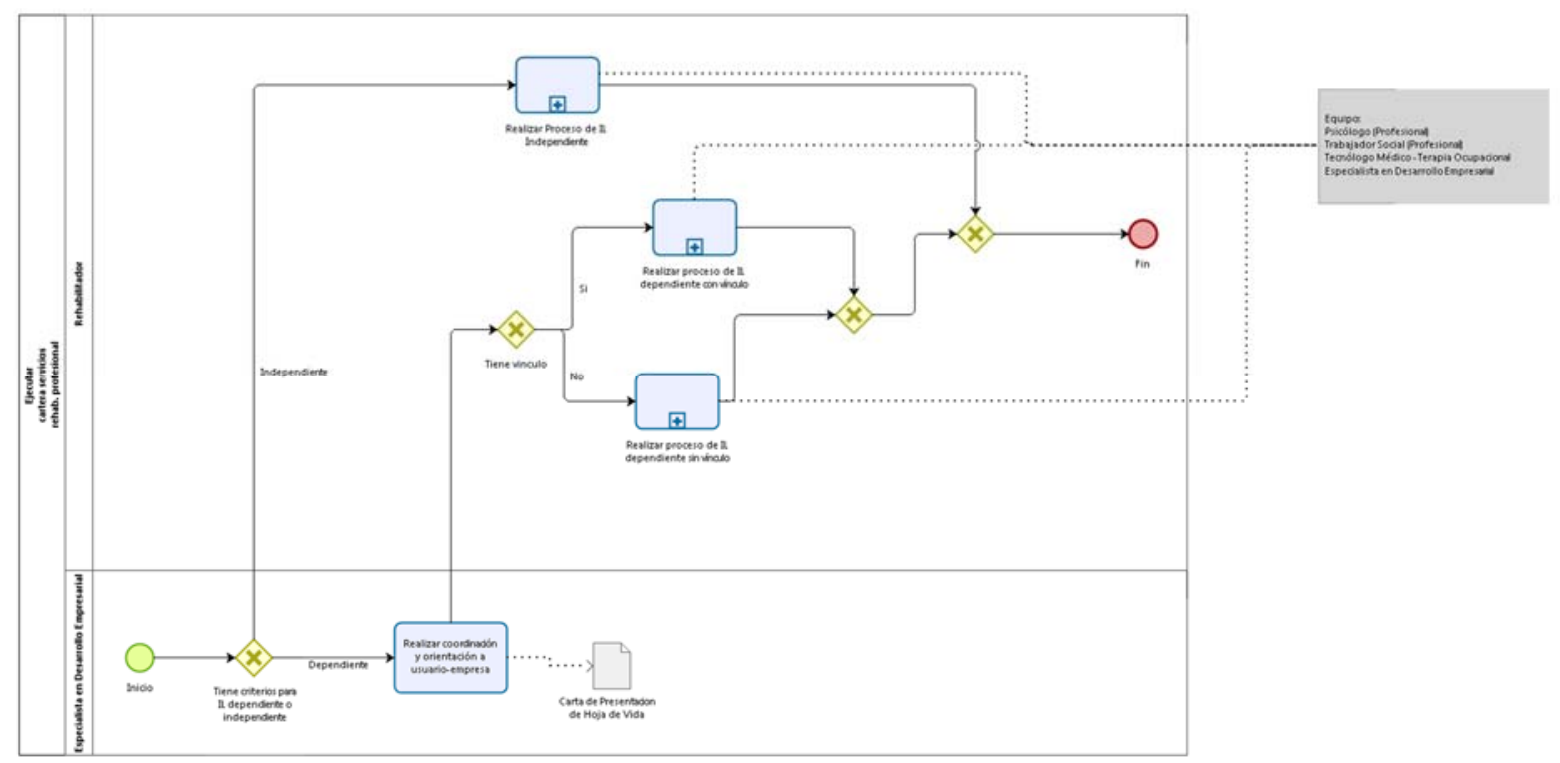

Fuente: Elaboración Propia

Sub proceso:

- Realizar proceso de IL independiente

- Realizar proceso de dependiente con vínculo

- Realizar proceso de dependiente sin vínculo

Actividad:

- Realizar coordinación y orientación a usuario - empresa

Caracterización:

Tabla 29: Caracterización de Ejecutar Cartera Servicios Rehab. Profesional

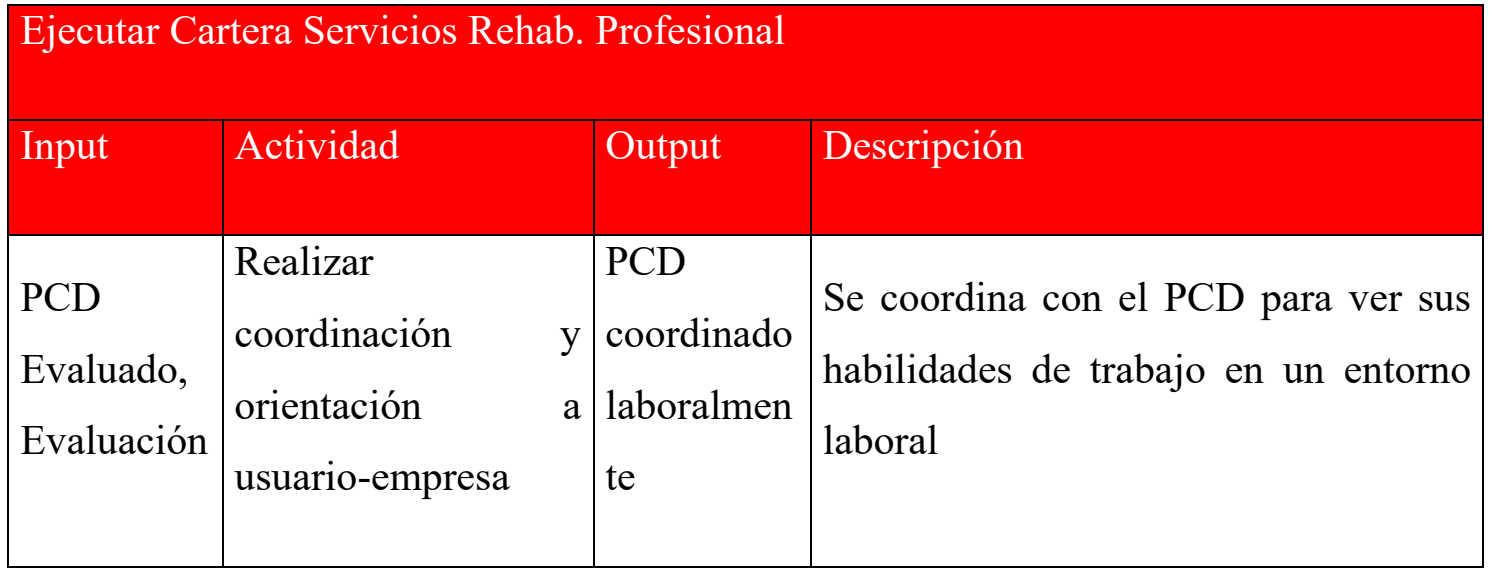




\begin{tabular}{|l|l|l|l|l|}
$\begin{array}{l}\text { PCD } \\
\text { Independie }\end{array}$ & $\begin{array}{l}\text { Realizar Proceso de } \\
\text { IL Independiente }\end{array}$ & $\begin{array}{l}\text { Paciente en } \\
\text { Post-Rehab }\end{array}$ & $\begin{array}{l}\text { Sealiza el proceso de integración de } \\
\text { un PCD para que trabaje } \\
\text { independientemente }\end{array}$ \\
\hline $\begin{array}{l}\text { PCD } \\
\text { dependient } \\
\text { e con } \\
\text { vinculo }\end{array}$ & $\begin{array}{l}\text { Realizar proceso de dependiente con } \\
\text { vínculo }\end{array}$ & $\begin{array}{l}\text { Paciente en } \\
\text { Post-Rehab }\end{array}$ & $\begin{array}{l}\text { Se realiza el proceso de integración de } \\
\text { un PCD para que trabaje en una } \\
\text { empresa si el posee un vinculo }\end{array}$ \\
\hline $\begin{array}{l}\text { PCD } \\
\text { dependient } \\
\text { e } \\
\text { vinculo }\end{array}$ & $\begin{array}{l}\text { Realizar proceso de } \\
\text { IL dependiente sin } \\
\text { vínculo }\end{array}$ & $\begin{array}{l}\text { Paciente en } \\
\text { Post-Rehab }\end{array}$ & $\begin{array}{l}\text { Se realiza el proceso de integración de } \\
\text { un PCD para que trabaje en una } \\
\text { empresa sino posee un vinculo }\end{array}$ \\
\hline
\end{tabular}

Fuente: Elaboración Propia

Ilustración 43: Realizar Proceso de IL Independiente

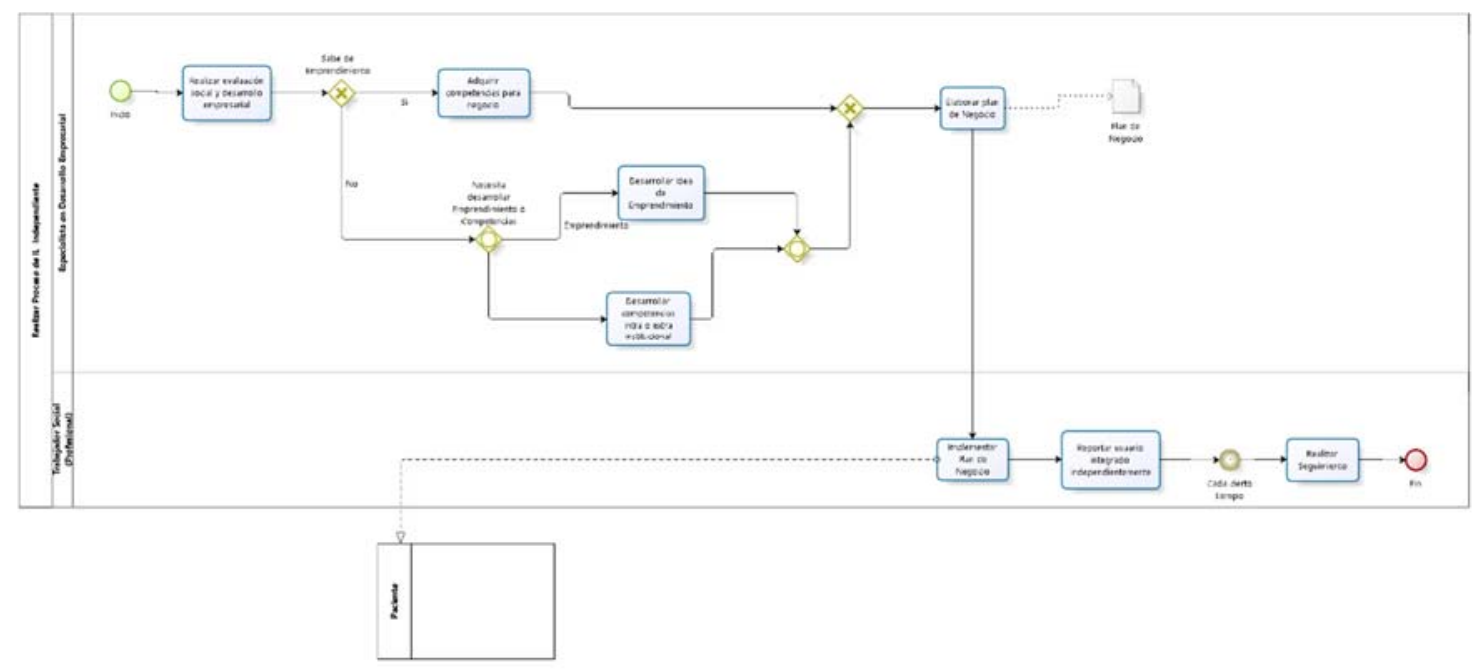

Fuente: Elaboración Propia

Actividades:

- Realizar evaluación social y desarrollo empresarial

- Adquirir competencias para negocio

- Desarrollar idea de emprendimiento 
- Desarrollar competencias intra o extra institucional

- Elaborar plan de negocio

- Implementar plan de negocio

- Reportar usuario integrado independientemente

- Realizar seguimiento

Caracterización:

Tabla 30: Caracterización de Realizar Proceso de IL Independiente

\begin{tabular}{|c|c|c|c|}
\hline \multicolumn{4}{|c|}{ Realizar Proceso de IL Independiente } \\
\hline Input & Actividad & Output & Descripción \\
\hline $\begin{array}{l}\text { PCD } \\
\text { Independiente }\end{array}$ & $\begin{array}{l}\text { Realizar evaluación } \\
\text { social y desarrollo } \\
\text { empresarial }\end{array}$ & $\begin{array}{l}\text { PCD evaluado } \\
\text { social y } \\
\text { laboralmente }\end{array}$ & $\begin{array}{l}\text { Se realiza otra evaluación } \\
\text { social y empresarial }\end{array}$ \\
\hline $\begin{array}{l}\text { PCD evaluado } \\
\text { social y } \\
\text { laboralmente }\end{array}$ & $\begin{array}{l}\text { Adquirir } \\
\text { competencias para } \\
\text { negocio }\end{array}$ & $\begin{array}{l}\text { PCD } \\
\text { competente }\end{array}$ & $\begin{array}{l}\text { Se le otorga las habilidades } \\
\text { necesarias para trabajar al } \\
\text { PCD }\end{array}$ \\
\hline $\begin{array}{l}\text { PCD evaluado } \\
\text { social y } \\
\text { laboralmente }\end{array}$ & $\begin{array}{l}\text { Desarrollar Idea de } \\
\text { Emprendimiento }\end{array}$ & $\begin{array}{l}\text { PCD } \\
\text { competente }\end{array}$ & $\begin{array}{l}\text { Se ayuda a desarrollar ideas } \\
\text { de emprendimiento }\end{array}$ \\
\hline $\begin{array}{l}\text { PCD evaluado } \\
\text { social y } \\
\text { laboralmente }\end{array}$ & $\begin{array}{l}\text { Desarrollar } \\
\text { competencias intra o } \\
\text { extra institucional }\end{array}$ & $\begin{array}{l}\text { PCD } \\
\text { competente }\end{array}$ & $\begin{array}{l}\text { Se le ayuda a desarrollar } \\
\text { competencias } \\
\text { para su trabajo }\end{array}$ \\
\hline $\begin{array}{l}\text { PCD } \\
\text { competente }\end{array}$ & $\begin{array}{l}\text { Elaborar plan de } \\
\text { Negocio }\end{array}$ & $\begin{array}{l}\text { PCD con plan } \\
\text { de Trabajo }\end{array}$ & Se elabora el plan de trabajo \\
\hline
\end{tabular}




\begin{tabular}{|l|l|l|l|}
$\begin{array}{l}\text { PCD con plan } \\
\text { de Trabajo }\end{array}$ & $\begin{array}{l}\text { Implementar Plan de } \\
\text { Negocio }\end{array}$ & $\begin{array}{l}\text { Idea } \\
\text { Negocio }\end{array}$ & Se ejecuta el plan \\
\hline $\begin{array}{l}\text { Idea de } \\
\text { Negocio }\end{array}$ & $\begin{array}{l}\text { Reportar usuario } \\
\text { integrado } \\
\text { independientemente }\end{array}$ & $\begin{array}{l}\text { PCD } \\
\text { Reintegrado }\end{array}$ & $\begin{array}{l}\text { PCD reporta si se reintegró al } \\
\text { PCD }\end{array}$ \\
\hline $\begin{array}{l}\text { PCD } \\
\text { Reintegrado }\end{array}$ & Realizar Seguimiento & $\begin{array}{l}\text { Paciente en } \\
\text { Post-Rehab }\end{array}$ & $\begin{array}{l}\text { Se hace un seguimiento al } \\
\text { PCD }\end{array}$ \\
\hline
\end{tabular}

Fuente: Elaboración Propia

Ilustración 44: Realizar Proceso de IL Dependiente con Vínculo 


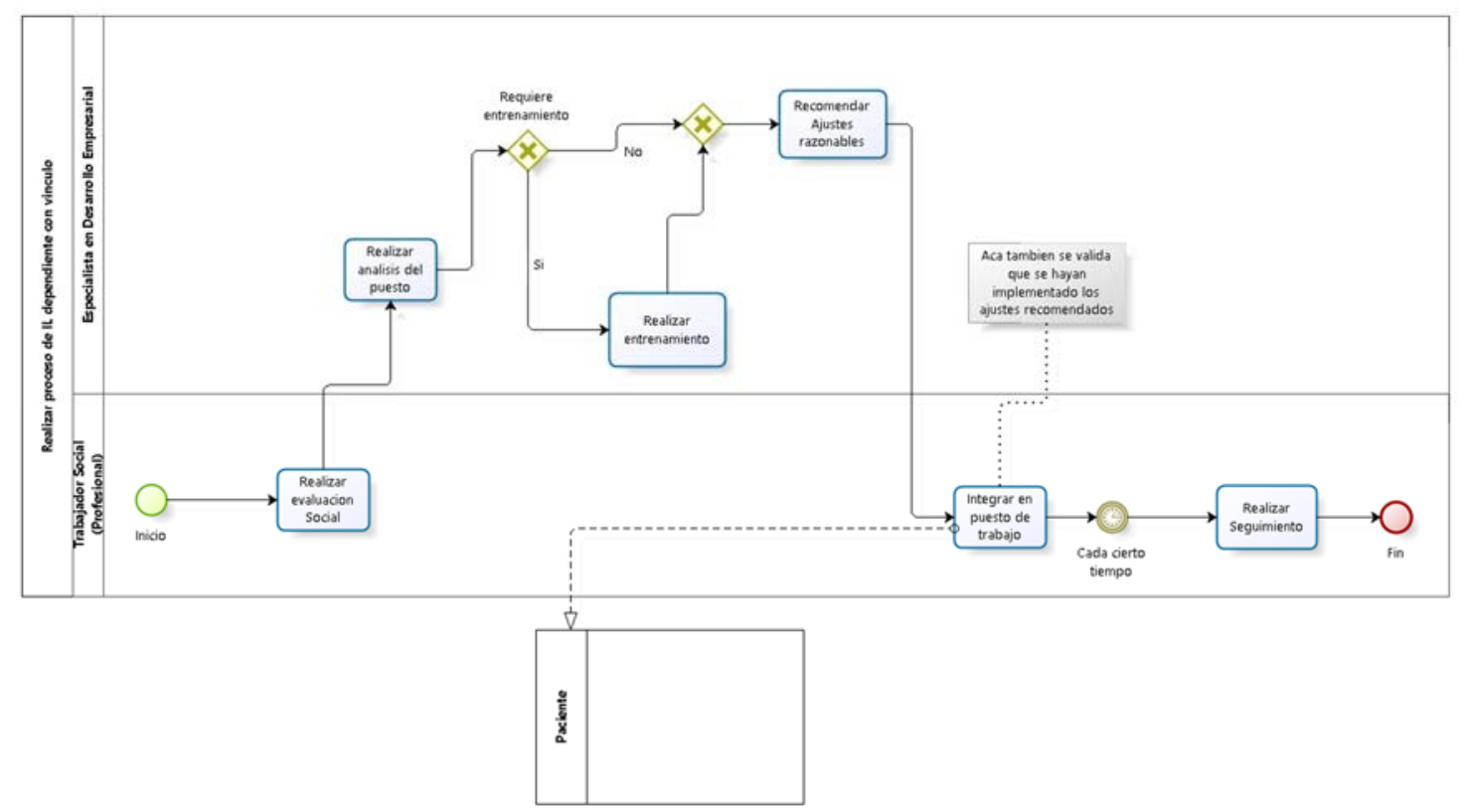

Fuente: Elaboración Propia

Actividades:

- Realizar evaluación social

- Realizar análisis de su puesto

- Realizar entrenamiento

- Recomendar ajustes razonables

- Integrar en puesto de trabajo

- Realizar seguimiento

Caracterización:

Tabla 31: Caracterización de Realizar Proceso de IL Dependiente con Vínculo

\begin{tabular}{|l|l|l|l|}
\hline \multicolumn{2}{|l|}{ Realizar proceso de IL dependiente con vínculo } \\
\hline Input & Actividad & Output & Descripción \\
\hline $\begin{array}{l}\text { PCD } \\
\text { Independient }\end{array}$ & $\begin{array}{l}\text { Realizar Evaluación } \\
\text { Social }\end{array}$ & $\begin{array}{l}\text { Análisis social } \\
\text { PCD }\end{array}$ & $\begin{array}{l}\text { Se realiza la evaluación social del } \\
\text { PCD }\end{array}$ \\
\hline
\end{tabular}




\begin{tabular}{|c|c|c|c|}
\hline $\begin{array}{l}\text { Análisis } \\
\text { social PCD }\end{array}$ & $\begin{array}{l}\text { Realizar Análisis del } \\
\text { Puesto }\end{array}$ & \begin{tabular}{|l} 
Puesto \\
Recomendado
\end{tabular} & $\begin{array}{l}\text { Se analiza que puestos podría } \\
\text { ocupar el PCD }\end{array}$ \\
\hline $\begin{array}{l}\text { Puesto } \\
\text { Recomendad } \\
\text { o }\end{array}$ & $\begin{array}{l}\text { Realizar } \\
\text { Entrenamiento }\end{array}$ & $\begin{array}{l}\text { PCD } \\
\text { Entrenado }\end{array}$ & $\begin{array}{l}\text { Se entrena al PCD según el perfil } \\
\text { laboral }\end{array}$ \\
\hline $\begin{array}{l}\text { PCD } \\
\text { Entrenado }\end{array}$ & $\begin{array}{l}\text { Recomendar Ajustes } \\
\text { Razonables }\end{array}$ & PCD Listo & $\begin{array}{l}\text { Se termina de entrenar si fuera } \\
\text { necesario algún ajuste }\end{array}$ \\
\hline PCD Listo & $\begin{array}{l}\text { Integrar en Puesto } \\
\text { de Trabajo }\end{array}$ & \begin{tabular}{|l} 
PCD \\
Reintegrado
\end{tabular} & Se reporta si se reintegró al PCD \\
\hline $\begin{array}{l}\text { PCD } \\
\text { Reintegrado }\end{array}$ & $\begin{array}{l}\text { Realizar } \\
\text { Seguimiento }\end{array}$ & $\begin{array}{l}\text { Paciente en } \\
\text { Post-Rehab }\end{array}$ & Se hace un seguimiento al PCD \\
\hline
\end{tabular}

Fuente: Elaboración Propia

Ilustración 45: Realizar Proceso de IL Dependiente sin Vínculo

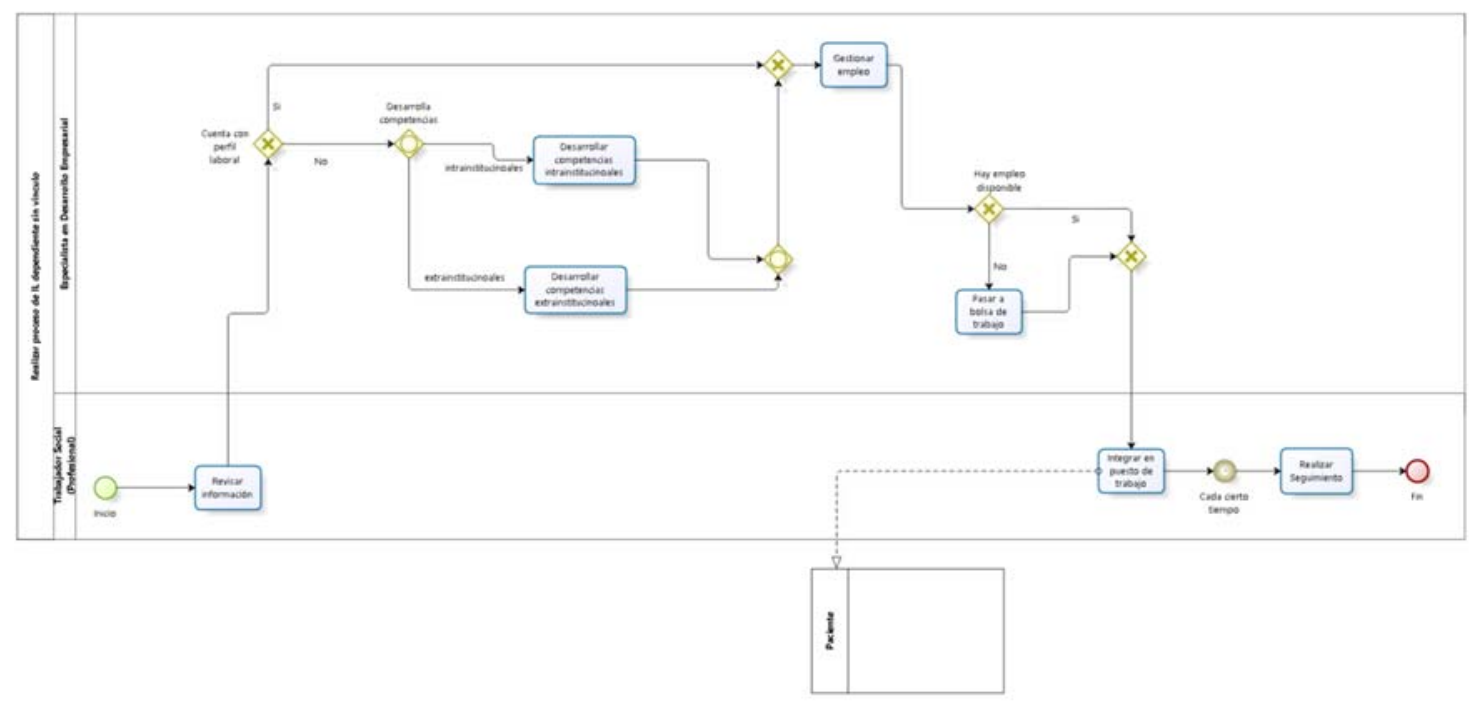

Fuente: Elaboración Propia

Actividades:

- Revisar información

- Desarrollar competencias intra institucionales 
- Desarrollar competencias extra institucionales

- Gestionar empleo

- Pasar a bolsa de trabajo

Caracterización:

Tabla 32: Caracterización Realizar Proceso de IL Dependiente sin Vínculo

\begin{tabular}{|c|c|c|c|}
\hline \multicolumn{4}{|c|}{ Realizar Proceso de IL Dependiente Sin Vínculo } \\
\hline Input & Actividad & Output & Descripción \\
\hline $\begin{array}{l}\text { PCD } \\
\text { Independien } \\
\text { te }\end{array}$ & Revisar Información & PCD analizado & $\begin{array}{l}\text { Se revisa el perfil del } \\
\text { PCD }\end{array}$ \\
\hline $\begin{array}{l}\text { PCD } \\
\text { analizado }\end{array}$ & $\begin{array}{l}\text { Desarrollar Competencias } \\
\text { Interinstitucionales }\end{array}$ & $\begin{array}{l}\text { PCD } \\
\text { competente }\end{array}$ & $\begin{array}{l}\text { Se desarrollan las } \\
\text { capacidades del PCD }\end{array}$ \\
\hline $\begin{array}{l}\text { PCD } \\
\text { analizado }\end{array}$ & $\begin{array}{l}\text { Desarrollar Competencias } \\
\text { Extra institucionales }\end{array}$ & $\begin{array}{l}\text { PCD } \\
\text { competente }\end{array}$ & $\begin{array}{l}\text { Se desarrollan las } \\
\text { capacidades del PCD }\end{array}$ \\
\hline $\begin{array}{l}\text { PCD } \\
\text { competente }\end{array}$ & Gestionar Empleo & $\begin{array}{l}\text { Empleo } \\
\text { Elegido }\end{array}$ & $\begin{array}{l}\text { Se busca un empleo } \\
\text { según el perfil }\end{array}$ \\
\hline $\begin{array}{l}\text { Empleo } \\
\text { Elegido }\end{array}$ & Pasar a Bolsa de Trabajo & PCD Listo & $\begin{array}{l}\text { Se postula al PCD en } \\
\text { bolsas de Trabajo }\end{array}$ \\
\hline PCD Listo & Integrar en Puesto de Trabajo & $\begin{array}{l}\text { PCD } \\
\text { Reintegrado }\end{array}$ & $\begin{array}{l}\text { Se reporta si se reintegró } \\
\text { al PCD }\end{array}$ \\
\hline
\end{tabular}




\begin{tabular}{|c|c|c|c|}
\hline $\begin{array}{l}\text { PCD } \\
\text { Reintegrado }\end{array}$ & Realizar Seguimiento & $\begin{array}{l}\text { Paciente en } \\
\text { Post-Rehab. }\end{array}$ & $\begin{array}{l}\text { Se hace un seguimiento } \\
\text { al PCD }\end{array}$ \\
\hline
\end{tabular}

Fuente: Elaboración Propia

Ilustración 46: Ejecutar Cartera Servicios Rehab. Social

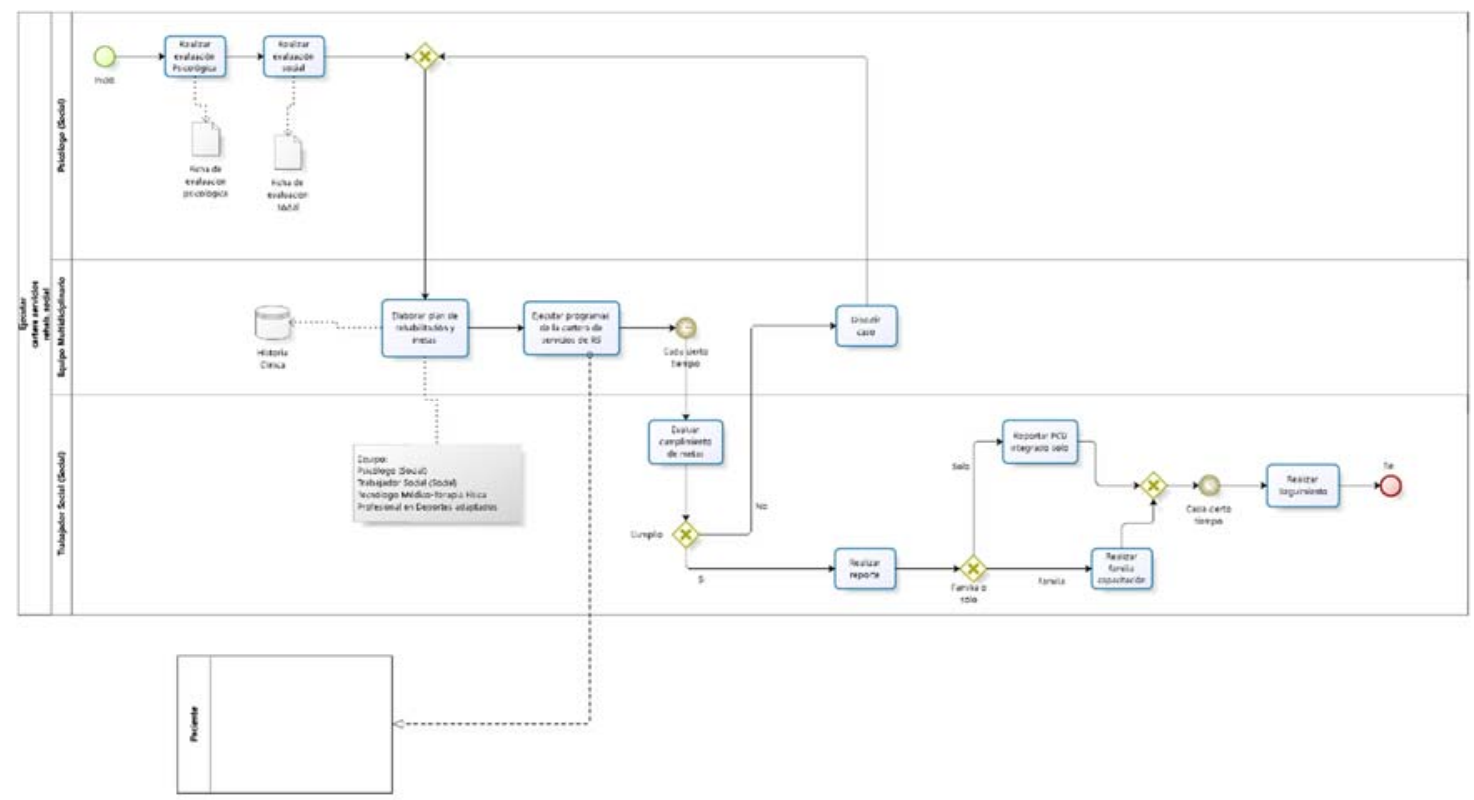

Fuente: Elaboración Propia

Actividades:

- Realizar evaluación psicológica

- Realizar evaluación social

- Elaborar plan de rehabilitación y metas

- Ejecutar programas de la cartera de servicios de RS

- Evaluar cumplimiento de metas

- Discutir caso

- Realizar reporte

- Reporte PCD

- Realizar familia capacitación 
- Realizar seguimiento

Caracterización:

Tabla 33: Caracterización Ejecutar Cartera Servicios Rehab. Social

\begin{tabular}{|c|c|c|c|}
\hline \multicolumn{4}{|c|}{ Ejecutar Cartera Servicios Rehab. Social } \\
\hline Input & Actividad & Output & Descripción \\
\hline $\begin{array}{l}\text { PCD Evaluado, } \\
\text { Evaluación }\end{array}$ & $\begin{array}{l}\text { Realizar } \\
\text { evaluación } \\
\text { Psicológica }\end{array}$ & $\begin{array}{l}\text { PCD Evaluado } \\
\text { Psicológicamente, } \\
\text { Evaluación }\end{array}$ & $\begin{array}{l}\text { Se hace una evaluación } \\
\text { psicológica del PCD para } \\
\text { saber su estado }\end{array}$ \\
\hline $\begin{array}{l}\text { PCD Evaluado } \\
\text { Psicológicamente, } \\
\text { Evaluación }\end{array}$ & $\begin{array}{l}\text { Realizar } \\
\text { evaluación social }\end{array}$ & $\begin{array}{l}\text { PCD Evaluado } \\
\text { Socialmente, } \\
\text { Evaluación }\end{array}$ & $\begin{array}{l}\text { Se hace una evaluación de } \\
\text { habilidades sociales del } \\
\text { PCD para saber su estado }\end{array}$ \\
\hline $\begin{array}{l}\text { PCD Evaluado } \\
\text { Totalmente, } \\
\text { Evaluación }\end{array}$ & $\begin{array}{l}\text { Elaborar plan de } \\
\text { rehabilitación } \mathrm{y} \\
\text { metas }\end{array}$ & $\begin{array}{l}\text { PCD con Historia } \\
\text { Clínica }\end{array}$ & $\begin{array}{l}\text { Se elabora la rehabilitación } \\
\text { y sus indicadores de éxitos }\end{array}$ \\
\hline $\begin{array}{l}\text { PCD con Historia } \\
\text { Clínica }\end{array}$ & $\begin{array}{l}\text { Ejecutar } \\
\text { programas de la } \\
\text { cartera de } \\
\text { servicios de RS }\end{array}$ & $\begin{array}{l}\text { Paciente en } \\
\text { Rehabilitación, } \\
\text { Reporte de } \\
\text { Rehabilitación }\end{array}$ & $\begin{array}{l}\text { Se empieza } \\
\text { rehabilitación social }\end{array}$ \\
\hline $\begin{array}{ll}\text { Paciente en } \\
\text { Rehabilitación, } \\
\text { Reporte de } \\
\text { Rehabilitación }\end{array}$ & $\begin{array}{l}\text { Evaluar } \\
\text { cumplimiento de } \\
\text { metas }\end{array}$ & Metas Evaluadas & $\begin{array}{l}\text { Se evalúa si se cumplen los } \\
\text { indicadores de la } \\
\text { rehabilitación exitosa }\end{array}$ \\
\hline Metas Evaluadas & Discutir caso & $\begin{array}{l}\text { Paciente } \\
\text { Reevaluado }\end{array}$ & $\begin{array}{l}\text { Se discute y evalúa si se } \\
\text { puede dar de alta o no }\end{array}$ \\
\hline $\begin{array}{l}\text { Paciente } \\
\text { Reevaluado }\end{array}$ & Realizar reporte & $\begin{array}{l}\text { Reporte } \\
\text { Paciente }\end{array}$ & $\begin{array}{l}\text { Se realiza el reporte de la } \\
\text { rehabilitación }\end{array}$ \\
\hline
\end{tabular}




\begin{tabular}{|c|c|c|c|}
\hline $\begin{array}{l}\text { Reporte } \\
\text { Paciente }\end{array}$ & $\begin{array}{l}\text { Reportar PCD } \\
\text { integrado solo }\end{array}$ & \begin{tabular}{|l} 
Paciente \\
Reinsertado
\end{tabular} & $\begin{array}{l}\text { Se reporta si el PCD fue } \\
\text { reintegrado } \\
\text { satisfactoriamente }\end{array}$ \\
\hline $\begin{array}{l}\text { Reporte } \\
\text { Paciente }\end{array}$ & $\begin{array}{l}\text { Realizar familia } \\
\text { capacitación }\end{array}$ & $\begin{array}{l}\text { Familia } \\
\text { Capacitada }\end{array}$ & $\begin{array}{l}\text { Se capacita a la familia si } \\
\text { fuera necesario }\end{array}$ \\
\hline $\begin{array}{l}\text { Paciente } \\
\text { Reinsertado }\end{array}$ & $\begin{array}{l}\text { Realizar } \\
\text { Seguimiento }\end{array}$ & $\begin{array}{l}\text { Paciente en Post- } \\
\text { Rehab }\end{array}$ & $\begin{array}{lll}\text { Se monitorea que } & \text { el } \\
\text { servicio se } & & \text { de } \\
\text { correctamente } & & \end{array}$ \\
\hline
\end{tabular}

Fuente: Elaboración Propia

Ilustración 47: Derivar Paciente

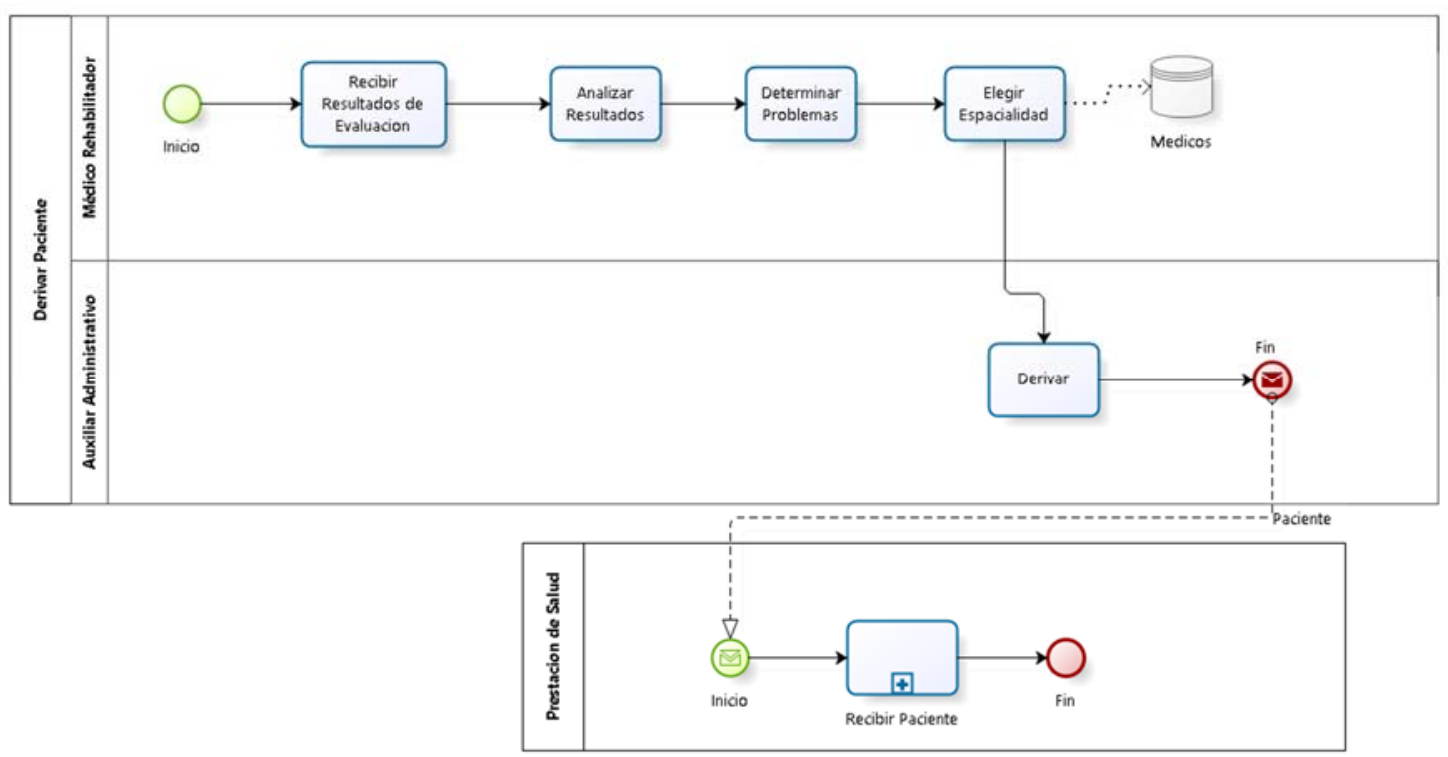

Fuente: Elaboración Propia

Actividades:

- Recibir resultados de evaluación

- Analizar resultados

- Determinar problemas

- Elegir especialidad 
Caracterización:

Tabla 34: Caracterización de Derivar Paciente

\begin{tabular}{|c|c|c|c|}
\hline \multicolumn{4}{|l|}{ Derivar Paciente } \\
\hline Input & Actividad & Output & Descripción \\
\hline $\begin{array}{l}\text { Adulto Mayor } \\
\text { Evaluado, } \\
\text { Evaluación }\end{array}$ & $\begin{array}{l}\text { Recibir } \\
\text { Resultados de } \\
\text { Evaluación }\end{array}$ & $\begin{array}{l}\text { Evaluación } \\
\text { recibida }\end{array}$ & $\begin{array}{l}\text { Se reciben los resultados de la } \\
\text { evaluación }\end{array}$ \\
\hline Evaluación recibida & $\begin{array}{l}\text { Analizar } \\
\text { Resultados }\end{array}$ & $\begin{array}{l}\text { Evaluación } \\
\text { Analizada }\end{array}$ & $\begin{array}{l}\text { Se analizan los resultados de } \\
\text { capacidades del PCD }\end{array}$ \\
\hline $\begin{array}{l}\text { Evaluación } \\
\text { Analizada }\end{array}$ & $\begin{array}{l}\text { Determinar } \\
\text { Problemas }\end{array}$ & $\begin{array}{l}\text { Problemas } \\
\text { detectados }\end{array}$ & $\begin{array}{l}\text { Se determinan los problemas } \\
\text { de salud que tiene el PCD }\end{array}$ \\
\hline $\begin{array}{l}\text { Problemas } \\
\text { detectados }\end{array}$ & $\begin{array}{l}\text { Elegir } \\
\text { Espacialidad }\end{array}$ & $\begin{array}{l}\text { Especialida } \\
\text { des elegida }\end{array}$ & $\begin{array}{l}\text { Se eligen que especialistas } \\
\text { deben atender al paciente }\end{array}$ \\
\hline $\begin{array}{l}\text { Especialidades } \\
\text { elegida }\end{array}$ & Derivar & $\begin{array}{l}\text { Paciente } \\
\text { Derivado }\end{array}$ & Se deriva al paciente \\
\hline
\end{tabular}

Fuente: Elaboración Propia

Una vez acaba la reorganización y optimización de los procesos se elaboró la integración con el macro proceso de prestación de salud, para que haya una interconexión de información y se logra agilizar el tiempo de atención de un asegurado al momento de su registro, historia clínica, derivación, asignación de talleres y/o de salud.

Ilustración 48: Prestación de Salud

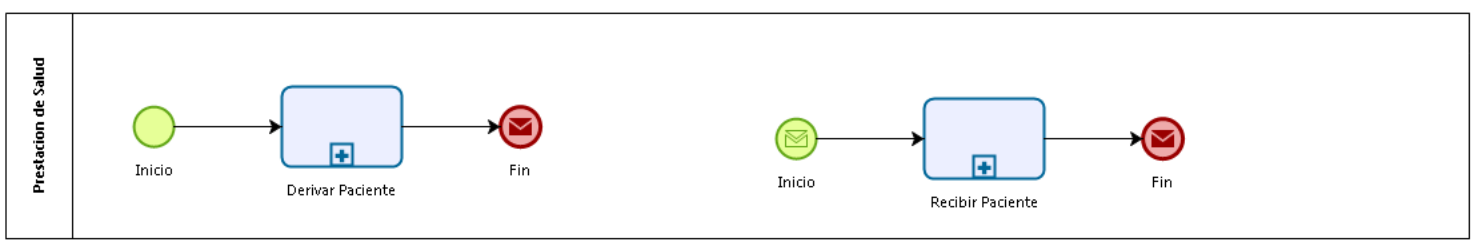


Fuente: Elaboración Propia

Sub proceso:

- Derivar paciente

- Recibir paciente

Al concluir todos los requerimientos a nivel negocio (el R6 se mostrará en la Validación), se pasó a la etapa del diseño de la arquitectura empresarial To Be en base a los requerimientos planteados y validados por el cliente del proyecto. 
Ilustración 49: Mapa de Procesos de EsSalud To Be

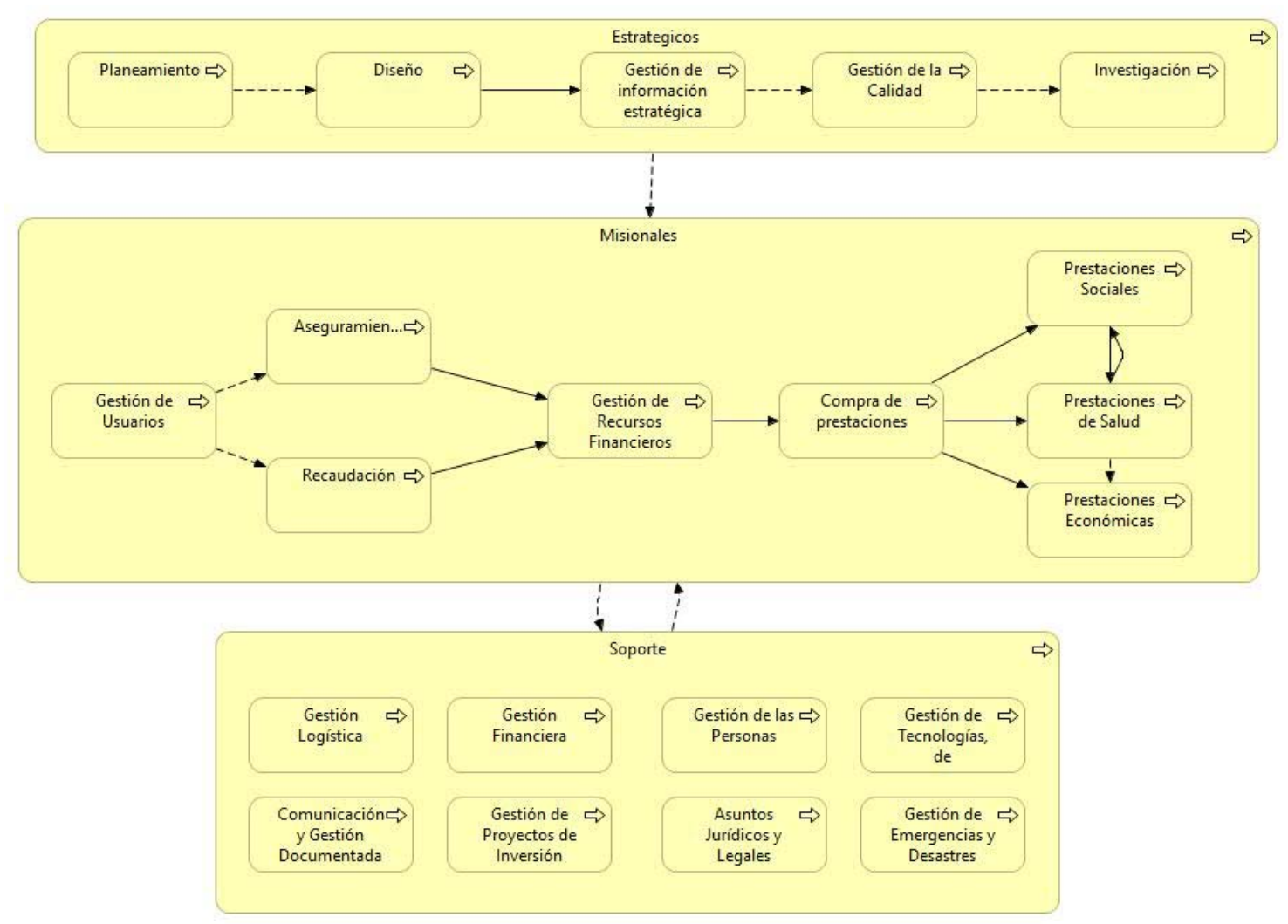

Fuente: Elaboración Propia

La propuesta de conectar los macro procesos de prestación social a prestación de salud y no solo de flujo de información, ayudara a agilizar el tiempo de atención y eliminar la tarea manual de verificar una derivación y/o afiliación de un asegurado que valla a un CERP o un CAM. 
Ilustración 50: Gestionar Atención del CAM To Be

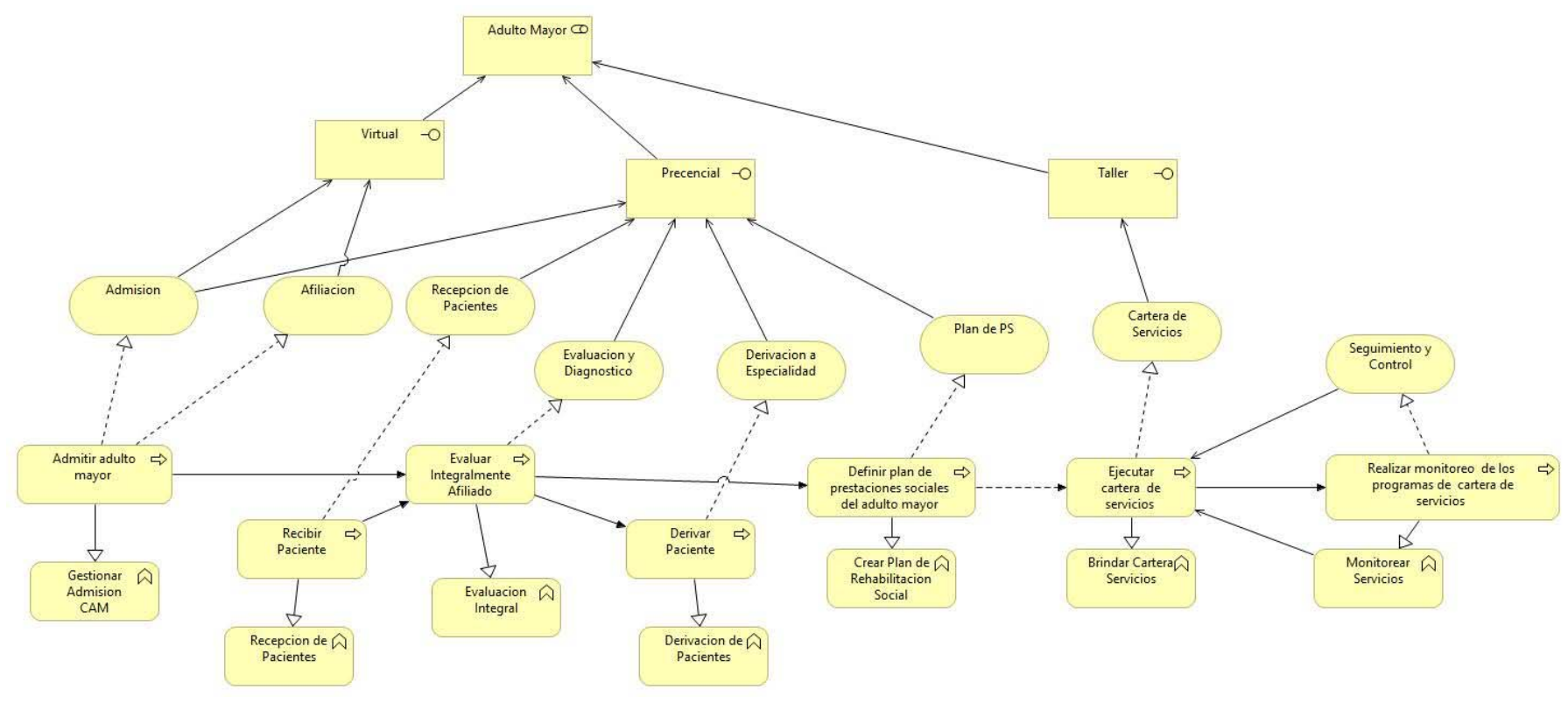

Fuente: Elaboración Propia

Ilustración 51: Gestionar Atención del CERP To Be

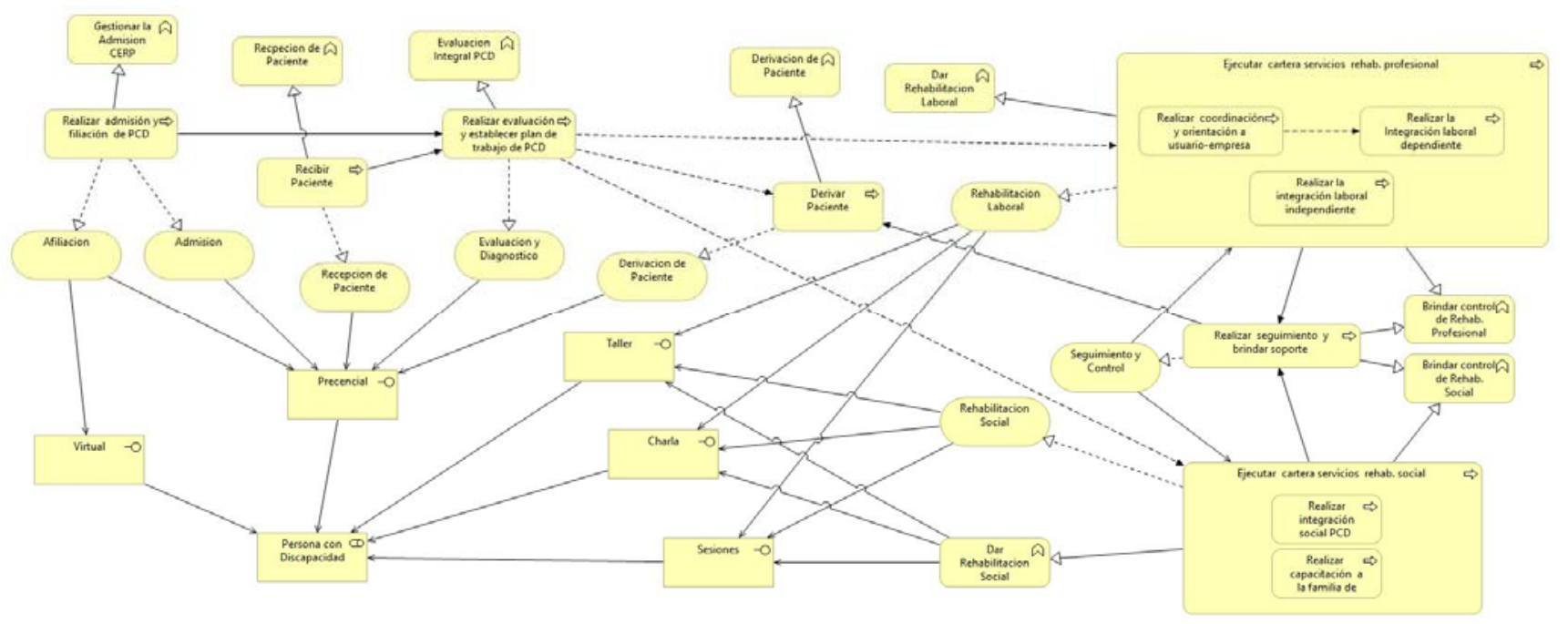

Fuente: Elaboración Propia 
Para un mayor detalle de visualización se creó cinco vistas, las siguientes:

Vista de estructura de información

Ilustración 52: Vista de Estructura de Información

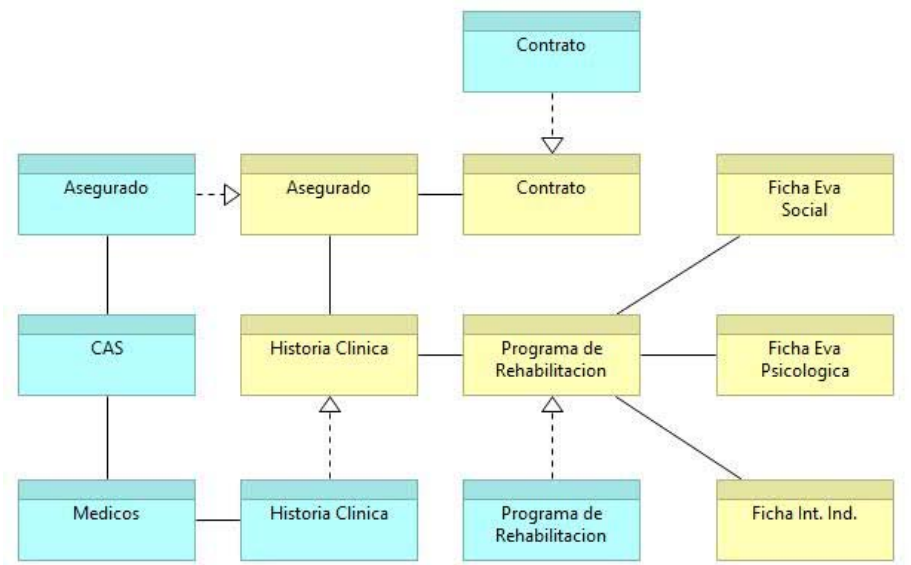

Fuente: Elaboración Propia

Vista de estructura de aplicación

Ilustración 53: Vista de Estructura de Aplicación

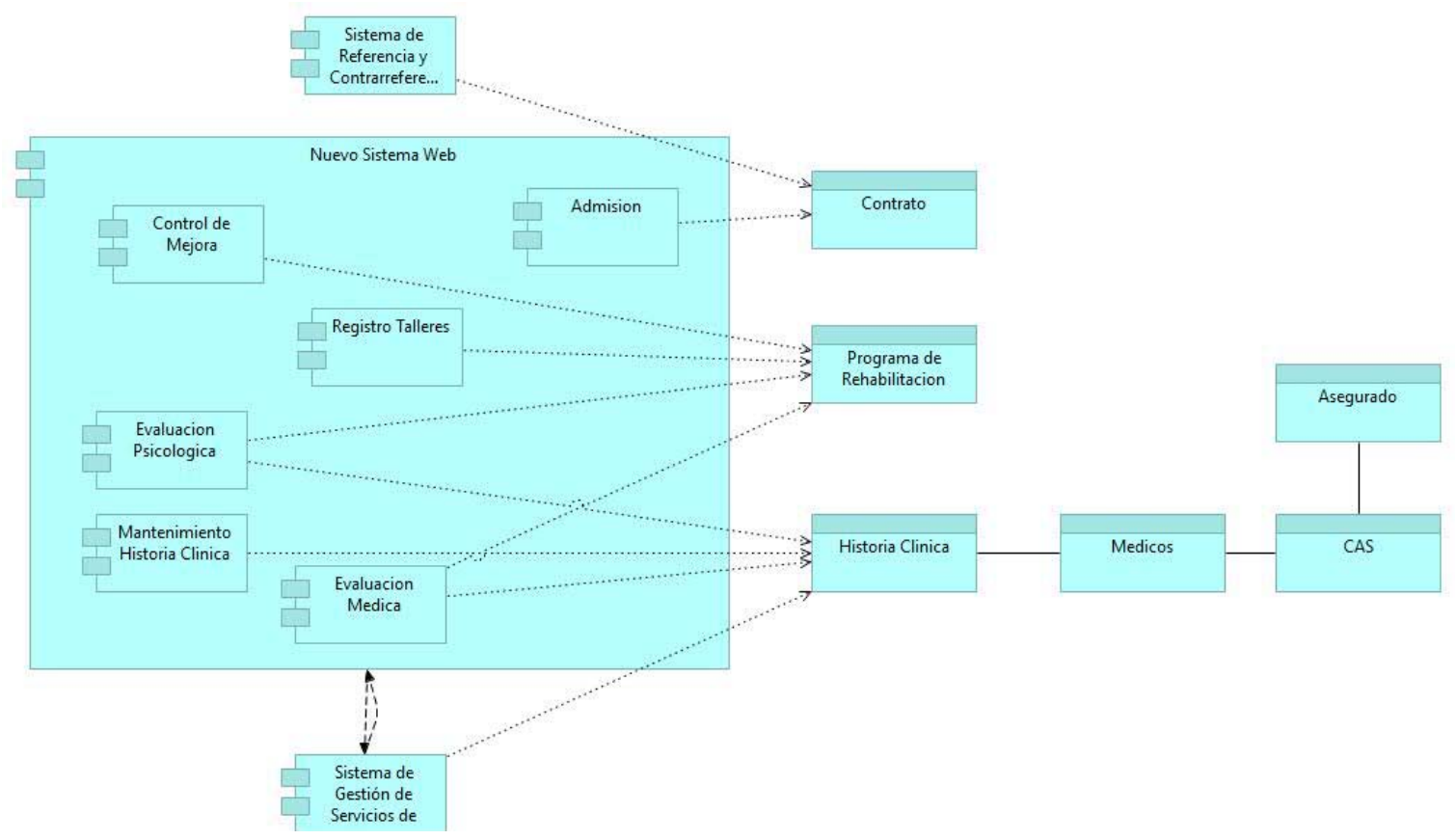


Fuente: Elaboración Propia

Vista de infraestructura de tecnología

Ilustración 54: Vista de Infraestructura de Tecnología

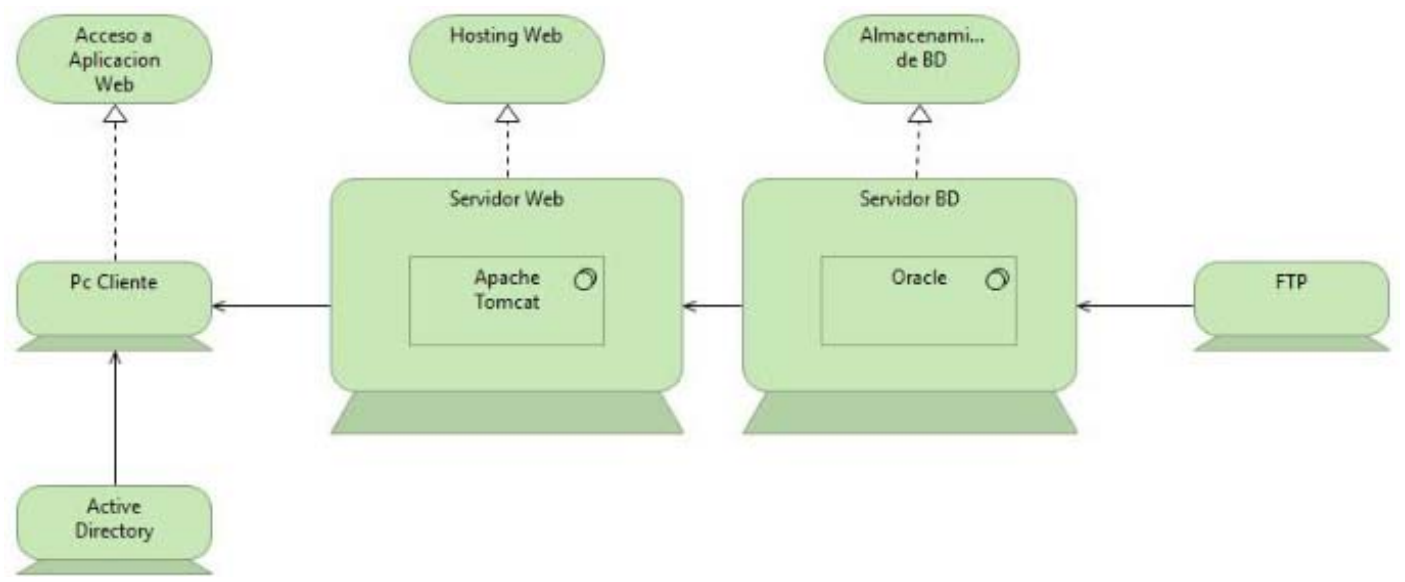

Fuente: Elaboración Propia 


\section{Vista proceso de negocios}

\section{Ilustración 55: Vista Proceso de Negocios}

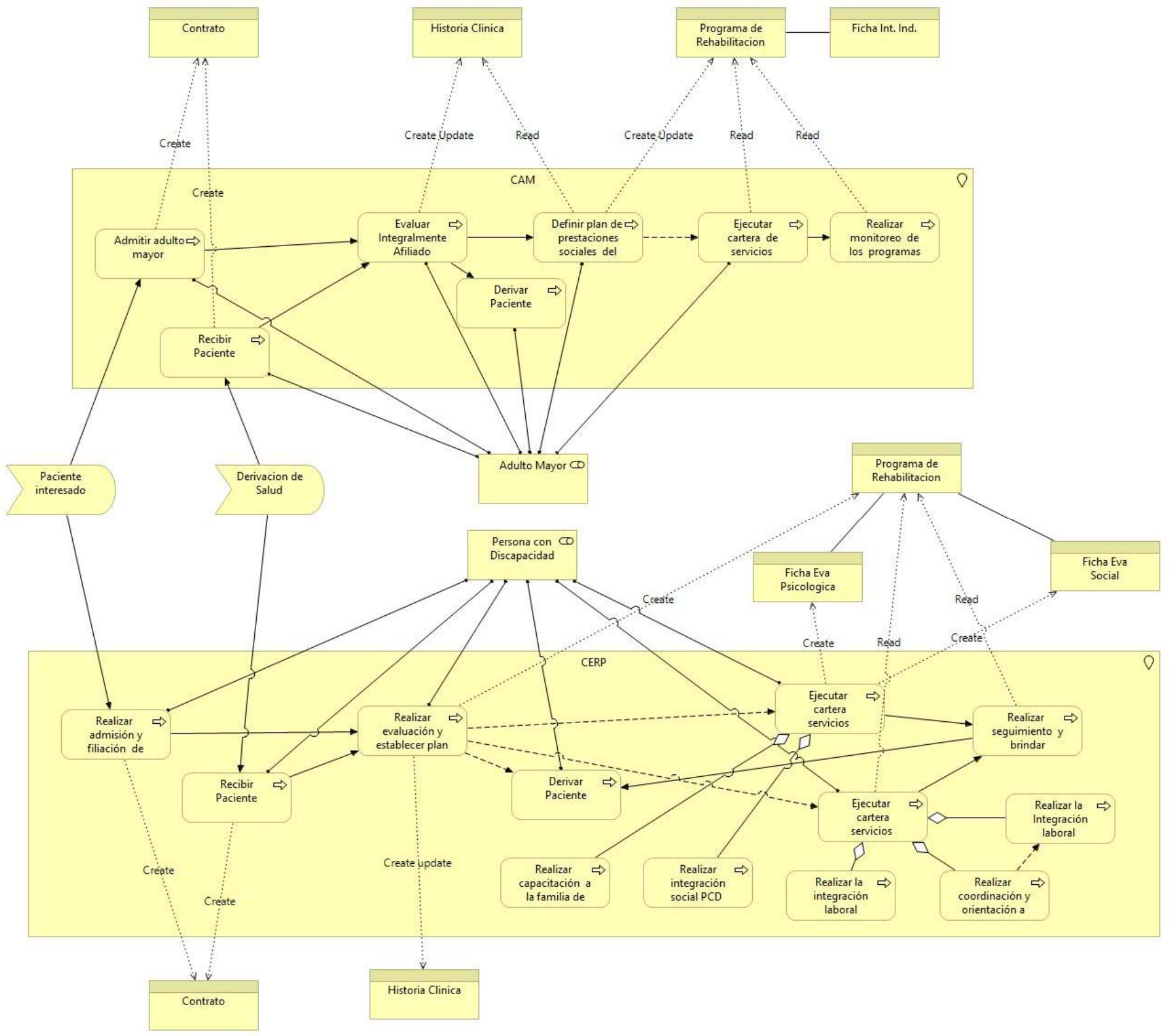

Fuente: Elaboración Propia 
Vista de realización de servicios

Ilustración 56: Vista de Realización de Servicios
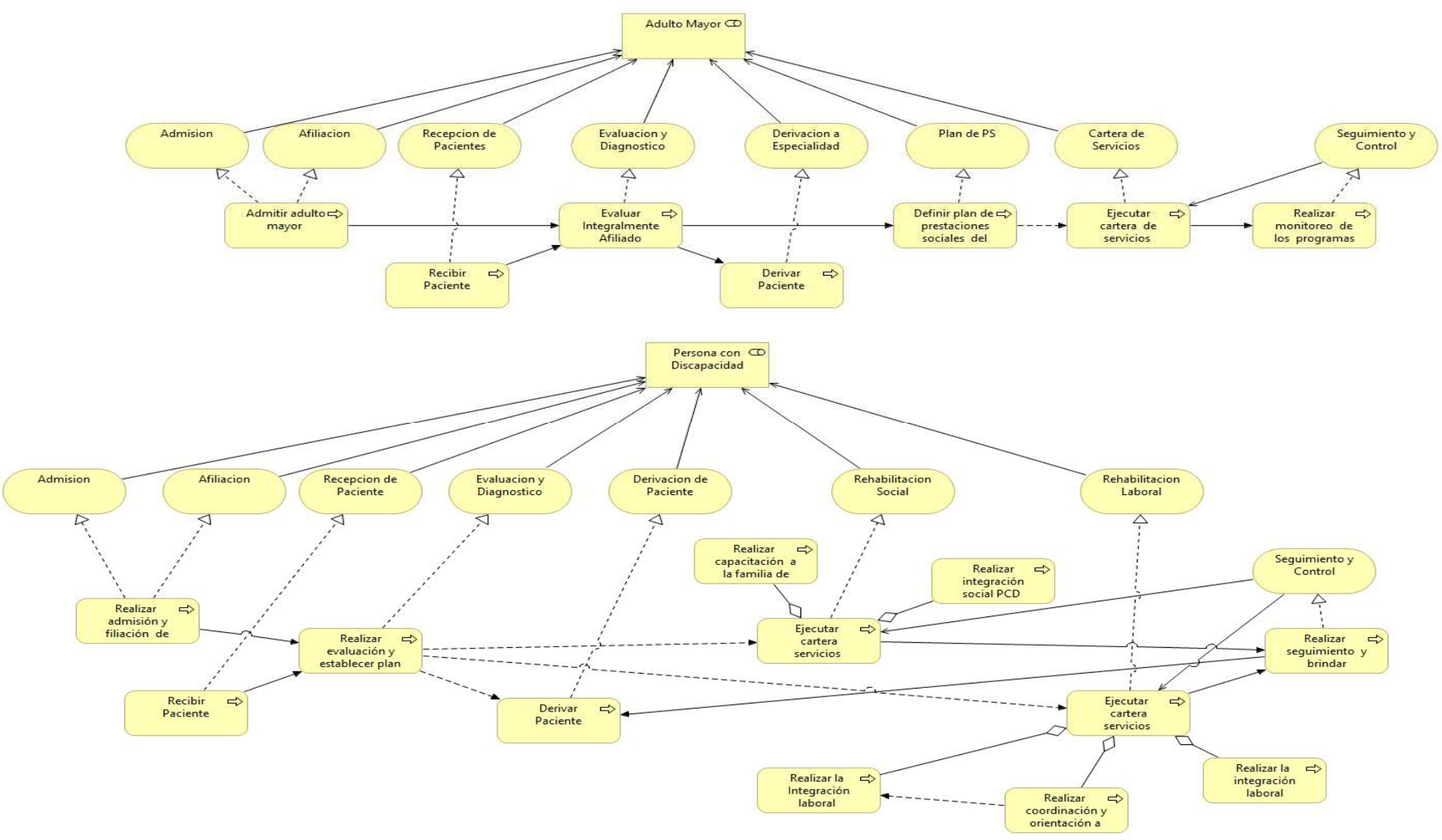

Fuente: Elaboración Propia 
Ilustración 57: Vista general To Be de la Arquitectura Empresarial del Macro Proceso de Prestación Social

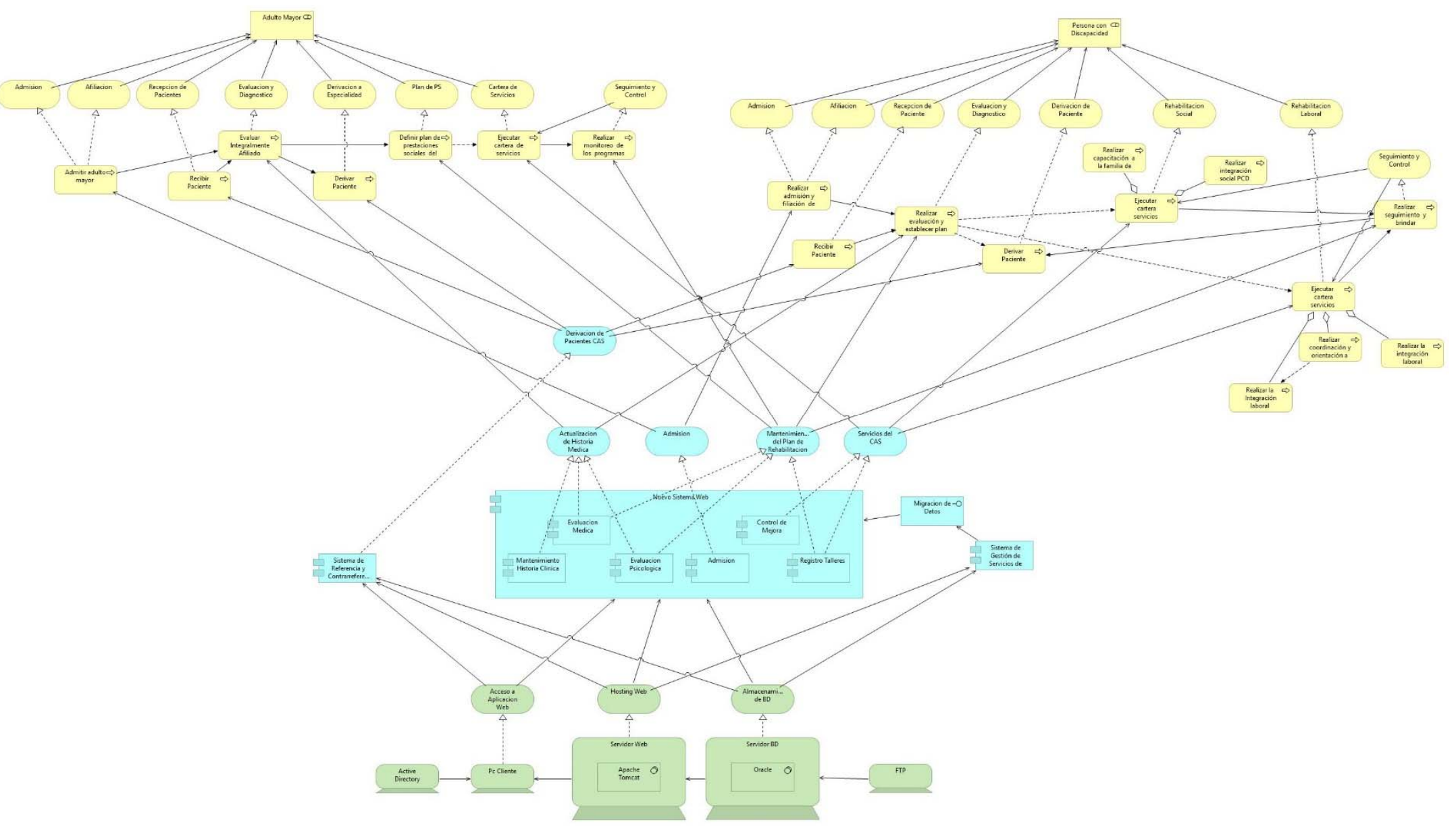

Fuente: Elaboración Propia 
Como siguiente paso de la solución y relación entre los diagramas de los procesos y el diseño de archimate, se pasó a elabora la matriz RACI To Be.

Tabla 35: Matriz RACI To Be

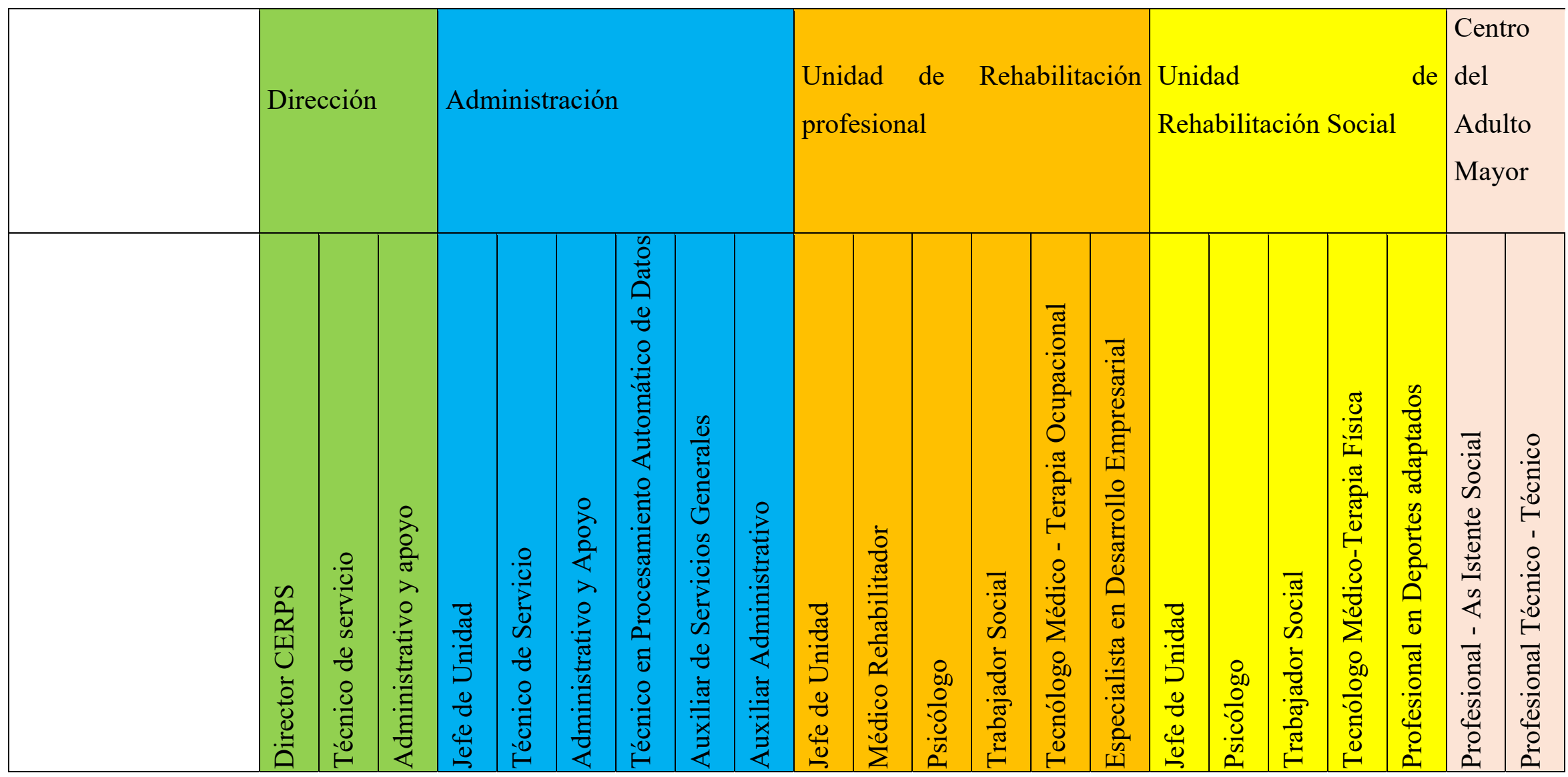




\begin{tabular}{|c|c|c|c|c|c|c|c|c|c|c|c|c|c|c|c|c|c|c|c|c|c|}
\hline $\begin{array}{ll}\text { Brindar } & \text { Cartera } \\
\text { Servicios } & \end{array}$ & AI & $\begin{array}{l}\mathrm{AC} \\
\mathrm{I}\end{array}$ & $\begin{array}{l}\mathrm{AC} \\
\mathrm{I}\end{array}$ & $\begin{array}{l}\mathrm{AC} \\
\mathrm{I}\end{array}$ & $\mathrm{C}$ & $\mathrm{C}$ & $\mathrm{C}$ & $\mathrm{C}$ & $\mathrm{C}$ & - & - & - & - & - & - & - & & & & $\begin{array}{l}\text { RA } \\
\text { CI }\end{array}$ & $\begin{array}{l}\mathrm{RA} \\
\mathrm{CI}\end{array}$ \\
\hline $\begin{array}{l}\text { Crear Plan de } \\
\text { Rehabilitación } \\
\text { Social }\end{array}$ & AI & I & CI & AI & CI & $\mathrm{CI}$ & $\mathrm{C}$ & $\mathrm{C}$ & $\mathrm{C}$ & - & - & - & - & - & - & - & - & - & & $\begin{array}{l}\text { RA } \\
\text { CI }\end{array}$ & $\begin{array}{l}\text { RA } \\
\text { CI }\end{array}$ \\
\hline $\begin{array}{l}\text { Gestionar Admisión } \\
\text { CAM }\end{array}$ & AI & $\mathrm{AI}$ & $\begin{array}{l}\mathrm{RC} \\
\mathrm{I}\end{array}$ & $\begin{array}{l}\mathrm{AC} \\
\mathrm{I}\end{array}$ & $\mathrm{CI}$ & $\mathrm{RC}$ & $\mathrm{RC}$ & $\mathrm{RC}$ & $\mathrm{RC}$ & - & - & - & - & - & - & - & - & - & & I & I \\
\hline Evaluación Medica & AI & I & $\mathrm{CI}$ & $\mathrm{AI}$ & $\mathrm{CI}$ & $\mathrm{CI}$ & $\mathrm{C}$ & $\mathrm{C}$ & $\mathrm{C}$ & - & - & - & - & - & - & - & - & - & & $\mathrm{RA}$ & RA \\
\hline Monitorear Servicios & AI & I & $\begin{array}{l}\mathrm{AC} \\
\mathrm{I}\end{array}$ & AI & CI & $\mathrm{C}$ & $\mathrm{CI}$ & $\mathrm{CI}$ & CI & - & - & - & - & - & - & - & - & - & & $\begin{array}{l}\mathrm{RC} \\
\mathrm{I}\end{array}$ & $\begin{array}{l}\mathrm{RC} \\
\mathrm{I}\end{array}$ \\
\hline Derivar Paciente & AI & I & I & $\mathrm{AI}$ & CI & $\mathrm{I}$ & $\mathrm{CI}$ & $\mathrm{I}$ & $\mathrm{RC}$ & - & - & - & - & - & - & - & - & - & & $\begin{array}{l}\text { RA } \\
\text { CI }\end{array}$ & $\mathrm{C}$ \\
\hline Recibir Paciente & AI & AI & $\begin{array}{l}\mathrm{RC} \\
\mathrm{I}\end{array}$ & $\begin{array}{l}\mathrm{AC} \\
\mathrm{I}\end{array}$ & CI & $\mathrm{RC}$ & $\mathrm{RC}$ & $\mathrm{RC}$ & $\mathrm{RC}$ & - & - & - & - & - & - & - & - & - & & I & I \\
\hline $\begin{array}{l}\text { Brindar control de } \\
\text { Rehab. Profesional }\end{array}$ & AI & I & $\begin{array}{l}\mathrm{AC} \\
\mathrm{I}\end{array}$ & $\mathrm{AI}$ & CI & C & CI & $\mathrm{CI}$ & CI & $\begin{array}{l}\mathrm{AC} \\
\mathrm{I}\end{array}$ & $\mathrm{R}$ & $\mathrm{R}$ & $\mathrm{R}$ & $\mathrm{R}$ & $\mathrm{R}$ & - & - & - & & - & - \\
\hline
\end{tabular}




\begin{tabular}{|c|c|c|c|c|c|c|c|c|c|c|c|c|c|c|c|c|c|c|c|c|c|c|}
\hline $\begin{array}{l}\text { Brindar control de } \\
\text { Rehab. Social }\end{array}$ & AI & I & $\begin{array}{l}\mathrm{AC} \\
\mathrm{I}\end{array}$ & AI & $\mathrm{CI}$ & $\mathrm{C}$ & $\mathrm{CI}$ & CI & $\mathrm{CI}$ & - & - & - & - & - & - & \begin{tabular}{|l|}
$\mathrm{AC}$ \\
$\mathrm{I}$
\end{tabular} & $\mathrm{R}$ & $\mathrm{R}$ & $\mathrm{R}$ & $\mathrm{R}$ & - & - \\
\hline Evaluación Medica & AI & I & $\mathrm{CI}$ & $\mathrm{AI}$ & CI & $\mathrm{CI}$ & $\mathrm{C}$ & $\mathrm{RC}$ & $\mathrm{C}$ & AI & RI & RI & I & I & I & AI & $\mathrm{R}$ & I & RI & I & - & - \\
\hline $\begin{array}{l}\text { Dar Rehabilitación } \\
\text { Laboral }\end{array}$ & AI & $\begin{array}{l}\mathrm{AC} \\
\mathrm{I}\end{array}$ & $\begin{array}{l}\mathrm{AC} \\
\mathrm{I}\end{array}$ & $\begin{array}{l}\mathrm{AC} \\
\mathrm{I}\end{array}$ & $\mathrm{C}$ & $\mathrm{C}$ & $\mathrm{C}$ & C & $\mathrm{C}$ & $\begin{array}{l}\mathrm{AC} \\
\mathrm{I}\end{array}$ & $\mathrm{R}$ & $\mathrm{R}$ & $\mathrm{R}$ & $\mathrm{R}$ & $\mathrm{R}$ & - & - & - & - & - & - & - \\
\hline $\begin{array}{l}\text { Dar Rehabilitación } \\
\text { Social }\end{array}$ & AI & $\begin{array}{l}\mathrm{AC} \\
\mathrm{I}\end{array}$ & $\begin{array}{l}\mathrm{AC} \\
\mathrm{I}\end{array}$ & $\begin{array}{l}\mathrm{AC} \\
\mathrm{I}\end{array}$ & $\mathrm{C}$ & $\mathrm{C}$ & $\mathrm{C}$ & C & $\mathrm{C}$ & - & - & - & - & - & - & $\begin{array}{l}\mathrm{AC} \\
\mathrm{I}\end{array}$ & $\mathrm{R}$ & $\mathrm{R}$ & $\mathrm{R}$ & $\mathrm{R}$ & - & - \\
\hline $\begin{array}{l}\text { Gestionar la } \\
\text { Admisión CERP }\end{array}$ & AI & AI & $\begin{array}{l}\mathrm{RC} \\
\mathrm{I}\end{array}$ & $\begin{array}{l}\mathrm{AC} \\
\mathrm{I}\end{array}$ & $\mathrm{CI}$ & $\mathrm{RC}$ & $\mathrm{RC}$ & $\mathrm{RC}$ & $\mathrm{RC}$ & I & - & - & - & - & - & I & - & - & - & - & - & - \\
\hline Derivar Paciente & AI & I & I & AI & $\mathrm{CI}$ & $\mathrm{I}$ & $\mathrm{CI}$ & $\mathrm{I}$ & $\mathrm{RC}$ & AI & $\begin{array}{l}\mathrm{RC} \\
\mathrm{I}\end{array}$ & $\mathrm{CI}$ & $\mathrm{I}$ & I & I & $\mathrm{I}$ & $\mathrm{CI}$ & $\mathrm{I}$ & CI & I & - & - \\
\hline Recibir Paciente & AI & AI & $\begin{array}{l}\mathrm{RC} \\
\mathrm{I}\end{array}$ & $\begin{array}{l}\mathrm{AC} \\
\mathrm{I}\end{array}$ & $\mathrm{CI}$ & $\mathrm{RC}$ & $\mathrm{RC}$ & $\mathrm{RC}$ & $\mathrm{RC}$ & I & - & - & - & - & - & $\mathrm{I}$ & - & - & - & - & - & - \\
\hline
\end{tabular}

Fuente: Elaboración Propia 


\section{Capítulo 6: Resultados del Proyecto}

En este capítulo se describe la validación, continuidad y factibilidad económica obtenidos con el desarrollo del proyecto. Para la visibilidad de los resultados se aplicó la simulación del proceso Gestionar atención de los CERP y CAM mediante la notación BPMN 2.0 


\section{Validación}

Una vez concluido la etapa de desarrollo se pasó a demostrar que el diseño de la arquitectura cumple con los requisitos y soluciona el problema. Se realizó una simulación utilizando la herramienta Bizagi Modeler con notación BPMN 2.0.

Teniendo la vista de arquitectura de negocio de los procesos CAM y CERP para la mejora, se decidió simular el proceso, considerando la validación por parte del cliente y análisis de tiempo.

Para la simulación se está tomando en cuenta una muestra de 100 personas del proceso As Is, para la mejora, este número es mayor, porque sé supone que habría otro inicio (Evento) del proceso y por ende el proceso empezaría con más personas.

La información de entrada para los procesos actuales fue proporcionada y coordinada con EsSalud, mientras que la información de entrada de la propuesta fue estimada ya aprobada por los usuarios.

\section{Indicadores del CERP:}

- Cantidad de Personas con discapacidad (PCD) que Inician el Proceso: Así podríamos saber si en efecto los cambios están logrando que más gente participe en el proceso. También nos ayudara a saber cuánta gente estaríamos atendiendo.

- Cantidad de Evaluaciones: Así podríamos saber que tan bien está funcionando el control y si en serio se está reevaluando a la gente que no tuvo buenos resultados en su primera evaluación, Además de tener una idea de la demanda en lo que pronosticamos habrá más concurrencia de gente.

- Cantidad de PCD en Rehabilitación Social: Para saber cuántas personas participaran en este proceso y ver si el número de personas con discapacidad aumento.

- Cantidad de PCD en Rehabilitación Para saber cuántas personas participaran en este proceso y ver si el número de personas con discapacidad aumento.

- Pacientes Derivados: Para saber cuántos pacientes de la muestra llega a ser derivada. 
- Tiempo de Atención en la Admisión y Afiliación: Para determinar si las mejoras que se implementan y el sistema tiene un resultado importante.

- Tiempo de Atención de los Pacientes Derivados: Para determinar si las mejoras que se implementan y el sistema tiene un resultado importante.

- Tiempo de Atención de la Evaluación: Para determinar si las mejoras que se implementan y el sistema tiene un resultado importante.

- Tiempo de Atención de la Derivación: Para determinar si las mejoras que se implementan y el sistema tiene un resultado importante.

Indicadores del CAM:

- Cantidad de Adultos Mayores Atendidos: Así podríamos saber si en efecto los cambios están logrando que más gente participe en el proceso. También nos ayudara a saber cuánta gente estaríamos atendiendo.

- Cantidad de Adultos Mayores en los Talleres: Para saber cuántas personas participaran en este proceso y ver si el número de personas con discapacidad aumento.

- Cantidad de Evaluaciones: Así podríamos saber que tan bien está funcionando el control y si en serio se está reevaluando a la gente que no fue reinsertada con éxito social o profesionalmente, Además de tener una idea de la demanda en lo que pronosticamos habrá más concurrencia de gente.

- Pacientes Derivados: Para saber cuántos pacientes de la muestra llega a ser derivada.

- Tiempo de Atención en la Admisión y Afiliación: Para determinar si las mejoras que se implementan y el sistema tiene un resultado importante.

- Tiempo de Atención de los Pacientes Derivados: Para determinar si las mejoras que se implementan y el sistema tiene un resultado importante.

- Tiempo de Atención de la Evaluación: Para determinar si las mejoras que se implementan y el sistema tiene un resultado importante.

- Tiempo de Atención para determinar el plan de Rehabilitación: Para determinar si las mejoras que se implementan y el sistema tiene un resultado importante.

- Tiempo de Atención de la Derivación: Para determinar si las mejoras que se implementan y el sistema tiene un resultado importante. 


\section{Resultado de simulación:}

Tabla 36: Simulación del Proceso Gestionar Atención del CERP

\begin{tabular}{|c|c|c|c|}
\hline Criterio & AS IS & TO BE & Resultado \\
\hline Cantidad de PCD que Inicia el Proceso & 85 & 186 & Aumento $97.65 \%$ \\
\hline Cantidad de Evaluaciones & 85 & 221 & Aumento $160 \%$ \\
\hline Cantidad de PCD en Rehabilitación Social & 72 & 116 & Aumento $61.11 \%$ \\
\hline $\begin{array}{l}\text { Cantidad de PCD en Rehabilitación } \\
\text { Profesional }\end{array}$ & 81 & 205 & $\begin{array}{l}\text { Aumento } \\
153.09 \%\end{array}$ \\
\hline Pacientes Derivados & - & 13 & - \\
\hline $\begin{array}{l}\text { Tiempo de Atención en la Admisión y } \\
\text { Afiliación }\end{array}$ & $50 \mathrm{~min}$ & $18 \mathrm{~min}$ & Disminuyo 64\% \\
\hline $\begin{array}{l}\text { Tiempo de Atención de los Pacientes } \\
\text { Derivados }\end{array}$ & - & $13 \mathrm{~min}$ & - \\
\hline Tiempo de Atención de la Evaluación & $\begin{array}{l}200 \\
\min \end{array}$ & $\begin{array}{l}102 \\
\min \end{array}$ & Disminuyo 49\% \\
\hline Tiempo de Atención de la Derivación & - & $81 \mathrm{~min}$ & - \\
\hline
\end{tabular}

Fuente: Elaboración Propia

Tabla 37: Simulación del Proceso Gestionar Atención del CAM

\begin{tabular}{|l|l|l|l|}
\hline Criterio & AS IS & TO BE & Resultado \\
\hline Cantidad de Adultos Mayores Atendidos & 85 & 353 & $315.29 \%$ \\
\hline $\begin{array}{l}\text { Cantidad de Adultos Mayores en los } \\
\text { Talleres }\end{array}$ & 85 & 435 & $160 \%$ \\
\hline
\end{tabular}




\begin{tabular}{|l|l|l|l|}
\hline Cantidad de Evaluaciones & 85 & 542 & $537.65 \%$ \\
\hline Pacientes Derivados & - & 107 & - \\
\hline $\begin{array}{l}\text { Tiempo de Atención en la Admisión y } \\
\text { Afiliación }\end{array}$ & $53 \mathrm{~min}$ & $21 \mathrm{~min}$ & $\begin{array}{l}\text { Disminuyo } \\
66.04 \%\end{array}$ \\
\hline $\begin{array}{l}\text { Tiempo de Atención de los Pacientes } \\
\text { Derivados }\end{array}$ & - & $18 \mathrm{~min}$ & - \\
\hline $\begin{array}{l}\text { Tiempo de Atención de la Evaluación } \\
\text { Tiempo de Atención para determinar el } \\
\text { plan de Rehabilitación }\end{array}$ & $160 \mathrm{~min}$ & $180 \mathrm{~min}$ & Aumento 12.5\% \\
\hline \begin{tabular}{l} 
Tiempo de Atención de la Derivación \\
\hline
\end{tabular} & - & $85 \mathrm{~min}$ & $\begin{array}{l}\text { Disminuyo } \\
20.83 \%\end{array}$ \\
\hline
\end{tabular}

Fuente: Elaboración Propia

Como se puede visualizar resultados, efectivamente hay un aumenta en la cantidad de personas con discapacidad y adultos mayores que empiezan el proceso como era previsto, además vemos como los tiempos de atención, al tener más actividades automatizadas, es mucho más rápido.

La única desventaja en la mejora es que el tiempo de la evaluación se incrementa un $12.5 \%$ porque hay que registrar varias actividades y mantener los resultados en el sistema.

\section{Metamodelo del Proceso de Prestación Social de EsSalud}

La propuesta de arquitectura empresarial como solución al proceso de prestación social de EsSalud abarca las secciones:

- Arquitectura de Negocio

- Organización

- Comportamiento

- Arquitectura de Sistemas de Información

- Aplicaciones 
- Datos

- Arquitectura de Tecnología

- Servicios

- Tecnología Lógica

- Arquitectura de Realización

- Capacidades 
Ilustración 58: Metamodelo de Arquitectura Empresarial del Proceso de Prestación Social

\begin{tabular}{|l|}
\hline CAPACIDADES \\
\hline G.Atención de \\
CAM
\end{tabular}
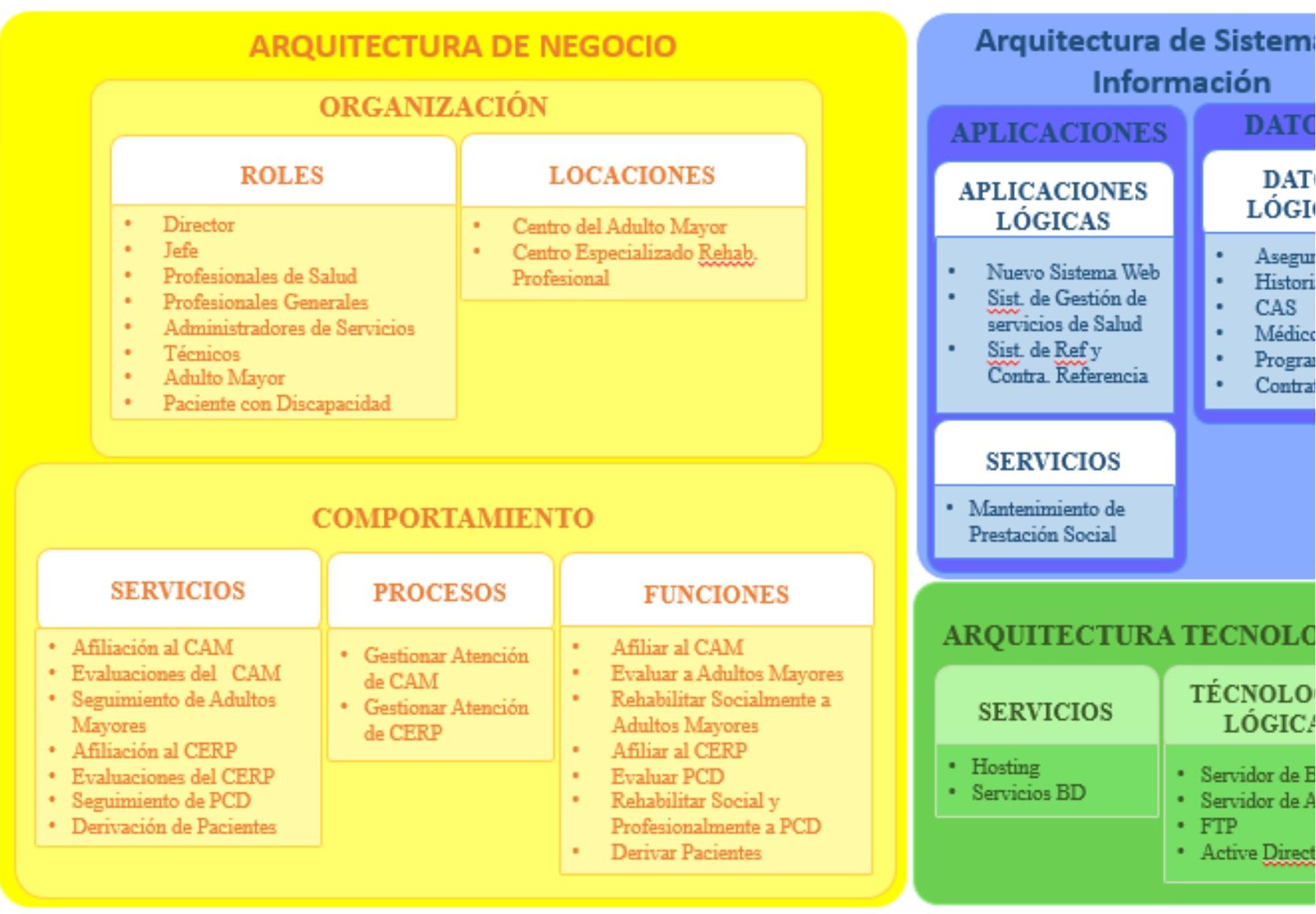

de EsSalud

Fuente: Elaboración Propia 


\section{Continuidad}

El plan de continuidad consiste en medir la efectividad del proceso de atención en el CAM pues este presenta una fuerte inversión. Según la OMS no se puede predecir, pero se puede medir.

Actualmente 1, 465,216 Adultos Mayores asegurados en EsSalud, pero hay 77,952 Adultos Mayores en el CAM. Por tal se realizará tres muestras de 10 mil Adultos Mayores cada una. De las cuales esta muestra será variada entre hombres, mujeres de diferentes edades y clases sociales. Es importante mencionar que el primero grupo debe tener en lo posible la misma distribución demográfica (sexo, edad, clase social, etc.) que el segundo y el tercer grupo.

El primer grupo deben pertenecer al CAM actualmente y lleven al menos un año participando y medir cuanto es el gasto hospitalario que presentan estos asegurados y por lo cual se debe hacer seguimiento de los gastos durante 1 años.

El segundo grupo deben ser adultos mayores que no pertenezca ni hayan pertenecido al CAM y medir también sus gastos hospitalarios y el seguimiento de los gastos durante 1 años.

Con estas cifras podremos saber un gasto aproximado de la población de Adultos Mayores que participan activamente en el CAM y los que no.

El tercer grupo, es el más complicado de obtener, pues deben ser adultos mayores que no pertenezcan ni hayan pertenecido a ningún CAM, pero deben asistir. En este caso se debe hacer un seguimiento de los gastos durante 3 años. A este grupo se le debe medir de la siguiente forma: el primer año, sin participar en el CAM, durante el segundo año empezar a medir las actividades a los adultos mayores As Is tiendo a los centros especializados, este es el año más importante, hay que tener control total sobre las visitas y gastos a los CAS. Por último, una vez los 10 mil Adultos Mayores elegidos estén ya totalmente participativos en los CAM, empezara la medición del tercer año.

Con esto podremos saber cómo cambia la población de no tener un envejecimiento activo a tenerlo, como reducen sus gastos y en qué proporción, incluso avanzando en edad. 
Además de poder determinar en qué momento (mes) de participación en el CAM, empiezan a presentarse las diferencias.

Para este análisis de medición es importante, descartar que no interfieran plagas ni epidemias y eliminar los outsiders. Y por el lado si un adulto mayor se retira del CAM o fallece, debe ser descartado, no reemplazado.

\section{Factibilidad Financiera}

El costo total del proyecto para las mejoras propuesta es el siguiente:

Tabla 38: Costo de Capacitación de la Reestructuración de los Procesos CERP y CAM

\begin{tabular}{|l|l|l|l|l|}
\hline Recurso & Cantidad & Total de Horas & Costo & Costo Total \\
\hline $\begin{array}{l}\text { Arquitecto } \\
\text { Empresarial }\end{array}$ & 1 & 160 & 32 & S/. 5,120.00 \\
\hline Jefe de Proyecto & 1 & 160 & 30 & S/. 4,800.00 \\
\hline Capacitador CAM & 124 & 45 & 25 & S/. 139,500.00 \\
\hline Capacitador CERP & 4 & 45 & 25 & S/. 4,500.00 \\
\hline Capacitador MBPRS & 13 & 45 & 25 & S/. 14,625.00 \\
\hline Total & & & & S/. 168,545.00 \\
\hline
\end{tabular}

Fuente: Elaboración Propia

Tabla 39: Tiempo de Capacitación de los Procesos CERP y CAM

\begin{tabular}{|l|l|}
\hline Actividad & Semanas \\
\hline Plan de Capacitación & 4 \\
\hline Crear Plan de Capacitación & 1 \\
\hline
\end{tabular}




\begin{tabular}{|l|l|}
\hline $\begin{array}{l}\text { Contrataciones de } \\
\text { Capacitadores }\end{array}$ & 4 \\
\hline Capacitaciones & 15 \\
\hline 1er Grupo de Capacitaciones & 3 \\
\hline 2do Grupo de Capacitaciones & 3 \\
\hline 3er Grupo de Capacitaciones & 3 \\
\hline 4to Grupo de Capacitaciones & 3 \\
\hline 5to Grupo de Capacitaciones & 3 \\
\hline Total: & 19 \\
\hline
\end{tabular}

Fuente: Elaboración Propia

Tabla 40: Costo del Desarrollo del Sistema Web

\begin{tabular}{|c|c|c|c|c|}
\hline Recurso & $\begin{array}{l}\text { Cantida } \\
\text { d }\end{array}$ & Costo & Costo Total & $\begin{array}{l}\text { Estimación } \\
\text { Consultora }\end{array}$ \\
\hline $\begin{array}{l}\text { Arquitecto } \\
\text { Empresarial }\end{array}$ & 1 & 32 & S/. 23,040.00 & S/. 23,040.00 \\
\hline Jefe de Proyecto & 1 & 30 & $\mathrm{~S} / .21,600.00$ & $\mathrm{~S} / .21,600.00$ \\
\hline Desarrollador Jr. & 3 & 15 & $\mathrm{~S} / .73,800.00$ & $\mathrm{~S} / .253,380.00$ \\
\hline Desarrollador Sr. & 2 & 45 & $\begin{array}{l}\mathrm{S} / . \\
158,400.00\end{array}$ & $\mathrm{~S} / .181,280.00$ \\
\hline Analista Funcional & 1 & 40 & S/. 22,400.00 & S/. 28,840.00 \\
\hline $\begin{array}{l}\text { Arquitecto de } \\
\text { Software }\end{array}$ & 1 & 50 & S/. 26,000.00 & $\mathrm{S} / .26,780.00$ \\
\hline
\end{tabular}




\begin{tabular}{|c|c|c|c|c|}
\hline Capacitador CAM & 124 & 25 & S/. 27,900.00 & $\mathrm{S} / .27,900.00$ \\
\hline Capacitador CERP & 4 & 25 & $\mathrm{~S} / .900 .00$ & $\mathrm{~S} / .900 .00$ \\
\hline Capacitador MBPRS & 13 & 25 & $\mathrm{~S} / .2,925.00$ & $\mathrm{~S} / .2,925.00$ \\
\hline Servidor WEB & 1 & $\begin{array}{l}23503.6966 \\
7\end{array}$ & $\mathrm{~S} / .23,504.00$ & $\mathrm{~S} / .23,504.00$ \\
\hline Servidor BD & 1 & $\begin{array}{l}11247.6966 \\
7\end{array}$ & S/. 11,248.00 & $\mathrm{S} / .11,248.00$ \\
\hline Servidor FTP & 1 & $\begin{array}{l}13578.6966 \\
7\end{array}$ & S/. 13,579.00 & $\mathrm{S} / .13,579.00$ \\
\hline Total & & & $\begin{array}{l}\text { S/. } \\
405,296.00\end{array}$ & $\mathrm{~S} / .614,976.00$ \\
\hline
\end{tabular}

Fuente: Elaboración Propia

Tabla 41: Tiempo de Gestión del Desarrollo del Sistema Web

\begin{tabular}{|l|l|}
\hline Actividad & Semanas \\
\hline Pre Venta & 6 \\
\hline Búsqueda de Proveedores & 3 \\
\hline Estimaciones de Costo/Tiempo & 1 \\
\hline Selección de Proveedor & 2 \\
\hline Estimación & 2 \\
\hline Estimación Final & 2 \\
\hline
\end{tabular}




\begin{tabular}{|l|l|}
\hline Reunión Kick Off & 1 \\
\hline Análisis & 6 \\
\hline Reunión de Análisis & 1 \\
\hline Definición de Requerimientos & 1 \\
\hline Creación de Casos de Uso de & 1 \\
\hline Negocio & \\
\hline Sreación de Casos de Uso & 1 \\
\hline Documento de Análisis & 2 \\
\hline Diseño & 5 \\
\hline Diseño de Arquitectura & 2 \\
\hline Diseño de Prototipos & 2 \\
\hline Documento de Diseño & 1 \\
\hline Desarrollo & 30 \\
\hline Pruebas Unitarias & 3 \\
\hline Preparación de Ambiente & 1 \\
\hline Correcciones de Bugs & 3 \\
\hline
\end{tabular}




\begin{tabular}{|l|l|}
\hline Pase a Producción & 1 \\
\hline Despliegue en Red & 1 \\
\hline Plan de Capacitación & 4 \\
\hline Crear Plan de Capacitación & 1 \\
\hline Contrataciones de Capacitadores & 4 \\
\hline Capacitaciones & 5 \\
\hline 1er Grupo de Capacitaciones & 1 \\
\hline 2do Grupo de Capacitaciones & 1 \\
\hline 3er Grupo de Capacitaciones & 1 \\
\hline 4to Grupo de Capacitaciones & 1 \\
\hline 5to Grupo de Capacitaciones & 1 \\
\hline Total: & 67 \\
\hline
\end{tabular}

Fuente: Elaboración Propia

Tabla 42: Tiempo del Desarrollo del Sistema Web

\begin{tabular}{|l|l|}
\hline Actividad & Semanas \\
\hline Preparación de Ambiente de Desarrollo & 2 \\
\hline Preparación de Ambiente de Desarrollo & 1 \\
\hline Instalación de Software Necesario & 1 \\
\hline Base de Datos & 2 \\
\hline Diseño de Base de Datos & 1 \\
\hline
\end{tabular}




\begin{tabular}{|c|c|}
\hline Implementación de Base de Datos & 1 \\
\hline Implementación de Active Directory & 1 \\
\hline Llenar Tablas & 1 \\
\hline Plantilla Web & 2 \\
\hline Creación de Web Service & 1 \\
\hline Creación de Web Site & 1 \\
\hline Creación de Login & 1 \\
\hline Módulo de Admisión & 3 \\
\hline Creación de Procedimientos & 1 \\
\hline Creación de Web Site & 2 \\
\hline Creación de Web Service & 3 \\
\hline Módulo de Historia Clínica & 4 \\
\hline Creación de Procedimientos & 1 \\
\hline Creación de Web Site & 3 \\
\hline Creación de Web Service & 4 \\
\hline Módulo de Registro de Talleres & 3 \\
\hline Creación de Procedimientos & 1 \\
\hline Creación de Web Site & 2 \\
\hline Creación de Web Service & 3 \\
\hline Módulo de Evaluación Medica & 4 \\
\hline
\end{tabular}




\begin{tabular}{|l|l|}
\hline Creación de Procedimientos & 1 \\
\hline Creación de Web Site & 3 \\
\hline Creación de Web Service & 4 \\
\hline Módulo de Evaluación Psicológica & 4 \\
\hline Creación de Procedimientos & 1 \\
\hline Creación de Web Site & 3 \\
\hline Creación de Web Service & 4 \\
\hline Módulo de Registro de Talleres & 3 \\
\hline Creación de Procedimientos & 1 \\
\hline Creación de Web Site & 3 \\
\hline Creación de Web Service & 4 \\
\hline Integración & 1 \\
\hline Integración & 3 \\
\hline Pruebas de Integración & 1 \\
\hline Integración Final & 30 \\
\hline Total & 1 \\
\hline
\end{tabular}

Fuente: Elaboración Propia

Tabla 43: Costo del Desarrollo del Servicio de Derivación

\begin{tabular}{|l|l|ll|l|l|l|}
\hline Recurso & Cantida & Total de & Cost & Costo Total & $\begin{array}{l}\text { Estimación } \\
\text { Consultora }\end{array}$ \\
\hline
\end{tabular}




\begin{tabular}{|c|c|c|c|c|c|}
\hline $\begin{array}{l}\text { Arquitecto } \\
\text { Empresarial }\end{array}$ & 1 & 360 & 32 & $\begin{array}{l}\mathrm{S} / . \\
11,520.00\end{array}$ & $\mathrm{~S} / .11,520.00$ \\
\hline Jefe de Proyecto & 1 & 360 & 30 & $\begin{array}{l}\text { S/. } \\
10,800.00\end{array}$ & $\mathrm{~S} / .10,800.00$ \\
\hline Capacitador CAM & 124 & 9 & 25 & $\begin{array}{l}\text { S/. } \\
27,900.00\end{array}$ & $\mathrm{~S} / .27,900.00$ \\
\hline Capacitador CERP & 4 & 9 & 25 & $\mathrm{~S} / .900 .00$ & $\mathrm{~S} / .900 .00$ \\
\hline $\begin{array}{l}\text { Capacitador } \\
\text { MBPRS }\end{array}$ & 13 & 9 & 25 & $\mathrm{~S} / .2,925.00$ & S/. 2,925.00 \\
\hline Desarrollador Jr. & 2 & 600 & 15 & $\begin{array}{l}\text { S/. } \\
18,000.00\end{array}$ & $\mathrm{~S} / .61,800.00$ \\
\hline Desarrollador Sr. & 1 & 760 & 45 & $\begin{array}{l}\text { S/. } \\
34,200.00\end{array}$ & S/. 39,140.00 \\
\hline Analista Funcional & 1 & 200 & 40 & $\mathrm{~S} / .8,000.00$ & $\mathrm{~S} / .10,300.00$ \\
\hline Total & & & & $\begin{array}{l}\text { S/. } \\
114,245.00\end{array}$ & S/. $165,285.00$ \\
\hline
\end{tabular}

Fuente: Elaboración Propia

Tabla 44: Tiempo de Gestión del Desarrollo del Servicio de Derivación

\begin{tabular}{|l|l|l|l|l|l|}
\hline Recurso & $\begin{array}{l}\text { Cantida } \\
\mathrm{d}\end{array}$ & $\begin{array}{l}\text { Total de } \\
\text { Horas }\end{array}$ & Costo & Costo Total & $\begin{array}{l}\text { Estimación } \\
\text { Consultora }\end{array}$ \\
\hline $\begin{array}{l}\text { Arquitecto } \\
\text { Empresarial }\end{array}$ & 1 & 360 & 32 & S/. 11,520.00 & S/. 11,520.00 \\
\hline $\begin{array}{l}\text { Jefe de } \\
\text { Proyecto }\end{array}$ & 1 & 360 & 30 & S/. 10,800.00 & S/. 10,800.00 \\
\hline
\end{tabular}




\begin{tabular}{|l|l|l|l|l|l|}
\hline $\begin{array}{l}\text { Capacitador } \\
\text { CAM }\end{array}$ & 124 & 9 & 25 & $\mathrm{~S} / .27,900.00$ & $\mathrm{~S} / .27,900.00$ \\
\hline $\begin{array}{l}\text { Capacitador } \\
\text { CERP }\end{array}$ & 4 & 9 & 25 & $\mathrm{~S} / .900 .00$ & $\mathrm{~S} / .900 .00$ \\
\hline $\begin{array}{l}\text { Capacitador } \\
\text { MBPRS }\end{array}$ & 13 & 9 & 25 & $\mathrm{~S} / .2,925.00$ & S/. 2,925.00 \\
\hline $\begin{array}{l}\text { Desarrollador } \\
\text { Jr. }\end{array}$ & 2 & 600 & 15 & $\mathrm{~S} / .18,000.00$ & $\mathrm{~S} / .61,800.00$ \\
\hline $\begin{array}{l}\text { Desarrollador } \\
\text { Sr. }\end{array}$ & 1 & 760 & 45 & S/. 34,200.00 & S/. 39, 140.00 \\
\hline $\begin{array}{l}\text { Analista } \\
\text { Funcional }\end{array}$ & 1 & 200 & 40 & S/. 8,000.00 & S/. 10,300.00 \\
\hline \begin{tabular}{l} 
Total \\
\hline
\end{tabular} & & & S/. 114,245.00 & S/. 165,285.00 \\
\hline
\end{tabular}

Fuente: Elaboración Propia

Tabla 45: Tiempo de Desarrollo del Servicio de Derivación

\begin{tabular}{|l|l|}
\hline Actividad & Semanas \\
\hline Preparación de Ambiente de Desarrollo & 2 \\
\hline Preparación de Ambiente de Desarrollo & 1 \\
\hline Instalación de Software Necesario & 1 \\
\hline Base de Datos & \\
\hline Modificaciones en Base de Datos & 2 \\
\hline Modificaciones & 2 \\
\hline
\end{tabular}




\begin{tabular}{|l|l|}
\hline Modificación de Web Service & 1 \\
\hline Modificación de Web Site & 1 \\
\hline Integración & 3 \\
\hline Integración & 1 \\
\hline Pruebas de Integración & 1 \\
\hline Integración Final & 1 \\
\hline Total & 9 \\
\hline
\end{tabular}

Fuente: Elaboración Propia

Tabla 46: Costo de Infraestructura de la Solución

\begin{tabular}{|l|l|l|l|}
\hline Servidor WEB & Cantidad / GB & Costo unitario & Total \\
\hline Servidor & 1 & S/. 13,945.00 & S/. 13,945.00 \\
\hline Almacenamiento & $500 \mathrm{~GB}$ & $\mathrm{~S} / .1,056.00$ & $\mathrm{~S} / .528 .00$ \\
\hline RAM & $32 \mathrm{~GB}$ & $\mathrm{~S} / .485 .00$ & $\mathrm{~S} / .1,940.00$ \\
\hline Cores & 12 núcleos & $\mathrm{S} / .704 .00$ & $\mathrm{~S} / .2,112.00$ \\
\hline licencia Linux & 1 & $\mathrm{~S} / .862 .03$ & $\mathrm{~S} / .862 .03$ \\
\hline Soporte Linux & 1 & $\mathrm{~S} / .4,116.67$ & $\mathrm{~S} / .4,116.67$ \\
\hline & & & $\mathrm{S} / .23,503.70$ \\
\hline Servidor base de datos & Cantidad & costo unitario & costo total \\
\hline Servidor & 1 & S/. 5,299.00 & S/. 5,299.00 \\
\hline Almacenamiento & $100 \mathrm{~GB}$ & 105,6 & 105,6 \\
\hline
\end{tabular}




\begin{tabular}{|c|c|c|c|}
\hline RAM & $16 \mathrm{~GB}$ & S/. 485.00 & S/. 970.00 \\
\hline Cores & 6 Cores & S/. 704.00 & 1196,8 \\
\hline licencia Linux & 1 & $\mathrm{~S} / .862 .03$ & S/. 862.03 \\
\hline Soporte Linux & 1 & S/. 4,116.67 & S/. 4,116.67 \\
\hline & & & S/. 11,247.70 \\
\hline Servidor FTP & Cantidad / GB & Costo unitario & Total \\
\hline Servidor & 1 & S/. 5,299.00 & S/. 5,299.00 \\
\hline Almacenamiento & $2 \mathrm{~TB}$ & $\mathrm{~S} / .1,056.00$ & $\mathrm{~S} / .2,112.00$ \\
\hline RAM & $8 \mathrm{~GB}$ & $\mathrm{~S} / .485 .00$ & S/. 485.00 \\
\hline Cores & 4 núcleos & S/. 704.00 & S/. 704.00 \\
\hline licencia Linux & 1 & $\mathrm{~S} / .862 .03$ & 862.03 \\
\hline Soporte Linux & 1 & S/. 4,116.67 & S/. 4,116.67 \\
\hline & & & S/. $13,578.70$ \\
\hline Leasing PC & 705 & $\$ 784,242.00$ & S/. $1,937,077.74$ \\
\hline gabinete servidor & 1 & S/. 680.00 & S/. 680.00 \\
\hline & & Total & S/. $1,986,087.83$ \\
\hline
\end{tabular}

Fuente: Elaboración Propia

Tabla 47: Tiempo Total de la Solución

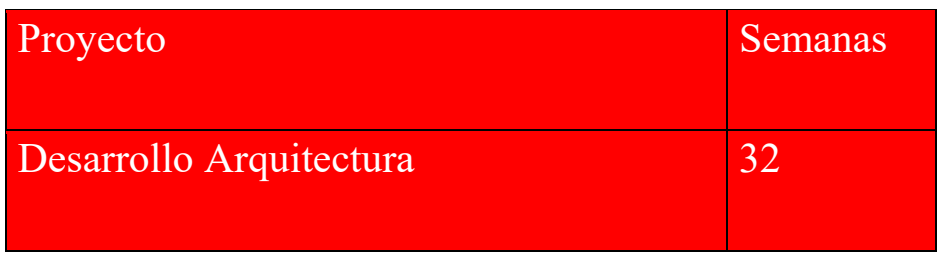




\begin{tabular}{|l|l|}
\hline Desarrollo Arquitectura & 32 \\
\hline Proyectos & 118 \\
\hline Estandarización de Actividades & 19 \\
\hline Implementación del Sistema Web & 67 \\
\hline $\begin{array}{l}\text { Integración de Referencias (Derivar } \\
\text { Pacientes) }\end{array}$ & 32 \\
\hline Total: & 150 \\
\hline
\end{tabular}

Fuente: Elaboración Propia

Tabla 48: Costo Total del Proyecto

\begin{tabular}{|l|l|l|}
\hline Proyecto & Costo Total & Costo Consultora \\
\hline Desarrollo Arquitectura & S/. 23,808.00 & S/. 23,808.00 \\
\hline Arquitecto Empresarial & S/. 12,288.00 & S/. 12,288.00 \\
\hline Jefe de Proyecto & S/. 11,520.00 & S/. 11,520.00 \\
\hline Proyectos & S/. 688,086.00 & S/. 948,806.00 \\
\hline Estandarización de Actividades & S/. 168,545.00 & S/. 168,545.00 \\
\hline Implementación del Sistema Web & S/. 405,296.00 & S/. 614,976.00 \\
\hline Integración de Referencias (Derivar Pacientes) & S/. 114,245.00 & S/. 165,285.00 \\
\hline Leasing & S/. 40,356.00 & S/. 40,356.00 \\
\hline Leasing Mensual & S/. 40,355.79 & S/. 40,355.79 \\
\hline Total & S/. 752,250.00 & S/. 1,012,970.00 \\
\hline
\end{tabular}

Fuente: Elaboración Propia 
Tabla 49: Ahorro en Tiempo de Actividades del CERP

\begin{tabular}{|l|l|l|}
\hline Actividad CERP & Tiempo (min) & Precio \\
\hline Tiempo de Atención en la Admisión y Afiliación & 60 & S/. 15.00 \\
\hline Tiempo de Atención en la Admisión y Afiliación (As Is) & 50 & S/. 12.50 \\
\hline Tiempo de Atención en la Admisión y Afiliación (To Be) & 18 & S/. 4.50 \\
\hline Ahorro & & S/. 8.00 \\
\hline Tiempo de Atención de la Evaluación & 60 & S/. 40.00 \\
\hline Tiempo de Atención de la Evaluación (As Is) & 200 & S/. 133.33 \\
\hline Tiempo de Atención de la Evaluación (To Be) & 102 & S/. 68.00 \\
\hline Ahorro & & S/. 65.33 \\
\hline Ahorro Total & S/. 73.33 \\
\hline
\end{tabular}

Fuente: Elaboración Propia

Tabla 50: Ahorro en Tiempo de Actividades del CAM

\begin{tabular}{|l|l|l|}
\hline Actividad CAM & Tiempo (min) & Precio \\
\hline Tiempo de Atención en la Admisión y Afiliación & 60 & $\mathrm{~S} / .15 .00$ \\
\hline Tiempo de Atención en la Admisión y Afiliación (As Is) & 53 & $\mathrm{~S} / .13 .25$ \\
\hline Tiempo de Atención en la Admisión y Afiliación (To Be) & 21 & $\mathrm{~S} / .5 .25$ \\
\hline Ahorro & & $\mathrm{S} / .8 .00$ \\
\hline Tiempo de Atención de la Evaluación & 60 & $\mathrm{~S} / .40 .00$ \\
\hline
\end{tabular}




\begin{tabular}{|l|l|l|l|}
\hline Tiempo de Atención de la Evaluación (As Is) & 160 & S/. 106.67 \\
\hline Tiempo de Atención de la Evaluación (To Be) & 180 & S/. 120.00 \\
\hline Ahorro & & S/. -13.33 \\
\hline $\begin{array}{l}\text { Tiempo de Atención para determinar el plan de } \\
\text { Rehabilitación }\end{array}$ & 60 & S/. 40.00 \\
\hline $\begin{array}{l}\text { Tiempo de Atención para determinar el plan de } \\
\text { Rehabilitación (As Is) }\end{array}$ & 120 & S/. 80.00 \\
\hline $\begin{array}{l}\text { Tiempo de Atención para determinar el plan de } \\
\text { Rehabilitación (To Be) }\end{array}$ & S/. 63.33 \\
\hline $\begin{array}{l}\text { Ahorro } \\
\text { Ahorro Total }\end{array}$ & S/. 16.67 \\
\hline
\end{tabular}

Fuente: Elaboración Propia

Tabla 51: Ahorro Total de los Procesos

\begin{tabular}{|l|l|l|}
\hline Año & Personas Atendidas & Total \\
\hline CAM Año 1 & 0 & S/. - \\
\hline CAM Año 2 & 6062 & S/. - \\
\hline CAM Año 3 & 24248 & S/. 274,810.67 \\
\hline CERP Año 1 & 0 & S/. - \\
\hline CERP Año 2 & 500 & S/. - \\
\hline CERP Año 3 & 1000 & S/. 73,333.33 \\
\hline
\end{tabular}




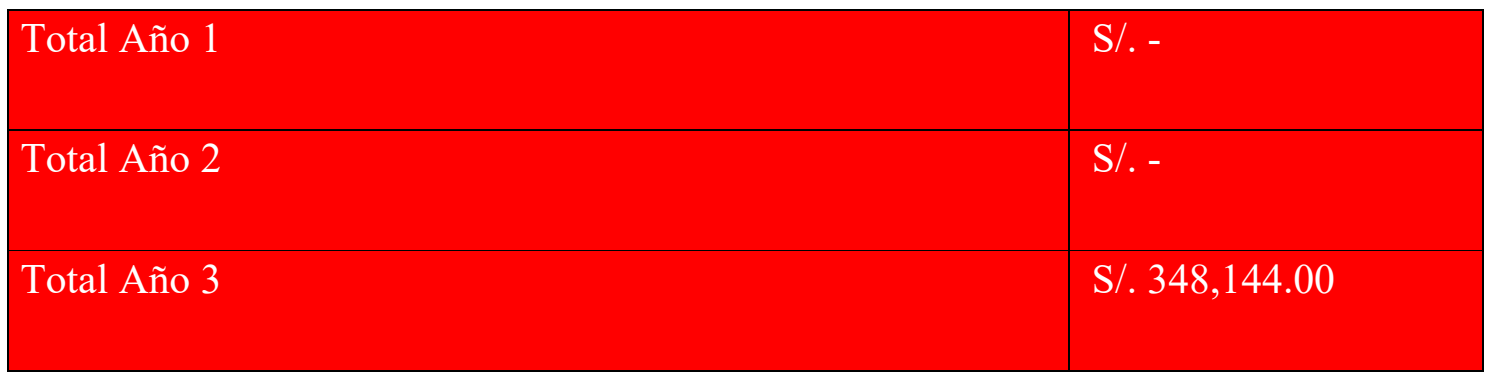

Fuente: Elaboración Propia

Tabla 52: Gasto de Salud del CAM

\begin{tabular}{|c|c|c|c|}
\hline \multirow{5}{*}{ Año 1} & Gasto & Porcentaje & Gasto \\
\hline & Gastos de Salud & $100 \%$ & $\begin{array}{l}\text { S/. } \\
10,611,357,423.00\end{array}$ \\
\hline & $\begin{array}{lll}\text { Gastos de } & \text { Adulto } \\
\text { Mayor } & & \end{array}$ & $21 \%$ & $\begin{array}{l}\text { S/. } \\
2,228,385,058.83\end{array}$ \\
\hline & $\begin{array}{l}\text { Gasto Adulto Mayor } \\
\text { To Be }\end{array}$ & $21 \%$ & $\begin{array}{l}\text { S/. } \\
2,228,385,058.83\end{array}$ \\
\hline & Ahorro & & $\mathrm{S} / .-$ \\
\hline \multirow{5}{*}{ Año 2} & Gasto & Porcentaje & Gasto \\
\hline & Gastos de Salud & $100 \%$ & $\begin{array}{l}\text { S/. } \\
10,611,357,423.00\end{array}$ \\
\hline & $\begin{array}{lll}\text { Gastos de } & \text { Adulto } \\
\text { Mayor } & & \end{array}$ & $21 \%$ & $\begin{array}{l}\mathrm{S} / . \\
2,228,385,058.83\end{array}$ \\
\hline & $\begin{array}{l}\text { Gasto Adulto Mayor } \\
\text { To Be }\end{array}$ & $21 \%$ & $\begin{array}{l}\mathrm{S} / . \\
2,228,385,058.83\end{array}$ \\
\hline & Ahorro & & $\mathrm{S} / .-$ \\
\hline Año 3 & Gasto & Porcentaje & Gasto \\
\hline
\end{tabular}




\begin{tabular}{|l|l|l|l|}
\hline \multicolumn{2}{|l|}{ Gastos de Salud } & $100 \%$ & $\begin{array}{l}\mathrm{S} / . \\
10,611,357,423.00\end{array}$ \\
\cline { 2 - 4 } & $\begin{array}{l}\text { Gastos de Adulto } \\
\text { Mayor }\end{array}$ & $21.00 \%$ & $\begin{array}{l}\mathrm{S} / . \\
2,228,385,058.83\end{array}$ \\
\cline { 2 - 4 } & $\begin{array}{l}\text { Gasto Adulto Mayor } \\
\text { To Be }\end{array}$ & $20.93 \%$ & $\mathrm{~S} /$. \\
\hline & Ahorro & $2,221,009,507.25$ \\
\hline
\end{tabular}

Fuente: Elaboración Propia

Tabla 53: Mejora en Atención de los Asegurados en el CAM

\begin{tabular}{|l|l|l|l|l|}
\hline Año & $\begin{array}{l}\text { Personas } \\
\text { Atendidas }\end{array}$ & Total Atención & $\begin{array}{l}\text { Porcentaje Atendido } \\
\text { (Total:1465216) }\end{array}$ & $\begin{array}{l}\text { Disminución de } \\
\text { Gasto Total }\end{array}$ \\
\hline $\begin{array}{l}\text { CAM Año } \\
1\end{array}$ & 0 & 77952 & $5.32 \%$ & $0.00 \%$ \\
\hline $\begin{array}{l}\text { CAM Año } \\
2\end{array}$ & 0 & 77952 & $5.32 \%$ & $0.00 \%$ \\
\hline $\begin{array}{l}\text { CAM Año } \\
3\end{array}$ & 24248 & 102200 & $6.98 \%$ & $0.07 \%$ \\
\hline
\end{tabular}

Fuente: Elaboración Propia

Tabla 54: Flujo de Costos y Beneficios del ROI

Ahorros logísticos(Años) 


\begin{tabular}{|c|c|c|c|c|c|}
\hline & \multirow[b]{2}{*}{ Detalle } & 1 & 2 & 3 & \\
\hline & & 2018 & 2019 & 2020 & \\
\hline Flujo de Costos & \multirow{4}{*}{$\begin{array}{l}\text { Inicio: } \\
2018\end{array}$} & $\begin{array}{l}\text { S/. } \\
807,329.00\end{array}$ & $\begin{array}{l}\mathrm{S} / . \\
649,557.00\end{array}$ & $\begin{array}{l}\text { S/. } \\
484,272.00\end{array}$ & $\begin{array}{l}\text { S/. } \\
1,941,158.00\end{array}$ \\
\hline $\begin{array}{ll}\text { Flujo } & \text { de } \\
\text { Beneficios } & \end{array}$ & & $\mathrm{S} / .$. & $\mathrm{S} / .-$ & $\begin{array}{l}\text { S/. } \\
7,723,695.58\end{array}$ & $\begin{array}{l}\mathrm{S} / . \\
7,723,695.58\end{array}$ \\
\hline Flujo Neto & & S/. $-807,329$ & S/. - 649,557 & $\mathrm{~S} / .7,239,424$ & \\
\hline $\begin{array}{l}\text { FLUJO } \\
\text { ACUMULADO }\end{array}$ & & $\begin{array}{l}\text { S/. } \\
807,329.00\end{array}$ & $\begin{array}{l}\text { S/. } \\
1,456,886.00\end{array}$ & $\begin{array}{l}\text { S/. } \\
5,782,537.58\end{array}$ & \\
\hline
\end{tabular}

Fuente: Elaboración Propia

Tabla 55: Tabla de Resultados del ROI

\begin{tabular}{|l|l|}
\hline COK (Costo de Oportunidad) & $60 \%$ \\
\hline VAN & S/. 338,076 \\
\hline TIR & $92.2 \%$ \\
\hline ROI & $298 \%$ \\
\hline $\begin{array}{l}\text { Periodo de } \\
\text { recuperación(Meses) }\end{array}$ & 3.00 \\
\hline Calculo Beneficio/Costo & $398 \%$ \\
\hline
\end{tabular}

Fuente: Elaboración Propia 


\section{Capítulo 7: Gestión del Proyecto}

En este capítulo se describen las actividades llevadas a cabo para la correcta gestión del proyecto de arquitectura empresarial para el macro proceso de prestación social de EsSalud. Asimismo, cada fase tales como: Iniciación, planificación, ejecución, seguimiento, finalizando con control y cierre. Para la realización del proyecto se realizó acciones e hitos para cumplir con la entrega de este en el plazo establecido. Para la gestión de proyecto se aplicó el PMBOK con las áreas conocimiento, habilidades, herramientas y técnicas, para alcanzar los objetivos del proyecto. 


\section{Producto Final}

El producto final del presente proyecto es brindar una propuesta de metamodelo de una arquitectura empresarial de negocios, aplicaciones, datos y tecnológico para la automatización del proceso de prestación social de EsSalud mediante el Framework TOGAF 9.1 con la metodología ADM y la notación Archimate. El proyecto se estará desarrollando en 2 ciclos académicos de la UPC (2016-02 y 2017-01), en el primer ciclo se definirá el alcance, herramientas, y se obtendrá toda la información relevante al proceso, mientras que en el segundo ciclo se diseñará y validará la propuesta de mejora en los 4 dominios y se realizará un plan de continuidad para el proyecto.

Para llevar a cabo el proyecto de una manera exitosa, se realizará lo siguiente:

Tabla 56: Actividades del Proyecto

\begin{tabular}{|l|l|l|l|}
\hline \multicolumn{2}{|l|}{ Actividad } & Estado & Comentario \\
\hline 1 & $\begin{array}{l}\text { Documentos de gestión de } \\
\text { proyecto basados en la guía } \\
\text { PMBOK en ambas etapas del } \\
\text { proyecto. }\end{array}$ & Cumplido & $\begin{array}{l}\text { Se realizó con normalidad y } \\
\text { subsanando los errores observados } \\
\text { por parte del jurado (Presentación } \\
\text { parcial). }\end{array}$ \\
\hline 2 & $\begin{array}{l}\text { pocumentación de la fase } \\
\text { preliminar del ADM. }\end{array}$ & $\begin{array}{l}\text { Entregables detallado en el } \\
\text { Project chárter adjunto }\end{array}$ & $\begin{array}{l}\text { Cumplido } \\
\text { Se realizó con normalidad y valido } \\
\text { con el cliente }\end{array}$ \\
\hline 3 & $\begin{array}{l}\text { Documentación de la fase A del } \\
\text { ADM. Entregables detallado en } \\
\text { el Project chárter adjunto. }\end{array}$ & Cumplido & $\begin{array}{l}\text { Se realizó con normalidad y valido } \\
\text { con el cliente }\end{array}$ \\
\hline $\begin{array}{l}\text { ADM. Entregables detallado en } \\
\text { el Project chárter adjunto }\end{array}$ & Cumplido & $\begin{array}{l}\text { Se está acabando los documentos } \\
\text { con diagramado previsto en el } \\
\text { plan de trabajo. }\end{array}$ \\
\hline
\end{tabular}




\begin{tabular}{|l|l|l|l|}
\hline 5 & $\begin{array}{l}\text { Documentación de la fase C del } \\
\text { ADM. Entregables detallado en } \\
\text { el Project chárter adjunto }\end{array}$ & Cumplido & Se realizará en el 2017 - 1 \\
\hline 6 & $\begin{array}{l}\text { Documentación de la fase D del } \\
\text { ADM. Entregables detallado en } \\
\text { el Project chárter adjunto. }\end{array}$ & Cumplido & Se realizará en el 2017 - 1 \\
\hline 7 & $\begin{array}{l}\text { Búsqueda y análisis de papers } \\
\text { con nivel de impacto y } \\
\text { contemporáneos que sustenten } \\
\text { el proyecto mencionado. }\end{array}$ & Cumplido & $\begin{array}{l}\text { validado por el profesor gerente de } \\
\text { IT consulting. }\end{array}$ \\
\hline 8 & $\begin{array}{l}\text { Diagramación del CERP y } \\
\text { CAM (As Is y To Be) }\end{array}$ & Cumplido & $\begin{array}{l}\text { Se realizó con normalidad y } \\
\text { validado por el cliente. }\end{array}$ \\
\hline 9 & $\begin{array}{l}\text { Búsqueda de modelos de } \\
\text { referencia }\end{array}$ & $\begin{array}{l}\text { Elaboración de plan de } \\
\text { continuidad }\end{array}$ & Pendiente \\
Cumplido & $\begin{array}{l}\text { Se realizará en el 2017 - 1 realizó con normalidad y } \\
\text { validado por el cliente. }\end{array}$ \\
\hline
\end{tabular}

Fuente: Elaboración Propia

\section{Gestión del Tiempo}

La lista de las actividades planificadas en el primer periodo del proyecto sí se llegó a cumplir y puede ser visualizado en el plan de trabajo bajo una plantilla definida por la empresa IT Consulting. Cabe mencionar que se eliminaron algunos artefactos que no tenían alto impacto en la arquitectura previa validación del cliente. Además, el plan detalla las actividades y el porcentaje de avance de las mismas. También se cuenta con un cronograma del proyecto donde se puede visualizar las fechas y tiempos estimados de las actividades establecidas para los hitos del mismo.

A continuación, se muestra una tabla donde se detalla el porcentaje avanzado del proyecto.

Tabla 57 Primera Etapa del Proyecto: 


\begin{tabular}{|c|c|c|c|}
\hline Semana & Descripción de Actividades & $\begin{array}{l}\text { Porcentaje } \\
\text { de Avance } \\
(\%)\end{array}$ & Entregables \\
\hline 1 & Reunión con el Profesor Gerente & 100 & Project Charter \\
\hline 1 & Reunión con el Cliente & 100 & Project Charter \\
\hline 1 & Definir el Alcance & 100 & Project Charter \\
\hline 2 & $\begin{array}{llll}\text { Definir } & \text { los } & \text { Entregables } & \text { de } \\
\text { TOGAF(ADM) } & & \end{array}$ & 100 & $\begin{array}{l}\text { Project Charter / Lista de } \\
\text { Entregables }\end{array}$ \\
\hline 2 & $\begin{array}{l}\text { Validación del Charter con el } \\
\text { Profesor Gerente (Alcance) }\end{array}$ & 100 & Project Charter \\
\hline 2 & $\begin{array}{l}\text { Validación con el Cliente del } \\
\text { Alcance y entregables }\end{array}$ & 100 & $\begin{array}{l}\text { Project Charter / Lista de } \\
\text { Entregables }\end{array}$ \\
\hline 2 & $\begin{array}{l}\text { Validación del Charter con el } \\
\text { Profesor Gerente (Entregables) }\end{array}$ & 100 & $\begin{array}{l}\text { Project Charter / Lista de } \\
\text { Entregables }\end{array}$ \\
\hline 2 & Elaboración del Plan de Trabajo & 100 & Plan de Trabajo \\
\hline 2 & Presentación del Project Charter & 100 & Project Charter \\
\hline 2 & Presentación del Plan de Trabajo & 100 & Plan de Trabajo \\
\hline 3 & Aprobación del Project Charter & 100 & Project Charter \\
\hline 3 & $\begin{array}{llll}\text { Acuerdo de } & \text { Entregables } & \text { con el } \\
\text { representante } & \text { del comité } & \text { (Jimmy } \\
\text { Armas) } & & & \\
\end{array}$ & 100 & $\begin{array}{l}\text { Project Charter / Lista de } \\
\text { Entregables }\end{array}$ \\
\hline 3 & $\begin{array}{l}\text { Elaborar el Organizational Model for } \\
\text { Enterprise Architecture }\end{array}$ & 100 & $\begin{array}{l}\text { Organizational Model for } \\
\text { Enterprise Architecture }\end{array}$ \\
\hline 3 & Elaborar el Principles catalog & 100 & Principles catalog \\
\hline
\end{tabular}




\begin{tabular}{|c|c|c|c|}
\hline 3 & Elaboración de encuestas a usuarios & 100 & Encuestas a Usuarios \\
\hline 3 & Diagrama de Gantt del Proyecto & 100 & $\begin{array}{l}\text { Diagrama de Gantt del } \\
\text { Proyecto (MS Project) }\end{array}$ \\
\hline 3 & Iniciar los documentos de Gestión & 100 & Documentos de Gestión \\
\hline 3 & Iniciar el Architecture Statement & 100 & Architecture Statement \\
\hline 3 & Iniciar el Architecture Vision & 100 & Architecture Vision \\
\hline 4 & Empezar el Capítulo 1 de la Memoria & 100 & Capítulo 1 Memoria \\
\hline 4 & $\begin{array}{l}\text { Entrega de documentos para la } \\
\text { primera revisión al comité }\end{array}$ & 100 & Documentos de Gestión \\
\hline 4 & Terminar el Architecture Statement & 100 & Architecture Statement \\
\hline 4 & Empezar Artefactos de Fase A & 100 & Value Chain diagram \\
\hline 4 & Primera Revisión de QS & 100 & $\begin{array}{l}\text { Project } \\
\text { Documento de Alcance, } \\
\text { Gantt, EDT, Architecture } \\
\text { Statement, Organizational } \\
\text { Model for Enterprise } \\
\text { Architecture, Principles } \\
\text { catalog }\end{array}$ \\
\hline 5 & Exposición con el comité & 100 & $\begin{array}{l}\text { Todos los entregables hasta } \\
\text { ahora }\end{array}$ \\
\hline 5 & Terminar los documentos de gestión & 100 & Documentos de Gestión \\
\hline 5 & Cerrar las observaciones de QS & 100 & $\begin{array}{l}\text { Project Charter, } \\
\text { Documento de Alcance, } \\
\text { Gantt, EDT, Architecture } \\
\text { Statement. }\end{array}$ \\
\hline
\end{tabular}




\begin{tabular}{|c|c|c|c|}
\hline 6 & Validar la Fase A con el cliente & 100 & $\begin{array}{l}\text { Todos los artefactos y } \\
\text { Entregables de la Fase A }\end{array}$ \\
\hline 6 & Segunda Revisión de QS & 100 & $\begin{array}{l}\text { Documentos de Gestión, } \\
\text { Architecture Vision }\end{array}$ \\
\hline 6 & Levantar observaciones de la Fase A & 100 & Documentos de la Fase A \\
\hline 6 & Entregar el Capítulo 1 de Memoria & 100 & Capítulo 1 Memoria \\
\hline 7 & Iniciar los diagramas & 100 & Diagramas de 4 Dominios \\
\hline 7 & Empezar el Capítulo 3 de la Memoria & 100 & Capítulo 3 Memoria \\
\hline 8 & Entregar el capítulo 3 & 100 & Capítulo 3 Memoria \\
\hline 8 & Empezar el capítulo 4 memoria & 100 & Capítulo 4 de la Memoria \\
\hline 8 & Validación de Diagramados As Is & 100 & Diagramas de 4 Dominios \\
\hline 8 & Empezar Diagramado To Be & 100 & Diagramas de 4 Dominios \\
\hline 9 & Realizar el artefacto & 100 & $\begin{array}{l}\text { Business Service/Function } \\
\text { catalog }\end{array}$ \\
\hline 10 & Entrega del capítulo 4 de la Memoria & 100 & Capítulo 4 de la Memoria \\
\hline 10 & Validar los diagramas con el cliente & 100 & Diagramas de 4 Dominios \\
\hline 11 & Terminar Artefactos Fase B & 100 & Artefactos Fase B \\
\hline 11 & Realizar el entregable & 100 & $\begin{array}{l}\text { Architecture Definition } \\
\text { Document }\end{array}$ \\
\hline 11 & Realizar el entregable & 100 & $\begin{array}{l}\text { Architecture Requirements } \\
\text { Specification }\end{array}$ \\
\hline 12 & Empezar capítulo 6 de la Memoria & 100 & Capítulo 6 de la Memoria \\
\hline
\end{tabular}




\begin{tabular}{|l|l|l|l|}
\hline 12 & Continuar entregables Fase B & 100 & Entregables Fase B \\
\hline 13 & Tener Capitulo 6 de la Memoria & 100 & Capítulo 6 de la Memoria \\
\hline 14 & Terminar los entregables de la Fase B & 100 & Entregables Fase B \\
\hline 14 & Validar Fase B con el cliente & 100 & Entregables Fase B \\
\hline 14 & Entregables Fase B & 100 & Entregables Fase B \\
\hline 15 & Levantar observaciones de la Fase B & 100 & Entregables Fase B \\
\hline 15 & Presentar documentos al comité & 100 & Todos los entregables \\
\hline 16 & Exposición con el comité & 100 & Todos los entregables \\
\hline
\end{tabular}

Fuente: Elaboración Propia

Tabla 58: Segunda Etapa del Proyecto

\begin{tabular}{|c|c|c|c|}
\hline Semana & Descripción de Actividades & $\begin{array}{l}\text { Porcentaje } \\
\text { de Avance } \\
(\%)\end{array}$ & Entregables \\
\hline 1 & Terminar Entregables Ciclo 2016-02 & 100 & $\begin{array}{l}\text { Todos los entregables Fases } \\
\text { Preliminar, A, B }\end{array}$ \\
\hline 1 & $\begin{array}{l}\text { Terminar Capítulos } 1,3,4,6 \text { de la } \\
\text { memoria }\end{array}$ & 100 & Memoria \\
\hline 1 & Terminar documentos de Gestión & 100 & Documentos de Gestión \\
\hline 2 & Realizar el Plan de Trabajo & 100 & Plan de Trabajo 2017-01 \\
\hline 2 & $\begin{array}{l}\text { Validar los entregables } \text { Fase } \\
\text { Preliminar, A y B }\end{array}$ & 100 & $\begin{array}{l}\text { Todos los entregables Fases } \\
\text { Preliminar, A, B }\end{array}$ \\
\hline 2 & $\begin{array}{l}\text { Terminar lo que se quitó del alcance } \\
\text { del ciclo } 2016-02\end{array}$ & 100 & Artefactos de la fase B \\
\hline
\end{tabular}




\begin{tabular}{|c|c|c|c|}
\hline 2 & Hacer solicitud a IT Services & 100 & Solicitud de RR \\
\hline 2 & Revisión del Alcance con el Cliente & 100 & Project charter \\
\hline 3 & $\begin{array}{l}\text { Empezar Levantamiento de } \\
\text { Información para las fases C y D }\end{array}$ & 100 & - \\
\hline 3 & $\begin{array}{l}\text { Empezar Architecture Definition con } \\
\text { la Información de la Fase C (As Is) }\end{array}$ & 100 & Architecture Definition \\
\hline 3 & $\begin{array}{l}\text { Empezar Architecture Definition con } \\
\text { la Información de la Fase D (As Is) }\end{array}$ & 100 & Architecture Definition \\
\hline 4 & $\begin{array}{l}\text { Terminar Levantamiento de } \\
\text { Información para las Fases C y D }\end{array}$ & 100 & - \\
\hline 4 & $\begin{array}{l}\text { Continuar Architecture Definition con } \\
\text { la Información de la Fase C (As Is) }\end{array}$ & 100 & Architecture Definition \\
\hline 4 & $\begin{array}{l}\text { Continuar Architecture Definition con } \\
\text { la Información de la Fase D (As Is) }\end{array}$ & 100 & Architecture Definition \\
\hline 5 & $\begin{array}{l}\text { Empezar Architecture Requirements } \\
\text { Specification con la Información de la } \\
\text { Fase C (As Is) }\end{array}$ & 100 & $\begin{array}{l}\text { Architecture Requirements } \\
\text { Specification }\end{array}$ \\
\hline 5 & $\begin{array}{l}\text { Empezar Architecture Requirements } \\
\text { Specification con la Información de la } \\
\text { Fase D (As Is) }\end{array}$ & 100 & $\begin{array}{l}\text { Architecture Requirements } \\
\text { Specification }\end{array}$ \\
\hline 5 & $\begin{array}{l}\text { Continuar Architecture Definition con } \\
\text { la Información de la Fase C (As Is) }\end{array}$ & 100 & Architecture Definition \\
\hline 5 & $\begin{array}{l}\text { Continuar Architecture Definition con } \\
\text { la Información de la Fase D (As Is) }\end{array}$ & 100 & Architecture Definition \\
\hline
\end{tabular}




\begin{tabular}{|c|c|c|}
\hline 6 & $\begin{array}{l}\text { Empezar el Diagrama en Archivo de } 100 \\
\text { Fase C y D (As Is) }\end{array}$ & Diagrama 4 capas \\
\hline 6 & $\begin{array}{l}\text { Continuar Architecture Definition con } \\
\text { la Información de la Fase C (As Is) }\end{array}$ & Architecture Definition \\
\hline 6 & $\begin{array}{l}\text { Continuar Architecture Definition con } \\
\text { la Información de la Fase D (As Is) }\end{array}$ & Architecture Definition \\
\hline 6 & $\begin{array}{l}\text { Continuar Architecture Requirements } \\
\text { Specification con la Información de la } 100 \\
\text { Fase C (As Is) }\end{array}$ & $\begin{array}{l}\text { Architecture Requirements } \\
\text { Specification }\end{array}$ \\
\hline 7 & $\begin{array}{l}\text { Terminar Diagrama As Is de fase C y } 100 \\
\text { D }\end{array}$ & Diagrama 4 capas \\
\hline 7 & $\begin{array}{l}\text { Terminar Architecture Requirements } \\
\text { Specification y Architecture } 100 \\
\text { Definition de Fase C y D (As Is) }\end{array}$ & $\begin{array}{l}\text { Architecture Definition y } \\
\text { Architecture Requirements } \\
\text { Specification }\end{array}$ \\
\hline 8 & $\begin{array}{l}\text { Empezar Architecture Definition con } \\
\text { la Información de la Fase C (To Be) }\end{array}$ & Architecture Definition \\
\hline 8 & $\begin{array}{l}\text { Empezar Architecture Definition con } \\
\text { la Información de la Fase D (To Be) }\end{array}$ & Architecture Definition \\
\hline 8 & $\begin{array}{l}\text { Empezar Architecture Requirements } \\
\text { Specification con la Información de la } 100 \\
\text { Fase C (To Be) }\end{array}$ & $\begin{array}{l}\text { Architecture Requirements } \\
\text { Specification }\end{array}$ \\
\hline 8 & $\begin{array}{l}\text { Empezar Architecture Requirements } \\
\text { Specification con la Información de la } 100 \\
\text { Fase D (To Be) }\end{array}$ & $\begin{array}{l}\text { Architecture Requirements } \\
\text { Specification }\end{array}$ \\
\hline 9 & $\begin{array}{l}\text { Continuar Architecture Definition con } \\
\text { la Información de la Fase C (To Be) }\end{array}$ & Architecture Definition \\
\hline
\end{tabular}




\begin{tabular}{|c|c|c|}
\hline 9 & $\begin{array}{l}\text { Continuar Architecture Definition con } \\
\text { la Información de la Fase D (To Be) }\end{array}$ & Architecture Definition \\
\hline 9 & $\begin{array}{l}\text { Continuar Architecture Requirements } \\
\text { Specification con la Información de la } 100 \\
\text { Fase C (To Be) }\end{array}$ & $\begin{array}{l}\text { Architecture Requirements } \\
\text { Specification }\end{array}$ \\
\hline 9 & $\begin{array}{l}\text { Continuar Architecture Requirements } \\
\text { Specification con la Información de la } 100 \\
\text { Fase D (To Be) }\end{array}$ & $\begin{array}{l}\text { Architecture Requirements } \\
\text { Specification }\end{array}$ \\
\hline 9 & Hacer Capitulo 2 Memoria & Memoria \\
\hline 10 & $\begin{array}{l}\text { Continuar Architecture Definition con } \\
\text { la Información de la Fase C (To Be) }\end{array}$ & Architecture Definition \\
\hline 10 & $\begin{array}{l}\text { Continuar Architecture Definition con } \\
\text { la Información de la Fase D (To Be) }\end{array}$ & Architecture Definition \\
\hline 10 & $\begin{array}{l}\text { Continuar Architecture Requirements } \\
\text { Specification con la Información de la } 100 \\
\text { Fase C (To Be) }\end{array}$ & $\begin{array}{l}\text { Architecture Requirements } \\
\text { Specification }\end{array}$ \\
\hline 10 & $\begin{array}{l}\text { Continuar Architecture Requirements } \\
\text { Specification con la Información de la } 100 \\
\text { Fase D (To Be) }\end{array}$ & $\begin{array}{l}\text { Architecture Requirements } \\
\text { Specification }\end{array}$ \\
\hline 10 & $\begin{array}{l}\text { Empezar Diagramas de fase C y D (To } 100 \\
\mathrm{Be})\end{array}$ & Diagramas To Be \\
\hline 11 & Continuar Diagramas (To Be) & Diagramas To Be \\
\hline 11 & Terminar Capitulo 2 Memoria & Memoria \\
\hline 11 & $\begin{array}{l}\text { Terminar Architecture Requirements } \\
\text { Specification y Architecture } 100 \\
\text { Definition de Fase C y D (As Is) }\end{array}$ & $\begin{array}{l}\text { Architecture Definition y } \\
\text { Architecture Requirements } \\
\text { Specification }\end{array}$ \\
\hline
\end{tabular}




\begin{tabular}{|c|c|c|c|}
\hline 12 & Continuar Diagramas (To Be) & 100 & Diagramas To Be \\
\hline 12 & Validar Documentos con el Cliente & 100 & $\begin{array}{l}\text { Architecture Definition y } \\
\text { Architecture Requirements } \\
\text { Specification }\end{array}$ \\
\hline 13 & Terminar Diagramas (To Be) & 100 & Diagramas To Be \\
\hline 13 & $\begin{array}{l}\text { Levantar Observaciones de los } \\
\text { documentos }\end{array}$ & 100 & $\begin{array}{l}\text { Architecture Definition y } \\
\text { Architecture Requirements } \\
\text { Specification }\end{array}$ \\
\hline 14 & Empezar Plan de Continuidad & 100 & Plan de Continuidad \\
\hline 14 & Continuar Plan de Continuidad & 100 & Plan de Continuidad \\
\hline 14 & Validar Diagrama TO BE & 100 & Diagramas To Be \\
\hline 15 & Firmar Actas de Aprobación de Todo & 100 & Todo \\
\hline 15 & Aprobar Plan de continuidad & 100 & Plan de Continuidad \\
\hline 16 & Entregar Trabajo Final & 100 & Todo \\
\hline
\end{tabular}

Fuente: Elaboración Propia

\section{Gestión de Riesgos}

Los riesgos encontrados durante el desarrollo del proyecto se lograron resolver de manera exitosa mediante la ejecución de las propuestas de mitigaciones y plan de riesgos.

Se detalla el listado de riesgos:

- Cambio en la estructura de Trabajo (tanto por la universidad como el equipo de trabajo)

- Cambios en el gobierno que modifiquen la estructura actual de gobierno de EsSalud, resultando en una dificultad para las coordinaciones

- Problemas con los recursos asignado 
- Falta de disponibilidad del profesor cliente

- Conocimientos insuficientes en los miembros del proyecto

- Que salga una nueva versión de alguno de los marcos de trabajo o metodologías elegidos

- Información sobre el proceso y cliente, inaccesible o escasa.

- Cambio en los requerimientos del cliente.

Para asegurar la gestión de riesgo se realizó el siguiente documento adjunto:

- Matriz de riesgos.xls en documentos de gestión PMBOK

\section{Gestión de los Recursos Humanos}

Los recursos que formaron parte del proyecto tuvieron cambios por parte de la organización de la carrera de ingeniería de sistemas de información UPC, pero lo planificado no tuvo inconvenientes para realizar las funciones asignadas. El equipo de trabajo se conformó de la siguiente manera:

Tabla 59: Matriz de Recursos Humanos del Proyecto

\begin{tabular}{|l|l|l|}
\hline Rol & Miembro & Responsabilidades \\
\hline Jefe de Proyecto & Sebastián Neira & $\begin{array}{l}\text { Encargado de validar la } \\
\text { gestión y el cumplimiento } \\
\text { del proyecto, así como que } \\
\text { se alcancen los objetivos. }\end{array}$ \\
\hline Arquitecto Empresarial & Joan Motta & $\begin{array}{l}\text { Validar y construir los } \\
\text { modelos As Is de todas las } \\
\text { arquitecturas, y de } \\
\text { proponer una solución } \\
\text { válida. }\end{array}$ \\
\hline
\end{tabular}




\begin{tabular}{|l|l|l|}
\hline \multirow{2}{*}{ Comité de Proyectos } & Rosario Villalta & Jimmy Armas \\
Pedro Shiguihara & Víctor Parasi & $\begin{array}{l}\text { Evaluar y aprobar el } \\
\text { desarrollo del proyecto. }\end{array}$ \\
\hline $\begin{array}{l}\text { Gerente Profesor }- \text { IT } \\
\text { Consulting }\end{array}$ & Emilio Herrera & $\begin{array}{l}\text { Monitorear y controlar el } \\
\text { avance del proyecto. }\end{array}$ \\
\hline Cliente & Jorge Sánchez & $\begin{array}{l}\text { Brindar orientación de } \\
\text { información del proceso y } \\
\text { validador de la solución. }\end{array}$ \\
\hline
\end{tabular}

Fuente: Elaboración Propia

\section{Gestión de las Comunicaciones}

El acuerdo y/o comunicaciones realizadas no tuvieron cambios con los miembros del proyecto (cliente), ya que quedaron registrado por medio de un correo formal, acta de reunión o un canal alternativo que haya sido establecido como medio de comunicación entre los miembros del proyecto y los demás roles definidos.

Para asegurar la comunicación se realizó los siguientes documentos:

- Registro de Interés

- Matriz de Comunicaciones del Proyecto 
Tabla 60: Registro de Interesados

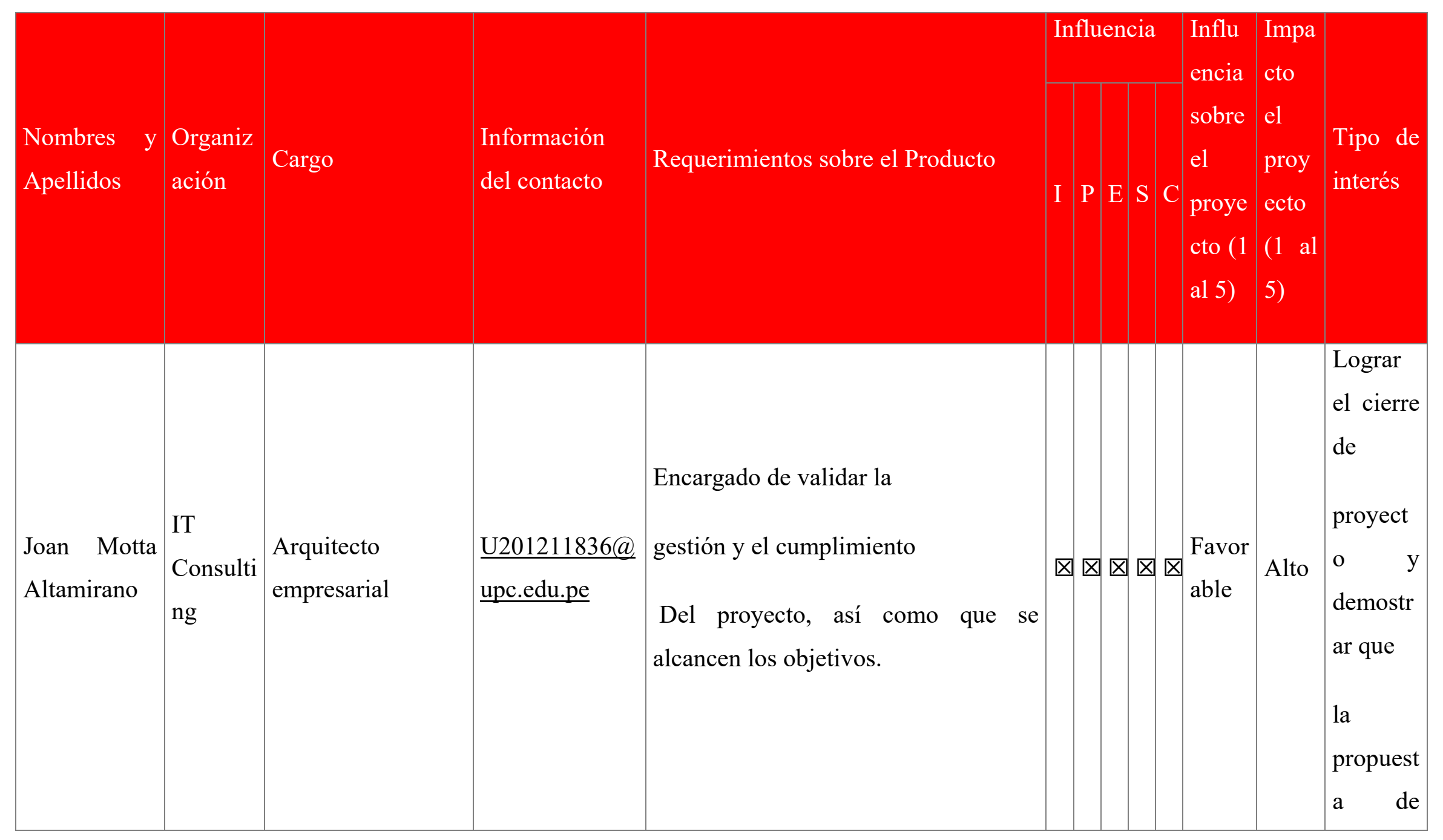




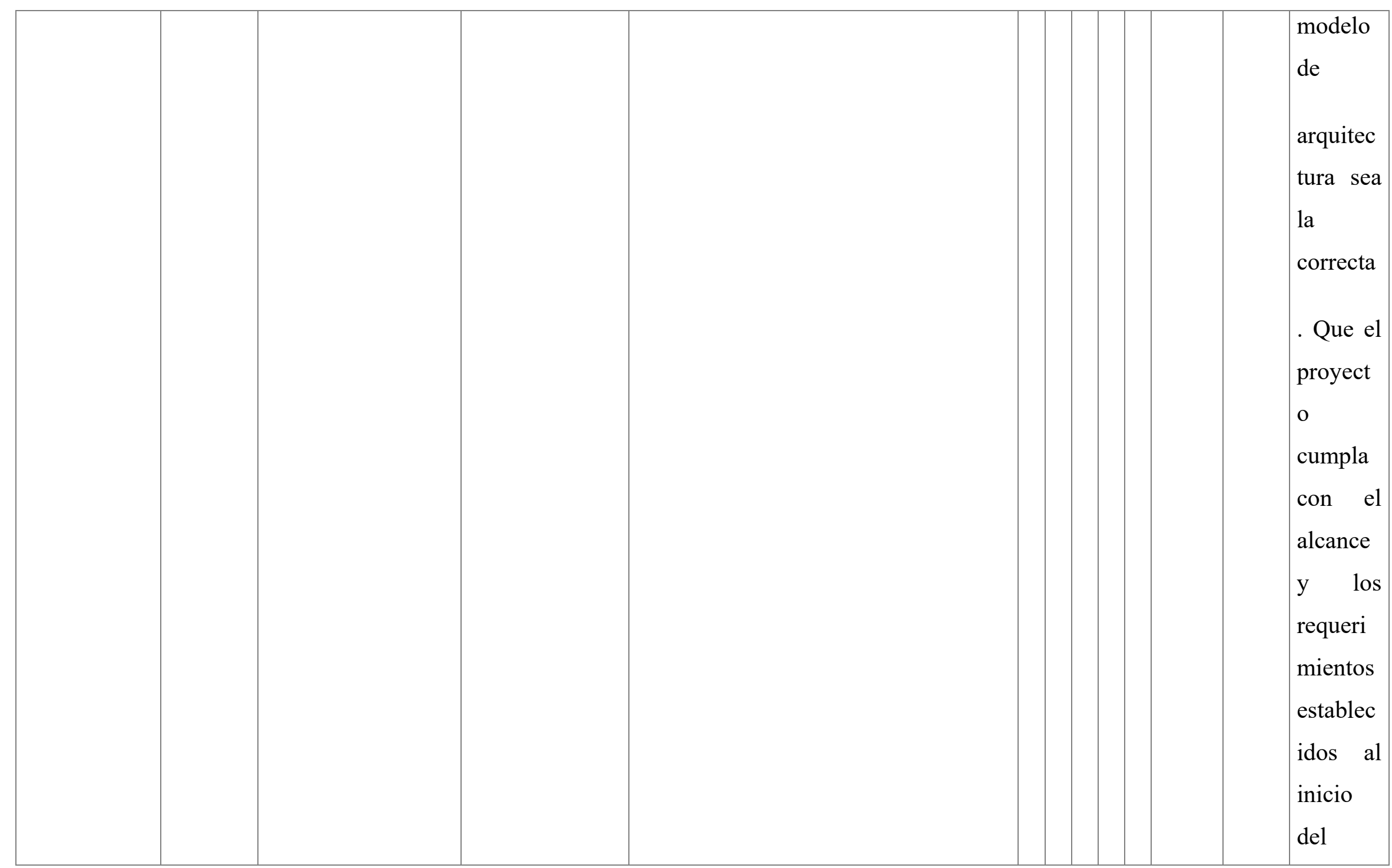




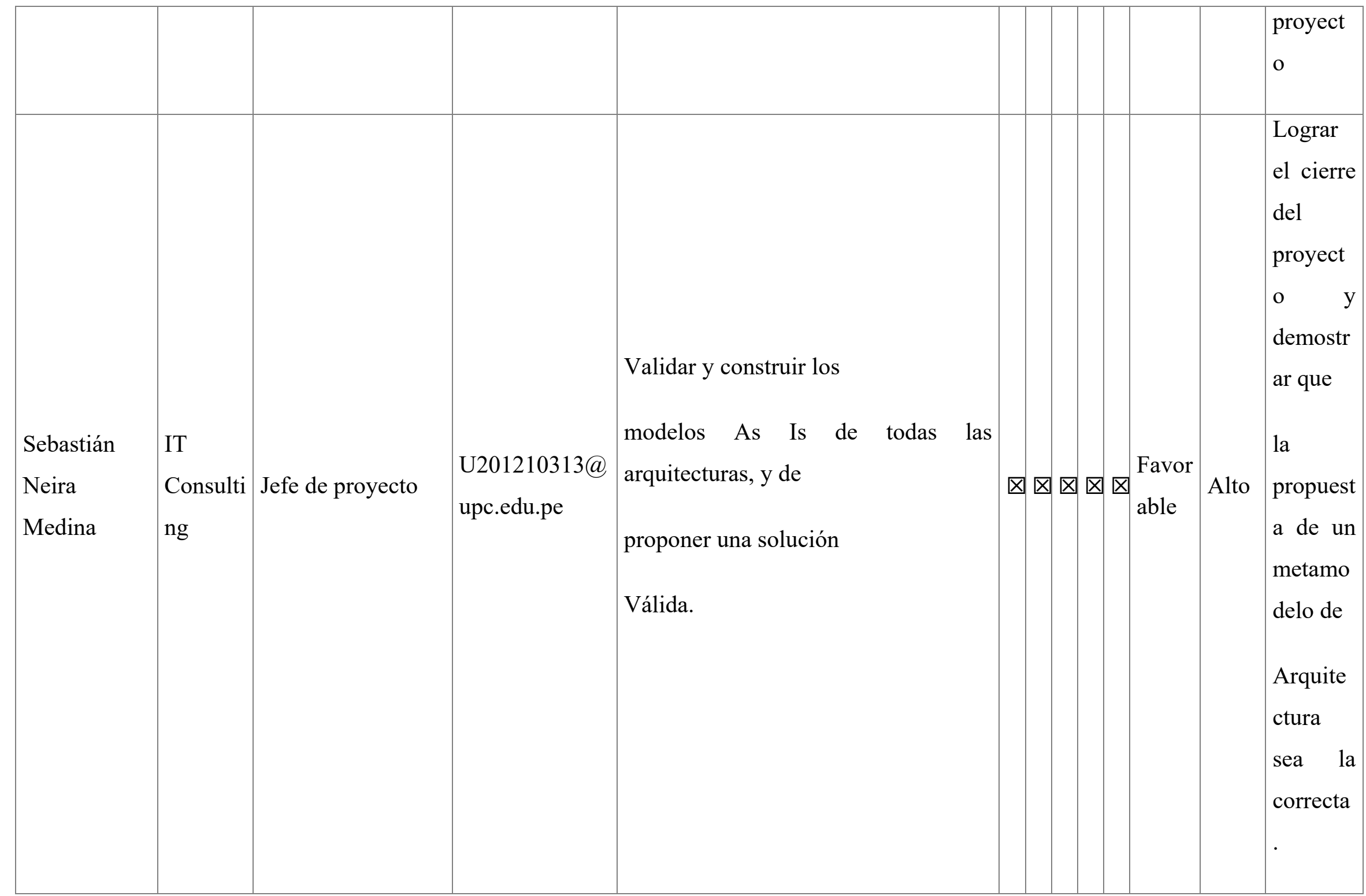




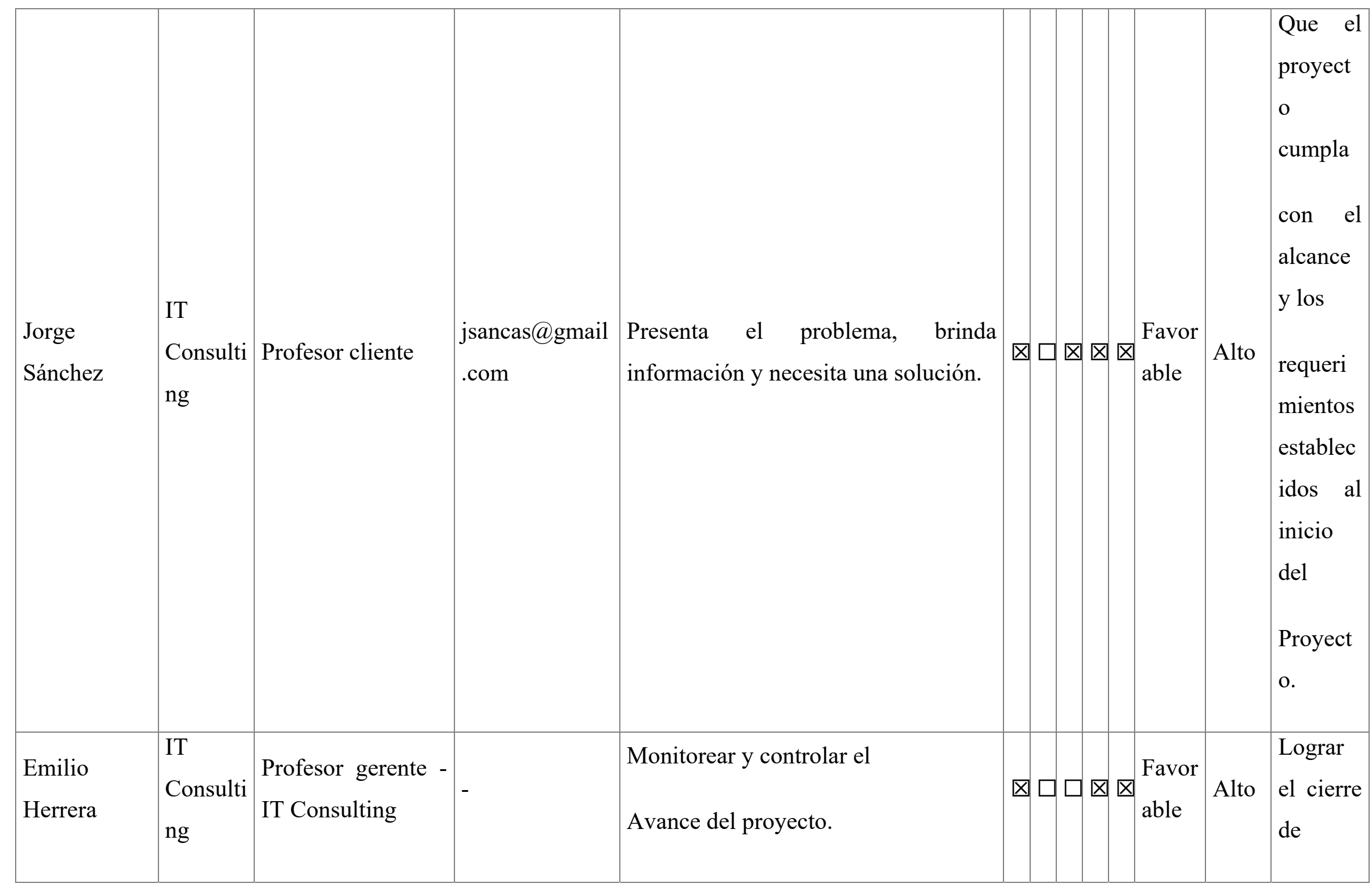




\begin{tabular}{|c|c|c|c|c|c|c|c|c|}
\hline & & & & & & & & $\begin{array}{l}\text { proyect } \\
\text { o de } \\
\text { manera } \\
\text { Exitosa. }\end{array}$ \\
\hline $\begin{array}{l}\text { Rosario } \\
\text { Villalta } \\
\text { Jimmy } \\
\text { Armas } \\
\text { Pedro } \\
\text { Shiguihara } \\
\text { Oscar } \\
\text { Gómez } \\
\text { Víctor Parasi }\end{array}$ & Comité & $\begin{array}{l}\text { Comité de } \\
\text { proyectos }\end{array}$ & - & $\begin{array}{l}\text { Evaluar y aprobar el } \\
\text { Desarrollo del proyecto. }\end{array}$ & $\square \square \square \square 凶$ & $\begin{array}{l}\text { Favor } \\
\text { able }\end{array}$ & Alto & $\begin{array}{l}\text { Lograr } \\
\text { que el } \\
\text { proyect } \\
\text { o } \\
\text { presenta } \\
\text { do sea lo } \\
\text { esperad } \\
\text { o para la } \\
\text { universi } \\
\text { dad }\end{array}$ \\
\hline $\begin{array}{l}\text { Recurso de } \\
\text { QS }\end{array}$ & QS & Analista QS & $\begin{array}{l}\text { Qservices.upc } \\
\text { @gmail.com }\end{array}$ & Valida los entregables entregados. & $\square \square \square \otimes 囚$ & $\begin{array}{l}\text { Favor } \\
\text { able }\end{array}$ & $\begin{array}{l}\text { Medi } \\
\text { a }\end{array}$ & $\begin{array}{l}\text { Lograr } \\
\text { que los } \\
\text { docume }\end{array}$ \\
\hline
\end{tabular}




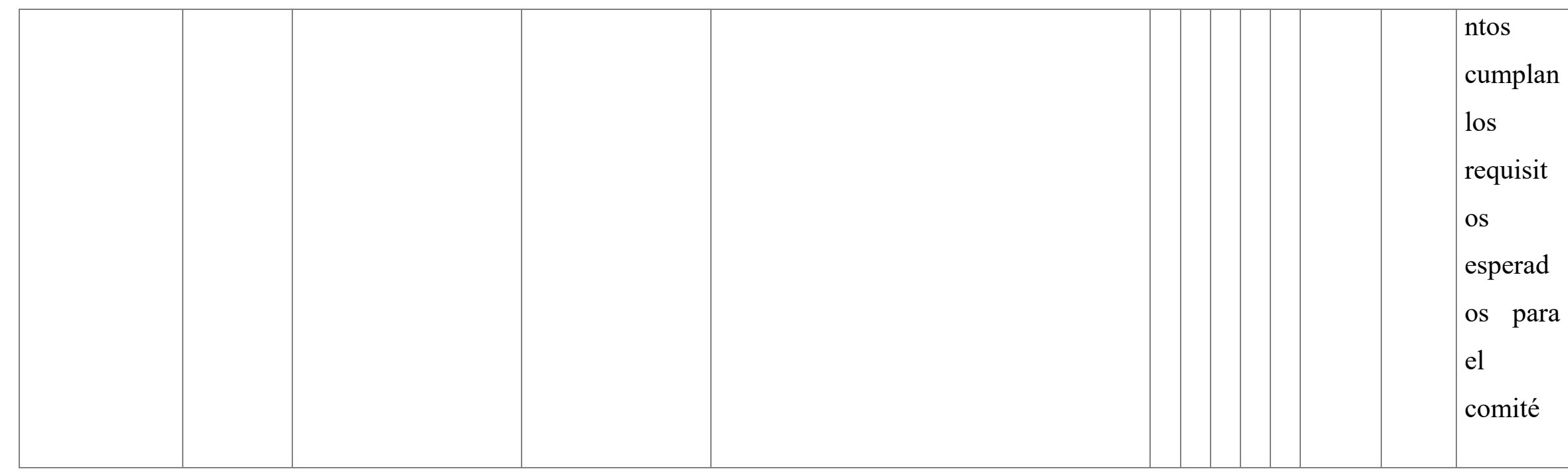

Fuente: Elaboración Propia 
Tabla 61: Matriz de Comunicaciones del Proyecto

\begin{tabular}{|c|c|c|c|c|c|c|}
\hline Información requerida & Contenido & $\begin{array}{ll}\text { Respons. } & \text { De } \\
\text { elaborarlo } & \end{array}$ & $\begin{array}{l}\text { Para su entrega } \\
\text { a los } \\
\text { Stakeholders }\end{array}$ & $\begin{array}{l}\text { Método de } \\
\text { comunicación } \\
\text { a utilizar }\end{array}$ & Frecuencia & $\begin{array}{l}\text { Código de } \\
\text { EDT asociado }\end{array}$ \\
\hline Inicio & $\begin{array}{l}\text { Reunión con el } \\
\text { Profesor Gerente } \\
\text { Reunión con el Cliente } \\
\text { Definir el Alcance } \\
\text { Definir los Entregables } \\
\text { de TOGAF(ADM) } \\
\text { Validación del Charter } \\
\text { con el Profesor Gerente } \\
\text { (Alcance) }\end{array}$ & $\begin{array}{l}\text { Joan Motta } \\
\text { Altamirano y } \\
\text { Sebastián Neira } \\
\text { Medina }\end{array}$ & $\begin{array}{lr}\text { Profesor } & \\
\text { Gerente } & \text { IT } \\
\text { consulting } & \text { y } \\
\text { Cliente } & \\
\text { Profesor } & \end{array}$ & $\begin{array}{l}\text { Email(escrita) } \\
\text { y Oral }\end{array}$ & $\begin{array}{l}\text { Diario } \\
\text { semanal }\end{array}$ & $\begin{array}{l}1.1 \\
1.1 .1 .1 \\
1.1 .1 .2 \\
1.1 .1 .3 \\
1.1 .2 .1 \\
1.1 .2 .2 \\
1.1 .2 .3 \\
1.1 .2 .4 \\
1.1 .2 .5\end{array}$ \\
\hline
\end{tabular}




\begin{tabular}{|c|c|c|c|c|c|c|}
\hline & $\begin{array}{l}\text { Validación con el } \\
\text { Cliente del Alcance y } \\
\text { entregables } \\
\text { Validación del Charter } \\
\text { con el Profesor Gerente } \\
\text { (Entregables) } \\
\text { Elaboración del Plan de } \\
\text { Trabajo } \\
\text { Presentación } \\
\text { Project Charter } \\
\text { Presentación del Plan } \\
\text { de Trabajo }\end{array}$ & & & & & $\begin{array}{l}1.1 .2 .6 \\
1.1 .2 .7\end{array}$ \\
\hline Planificación & $\begin{array}{l}\text { Aprobación del Project } \\
\text { Charter } \\
\text { Acuerdo } \\
\text { Entregables con el }\end{array}$ & $\begin{array}{l}\text { Joan Motta } \\
\text { Altamirano y } \\
\text { Sebastián Neira } \\
\text { Medina }\end{array}$ & $\begin{array}{lr}\text { Profesor } & \\
\text { Gerente } & \text { IT } \\
\text { consulting } & \text { y } \\
\text { Cliente } & \\
\text { Profesor } & \end{array}$ & $\begin{array}{l}\text { Email(escrita) } \\
\text { y Oral }\end{array}$ & $\begin{array}{l}\text { Diario } \\
\text { semanal }\end{array}$ & $\begin{array}{l}1.2 .1 .1 \\
1.2 .1 .2 \\
1.2 .1 .3 \\
1.2 .1 .4\end{array}$ \\
\hline
\end{tabular}




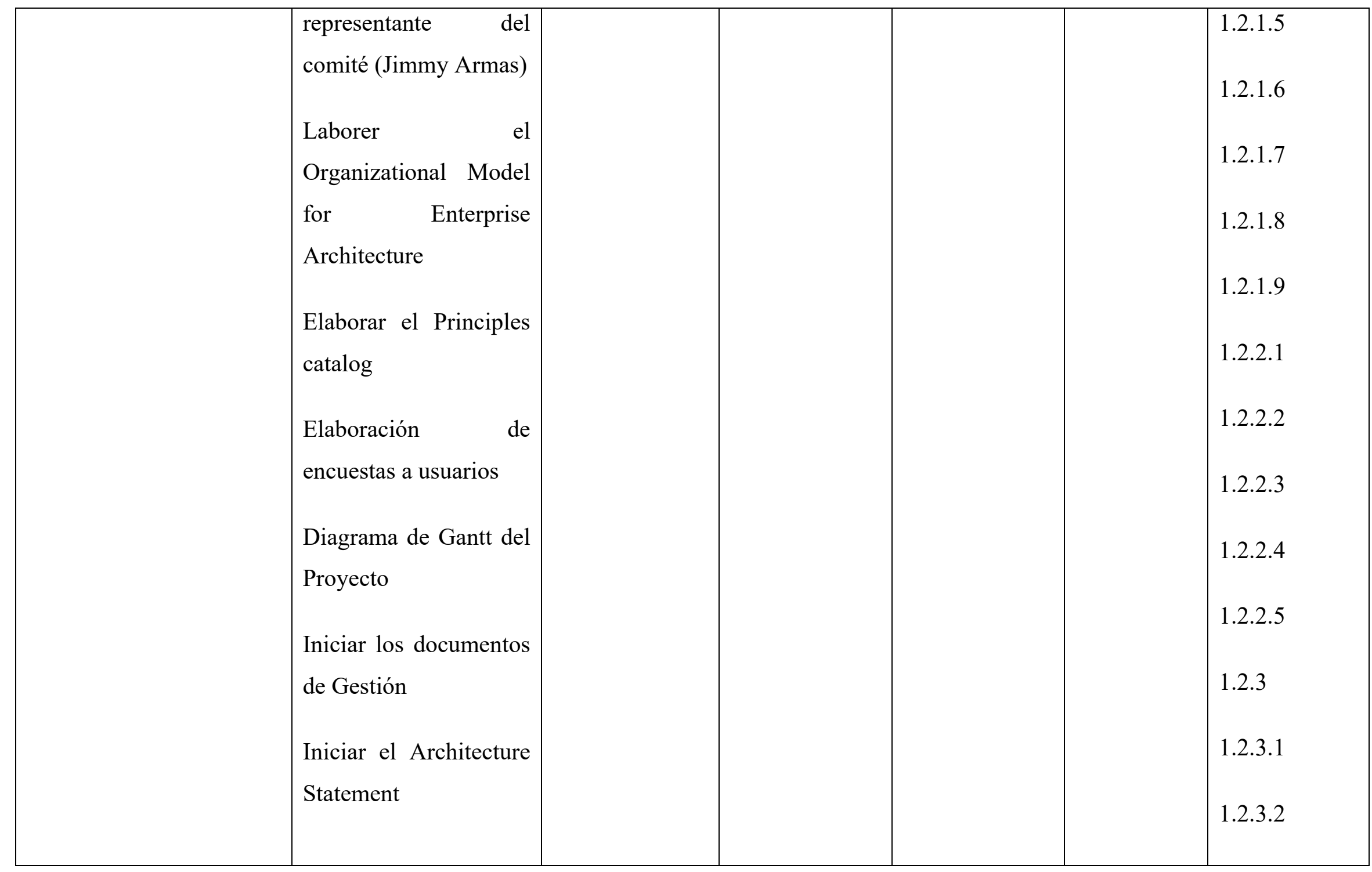




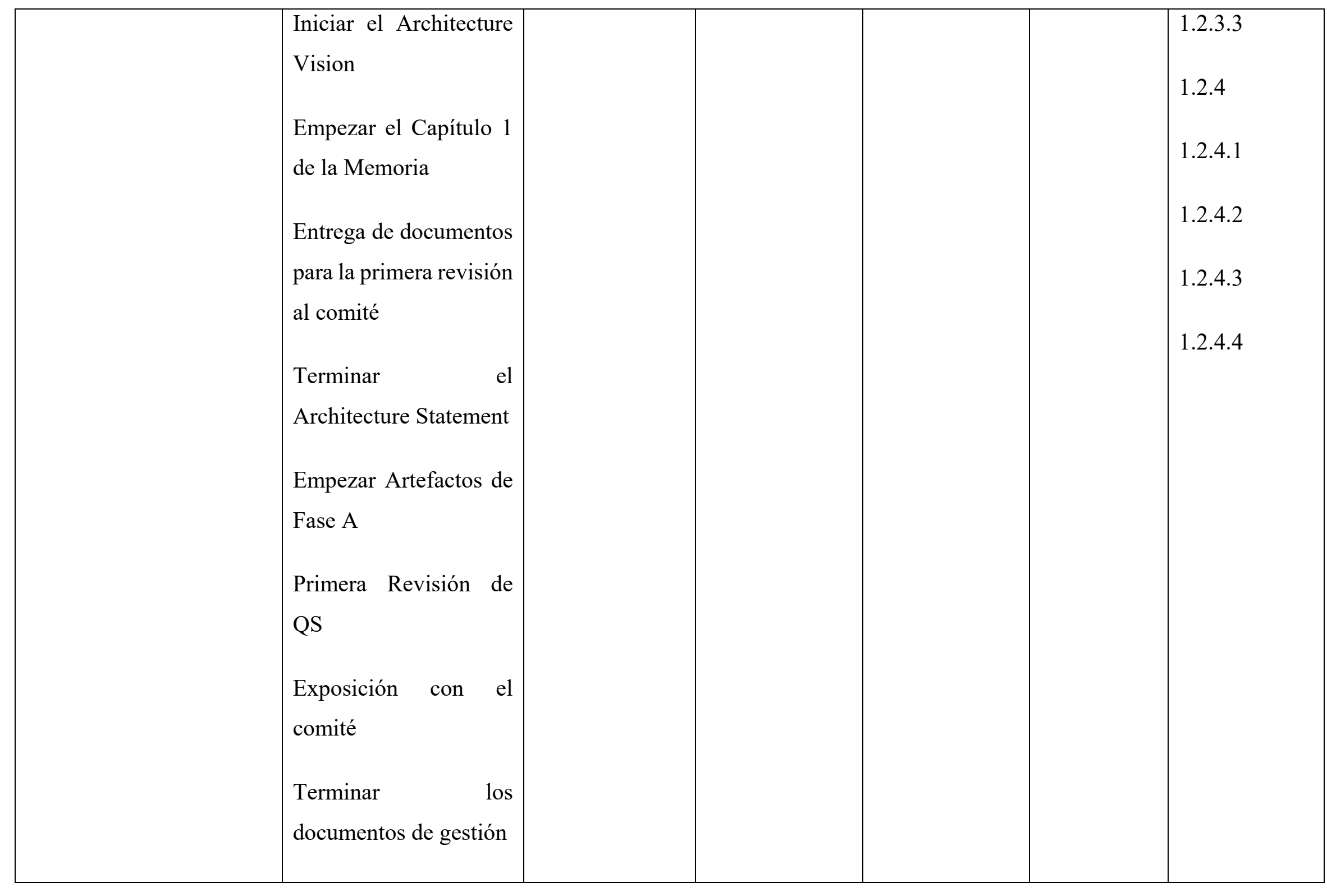




\begin{tabular}{|c|c|c|c|c|c|c|}
\hline & $\begin{array}{l}\text { Cerrar las } \\
\text { observaciones de QS } \\
\text { Validar la Fase A con el } \\
\text { cliente } \\
\text { Segunda Revisión de } \\
\text { QS } \\
\text { Levantar observaciones } \\
\text { de la Fase A } \\
\text { Entregar el Capítulo } 1 \\
\text { de Memoria }\end{array}$ & & & & & \\
\hline Ejecución & $\begin{array}{l}\text { Iniciar los diagramas } \\
\text { Empezar el Capítulo } 3 \\
\text { de la Memoria } \\
\text { Entregar el capítulo } 3 \\
\text { Empezar el capítulo } 4 \\
\text { memoria }\end{array}$ & $\begin{array}{l}\text { Joan Motta } \\
\text { Altamirano y } \\
\text { Sebastián } \\
\text { Neira Medina }\end{array}$ & $\begin{array}{l}\text { Profesor } \\
\text { Gerente } \quad \text { IT } \\
\text { consulting } \quad \text { y } \\
\text { Cliente } \\
\text { Profesor }\end{array}$ & $\begin{array}{l}\text { Email(escrita) y } \\
\text { Oral }\end{array}$ & $\begin{array}{l}\text { Diario } \\
\text { semanal }\end{array}$ & $\begin{array}{l}1.3 .1 .1 \\
1.3 .1 .2 \\
1.3 .2 .1 \\
1.3 .2 .2 \\
1.3 .2 .3\end{array}$ \\
\hline
\end{tabular}




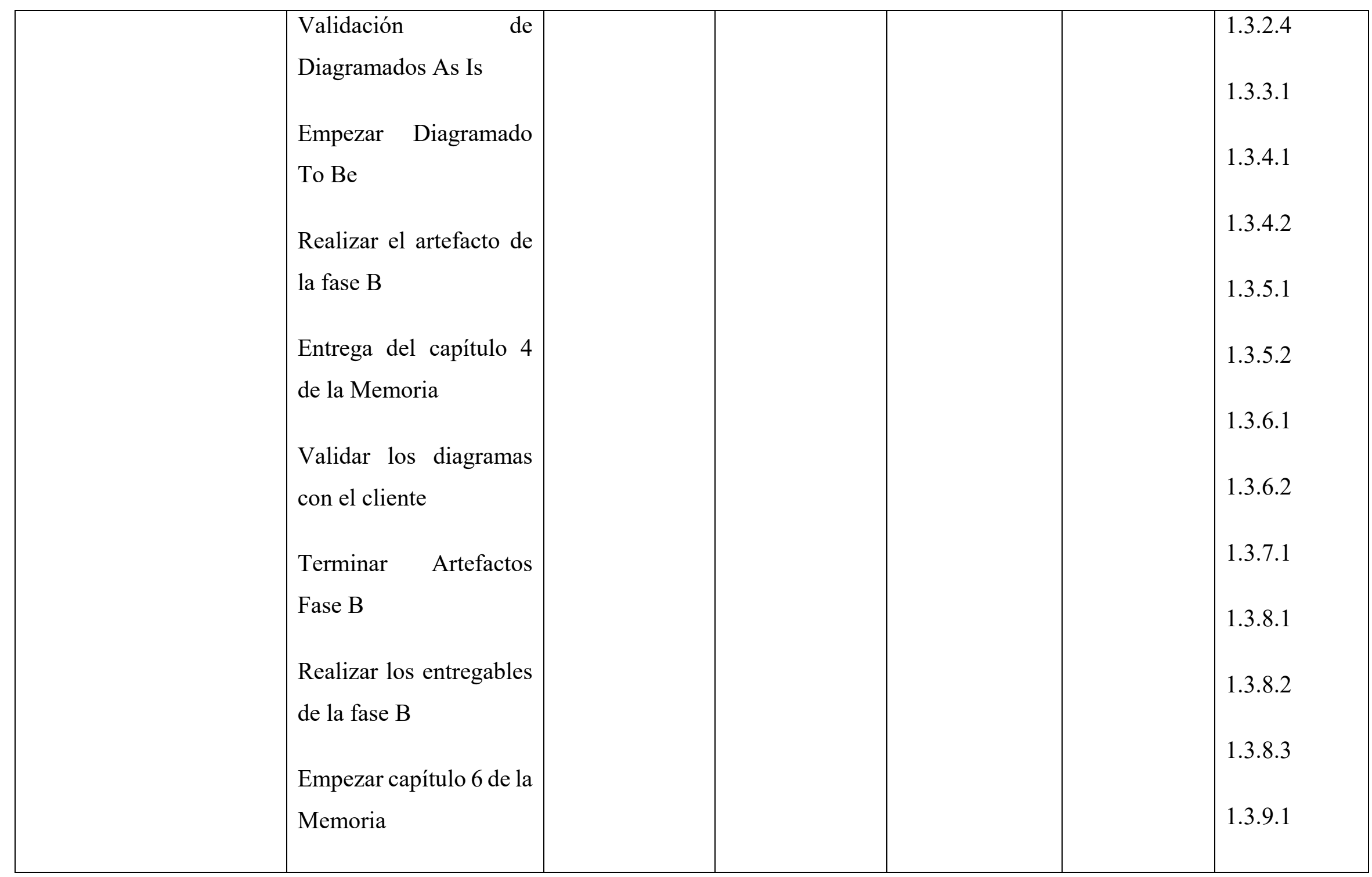




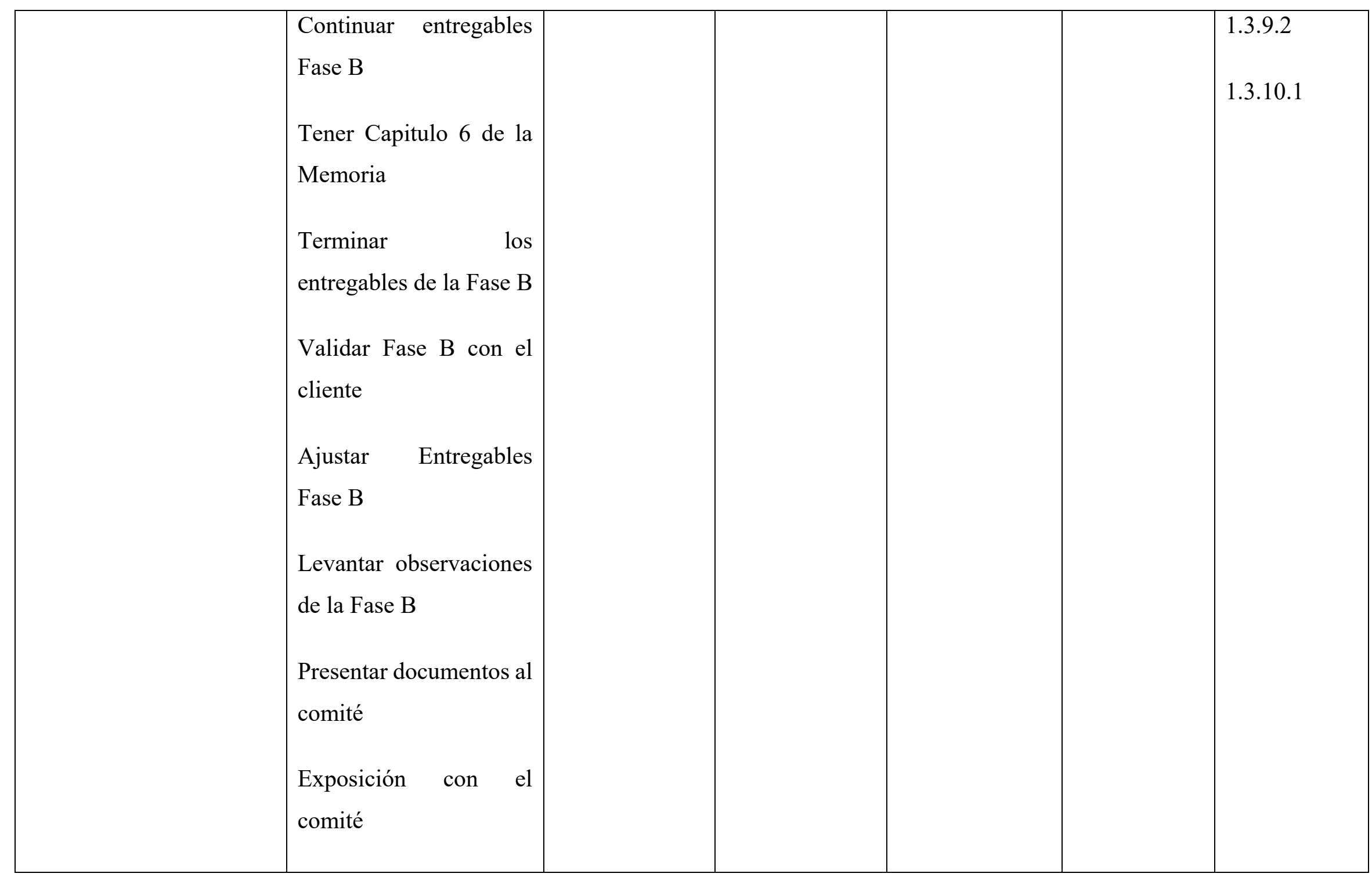




\begin{tabular}{|c|c|c|c|c|c|c|}
\hline Control & $\begin{array}{l}\text { Firmar Actas de } \\
\text { Aprobación de Todo. } \\
\text { Aprobación del plan de } \\
\text { continuidad }\end{array}$ & $\begin{array}{l}\text { Joan Motta } \\
\text { Altamirano y } \\
\text { Sebastián } \\
\text { Neira Medina }\end{array}$ & $\begin{array}{lr}\text { Profesor } & \\
\text { Gerente IT } \\
\text { consulting } \quad y \\
\text { Cliente } & \\
\text { Profesor } & \end{array}$ & $\begin{array}{l}\text { Email(escrita) y } \\
\text { Oral }\end{array}$ & $\begin{array}{l}\text { Diario } \\
\text { semanal }\end{array}$ & $\begin{array}{l}1.4 .1 \\
1.4 .1 .1 \\
1.4 .1 .2\end{array}$ \\
\hline Cierre & $\begin{array}{l}\text { Entregar trabajo final } \\
\text { Exposición }\end{array}$ & $\begin{array}{l}\text { Joan Motta } \\
\text { Altamirano y } \\
\text { Sebastián } \\
\text { Neira Medina }\end{array}$ & $\begin{array}{lr}\text { Profesor } & \\
\text { Gerente IT } \\
\text { consulting } \quad y \\
\text { Cliente } \\
\text { Profesor }\end{array}$ & $\begin{array}{l}\text { Email(escrita) y } \\
\text { Oral }\end{array}$ & $\begin{array}{l}\text { Diario } \\
\text { semanal }\end{array}$ & $\begin{array}{l}1.5 .1 \\
1.5 .1 .1 \\
1.5 .1 .2\end{array}$ \\
\hline
\end{tabular}

Fuente: Elaboración Propia 


\section{Conclusiones}

El proceso de prestación social de EsSalud no cuenta con actividades estandarizadas ni definidas.

La prestación social actual carece de documentación de procesos y manuales de usuario para el trabajo cotidiano.

El proceso en mención no cuenta con ningún tipo de soporte tecnológico, solo si el uso de Excel para almacenar información.

El proceso de prestación social es de categoría misional que no se encuentra conectado a nivel de negocio con ningún otro macro proceso de EsSalud, pero si tiene un flujo de información entre el proceso Core y el macro proceso de prestación de salud. 


\section{Recomendaciones}

Diseñar diagramas BPMN y casos de uso con documentación estandarizada de los procesos misionales, estratégicos y de soporte de EsSalud.

Implementar una arquitectura empresarial que abarque los cuatro dominios de negocio, tecnología datos y aplicaciones como soporte para el problema actual del proceso de prestación social de EsSalud.

Crear una integración entre los procesos estratégicos, misionales y soporte.

Invertir en expandir el proceso de prestación social con más equipamiento tecnológico y personal preparado antes de crear nuevos locales a lo largo del Perú.

Crear métricas para poder medir el éxito de los procesos o por ende generar puntos de mejora. 


\section{Glosario}

A continuación, se detallará la lista de glosario de términos del proyecto para un mejor entendimiento:

TOGAF: Framework de arquitectura empresarial.

ADM: Metodología de trabajo de TOGAF.

Archimate: lenguaje de modelado de arquitectura empresarial.

Archi: Software usado para el modelado de una arquitectura empresarial.

As Is: Composición actual de la empresa.

To Be: Modelo al que se debe llegar o se quiere alcanzar.

Procesos Misionales: Procesos más importantes de la empresa, que apoyan a la misión.

IAFAS: Institución encargada de la administración de los fondos de los asegurados.

IPRESS: Institutos médicos, como hospitales, clínicas, postas médicas y centros de atención especializados, estos pueden ser públicos, privados o híbridos.

CAM: Centros del adulto mayor donde se propone mejorar el estilo de vida de una persona anciana.

CERP: Centros de rehabilitación que inserta laboralmente y apoyo psicológico a personas con discapacidad.

Inserción Social: El acto de integrar a una persona en la sociedad.

ROI: Medida del valor de negocio de un proyecto, basado en el aumento de los beneficios (ya sea debido al aumento de los ingresos o la disminución de los gastos), dividido por el coste del proyecto 


\section{Siglario}

A continuación, se detallará la lista de siglario de términos del proyecto para un mejor entendimiento.

TOGAF: The Open Group Architecture Framework

ADM: Architecture Development Method (Método de Desarrollo de Arquitectura)

A.E: Arquitectura empresarial

A.F.P.: Administradora de Fondos de Pensiones

EUP: Enterprise Unified Process.

XP: Extreme Programming

EsSalud: Seguro Social de Salud del Perú

CERPS: Centro Especializados de Rehabilitación Profesional Y Social

MBRPS: Modelo Básico de Rehabilitación Profesional Y Social

CIRAM: Círculo del Adulto Mayor

CAM: Centro del Adulto Mayor

IPRESS: Instituciones Prestadoras de Servicios de Salud.

IAFAS: Instituciones Administradoras de Fondos de Aseguramiento en Salud

ROF: Reglamento De Organización Y Funciones Del Seguro Social De Salud

ROI: Retorno de inversión 


\section{Bibliografía}

A continuación, se detallará las referencias bibliográficas del proyecto en mención.

(2016). Obtenido de Greengeriatric: https://geriatric.greensoft.es/es/presentacion/

Accuys. (2009). Obtenido de Accuys: http://www.accusys.com.ar/productos/acsel-x/

Ahsan, M. S. (2016). ROLE OF ENTERPRISE ARCHITECTURE IN HEALTHCARE ORGANIZATIONS AND KNOWLEDGE-BASED MEDICAL DIAGNOSIS SYSTEM. Journal ofinformation systems and technology management.

AIT. (2015). Obtenido de http://www.ait.org.ar/geriatricos.php

Anonimo. (21 de 07 de 2015). Andina. Obtenido de Web site de Andina: http://www.andina.com.pe/agencia/noticia-essalud-brinda-atencion-y-prestacionessociales-a-12-millones-adultos-mayores-566761.aspx

Anonimo. (18 de 12 de 2015). Diario el comercio. Obtenido de Web site del Diario el comercio: http:/elcomercio.pe/sociedad/lima/adulto-mayor-verano-vejez-mas-allapiscina-noticia-1864841?ref=flujo_tags_515473\&ft=nota_13\&e=titulo

Anonimo. (01 de 09 de 2016). Diario el comercio. Obtenido de Web site del diario el comercio: http:/elcomercio.pe/sociedad/lima/adultos-mayores-y-personas-discapacidadestamos-olvidados-noticia-1928405?ref=flujo_tags_515473\&ft=nota_2\&e=titulo

Axxis systems. (2015). Obtenido de https://www.axxis-systems.com/sis10/\#tab-id-3

Badilla, G. E. (31 de 07 de 1997). Scielo. Obtenido de Web site de Scielo: http://www.scielo.sa.cr/scielo.php?script=sci_arttext\&pid=S1409-

$00151997000200005 \# 9$

Congreso de la republica. (11 de 2012). Congreso de la republica. Obtenido de Web site del Congreso de la republica: http://www2.congreso.gob.pe/sicr/cendocbib/con4_uibd.nsf/4355048598C6920705257 
E8A0072001B/\$FILE/CENTROS_ADULT_MAY_COMO_MOD_GERONT_1RA_E DIC_NOV2012.pdf

Daniel Simon, K. F. (2013). An Exploration of Enterprise Architecture Research. Communications of the Association for Information Systems.

Educar chile. (s.f.). Educar chile. Obtenido de Web site de Educar chile: http://ww2.educarchile.cl/UserFiles/P0001/Image/portal/ODAS_TP/Materiales_para_od as_2012/3\%20Cuidados\%20adulto\%20mayor/ODA\%2016\%20Actividades\%20recreati vas/LA\%20ESCALA\%20DE\%20VALORACION\%20DE\%20AUTOVALENCIA.pdf

EsSalud - Reglamento de organización y funciones del seguro social de salud. (2014). Portal de transparncia estándar y de acceso a la información pública. Obtenido de http://www.essalud.gob.pe/transparencia/

EsSalud. (2015). Portal de transparencia estándar y de acceso a la información pública. Obtenido de http://www.essalud.gob.pe/transparencia/pdf/Macroprocesos_EsSalud_Res127GG2016. pdf

EsSalud. (2016). Plan operativo Institucional 2017. Lima.

ESSALUD. (s.f.). Seguro Social de Salud del Perú. Obtenido de Web site de ESSALUD: http://www.essalud.gob.pe/transparencia/pdf/publicacion/LEY27056ESSALUD.pdf

García, A. S. (2015). plicación de una Arquitectura Orientada a Servicios para la Interoperabilidad de los Servicios de Salud Públicos y Privados del Ecuador.

Gartner. (s.f.). Gartner. Obtenido de Web site del Gartner: https://www.gartner.com/doc/reprints?id=1-2Q45NIB\&ct=151020\&st=sb

Gerencia central de la persona con discapacidad. (2016). Portal de transparencia estándar y de acceso a la información publica. Obtenido de http://www.essalud.gob.pe/transparencia/pdf/informacion/RESOLUCION_227_GG_ES SALUD_2016.pdf

Gerencia central de las persona adulta mayor. (2016). Portal de transparencia estándar y de acceso a la información publica. Obtenido de 
http://www.essalud.gob.pe/transparencia/pdf/informacion/RESOLUCION_1064_GG_E SSALUD_2016.pdf

Guidewire. (2016). Obtenido de https://www.guidewire.com/products/insurancesuite

Hoogervorst, J. L. (2013). The discipline of enterprise engineering . Organisational Design and Engineering, , 86 - 114.

Instituto de seguro social - Uruguay. (s.f.). Instituto de seguro social - Uruguay. Obtenido de Web side del Instituto de seguro social: http://www.bps.gub.uy/1365/estructuraorganizativa.html

Instituto nacional de estadistica e informatica(INEI). (30 de 06 de 2015). Instituto nacional de estadistica e informatica(INEI). Obtenido de Web site del Instituto nacional de estadistica e informatica: https://www.inei.gob.pe/media/MenuRecursivo/publicaciones_digitales/Est/Lib1251/Li bro.pdf

Microsoft. (2007, Mayo). MSDN Microsoft. Retrieved from https://msdn.microsoft.com/en-us/library/bb466232.aspx

Ministerio de educación. (2010). Ministerio de educación. Obtenido de Web site del Ministerio de educación: http://www.minedu.gob.pe/files/266_201109141525.pdf

Ministerio de la mujer y población vulnerable. (s.f.). Ministerio de la mujer y población vulnerable(MIMP). Obtenido de Web site de Ministerio de la mujer y población vulnerable:

http:/www.mimp.gob.pe/files/direcciones/dgfc/diapam/Ley_28803_Ley_del_Adulto_ Mayor.pdf

Olmedo, A. E. (2003). Comportamiento epidemiologico del adutlo mayor según su tipologia familiar. Mexico: Universidad de Colima.

Organización mundial de la salud (OMS). (11 de 2016). Organización mundial de la salud (OMS). Obtenido de Web site de la Organización mundial de la salud: http://www.who.int/mediacentre/factsheets/fs352/es 
PMI. (2013). Fundamentos para la dirección de proyectos (Guía del PMBOK) - Quinta edisción. En PMI, Fundamentos para la dirección de proyectos (Guía del PMBOK) Quinta edisción (págs. 1-2). Newtown Square, Pensilvania EE.UU: Project Management Institute.

Portal del centro del adulto mayor. (s.f.). Portal del centro del adulto mayor. Obtenido de Web site del centro del adulto mayor: http:/www.essalud.gob.pe/adulto-mayor/

Portal del centro especialisado derehabilitación. (s.f.). Portal del centro especialisado de rehabilitación profesional. Obtenido de Web site del Portal del centro especialisado de rehabilitación profesional: http://www.essalud.gob.pe/cerp/

Ramtín Mesbahipour, A. N. (2014). Architectong the enterprise along communication paradigm using the TOGAF famework. $6^{\circ}$ International conference A-BPM ONE 2014 (págs. 157 - 163). Springer.

Rui Rijo, R. M. (2015). Developing an Enterprise Architecture Proof of Concept in a Portuguese Hospital. Procedia Computer Science, 1217 - 1225.

Sage. (2013). SAGE CORP. Obtenido de http://www.sage.com/en-ae/products/bms/sage300

The Open group framework. (s.f.). The open group framework. Obtenido de The open group framework: http://pubs.opengroup.org/architecture/togaf9-doc/arch/chap05.html

The Open group framework. (s.f.). The Open group framework. Obtenido de Web site de The Open group framework: http://www.togaf.org/togaf9/chap02.html

Tobias Mueller, D. S. (2013). Towards inter-organizational Enterprise Architecture Management -. Towards inter-organizational EAM, 1-13. 
Anexo 1: <Diccionario ETD $>$

\begin{tabular}{|c|c|c|}
\hline Nivel & $\begin{array}{l}\text { Código de } \\
\text { EDT }\end{array}$ & Nombre de Entregable \\
\hline 1 & 1 & Arquitectura en el proceso de prestación social de EsSalud \\
\hline 2 & 1.1 & Inicio \\
\hline 3 & 1.1 .1 & Semana 1 \\
\hline 4 & 1.1.1.1 & Reunión con el Profesor Gerente \\
\hline 4 & 1.1.1.2 & Reunión con el Cliente \\
\hline 4 & 1.1.1.3 & Definir el Alcance \\
\hline 3 & 1.1 .2 & Semana 2 \\
\hline 4 & 1.1.2.1 & Definir los Entregables de TOGAF(ADM) \\
\hline 4 & 1.1.2.2 & Validación del Charter con el Profesor Gerente (Alcance) \\
\hline 4 & 1.1.2.3 & Validación con el Cliente del Alcance y entregables \\
\hline 4 & 1.1.2.4 & $\begin{array}{l}\text { Validación del Charter con el Profesor Gerente } \\
\text { (Entregables) }\end{array}$ \\
\hline 4 & 1.1.2.5 & Elaboración del Plan de Trabajo \\
\hline 4 & 1.1.2.6 & Presentación del Project Charter \\
\hline 4 & 1.1.2.7 & Presentación del Plan de Trabajo \\
\hline 2 & 1.2 & Planificación \\
\hline 3 & 1.2 .1 & Semana 3 \\
\hline 4 & 1.2.1.1 & Aprobación del Project Charter \\
\hline
\end{tabular}




\begin{tabular}{|c|c|c|}
\hline 4 & 1.2.1.2 & $\begin{array}{l}\text { Acuerdo de Entregables con el representante del comité } \\
\text { (Jimmy Armas) }\end{array}$ \\
\hline 4 & 1.2.1.3 & $\begin{array}{l}\text { Elaborar el Organizational Model for Enterprise } \\
\text { Architecture }\end{array}$ \\
\hline 4 & 1.2.1.4 & Elaborar el Principles catalog \\
\hline 4 & 1.2.1.5 & Elaboración de encuestas a usuarios \\
\hline 4 & 1.2.1.6 & Diagrama de Gantt del Proyecto \\
\hline 4 & 1.2.1.7 & Iniciar los documentos de Gestión \\
\hline 4 & 1.2.1.8 & Iniciar el Architecture Statement \\
\hline 4 & 1.2.1.9 & Iniciar el Architecture Vision \\
\hline 3 & 1.2 .2 & Semana 4 \\
\hline 4 & 1.2.2.1 & Empezar el Capítulo 1 de la Memoria \\
\hline 4 & 1.2 .2 .2 & Entrega de documentos para la primera revisión al comité \\
\hline 4 & 1.2 .2 .3 & Terminar el Architecture Statement \\
\hline 4 & 1.2.2.4 & Empezar Artefactos de Fase A \\
\hline 4 & 1.2 .2 .5 & Primera Revisión de QS \\
\hline 3 & 1.2 .3 & Semana 5 \\
\hline 4 & 1.2.3.1 & Exposición con el comité \\
\hline 4 & 1.2.3.2 & Terminar los documentos de gestión \\
\hline 4 & 1.2 .3 .3 & Cerrar las observaciones de QS \\
\hline 3 & 1.2.4 & Semana 6 \\
\hline
\end{tabular}




\begin{tabular}{|c|c|c|}
\hline 4 & 1.2.4.1 & Validar la Fase A con el cliente \\
\hline 4 & 1.2 .4 .2 & Segunda Revisión de QS \\
\hline 4 & 1.2 .4 .3 & Levantar observaciones de la Fase A \\
\hline 4 & 1.2 .4 .4 & Entregar el Capítulo 1 de Memoria \\
\hline 2 & 1.3 & Ejecución \\
\hline 3 & 1.3 .1 & Semana 7 \\
\hline 4 & 1.3.1.1 & Iniciar los diagramas \\
\hline 4 & 1.3.1.2 & Empezar el Capítulo 3 de la Memoria \\
\hline 3 & 1.3 .2 & Semana 8 \\
\hline 4 & 1.3.2.1 & Entregar el capítulo 3 \\
\hline 4 & 1.3.2.2 & Empezar el capítulo 4 memoria \\
\hline 4 & 1.3.2.3 & Validación de Diagramados As Is \\
\hline 4 & 1.3.2.4 & Empezar Diagramado To Be \\
\hline 3 & 1.3 .3 & Semana 9 \\
\hline 4 & 1.3 .3 .1 & Realizar el artefacto de la fase B \\
\hline 3 & 1.3 .4 & Semana 10 \\
\hline 4 & 1.3 .4 .1 & Entrega del capítulo 4 de la Memoria \\
\hline 4 & 1.3.4.2 & Validar los diagramas con el cliente \\
\hline 3 & 1.3 .5 & Semana 11 \\
\hline 4 & 1.3 .5 .1 & Terminar Artefactos Fase B \\
\hline 4 & 1.3 .5 .2 & Realizar los entregables de la fase B \\
\hline
\end{tabular}




\begin{tabular}{|c|c|c|}
\hline 3 & 1.3 .6 & Semana 12 \\
\hline 4 & 1.3.6.1 & Empezar capítulo 6 de la Memoria \\
\hline 4 & 1.3.6.2 & Continuar entregables Fase B \\
\hline 3 & 1.3 .7 & Semana 13 \\
\hline 4 & 1.3.7.1 & Tener Capitulo 6 de la Memoria \\
\hline 3 & 1.3 .8 & Semana 14 \\
\hline 4 & 1.3.8.1 & Terminar los entregables de la Fase B \\
\hline 4 & 1.3.8.2 & Validar Fase B con el cliente \\
\hline 4 & 1.3.8.3 & Ajustar Entregables Fase B \\
\hline 3 & 1.3 .9 & Semana 15 \\
\hline 4 & 1.3.9.1 & Levantar observaciones de la Fase B \\
\hline 4 & 1.3.9.2 & Presentar documentos al comité \\
\hline 3 & 1.3 .10 & Semana 16 \\
\hline 4 & 1.3 .10 .1 & Preparar Exposición \\
\hline 4 & 1.3.10.2 & Exposición con el comité \\
\hline 3 & 1.3 .11 & Semana 17 \\
\hline 4 & 1.3 .11 .1 & Terminar Entregables Ciclo 2016-02 \\
\hline 4 & 1.3.11.2 & Terminar Capítulos $1,3,4,6$ de la memoria \\
\hline 4 & 1.3 .11 .3 & Terminar documentos de Gestión \\
\hline 3 & 1.3 .12 & Semana 18 \\
\hline
\end{tabular}




\begin{tabular}{|c|c|c|}
\hline 4 & 1.3.12.1 & Realizar el Plan de Trabajo \\
\hline 4 & 1.3.12.2 & Validar los entregables Fase Preliminar, A y B \\
\hline 4 & 1.3 .12 .3 & Terminar lo que se quitó del alcance del ciclo 2016-02 \\
\hline 4 & 1.3 .12 .4 & Hacer solicitud a IT Services \\
\hline 4 & 1.3 .12 .5 & Revisión del Alcance con el Cliente \\
\hline 3 & 1.3 .13 & Semana 19 \\
\hline 4 & 1.3.13.1 & $\begin{array}{l}\text { Empezar Levantamiento de Información para las fases C y } \\
\text { D }\end{array}$ \\
\hline 4 & 1.3.13.2 & $\begin{array}{l}\text { Empezar Architecture Definition con la Información de la } \\
\text { Fase C (As Is) }\end{array}$ \\
\hline 4 & 1.3.13.3 & $\begin{array}{l}\text { Empezar Architecture Definition con la Información de la } \\
\text { Fase D (As Is) }\end{array}$ \\
\hline 3 & 1.3 .14 & Semana 20 \\
\hline 4 & 1.3.14.1 & $\begin{array}{l}\text { Terminar Levantamiento de Información para las Fases C y } \\
\text { D }\end{array}$ \\
\hline 4 & 1.3.14.2 & $\begin{array}{l}\text { Continuar Architecture Definition con la Información de la } \\
\text { Fase C (As Is) }\end{array}$ \\
\hline 4 & 1.3.14.3 & $\begin{array}{l}\text { Continuar Architecture Definition con la Información de la } \\
\text { Fase D (As Is) }\end{array}$ \\
\hline 3 & 1.3 .15 & Semana 21 \\
\hline 4 & 1.3.15.1 & $\begin{array}{l}\text { Empezar Architecture Requirements Specification con la } \\
\text { Información de la Fase C (As Is) }\end{array}$ \\
\hline 4 & 1.3.15.2 & $\begin{array}{l}\text { Empezar Architecture Requirements Specification con la } \\
\text { Información de la Fase D (As Is) }\end{array}$ \\
\hline
\end{tabular}




\begin{tabular}{|c|c|c|}
\hline 4 & 1.3.15.3 & $\begin{array}{l}\text { Continuar Architecture Definition con la Información de la } \\
\text { Fase C (As Is) }\end{array}$ \\
\hline 4 & 1.3.15.4 & $\begin{array}{l}\text { Continuar Architecture Definition con la Información de la } \\
\text { Fase D (As Is) }\end{array}$ \\
\hline 3 & 1.3 .16 & Semana 22 \\
\hline 4 & 1.3.16.1 & Empezar el Diagrama en Archivo de Fase C y D (As Is) \\
\hline 4 & 1.3.16.2 & $\begin{array}{l}\text { Continuar Architecture Definition con la Información de la } \\
\text { Fase C (As Is) }\end{array}$ \\
\hline 4 & 1.3.16.3 & $\begin{array}{l}\text { Continuar Architecture Definition con la Información de la } \\
\text { Fase D (As Is) }\end{array}$ \\
\hline 4 & 1.3.16.4 & $\begin{array}{l}\text { Continuar Architecture Requirements Specification con la } \\
\text { Información de la Fase C (As Is) }\end{array}$ \\
\hline 4 & 1.3.16.5 & $\begin{array}{l}\text { Continuar Architecture Requirements Specification con la } \\
\text { Información de la Fase D (As Is) }\end{array}$ \\
\hline 3 & 1.3.17 & Semana 23 \\
\hline 4 & 1.3.17.1 & Terminar Diagrama As Is de fase C y D \\
\hline 4 & 1.3.17.2 & $\begin{array}{l}\text { Terminar Architecture Requirements Specification y } \\
\text { Architecture Definition de Fase C y D (As Is) }\end{array}$ \\
\hline 3 & 1.3 .18 & Semana 24 \\
\hline 4 & 1.3.18.1 & $\begin{array}{l}\text { Empezar Architecture Definition con la Información de la } \\
\text { Fase C (To Be) }\end{array}$ \\
\hline 4 & 1.3.18.2 & $\begin{array}{l}\text { Empezar Architecture Definition con la Información de la } \\
\text { Fase D (To Be) }\end{array}$ \\
\hline
\end{tabular}




\begin{tabular}{|c|c|c|}
\hline 4 & 1.3.18.3 & $\begin{array}{l}\text { Empezar Architecture Requirements Specification con la } \\
\text { Información de la Fase } \mathrm{C}(\mathrm{To} \mathrm{Be})\end{array}$ \\
\hline 4 & 1.3.18.4 & $\begin{array}{l}\text { Empezar Architecture Requirements Specification con la } \\
\text { Información de la Fase } \mathrm{D}(\mathrm{To} \mathrm{Be})\end{array}$ \\
\hline 3 & 1.3 .19 & Semana 25 \\
\hline 4 & 1.3.19.1 & $\begin{array}{l}\text { Continuar Architecture Definition con la Información de la } \\
\text { Fase C (To Be) }\end{array}$ \\
\hline 4 & 1.3.19.2 & $\begin{array}{l}\text { Continuar Architecture Definition con la Información de la } \\
\text { Fase D (To Be) }\end{array}$ \\
\hline 4 & 1.3.19.3 & $\begin{array}{l}\text { Continuar Architecture Requirements Specification con la } \\
\text { Información de la Fase } \mathrm{C}(\mathrm{To} \mathrm{Be})\end{array}$ \\
\hline 4 & 1.3.19.4 & $\begin{array}{l}\text { Continuar Architecture Requirements Specification con la } \\
\text { Información de la Fase } \mathrm{D} \text { (To Be) }\end{array}$ \\
\hline 4 & 1.3.19.5 & Hacer Capitulo 2 Memoria \\
\hline 3 & 1.3 .20 & Semana 26 \\
\hline 4 & 1.3.20.1 & $\begin{array}{l}\text { Continuar Architecture Definition con la Información de la } \\
\text { Fase C (To Be) }\end{array}$ \\
\hline 4 & 1.3.20.2 & $\begin{array}{l}\text { Continuar Architecture Definition con la Información de la } \\
\text { Fase D (To Be) }\end{array}$ \\
\hline 4 & 1.3.20.3 & $\begin{array}{l}\text { Continuar Architecture Requirements Specification con la } \\
\text { Información de la Fase } \mathrm{C}(\mathrm{To} \mathrm{Be})\end{array}$ \\
\hline 4 & 1.3.20.4 & $\begin{array}{l}\text { Continuar Architecture Requirements Specification con la } \\
\text { Información de la Fase } \mathrm{D} \text { (To Be) }\end{array}$ \\
\hline 4 & 1.3 .20 .5 & Continuar Capitulo 2 Memoria \\
\hline
\end{tabular}




\begin{tabular}{|c|c|c|}
\hline 4 & 1.3.20.6 & Empezar Diagramas de fase C y D (To Be) \\
\hline 3 & 1.3 .21 & Semana 27 \\
\hline 4 & 1.3.21.1 & Continuar Diagramas (To Be) \\
\hline 4 & 1.3.21.2 & Terminar Capitulo 2 Memoria \\
\hline 4 & 1.3.21.3 & $\begin{array}{l}\text { Terminar Architecture Requirements Specification y } \\
\text { Architecture Definition de Fase C y D (As Is) }\end{array}$ \\
\hline 3 & 1.3 .22 & Semana 28 \\
\hline 4 & 1.3.22.1 & Continuar Diagramas (To Be) \\
\hline 4 & 1.3.22.2 & Validar Documentos con el Cliente \\
\hline 3 & 1.3 .23 & Semana 29 \\
\hline 4 & 1.3.23.1 & Terminar Diagramas (To Be) \\
\hline 4 & 1.3.23.2 & Levantar Observaciones de los documentos \\
\hline 3 & 1.3 .24 & Semana 30 \\
\hline 4 & 1.3.24.1 & Empezar Plan de Continuidad \\
\hline 4 & 1.3.24.2 & Validar Diagrama TO BE \\
\hline 2 & 1.4 & Control \\
\hline 3 & 1.4 .1 & Semana 31 \\
\hline 4 & 1.4.1.1 & Firmar Actas de Aprobación de Todo \\
\hline 4 & 1.4.1.2 & Aprobar Plan de continuidad \\
\hline 2 & 1.5 & Cierre \\
\hline 3 & 1.5 .1 & Semana 32 \\
\hline
\end{tabular}




\begin{tabular}{|l|l|l|}
\hline 4 & 1.5 .1 .1 & Entregar Trabajo Final \\
\hline 4 & 1.5 .1 .2 & Exposición \\
\hline
\end{tabular}


Anexo 2: $<$ Matriz RAM del proyecto $>$

\begin{tabular}{|c|c|c|c|c|c|c|}
\hline $\begin{array}{l}\text { Código } \\
\text { EDT }\end{array}$ & Entregable & $\begin{array}{l}\text { Jefe de } \\
\text { Proyecto }\end{array}$ & $\begin{array}{l}\text { Arquitecto } \\
\text { Empresarial }\end{array}$ & Comité & Cliente & $\begin{array}{l}\text { Gerente } \\
\text { Profesor - IT } \\
\text { Consulting }\end{array}$ \\
\hline 1.1 & [Inicio] & $\mathrm{RCP}$ & $\mathrm{CP}$ & A & CAF & CAF \\
\hline 1.1.1.3 & $\begin{array}{l}\text { Project } \\
\text { Charter }\end{array}$ & $\mathrm{RCP}$ & $\mathrm{CP}$ & $\mathrm{A}$ & CAF & CAF \\
\hline 1.1.2.5 & $\begin{array}{ll}\text { Plan } & \text { de } \\
\text { Trabajo } & \end{array}$ & $\mathrm{RCP}$ & $\mathrm{CP}$ & - & - & - \\
\hline 1.2 & [Planificación] & $\mathrm{RCP}$ & $\mathrm{RCP}$ & - & CAF & CAF \\
\hline 1.2.1.3 & $\begin{array}{l}\text { Organizational } \\
\text { Model for } \\
\text { Enterprise } \\
\text { Architecture }\end{array}$ & $\mathrm{CP}$ & $\mathrm{RCP}$ & - & CAF & A \\
\hline 1.2.1.4 & $\begin{array}{l}\text { Principles } \\
\text { catalog }\end{array}$ & $\mathrm{CP}$ & $\mathrm{RCP}$ & - & $\mathrm{AF}$ & A \\
\hline 1.2.1.5 & $\begin{array}{l}\text { Documentos } \\
\text { de Gestión }\end{array}$ & $\mathrm{RCP}$ & $\mathrm{CP}$ & - & & CAF \\
\hline 1.2.1.8 & $\begin{array}{l}\text { Architecture } \\
\text { Statement }\end{array}$ & $\mathrm{CP}$ & $\mathrm{RCP}$ & - & CAF & A \\
\hline 1.2.1.9 & $\begin{array}{l}\text { Architecture } \\
\text { Vision }\end{array}$ & $\mathrm{CP}$ & $\mathrm{RCP}$ & - & CAF & A \\
\hline 1.3 & [Ejecución] & $\mathrm{CP}$ & $\mathrm{RCP}$ & $\mathrm{A}$ & $\mathrm{AF}$ & $\mathrm{A}$ \\
\hline
\end{tabular}




\begin{tabular}{|l|l|l|l|l|l|l|}
\hline 1.3.5.2 & $\begin{array}{l}\text { Architecture } \\
\text { Definition } \\
\text { Document }\end{array}$ & CP & RCP & A & AF & A \\
\hline 1.3 .5 .2 & $\begin{array}{l}\text { Architecture } \\
\text { Requirments } \\
\text { Specification }\end{array}$ & $\mathrm{CP}$ & $\mathrm{RCP}$ & $\mathrm{A}$ & $\mathrm{AF}$ & $\mathrm{A}$ \\
\hline 1.3 .5 .2 & $\begin{array}{l}\text { Architecture } \\
\text { Roadmap }\end{array}$ & $\mathrm{CP}$ & $\mathrm{RCP}$ & $\mathrm{A}$ & $\mathrm{AF}$ & $\mathrm{A}$ \\
\hline 1.4 & $\begin{array}{l}\text { Control }] \\
1.4 .1\end{array}$ & $\begin{array}{l}\text { EP } \\
\text { Fase C y }\end{array}$ & $\mathrm{RCP}$ & $\mathrm{A}$ & $\mathrm{AF}$ & $\mathrm{A}$ \\
\hline 1.5 & {$[$ Cierre $]$} & $\mathrm{RCP}$ & $\mathrm{CP}$ & $\mathrm{A}$ & $\mathrm{AF}$ & $\mathrm{CAF}$ \\
\hline 1.5 .1 & $\begin{array}{l}\text { Acta de Cierre } \\
\mathrm{RCP}\end{array}$ & $\mathrm{CP}$ & $\mathrm{A}$ & $\mathrm{AF}$ & $\mathrm{CAF}$ \\
\hline
\end{tabular}




\title{
Acta de Reunión $\mathrm{N}^{\circ} 012$
}

\author{
Sección 1. Información General
}

\begin{tabular}{|c|c|c|c|}
\hline Código y Nombre del Proyecto & Fecha de reunión & Hora Inicio & Hora fin \\
\hline $\begin{array}{l}\text { Arquitectura Empresarial dea proceso de prestación social de } \\
\text { EsSalud }\end{array}$ & $18 / 05 / 2017$ & $9: 00 \mathrm{pm}$ & $10: 00 \mathrm{pm}$ \\
\hline \multicolumn{4}{|l|}{ Elaborado por: } \\
\hline Joan Motta Altamirano & Sebastian Neira Medina & & \\
\hline Asistontes. & Cargo & & Asistió \\
\hline Jorge Sánchez & Cliente & & si \\
\hline Joan Motta Altamirano & Arquitecto Empresarial & & SI \\
\hline Sebastian Neira Medina & Jefe de proyecto & & SI \\
\hline
\end{tabular}

Sección 2. Agenda

\begin{tabular}{|l|l|}
\hline Nro. & Tema \\
1 & Revisar el objetivo específico 1 (OE1): Analizar el proceso de Prestación Social de EsSalud \\
2 & $\begin{array}{l}\text { Revisar el indicador de éxito 1(IE 1): Aprobación del cliente de la información levantada acerca del proceso, referente al } \\
\text { OE1 }\end{array}$ \\
3 Revisar el indicador de éxito 2(IE 2): Aprobación del cliente del correcto levantamiento de los requerimientos minimos \\
para la propuesta de solución, referente al OE1
\end{tabular}

Sección 3. Detalle de lo Tratado

\begin{tabular}{|c|c|}
\hline $\begin{array}{l}\text { Nro. } \\
\text { Tema }\end{array}$ & Descripción \\
\hline 1 & Aprobación del objetivo especifico $1(\mathrm{OE} 1)$ \\
2 & Aprobación del indicadores de éxito 1 (IE1) referente al OE1 \\
3 & Aprobación del indicadores de éxito 2 (IE2) referente al OE1 \\
\hline
\end{tabular}


Sección 4. Acuerdos

Nro. Acuerdo1 Acuerdo

1

Enviar cocumentación que acredite el cumplimiento del OB́1 y los IÊ 1 IE2

Seççión 5. Tareas

\begin{tabular}{|c|c|c|c|}
\hline $\begin{array}{c}\text { Nro. } \\
\text { Tarea }\end{array}$ & Descripción de la Tarea & Responsable & Fecha \\
\hline 1 & Seguir con las actividades del objetivo especifico 2 & Joan Motta / Sebastián Neira & $17 / 05 / 2017$ \\
\hline
\end{tabular}

\section{Firma}

\begin{tabular}{|l|l|l|l|}
\hline Jorgefanchez & Joan Motta Altamirano & Sebastián Neira Medina & Sabtar \\
\hline
\end{tabular}


Anexo 4: <ACTA DE APROBACIÓN OBETIVO 2 CON INDICADORES>

\section{Acta de Reunión $\mathrm{N}^{\circ} 013$}

Sección 1. Información General

\begin{tabular}{|c|c|c|c|}
\hline Código y Nombre del Proyecto & Fecha de reunión & Hora Inicio & Hora fin \\
\hline $\begin{array}{l}\text { Arquitectura Empresarial del proceso de prestación social de } \\
\text { EsSalud }\end{array}$ & $18 / 05 / 2017$ & $9: 00$ pm & $10: 00 \mathrm{pm}$ \\
\hline \multicolumn{4}{|l|}{ Elaborado por: } \\
\hline Joan Motțą Altạmirąne & Sębąștiąn Nęira Mędina & & \\
\hline Asistentes & Cargo & & Asistio \\
\hline Jorge Sánchez & Cliente & & SI \\
\hline Joan Motta Altamirano & Arquitecto Empresarial & & St \\
\hline Sebastian Neira Medina & Jefe de proyecto & & SI \\
\hline & & & \\
\hline
\end{tabular}

Sección 2. Agenda

Nro. Tema

1 Revisar el objetivo especifico 2 (OE2): Diseñar una propuesta de mejora para el proceso de Prestación Social

2

Revisar el indicador de éxito 3(IE3): Aprobación del cliente de la información levantada acerca del proceso.

Sección 3. Detalle de lo Tratado

\begin{tabular}{|c|l|}
\hline $\begin{array}{l}\text { Nro. } \\
\text { Temá }\end{array}$ & Descripción \\
\hline 1 & Aprobación del objetivo específico 2 (OE2) \\
\hline 2 & Aprobación del indicadores de éxito 3 (IE3) referente al OE2 \\
\hline
\end{tabular}


Sección 4. Acuẹrdos

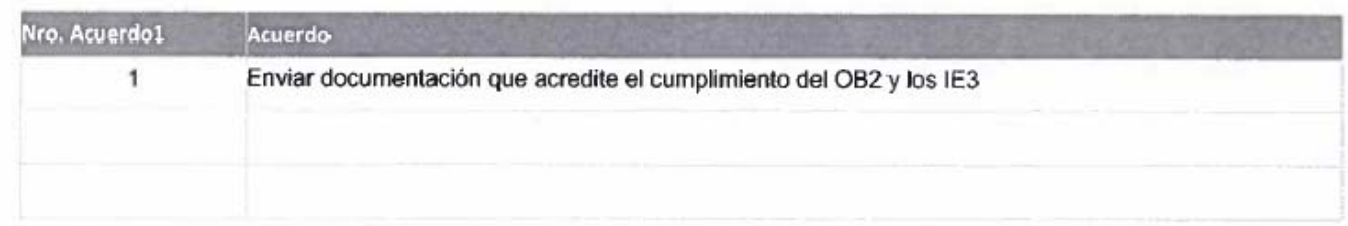

Secçión 5. Taręas

\begin{tabular}{|c|c|c|c|}
\hline $\begin{array}{c}\text { Nro. } \\
\text { Tarea }\end{array}$ & Descripción de la Tarea & Responsable & Fecha \\
\hline 1 & Seguir con las actividades del objetivo especifico 3 & Joan Motta / Sebastiạn Neira & $17 / 05 / 2017$ \\
\hline
\end{tabular}

\section{Firma}

\begin{tabular}{|l|l|l|l|}
\hline Jorge Sánchez Soan Motta Altamirano & Sebastián Neira Medina \\
\hline
\end{tabular}




\section{Anexo 5: <ACTA DE APROBACIÓN OBETIVO 3 CON INDICADORES>}

\section{Acta de Reunión $N^{\circ} 014$}

Sección 1. Información General

\begin{tabular}{|c|c|c|c|}
\hline Código y Nombre del Proyecto & Fecha de reunión & Hora inicio & Hora fin \\
\hline $\begin{array}{l}\text { Arquitectura Empresarial del proceso de prestación social de } \\
\text { EsSalud }\end{array}$ & $18 / 05 / 2017$ & $9: 00 \mathrm{pm}$ & $10: 00 \mathrm{pm}$ \\
\hline \multicolumn{4}{|l|}{ Elaborado por: } \\
\hline Joan Motta Altamirano & Sębaștiąn Nęirą Mędiną & & \\
\hline Asistentes & Cargo & & Asistió \\
\hline Jorge Sánchez & Cliente & & SI \\
\hline Joan Motta Altamirano & Arquitecto Empresarial & & Sl \\
\hline Sebastian Neira Medina & Jefe de proyecto & & SI \\
\hline
\end{tabular}

Sección 2. Agenda

\begin{tabular}{|c|c|}
\hline Nro. & Tema \\
\hline 1 & Revisar el objetivo específico 3(OE3): Validar que la propuesta cumpla con los requerimientos del negocio. \\
2 & Revisar el indicador de éxito 4(IE4): Aprobación del cliente de que la propuesta soluciona el problema o necesidad \\
\hline
\end{tabular}

Sección 3. Detalle de lo Tratado

\begin{tabular}{|c|l|}
\hline $\begin{array}{c}\text { Nro. } \\
\text { Tema }\end{array}$ & Descripción \\
\hline 1 & Aprobación del objetivo especifico 3 (OE3) \\
\hline 2 & Aprobación del indicadores de éxito 4 (IE3) referente al OE3: \\
\hline
\end{tabular}


Sección 4. Acuerdos

\begin{tabular}{|c|l|}
\hline Nro. Acuerdo1 & Açuerdo \\
\hline 1 & Enviar documentación que acredite el cumplimiento del OB3 y los IE4 \\
\hline & \\
\hline
\end{tabular}

Sección 5. Tarẹaș

\begin{tabular}{|c|c|c|c|}
\hline $\begin{array}{c}\text { Nro. } \\
\text { Tarẹa }\end{array}$ & Descripción de la Tarea & Responsable & Fecha \\
\hline 1 & Seguir con las actividades del objetivo especifico 4 & Joan Motta / Sebastian Neira & $17 / 05 / 2017$ \\
\hline
\end{tabular}

\section{Firma}

\begin{tabular}{|l|l|l|}
\hline Jorge Sánchẹz Joan Motta Altamiranọ & Sebastián Neira Medina \\
\hline
\end{tabular}

